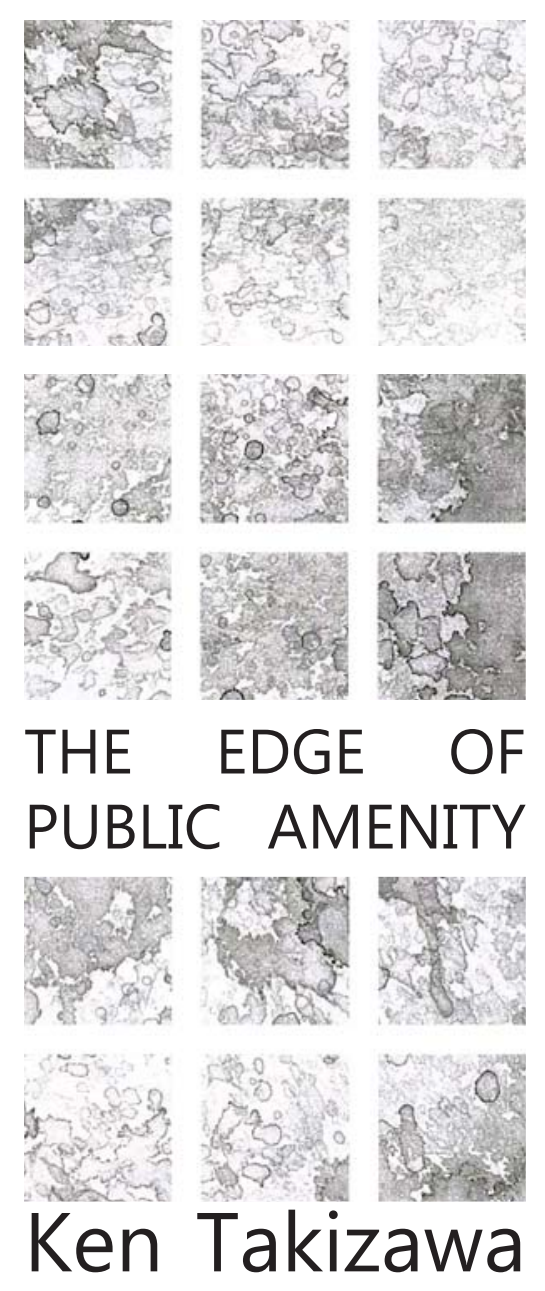




\section{The Edge of Public Amenity}

Ken Takizawa

A 120-point thesis submitted to the Victoria University of Wellington in partial fulfilment of the requirements for the degree of

Master of Interior Architecture

Victoria University of Wellington 2014 


\section{Acknowledgments}

First of all, I must thank my parents,

Isamu and Chikako, for their support

throughout my life.

Furthermore, thanks to all lecturers,

tutors and especially my supervisor Sam

Kebbell for their passion in their work. I

am grateful for your straightforwardness and sometimes harsh but necessary

criticisms to straighten my uncertainties.

And to my classmates it was with great enjoyment to reflect among your inspiring work and the years spent together through this struggle.

Thank you everybody. 


\section{Part 1 - Goal}

Abstract

Introduction

Goal: public amenity and density

Methodology

\section{Part 2 - Reality}

Site

254 Willis Street, Wellington $\quad 14$

The context, reality 15

Site location 17

Existing interior fit-out $\quad 21$

Case study: Chungking Mansions $\quad 22$ Cellular interiors $\quad 24$

Exterior public amenities $\quad 26$

City to park/garden $\quad 27$

City to sea

27

\section{Part 3 - Opportunity}

$\begin{array}{ll}\text { Public interiors } & 30\end{array}$

Design strategy 33

Case study: Gary Chang's apartment $\quad 37$

Early progressions 38

One room living $\quad 39$

Soho apartment and 1976 Chang's apartment $\quad 41$

Proposed changes $\quad 42$

Reveal \& conceal - Mechanism 1

Case study: Gary Chang $\quad 45$

Expansion \& compression $\quad 48$

Case study: art gallery and living area $\quad 50$ 
Mobile/Isolated - Mechanism 2

Mobile rooms - case study: Naked House $\quad 84$

Isolated interiors - case study: Warehouse 86

Divergent - case study: Three Small Rooms 88

Case study: Lyon housemuseum 90

Mobile experiments 93

Summary $\quad 95$

$\begin{array}{ll}\text { Corridors - Mechanism } 3 & 102\end{array}$

Figures, doors and passages 102

Case study: Unite d'Habitation - Le Corbusier 106

Case study: Saishunkan Seiyaku women's dormitory - SANAA 108

Case study summary 110

Corridors experiments 114

17th July review discussion 119

Public Amenity - Mechanism 4 121

10th October review 123

Final adjustments 123

Case study: Collins Gallery - Tighe Architects $\quad 124$

Final proposed design

\section{Part 4 - Way Forward}

Reflection

Weaknesses

Further research questions

Closing comments

Bibliography 


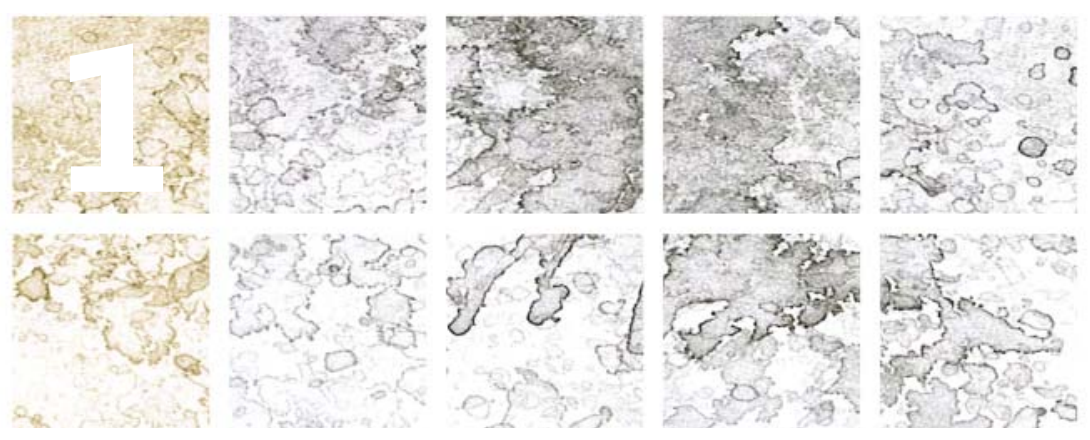




\section{Part 1_Goal Interior Public Amenity}




\section{Abstract}

We have the techniques to design smaller and more efficient apartments, but those small apartments are often less attractive than their suburban alternatives. Some of the most attractive suburban houses are adjacent to significant natural public amenities, like beaches and parks, which gives the occupants convenient access to these public amenities. Valuable waterfront houses, for example, often open directly onto the beach. Houses adjacent to the town belt in Wellington often have direct access to these natural environments.

While some small apartments can also have high value when adjacent to public amenities, they seldom have direct access to interior public amenities.

What opportunities are there to making apartments more attractive by providing a shared interior public space directly accessible from the apartments door step? What is the interior equivalent of a beach front house? This project explores the possibility of setting apartment's directly adjacent to interior public amenities like a gallery space, giving occupants privilege access to these spaces. 
With a growing urban population, our cities can either become denser or sprawl. The latter is not a positive outcome. Cities with limited access to land often handle density better since it is an urgent issue while others do not face these issues the same way but it is a reality.

There are many benefits to living in the city; however we require places for recreation such as public amenities like the beaches and parks. Distinctively they are an escape from the built environment where there is a growing demand for density. Apartments are the norm in inner city living and they do not have relative proximity to these public amenities.
Interiors also can be public amenities and there is an opportunity to bring these interior public amenities into the apartment. This opportunity could well improve the quality of apartment interiors because of this new adjacency to a public interior amenity.

There are many examples of flexible designs but all are individual cases, such as the building in which Gary Chang lives. It is a small $32 \mathrm{~m}^{2}$ apartment known as a domestic transformer because of its sliding walls. Out of the hundreds of similar sized apartments, none is as flexible as Chang's apartment. Typical apartments have a systematic problem of cramping more space at the cost a spatial configuration. Furthermore apartments rarely have any significant interior spaces that are adjacent to them. 


\section{Goals}

The focus is on the qualitative aspect of apartment interiors by adding a public interior amenity. There are multiple factors for this design thesis that will hopefully all establish the possibilities for an apartment that successfully integrates the apartment interior with a public amenity such as a gallery space.

Categories of mechanisms will be established through certain case studies with a unique element that could provide useful elements for this project, by analysing the experiments, identifying the strengths and weaknesses of each. The key issues that require resolution include:

-The composition between public and private amenities

- How the exchange between the public and private works

-Social implications the design could have on the occupants

After the design research a final proposal will be made after the assembly of the strengths and findings of the case studies and experiments. Upon evaluating the final proposal, weaknesses and findings will be explained with potential future design questions as a result of the findings. 


\section{Design Method}

This design led research starts with simple ideas that could ultimately

lead to a thesis. Once those ideas are established, research on relevant case studies will be conducted, followed by experimenting with some of the key design aspects from the case study.

Through these experiments, they will be analysed and understood, finding the weaknesses and strengths of each. Furthermore refined versions of these experiments will be discussed in the design presentation to collect views and more possibi

Through the discoveries of these case studies, experiments and reviews, they will further establish a refined thesis proposition, taking in a variety of methods and ideas together found through the research to develop a final design proposal.
What opportunities are there for making apartments more attractive by providing a shared interior public space directly accessible from the apartment's door step? What is the interior equivalent of a beach front house?

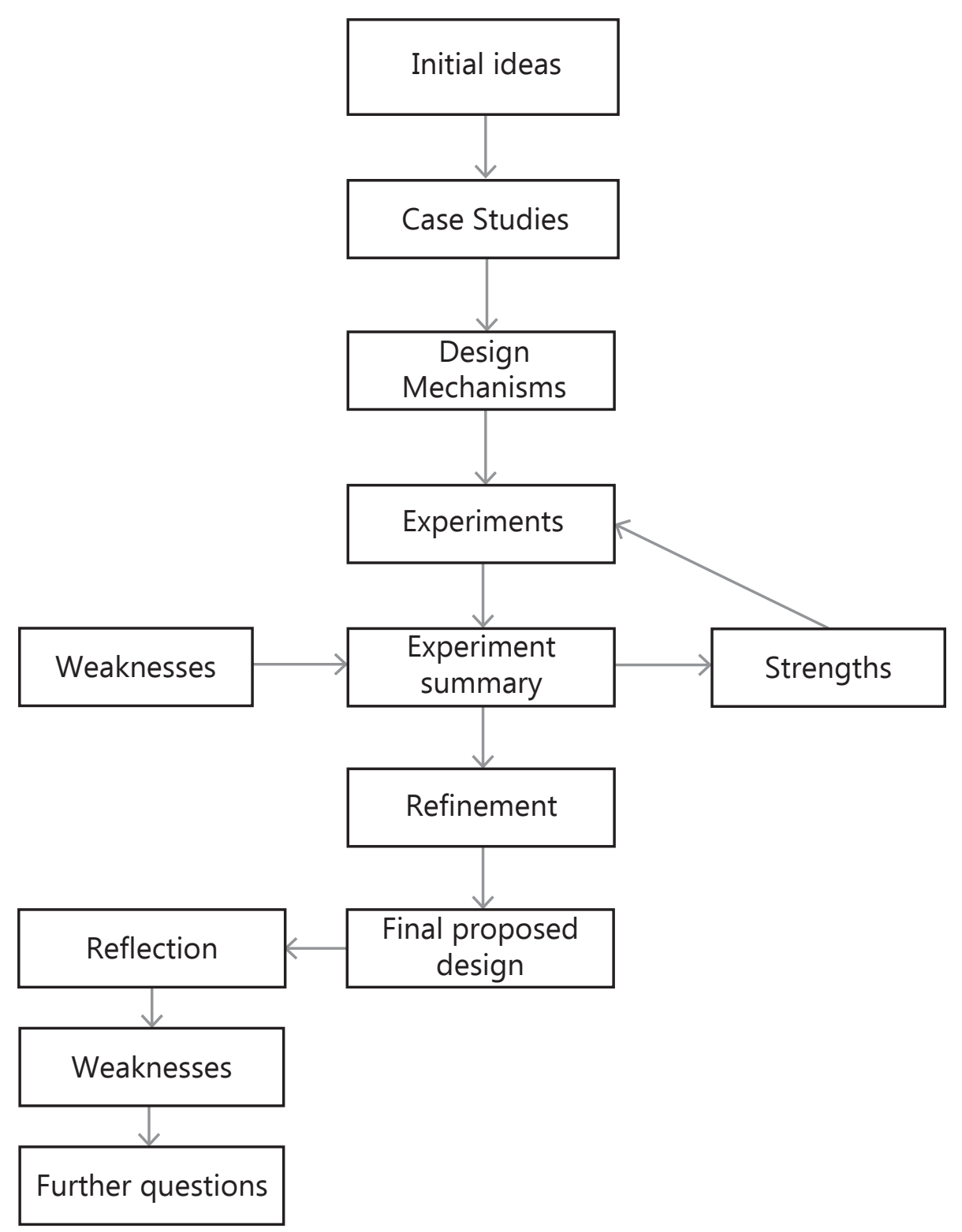




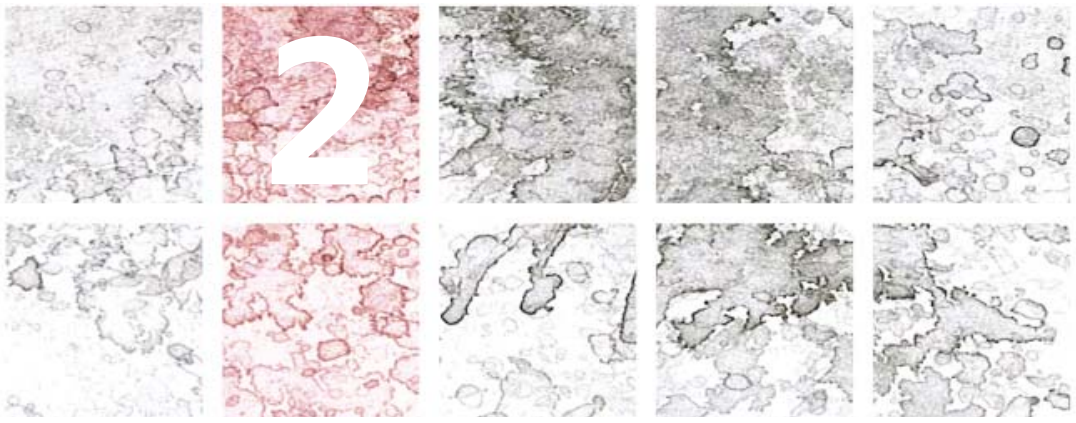




\section{Part 2_Reality Site and Context}




\section{Willis Street, Wellington}

As a thesis on interior architecture, this design will use an existing building to investigate how housing and public interiors can be brought together. The site is the former Children's Dental Clinic built in 1938 that is now an apartment building like many other buildings of this type.

A heritage building and like many others (Fig. 2.0, Fig. 2.1 and Fig. 2.2) the former Children's Dental Clinic is now an apartment building. "All buildings, once handed over by the builders to the client, have three possible fates, namely to remain unchanged, to be altered or to be demolished." "It is interesting that housing is one of the very few building types with a physical form that can remain largely unchanged for decades in some instances, even centuries."

These buildings are key to maintaining the city's character and also providing inner city housing. How these buildings are converted into housing is something that is being seriously considered.

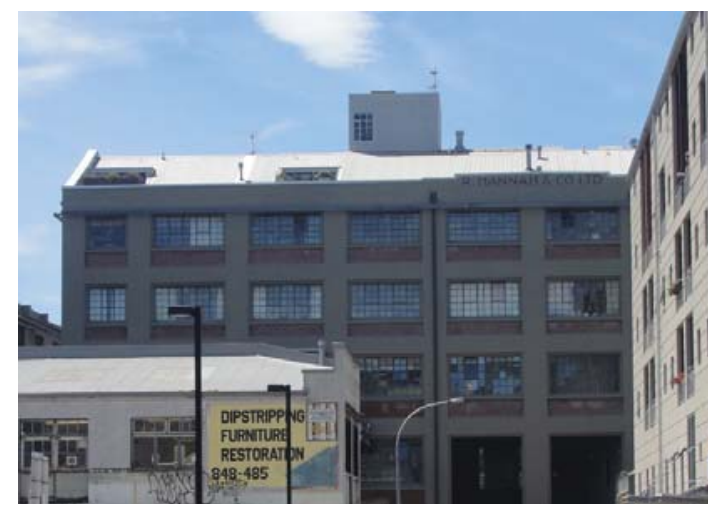

Fig. 2.0 Hannah's Factory

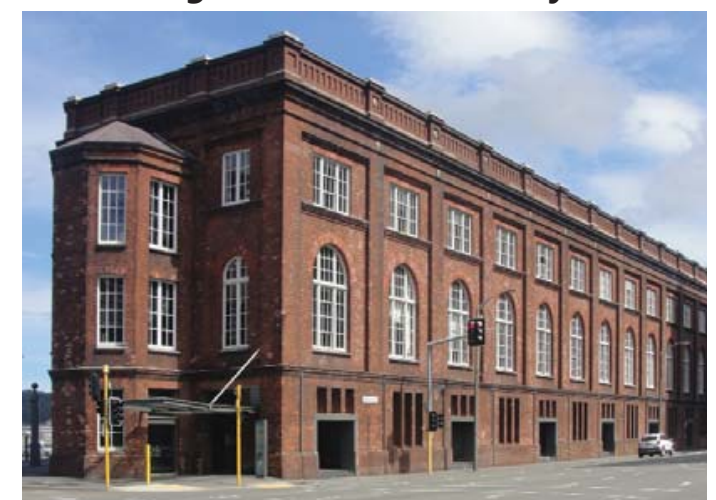

Fig. 2.1 Shed 21

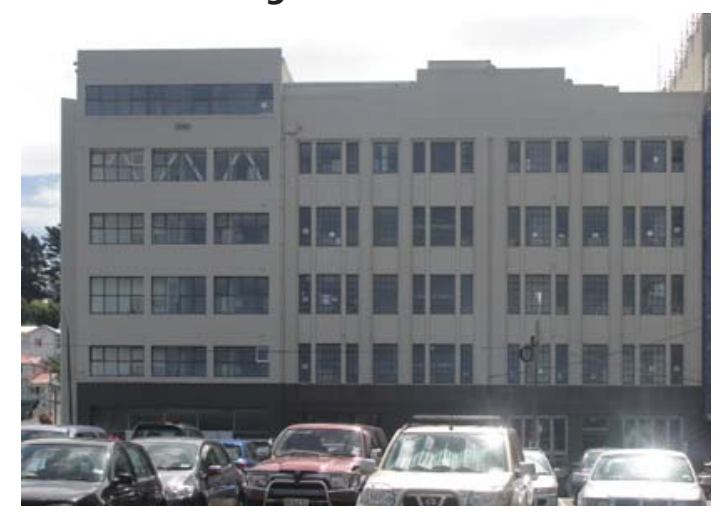

Fig. 2.2 McKenzies Building

${ }^{1}$ F. Scott 1

${ }^{2}$ Q. Pickard 155 


\section{The Context, Reality}

Apartments already offer high density housing and there are precedents for micro apartments such as architect

Chang's apartment in Hong Kong. Both provide answers related to high density housing. However they are a response to quantitative demands rather than improving the living conditions of apartment interiors.

There is a rising need for denser housing, especially minimising urban sprawl as the population grows within urban areas. Solutions for denser housing already exist, but they are characterised as a cluster of apartments that are secluded from each other with no significant common space. "Among the most difficult problems in housing layout is striking the right balance between the need for privacy and the need to avoid social exclusion". ${ }^{3}$ 


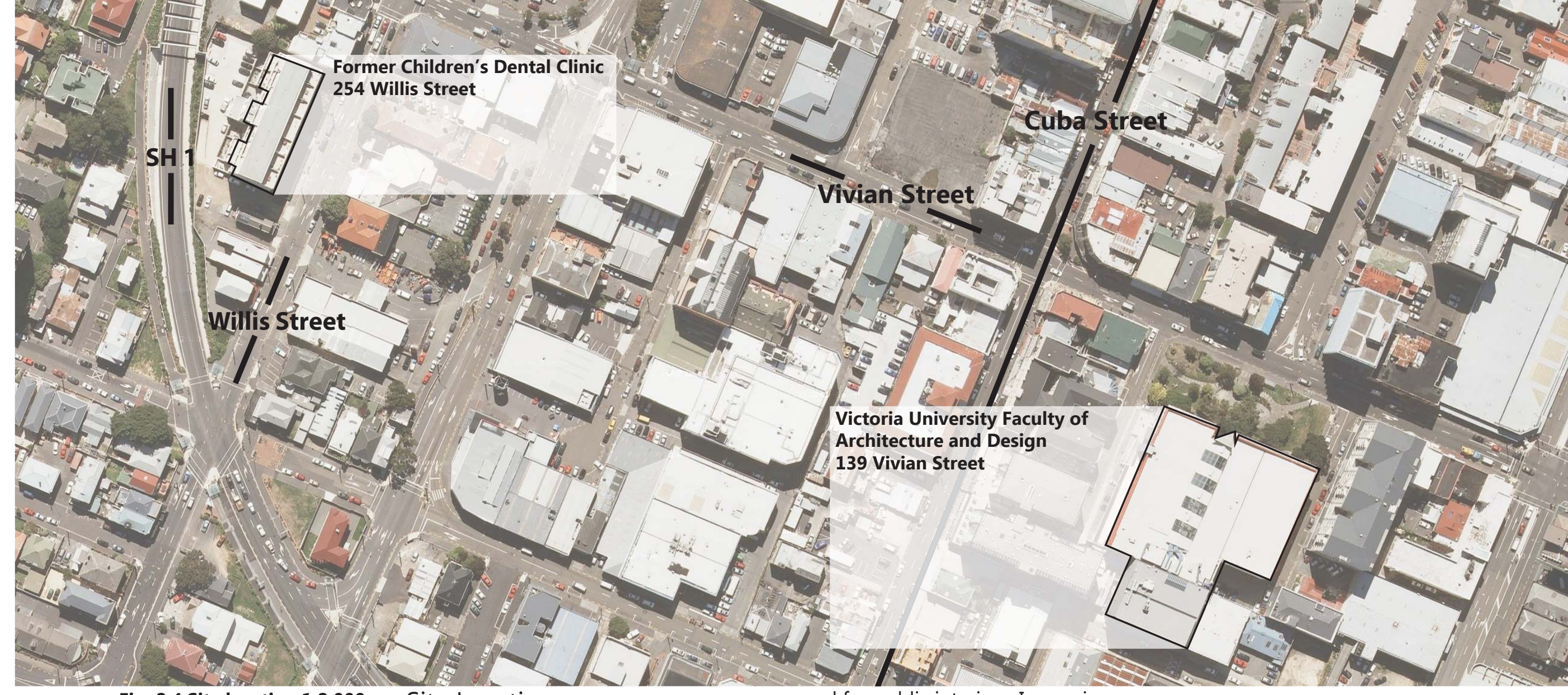

Fig. 2.4 Site location 1:2,000

Site Location

Located a few blocks down from the Victoria Uiversity Faculty of Architecture and Design campus, the building is close to the heart of Wellington City. The adjacency to urban amenities is the attraction for people to live in urban centres.

The location of the site, as you can see, is deep within the city (Fig 2.4). "There are several reasons for this growing need for public interiors. Increasing motor traffic means that much public exterior space in the city has become unsuitable for spending any great length of time in. Public interiors must replace that exterior space."

${ }^{4}$ M. Kloos 21 
Fig. 2.5 Existng building axonometric

Thesis will not focus on penthouse floors

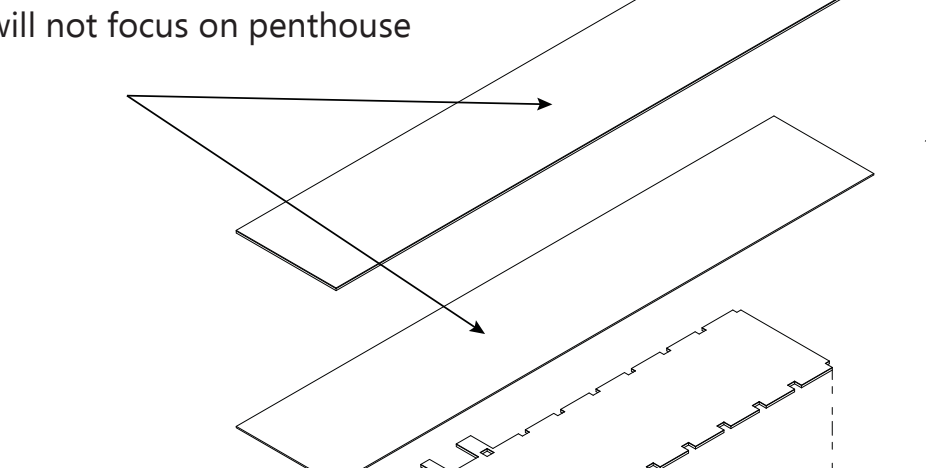

EVEL 7 PENTHOUSE

Added in 2004

\section{LEVEL 6 PENTHOUSE}

Head space $2470 \mathrm{~mm}$

Added in 2004

LEVEL 5 MEZZANINE

Head space $3525 \mathrm{~mm}(3125 \mathrm{~mm})$

LEVEL 4

Head space $3810 \mathrm{~mm}(3410 \mathrm{~mm})$

LEVEL 3

Head space $5230 \mathrm{~mm}(4830 \mathrm{~mm})$ Double floor height

\section{LEVEL 2}

Head space $4660 \mathrm{~mm}(4260 \mathrm{~mm})$

\section{LEVEL 1 BASEMENT}

Head space $3410 \mathrm{~mm}(3010 \mathrm{~mm}$ lowest point under beams)

11 stairs leading up to Level 2 


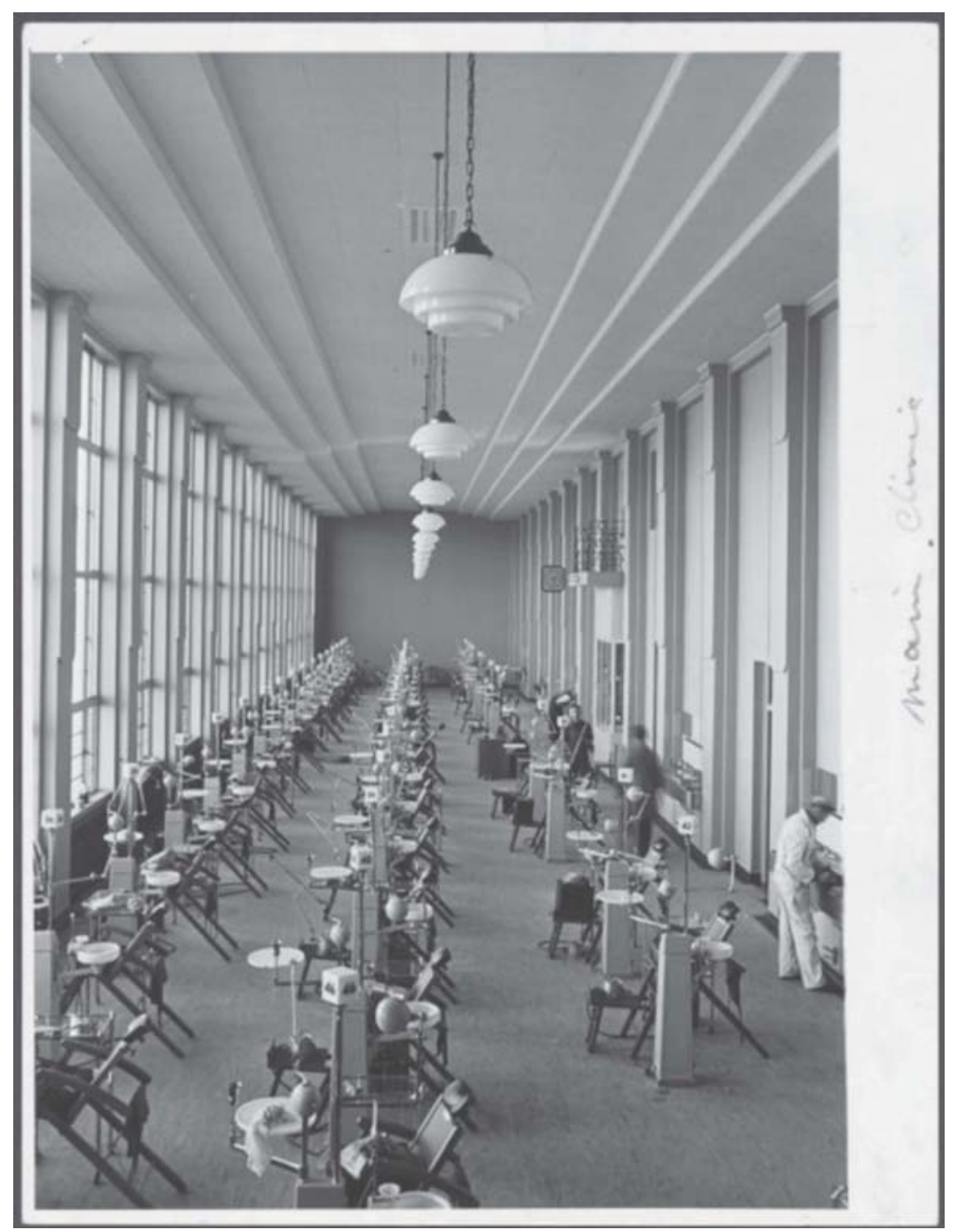

Fig. 2.6 Original interior of Children's

Dental Clinic level 4 (Retrieved Feb. 6 2014).

http://natlib.govt.nz/records/22905334?search\%5B

i\%5D\%5Bcentury\%5D=1900\&search\%5Bi\%5D\%5B

decade $\% 5 \mathrm{D}=1940 \&$ search $\% 5 \mathrm{Bi} \% 5 \mathrm{D} \% 5 \mathrm{Bsubject} \% 5$

$\mathrm{D}=$ Wellington+Region\&search\%5Bpage\%5D=36\&-

$$
\text { search\% } 5 \text { Bpath\% } 5 \mathrm{D}=\text { photos }
$$




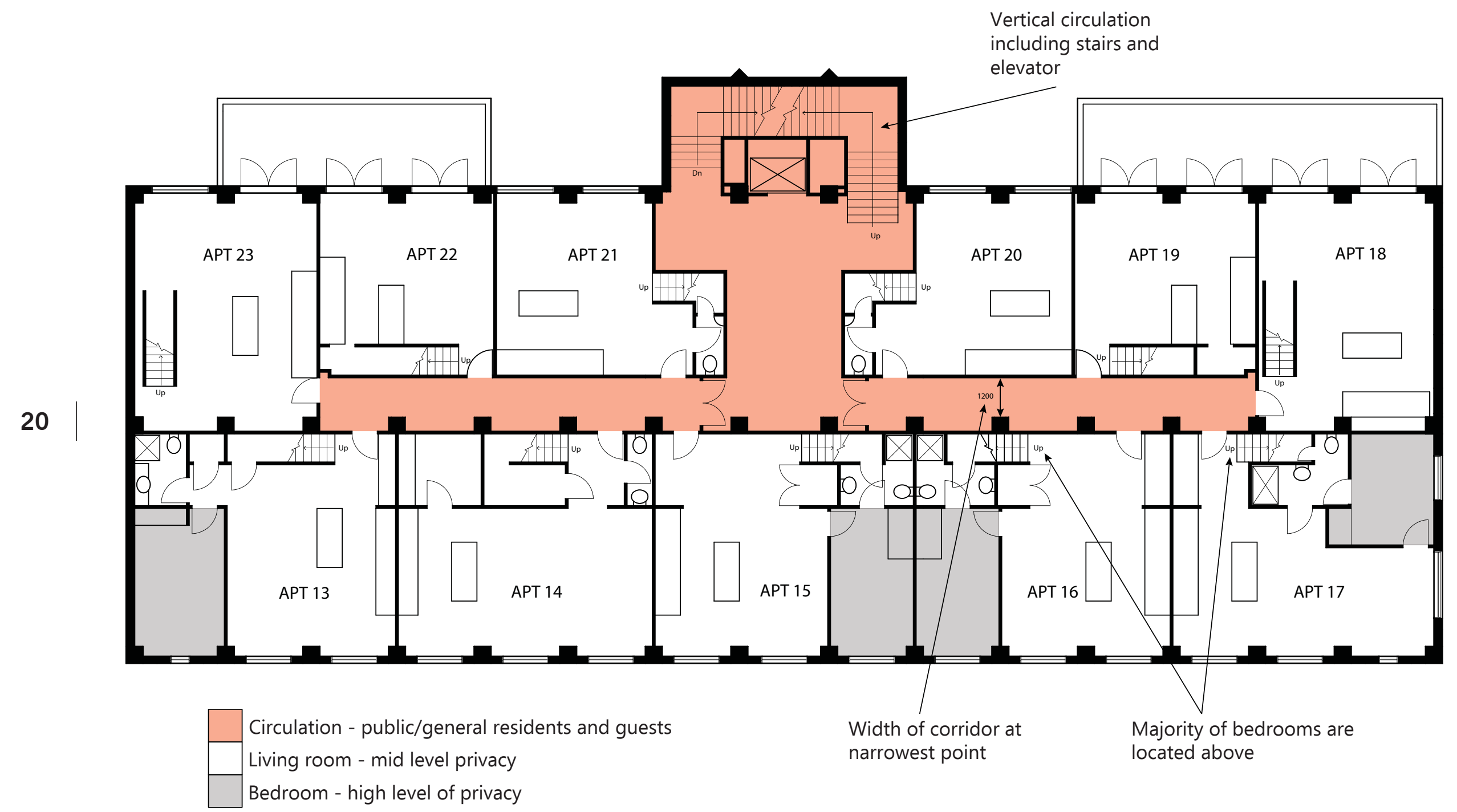

Fig. 2.7 Existing level 2 floor plan 1:200 


\section{The Exising Interior Fit-} out

The current layout of the site consists of apartments on both rows of each other floor, with a thin terminal space for circulation (Fig. 2.8). Often this central linear passage is rarely for anything but circulation and does not encourage any social interaction among residents. It is also a space in which people do not spend any extended amount of time.

Looking at the existing plans of the former Children's Dental Clinic, three zones were identified. These zones are identifiable through different levels of public/privacy.

-Circulation - general residents, guests

-Living spaces - secluded from general people

-Bedroom - for individuals, most privacy

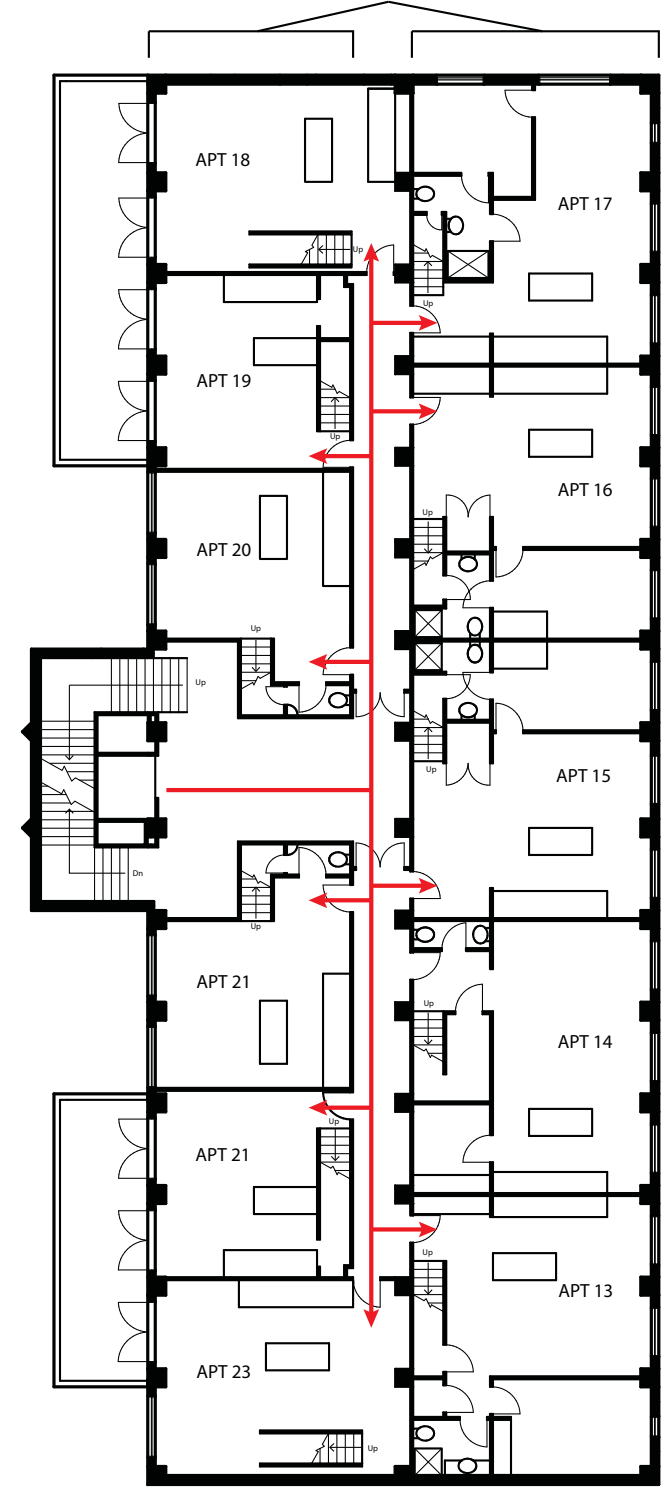

Figure 2.8 - Existing floor plan Circulation corridor

1:500 


\section{Chungking Mansions}

"From the outside, Chungking Mansions look like a single, imposing concrete block - 15 identical residential floors on top of a neon-lit, two-storey mall." In plan it appears to resemble a game of Tetris. "It was originally intended for housing but five decades later it is a bustling city within a building, from housing to restaurants to small businesses. Chungking succeeds where developers have miserably failed: a perfect example of a city as an organic mega structure, flexible enough to

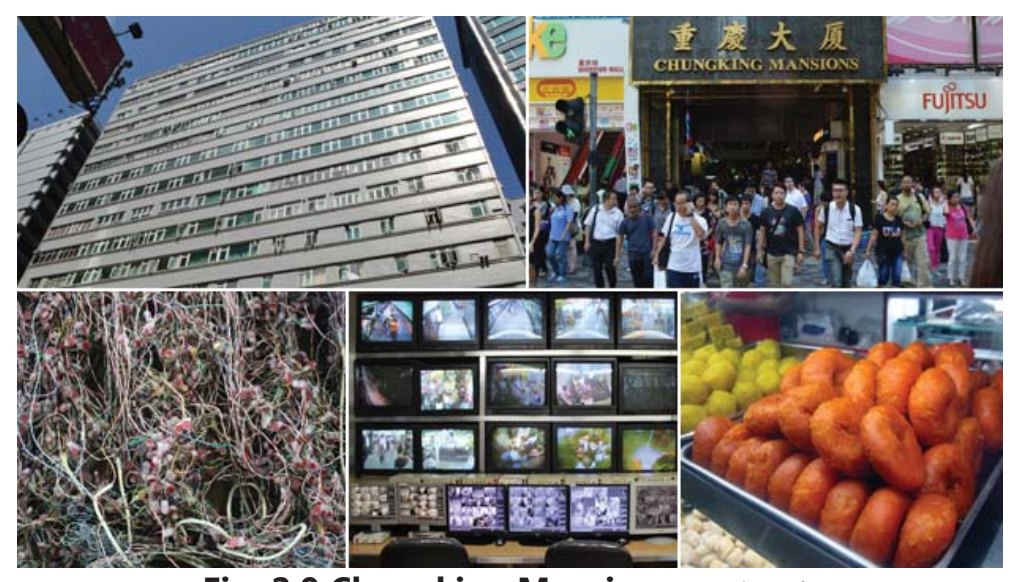

Fig. 2.9 Chungking Mansions (Retrieved-

$$
\text { Feb. } 7 \text { 2014). }
$$

http://www.bbc.co.uk/news/world-asia-24015987

fulfil every need from religion to water supply, yet providing an alternative to conventional space, culture and time." ${ }^{16}$ 

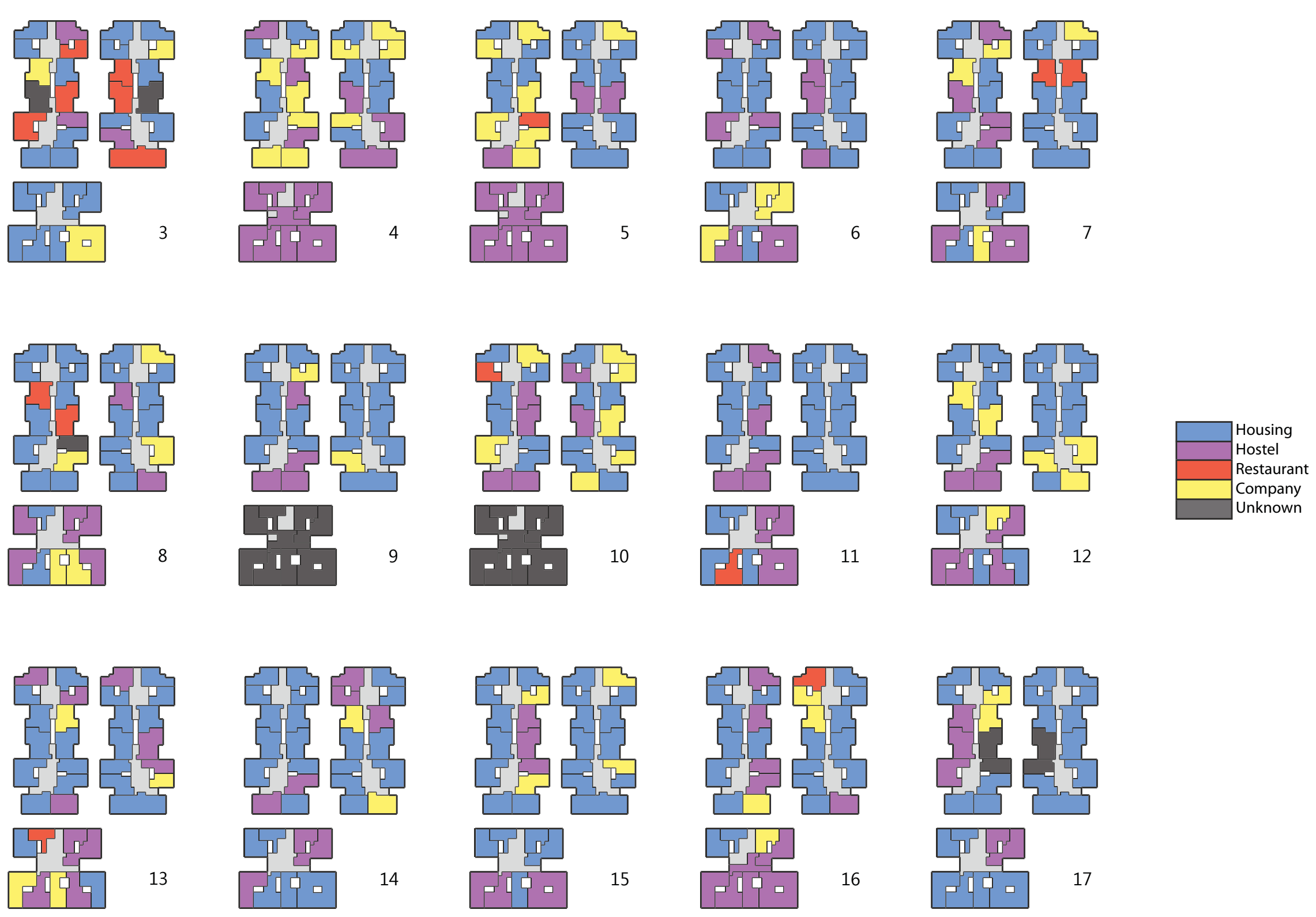

Fig. 2.10 Many faces of Chungking mansions 


\section{Cellular Interiors}

An often notable characteristic of large housing designs is their cellular like interiors in plan. Chungking Mansion is an example of many projects that result in the interiors becoming cellular in appearance. Chang's apartment is just one of many in a large building designed with an intention of cramming as many rooms in as possible. It was first perceived as a defect to interior planning. The purpose of cellular interiors is to create divisions and rooms, which often result in the loss of a spatial figure.

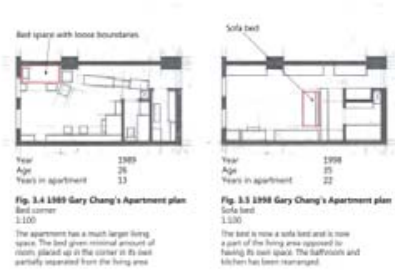

This was the flaw in Chang's apartment in its original form. $32 \mathrm{~m}^{2}$ was actually taken up by a series of smaller spaces, measuring approximately $8 \mathrm{~m}^{2}$ at most.

It was not until he removed the internal walls when his apartment became a more flexible environment. "Furthermore of all the senses, sight is the most appropriate for things at the boundary of experience, and that is exactly what a room, particularly a large room,

provides; an edge to perception." ${ }^{17}$
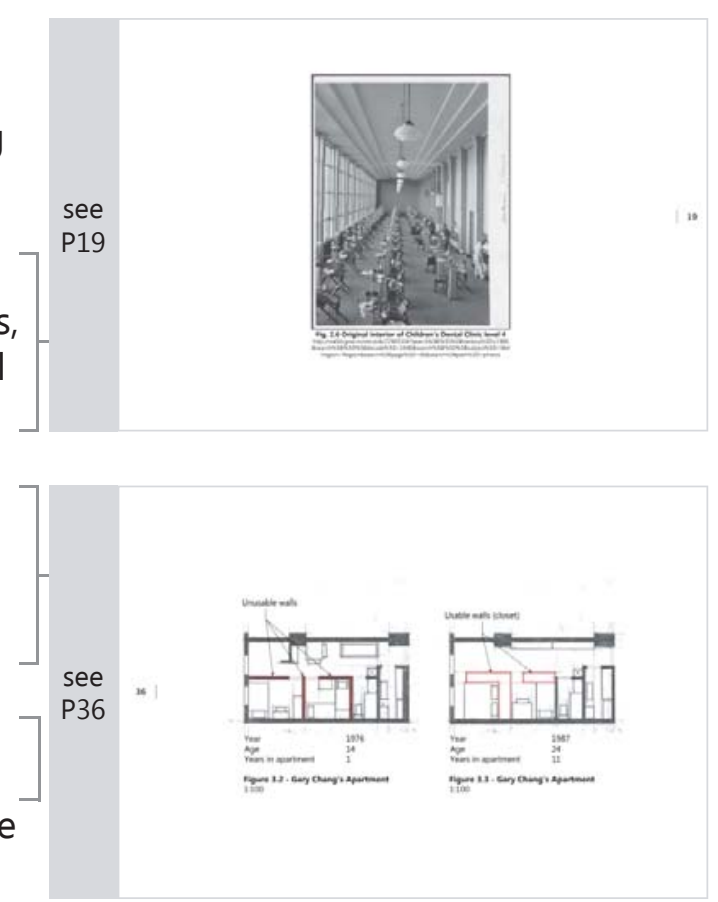


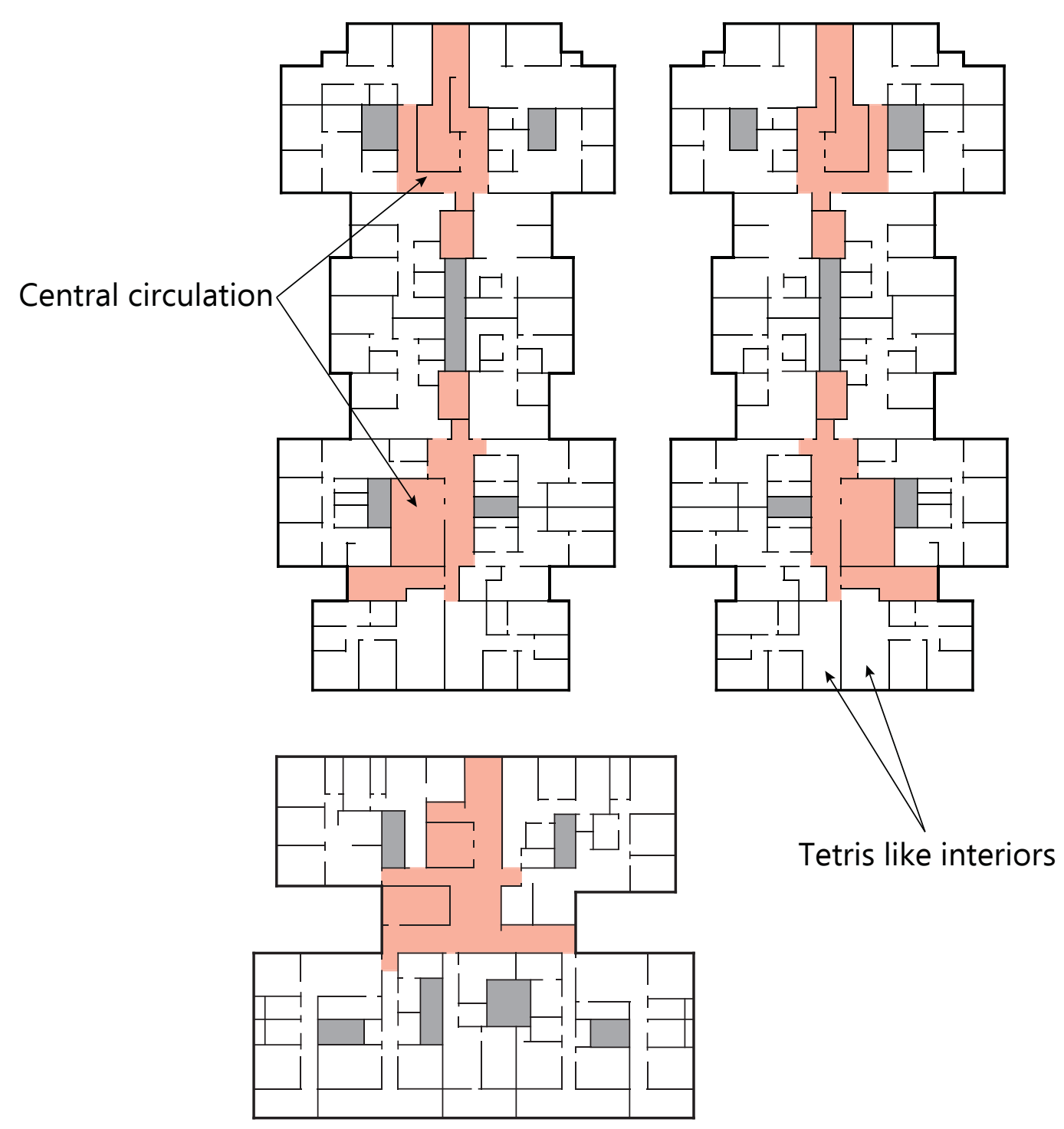

Fig. 2.11 Cellular interior 1:500 


\section{Public Amenities}

\section{Town belt}

Many inner city apartments were former light industrial, office buildings. It is one of many ways of providing inner city housing and also reinvigorates buildings that no longer serve their original purpose. It is an effort to provide inner city housing within the town belt.

Wellington's town belt was originally intended to be land protected from development. However a third of the original town belt from the 1840 plan has been consumed by development. It prevents the city centre from sprawling, however it does not stop suburbs outside the belt such as Karori.

\section{Early 2000s}

\section{0}

Sea

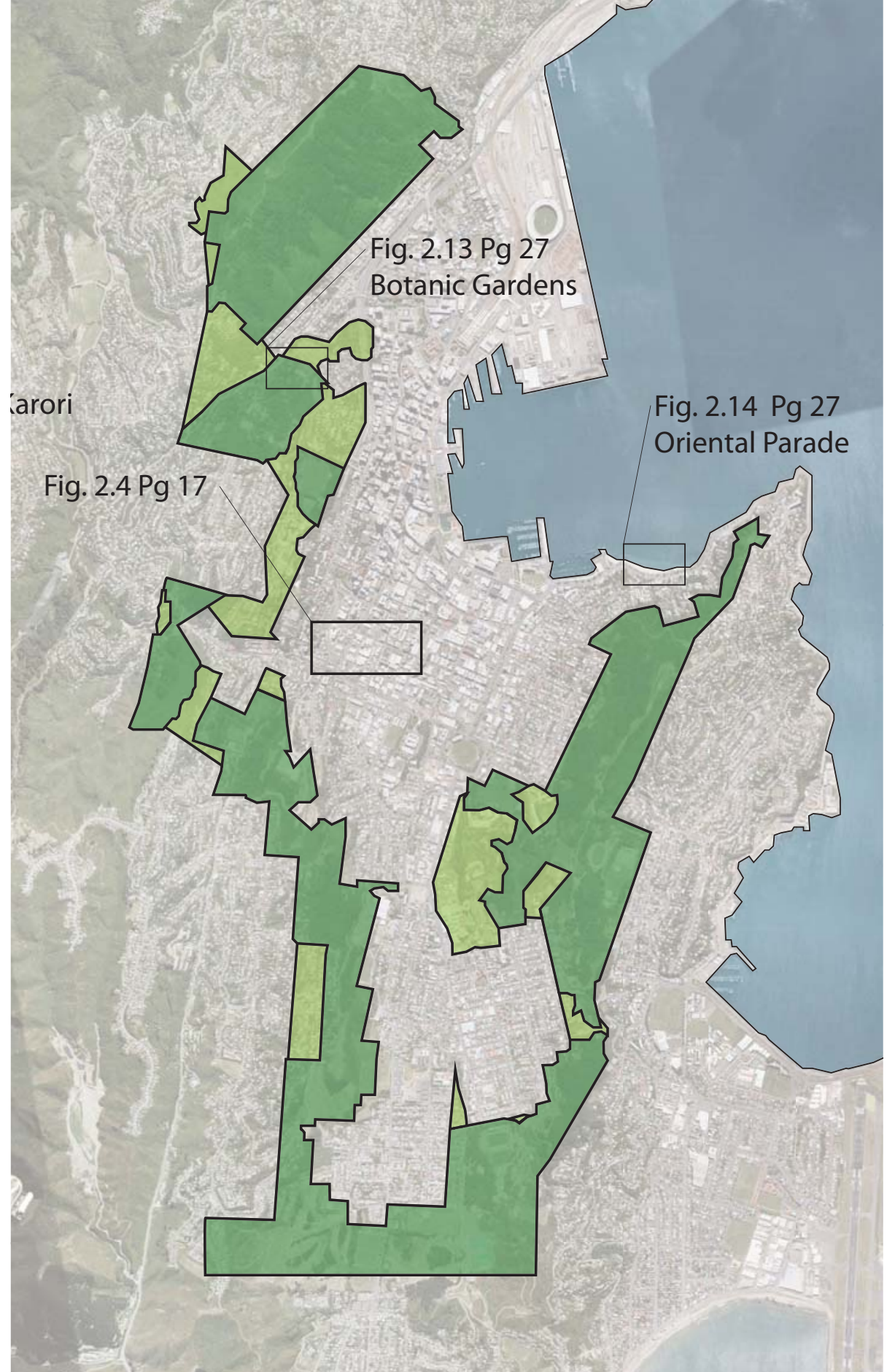

Fig. 2.12 Wellington town belt 1:50,000 


\section{City to Park/Garden}

Proximity to a park or some other natural amenity is an attraction to potential tenants and home owners.

\section{City to Sea}

Proximity to the sea and beach is also an attraction especially in New Zealand with its relationship to the sea.

The proximity to these areas contributes to the value of a property. These outdoor public spaces are also an extension of our homes as Chang has said about the home and the city. "The city is your home, not just your home."

"Parks offer urban residents a place away from the home that is essential to their physical and mental health and well-being. This is particularly true for the poor and working-class residents who do not have backyards, much less vacation homes, where they can rest and recreate."

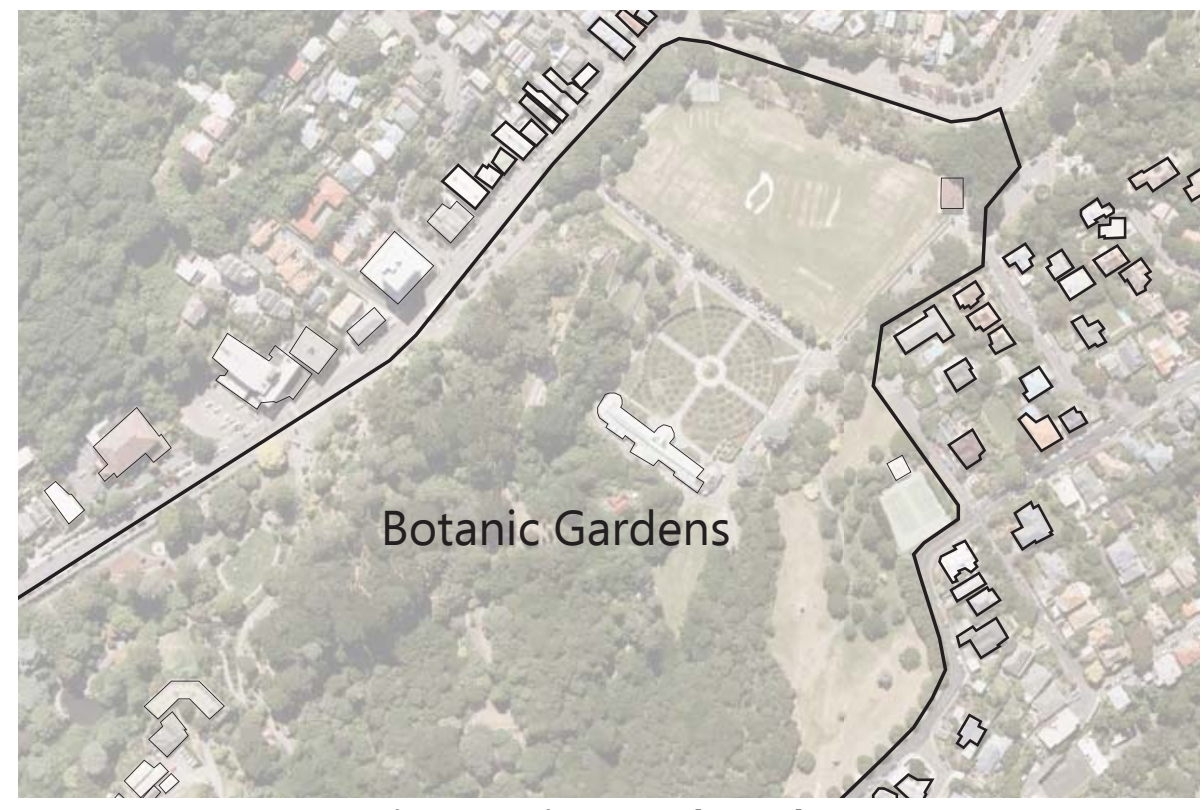

Fig. 2.13 City to park/garden

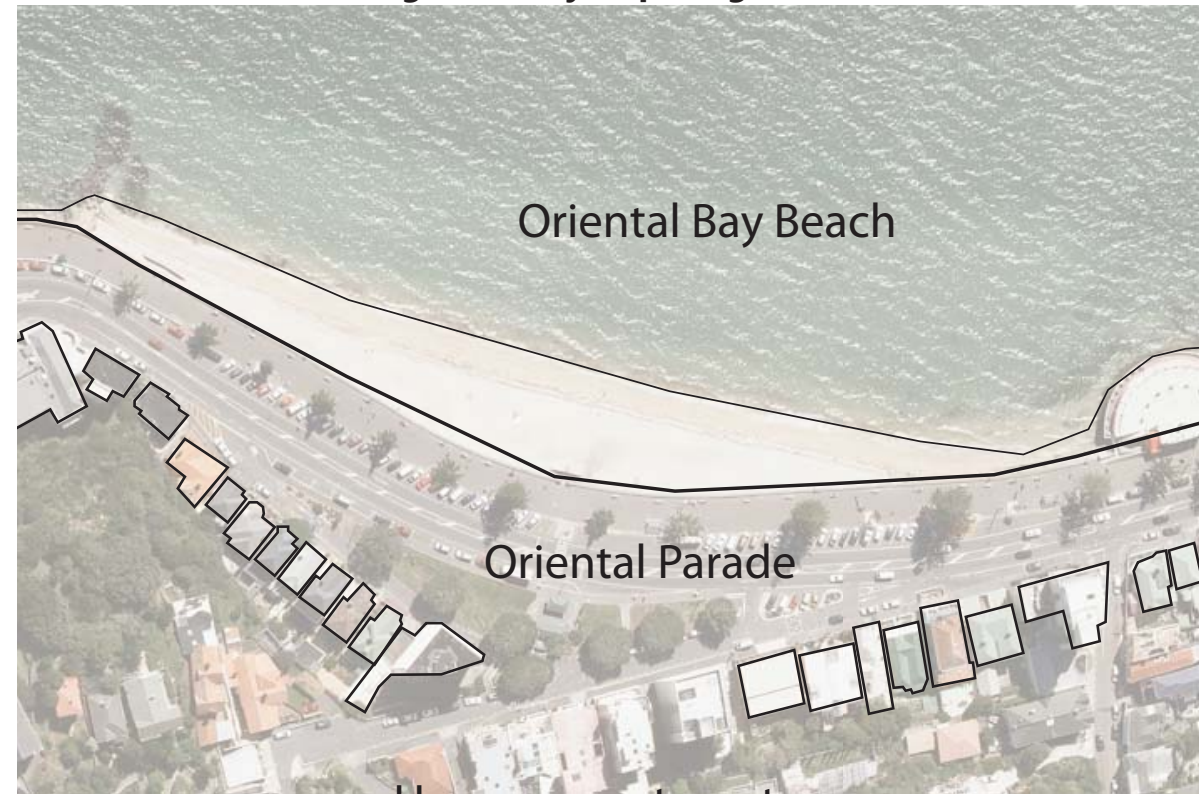

${ }^{8} \mathrm{http}: / /$ www.youtube.com/watch?v=WB2-2j9e4co (October 2014)

Fig. 2.14 City to Sea

${ }^{9}$ S. Low $17-18$ 


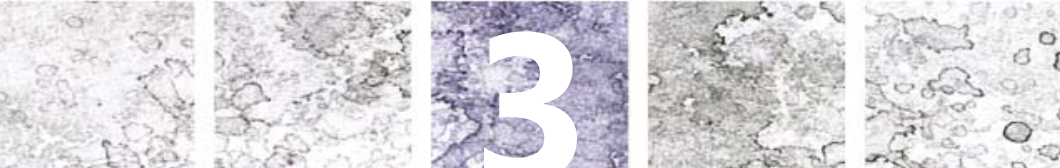

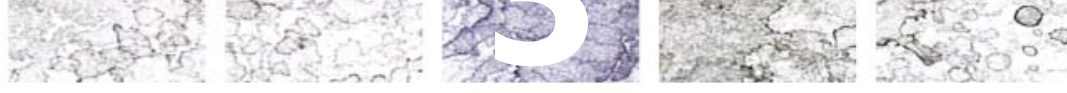

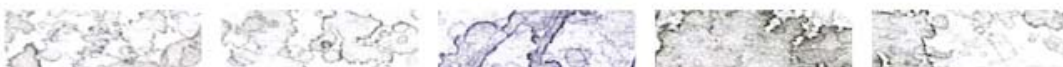

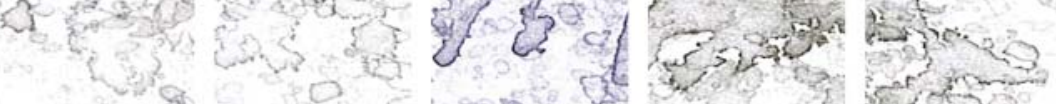

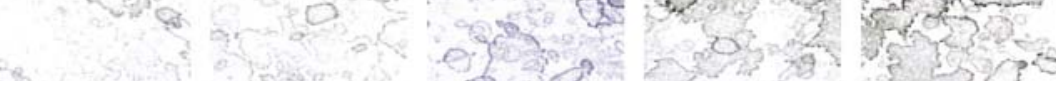




\section{Part 3_Opportunity Proposal, case studies and mechanisms}




\section{Public Interiors}

We do not ordinarily build adjacent to the public interior amenities. Public space can be inside, such as museums, galleries, lobbies and the city in general. "Outside and inside form a dichotomy of division. It has the sharpness of the dialectics of yes and no, which everything decides." ${ }^{10}$

Apartments commonly do not have a space reserved for public activities that is shared. They would provide high levels of interaction among people who are residents and visitors to the space.

\section{Design Strategy}

Some of the key strategies include reducing personal space. A key part is to merge all the living rooms into a shared space. Another will be improving shared living spaces through size, such as making them larger and utilising those spaces more like a public interior such as galleries, museums and such where anyone can use and recreate.
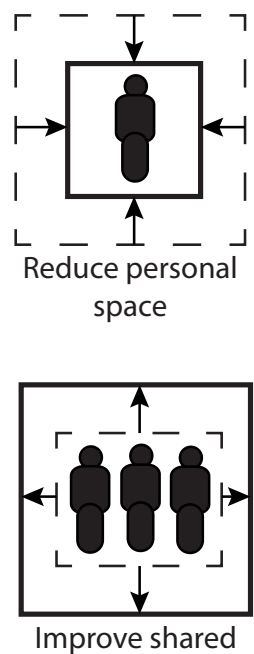

space through

size

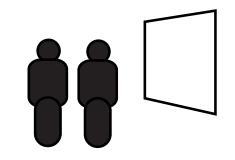

Improving shared spaces through

Art

Fig. 3.0 Key design strategy 


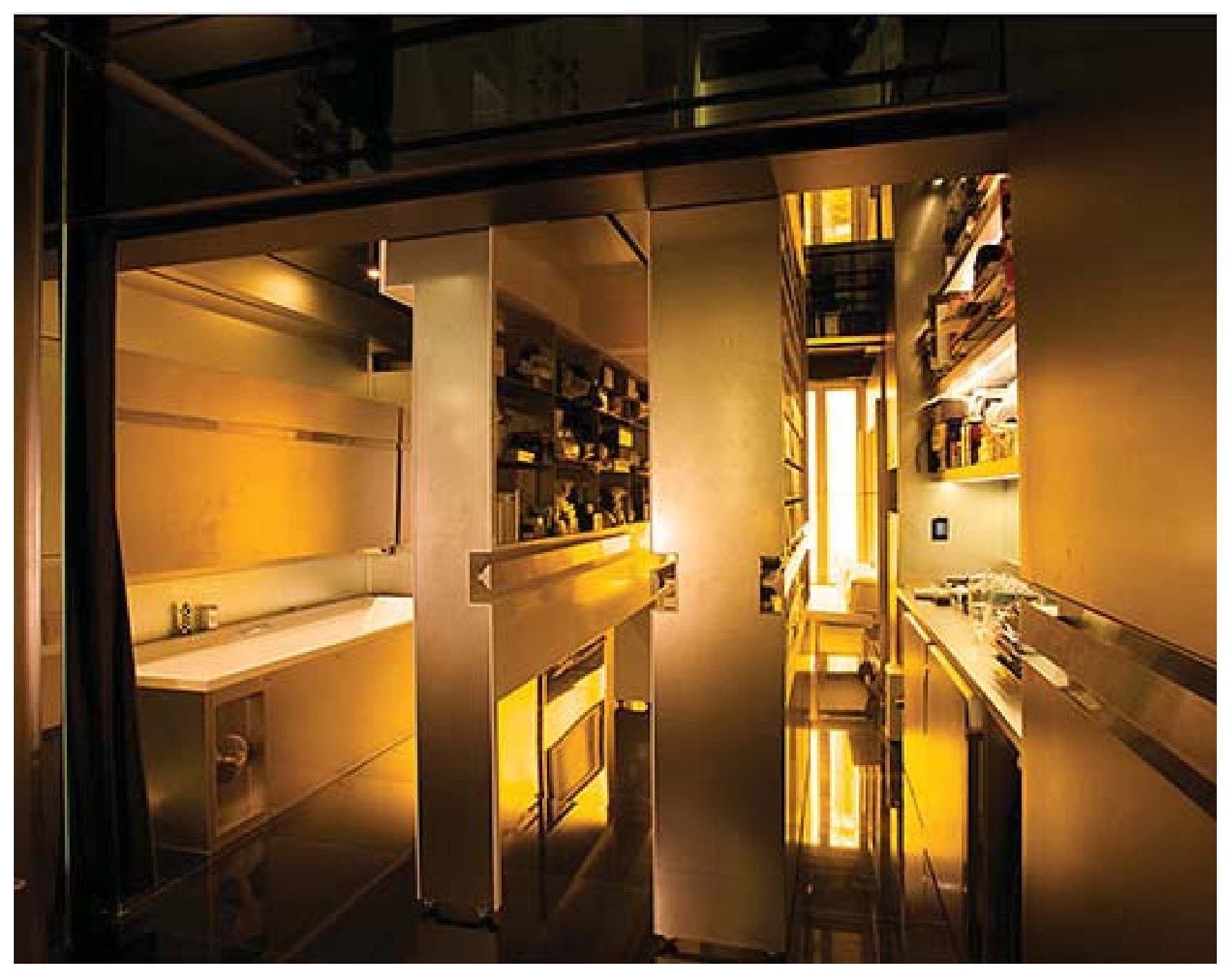

Fig. 3.1 Gary Chang's apartment (Retrieved Feb. 5 2014),

http://www.homedsgn.com/2011/05/07/a-tiny-apartment-in-hong-

kong-transforms-into-24-rooms/ 


\section{Gary Chang's Apartment}

Hong Kong

Gary Chang lives in a typical residential complex in Hong Kong. The apartment is one of 370 units in a 17-story building located in Hong Kong, China. "When Gary Chang was 14 years old he moved into the seventh floor of the residential high rise. His parents, three younger sisters and incredibly although not unusually for Hong Kong - another woman shared the $32 \mathrm{~m}^{2}$ small apartment. Gary Chang himself slept in

"The city is your home, not just your home." 12 Gary Chang the living corridor."11

The apartment was a life laboratory that Chang used to test the constraints of the $4 \mathrm{~m} \times 8 \mathrm{~m}$ apartment. The different renditions of the apartment occurred in 1987, 1989, 1998 and 2006.

${ }^{11}$ http://blog.kineticarchitecture.net/2011/03/32m2/ (November 2013)

${ }^{12} \mathrm{http}: / /$ www.youtube.com/watch?v=WB2-2j9e4co (October 2013) 


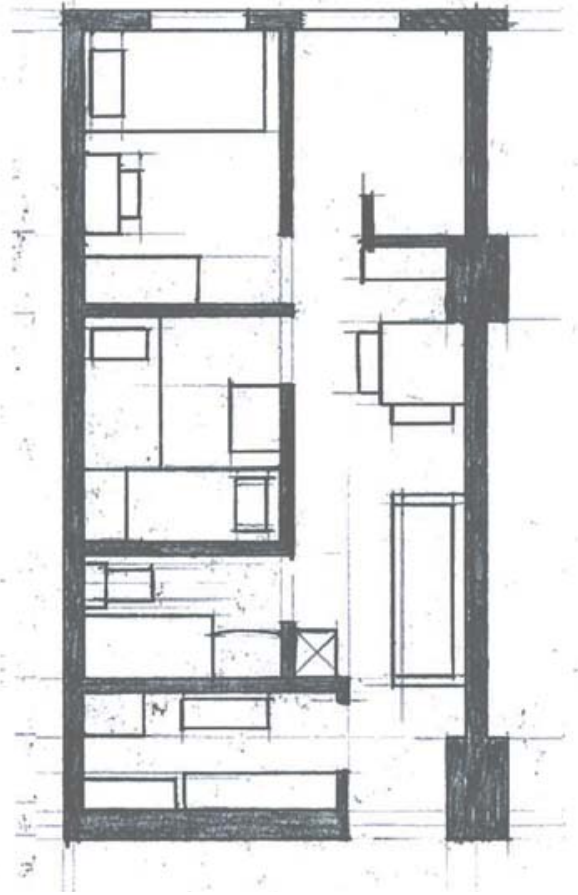

1976

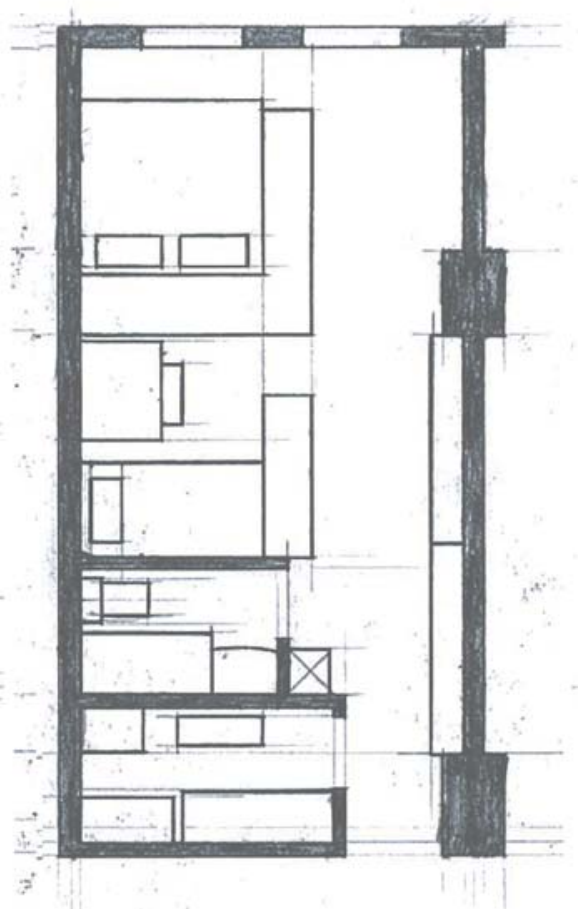

1987

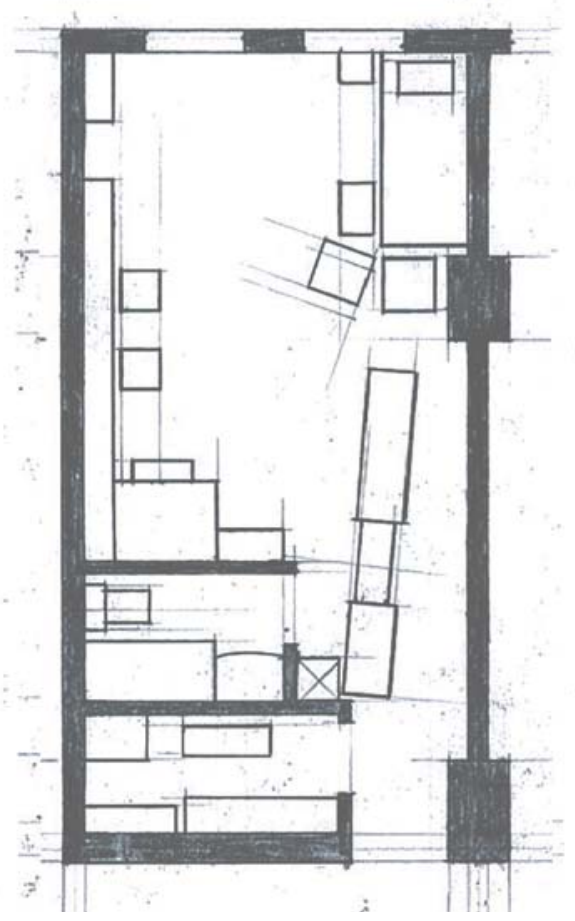

1989 


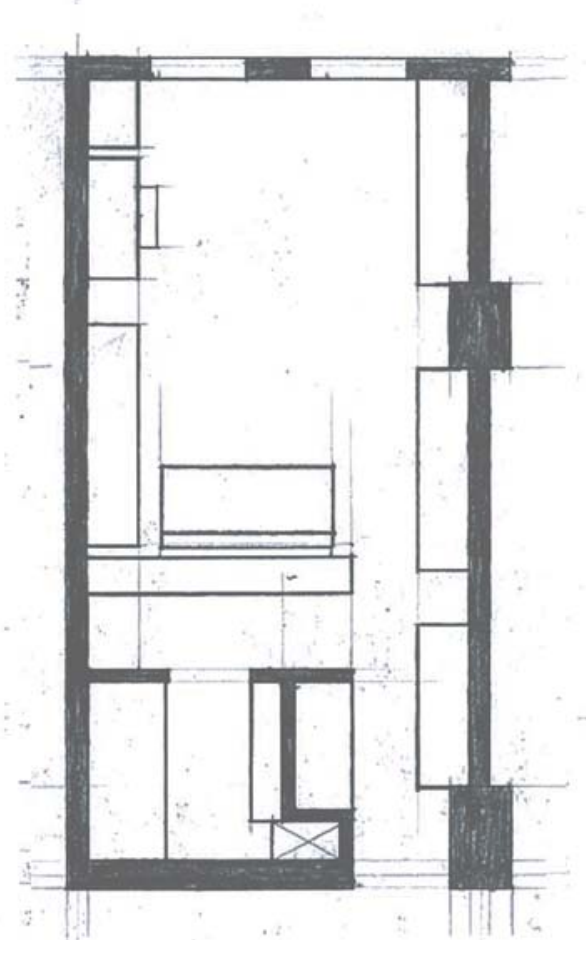

1998

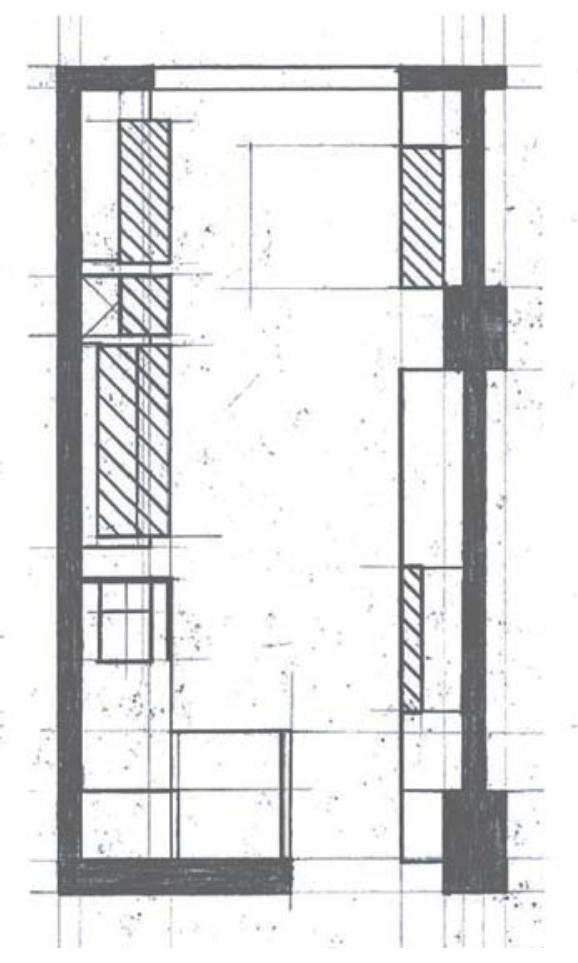

2006
Fig. 3.2 Gary Chang's apartment progression 1:100 


\section{Unusable walls}

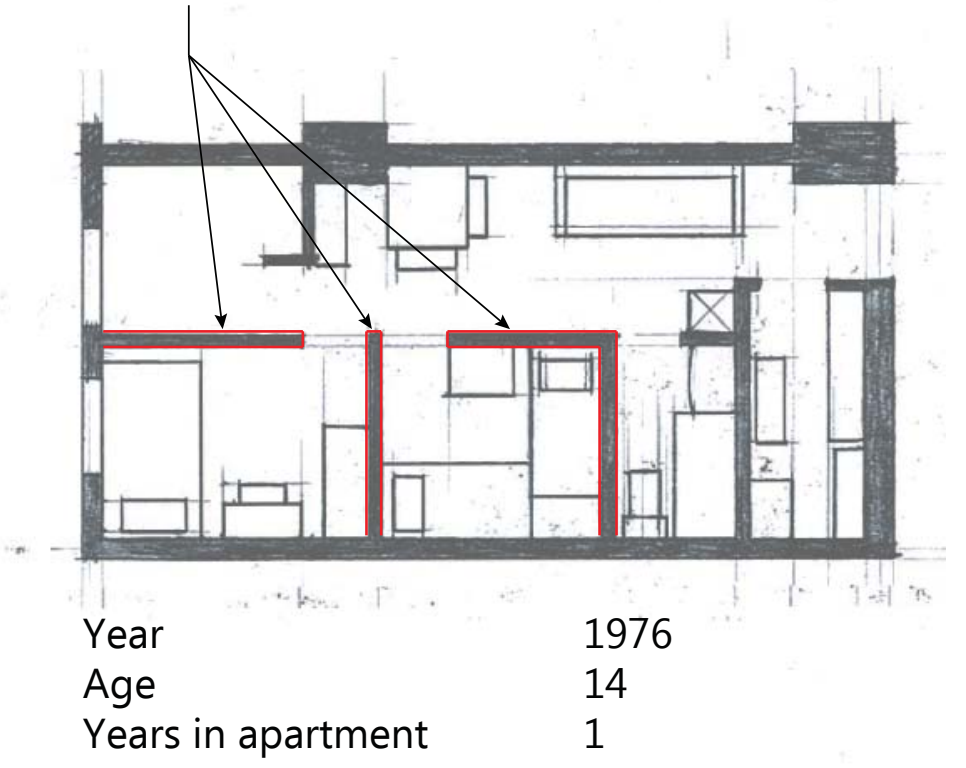

Figure 3.3 - Gary Chang's Apartment 1:100

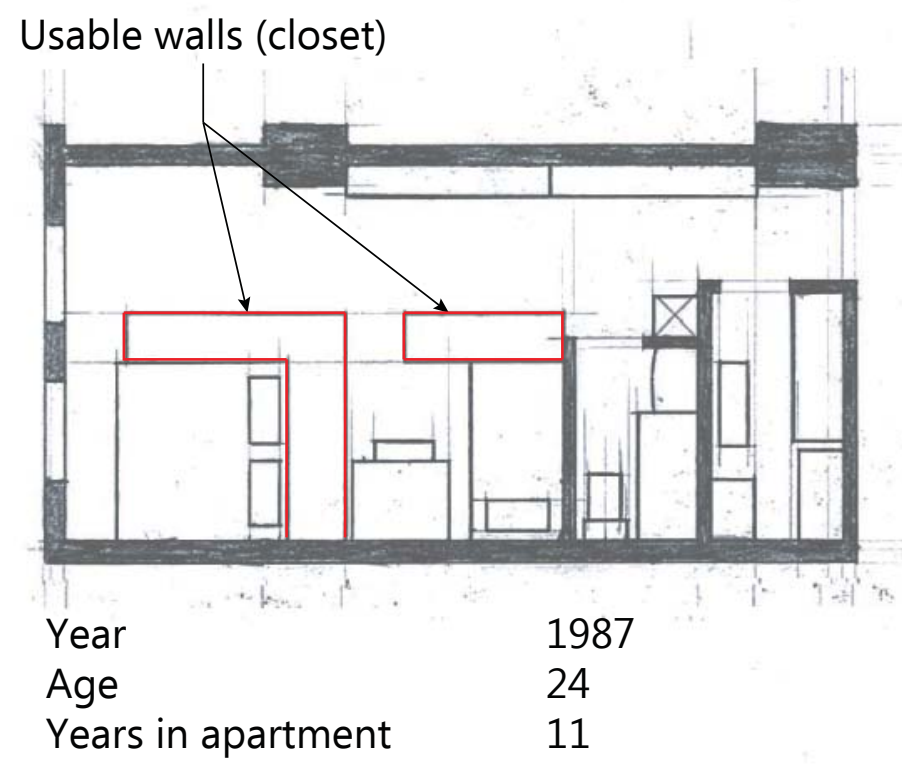

Figure 3.4 - Gary Chang's Apartment 1:100 


\section{Early Progression}

The first stage of Chang's apartment has an inefficiency that is exposed after his first renovation. Notably the walls forming the bedrooms simply acted as a physical barrier and nothing else.

-Walls serve only as partitions (Fig. 3.3)

Chang's first renovation, compared to the original, is the walls provide an added function which is storage. A minor consequence is adding width to these spatial dividers but in return increases the amount of storage space.

-Walls serve as partitions + storage (Fig. 3.4)

This can also be applied to corridors. Such as instead of corridors as circulation, it could also be used for circulation and public, social functions.

-Circulation + public amenity

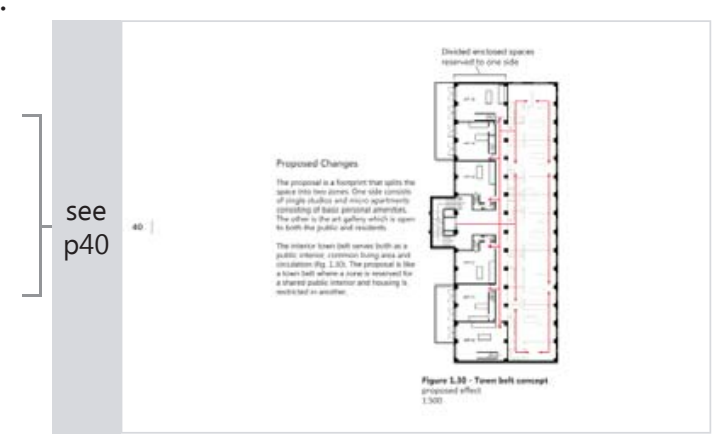


Bed space with loose boundaries

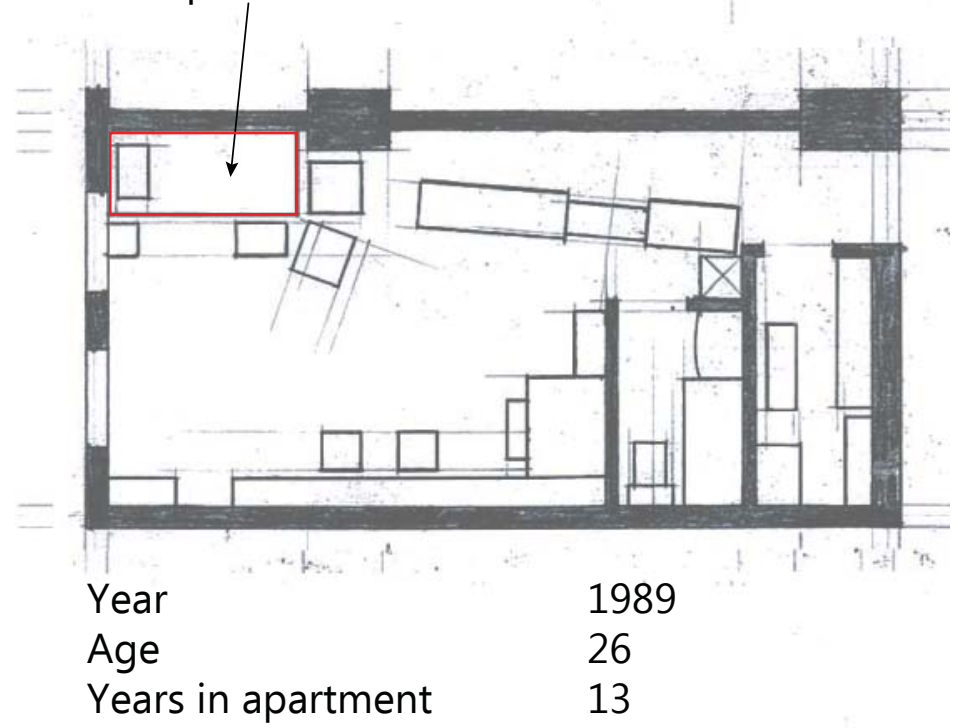

Fig. 3.5 1989 Gary Chang's Apartment plan

Bed corner

1:100

The apartment has a much larger living space. The bed is given a minimal amount of room, placed up in the corner in its own partially separated from the living area>

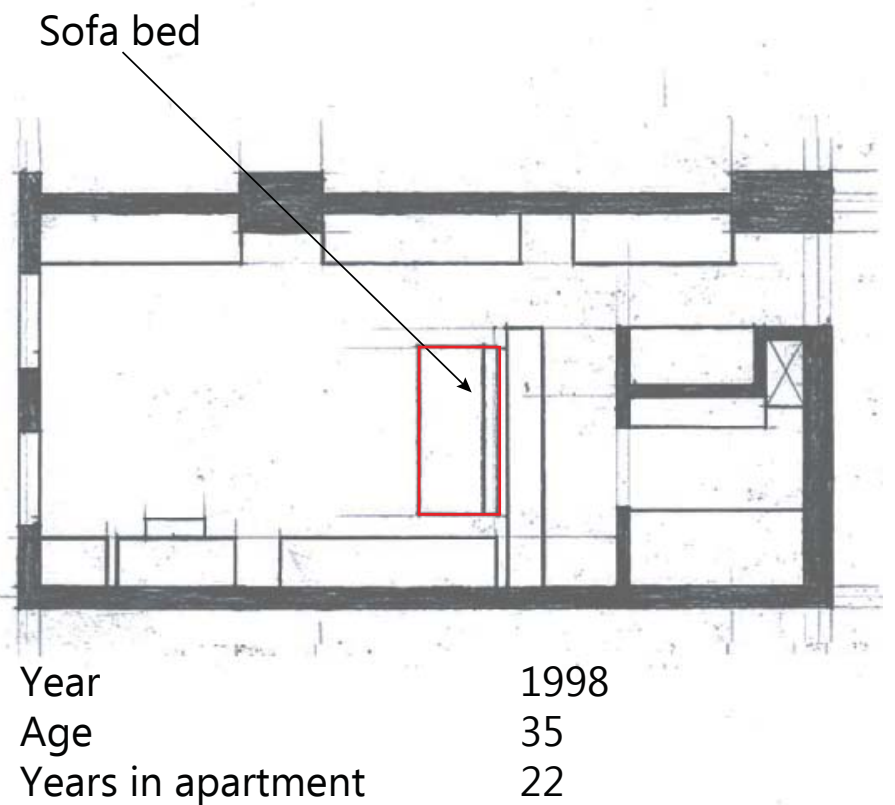

Fig. 3.6 1998 Gary Chang's Apartment plan Sofa bed

1:100

The bed is now a sofa bed and is now a part of the living area, as opposed to having its own space. The bathroom and kitchen hava been rearranged. 


\section{One Room Living}

A solution differing from cellular interiors is perhaps its opposite: one room living. In 1989 Chang took a major step in the next phase of his apartment's development (Fig 3.5). No longer is there a room reserved for sleeping.

"One of the most common ways to achieve that flexibility is to remove the interior walls and partitions, creating not just more space, but space that can be taken advantage of in its entirety for any household function." 13

"The term 'one room living' also encompasses the group of people

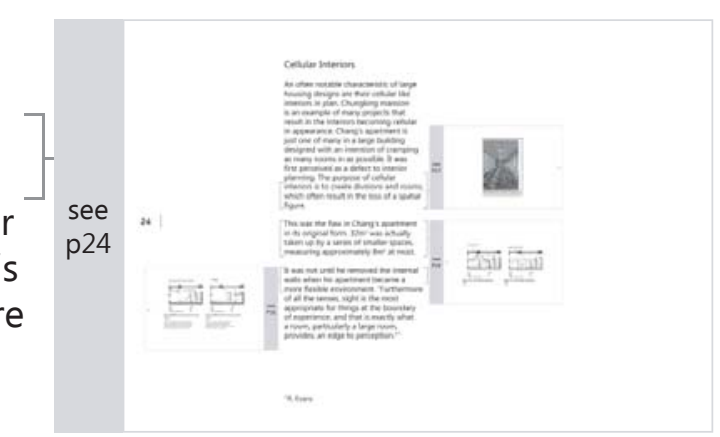
who choose to live open-plan, either because of increasing building costs or in a fight against the claustrophobia of little boxes. The idea behind open-plan, after all, is not really to have everything in full view, but to gain more space either physically or psychologically by disposing of walls, corridors and doors."14

"The central free-zone becomes the actual space for living, working, eating, resting, studying, dressing, etc." 15 


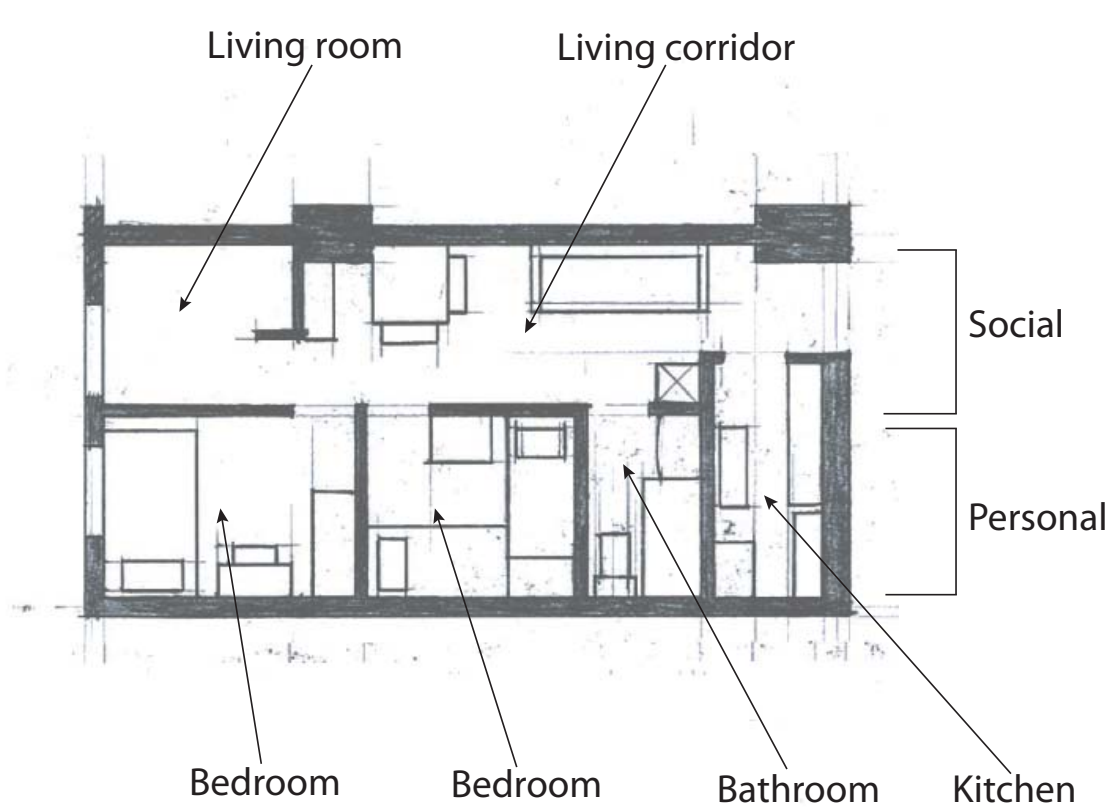

Figure 3.7 - 1976 Gary Chang apartment plan Social - personal zones 1:100

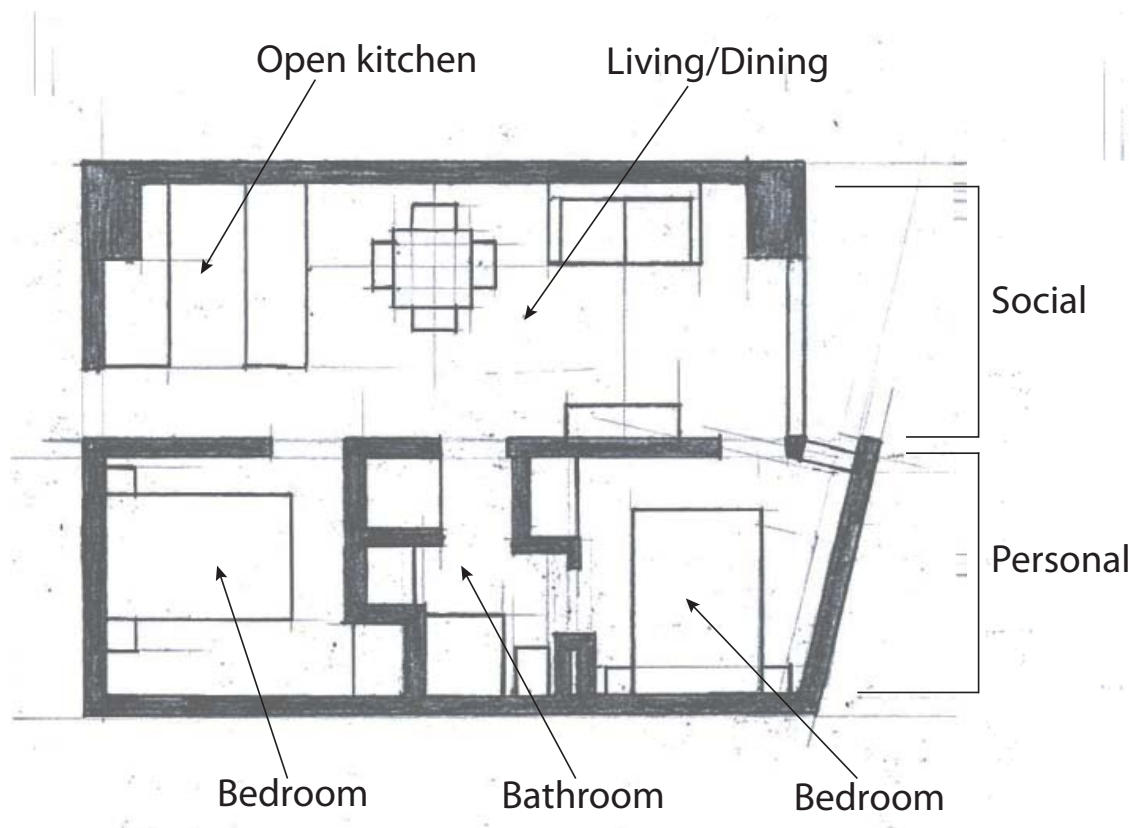

Figure 3.8 - Typical Soho apartment plan Social - personal zones 1:100 
Soho Apartment and 1976

Chang's Apartment

Notice the similarities between the Soho apartment in Wellington built in 2010 and Chang's flat in 1976 and even the version from 1987 (Fig. 3.8 and Fig. 3.7). All three have a similar half and half composition where the bedrooms and bathrooms are aligned next to a larger living space or common space.

A common similarity is there are two social zones: the social and personal space. However there is a third space that connects these apartments as a part of a larger building.

Generally the personal zone consists of the bathroom and bedrooms. In Chang's original apartment the kitchen was previously on the personal zone whereas the typical Soho apartment has an open kitchen on the social zone.

The social zone is generally the largest, most open space consisting of a living room. The living room is very much a private space relative to other residents in the apartment.

Notably some experiments employ a half and half footprint which are the precursor to the town belt concept.

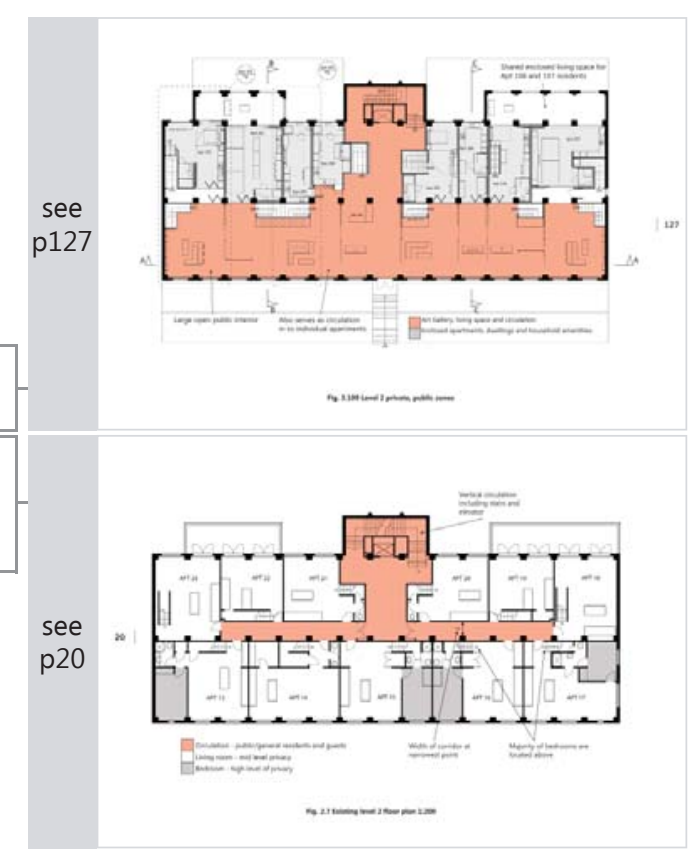




\section{Proposed Changes}

The proposal is a footprint that splits the space into two zones. It is similar to the social-personal zones that are common in some small apartments. One side consists of single studios and micro apartments consisting of basic personal amenities. The other is the art gallery which is open to both the public and residents.

The interior town belt serves both as a public interior, common living area and circulation (Fig. 3.9). The proposal is like a town belt where a zone is reserved for a shared public interior and housing is restricted in another.

Divided enclosed spaces reserved to one side

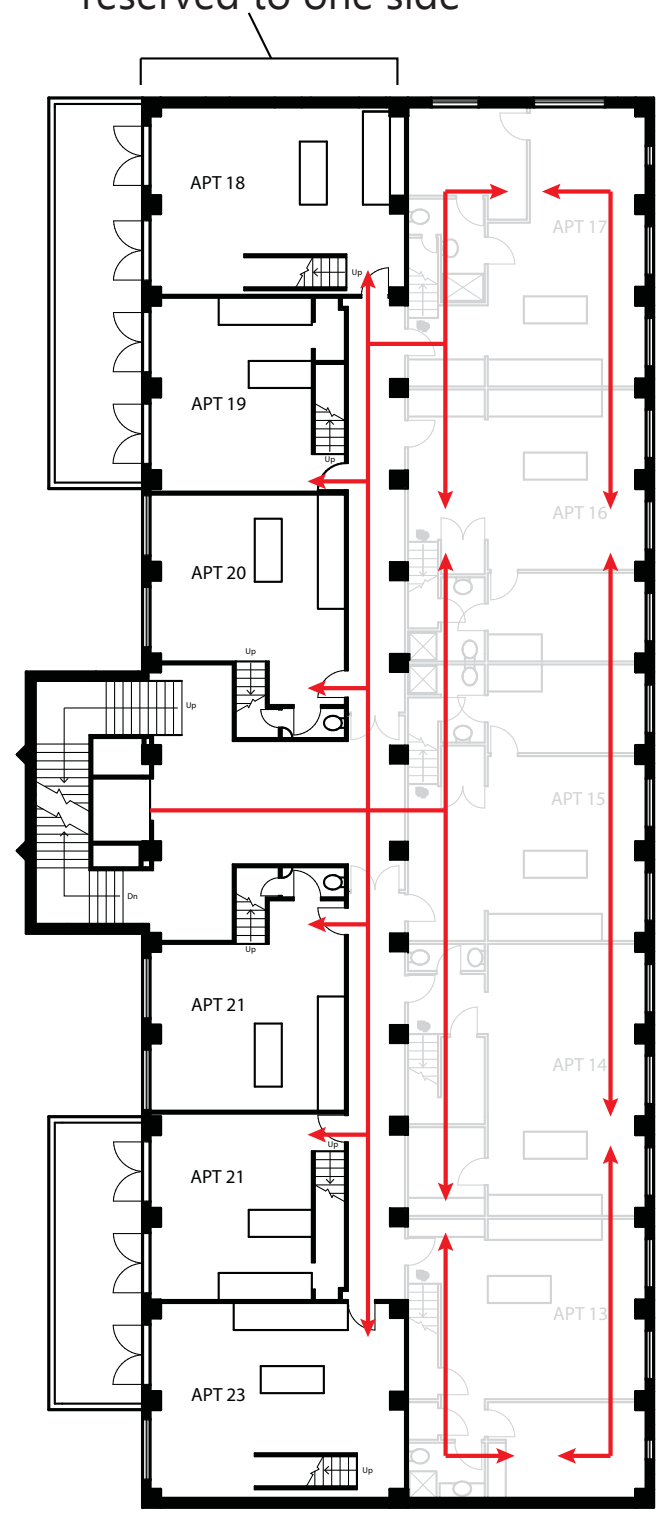

Figure 3.9 - Town belt concept proposed effect 


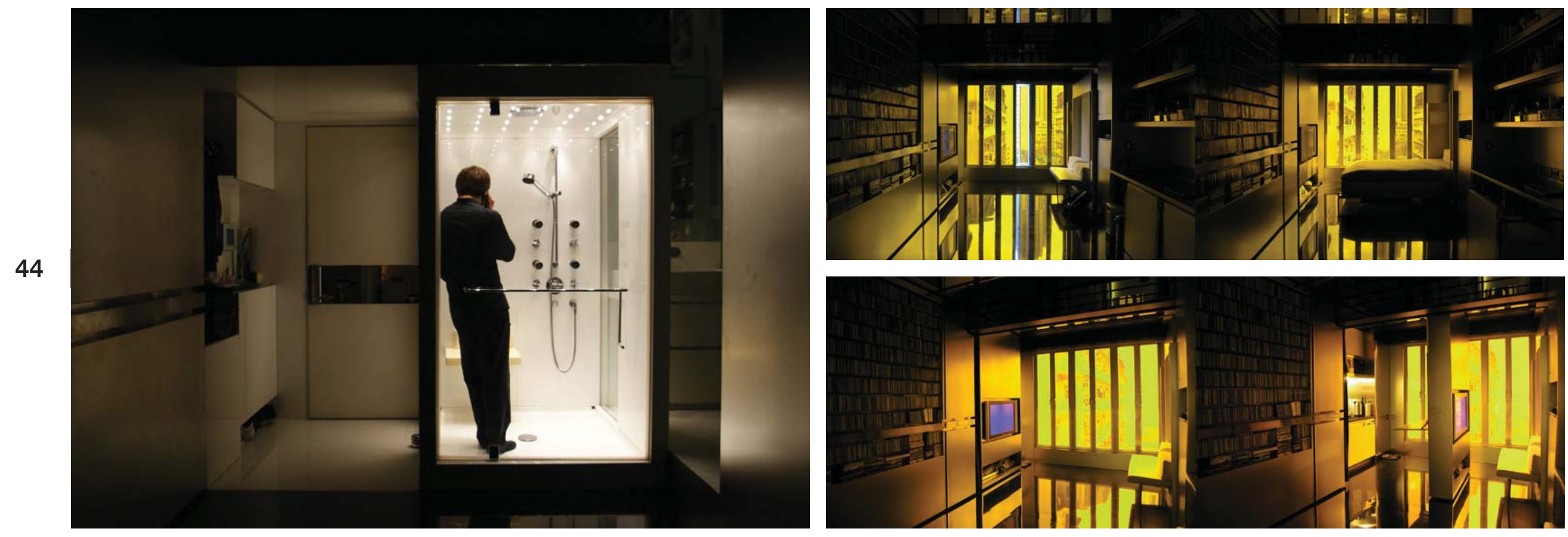

Fig. 3.11 Gary Chang's apartment $32 \mathrm{~m}^{\mathbf{2}}$ (Retrieve Feb. 5 2014). http://www.designboom.com/architecture/gary-chang-on-urbanism-and-hismetamorphic-apartment/ 


\section{Reveal \& Conceal}

\section{Mechanism 1}

\section{Case Study - Gary Chang}

The following experiments are that the apartments are concealed during the day and revealed in the afternoon.

Motivated from Chang's apartment, it is known for its sliding walls that can open up, revealing hidden amenities, such as a tub or kitchen and then conceal them when they are no longer needed. Furthermore it provides an ability to increase our usage of space without requiring much floor space.

It is a single studio and the following experiments will look at ways of applying similar techniques for public and private spaces such as the possibility of a public interior that can transform into a series of apartments.

Early on, this mechanism was tested to see the potential of a transforming interior. The early function of the interior was that the interior is a public interior during the day and opens into apartments later. 


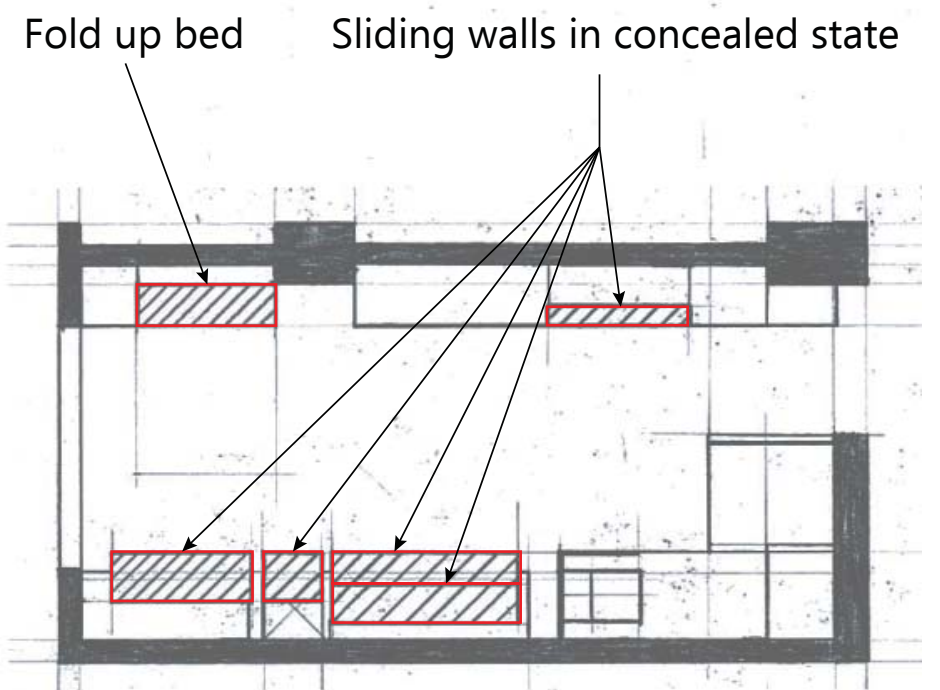

Fig. 3.12 2006 Gary Chang's apartment Closed Concealed

1:100

Known for its sliding walls, these 5 sliding componants dramatically alter the space and reveal and conceal various features and amenities at the requirement of the inhabitant.

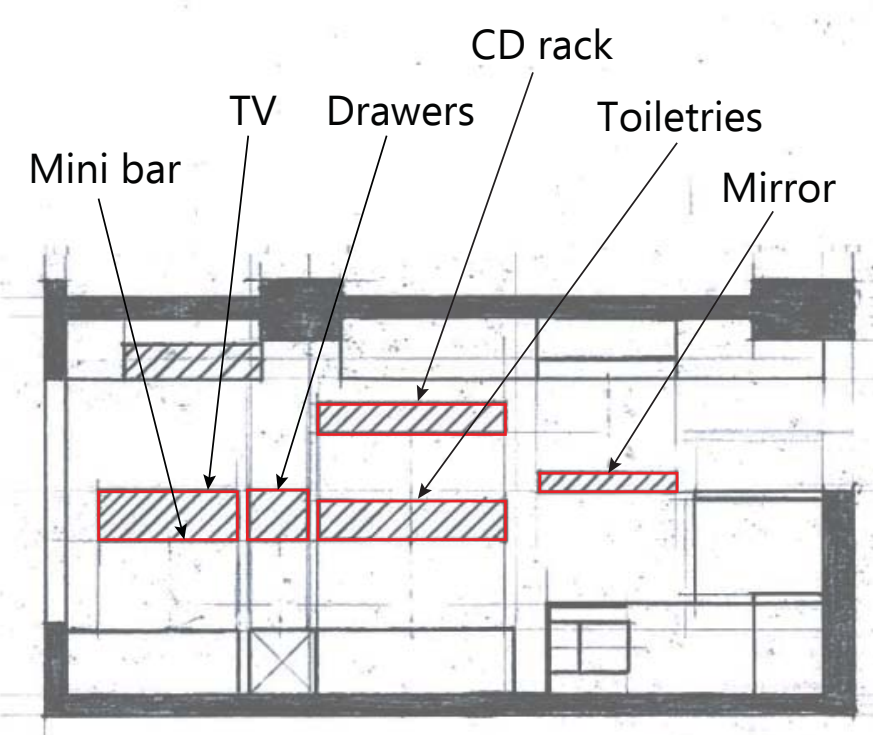

\section{Fig. 3.13 2006 Gary Chang's apartment}

Sliding walls

1:100

Because of the sliding walls, the number of wall surfaces double or triple, each serving a specific storage unit like $C D$ rack and toiletries.

Apart from walls that can slide, they also feature several uses and storage. This creates layers of different usages.

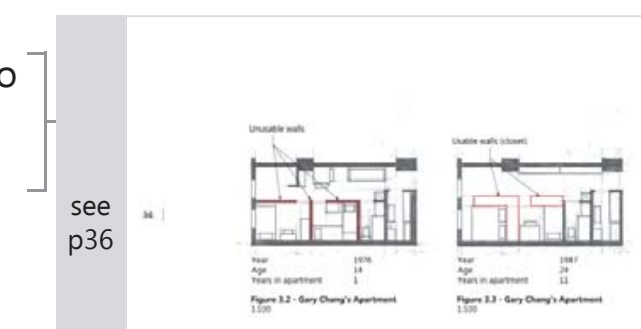


Walk in closet

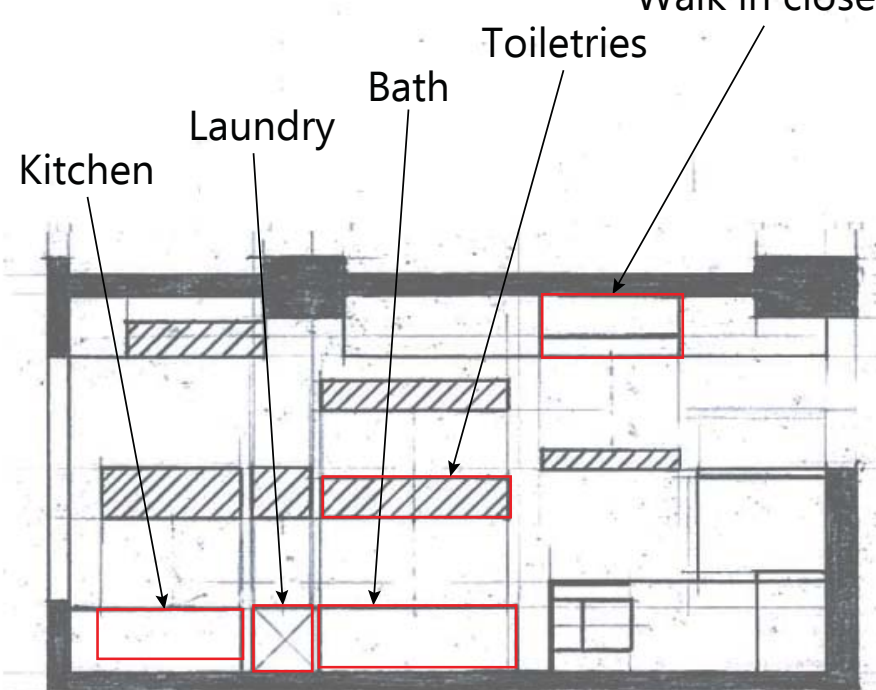

Fig. 3.14 2006 Gary Chang's apartment

Hidden utilities

1:100

Behind the series of sliding walls are various household features that do not require extensive usage. Those include the bed, kitchen, laundry and a bathtub.
Four sections,

four uses

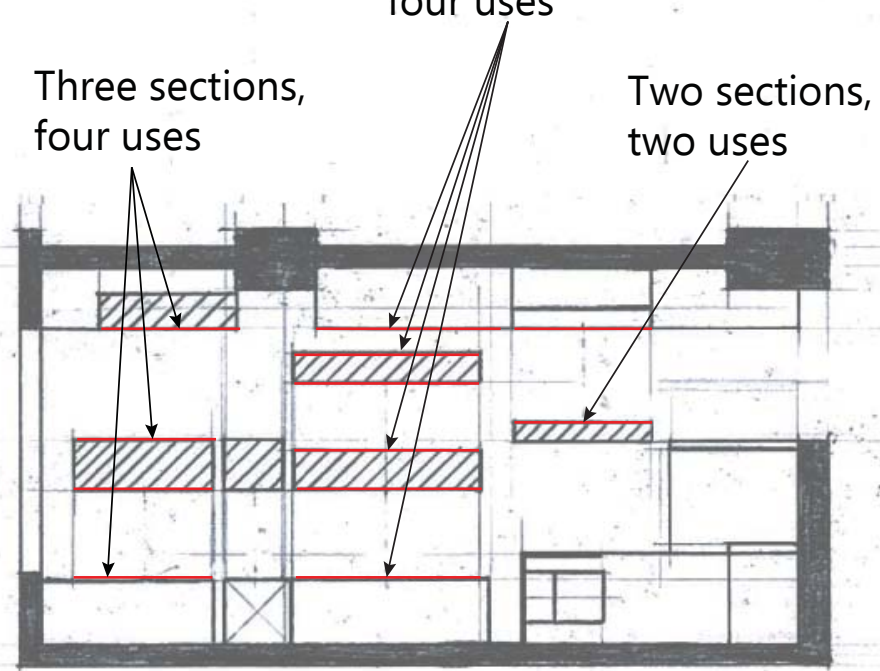

Fig. 3.15 2006 Gary Chang's apartment

Concealed - number of wall surfaces 1:100

The ability to increase the number of wall surfaces that have useful functions iincreases the usage and flexibility of the space. 


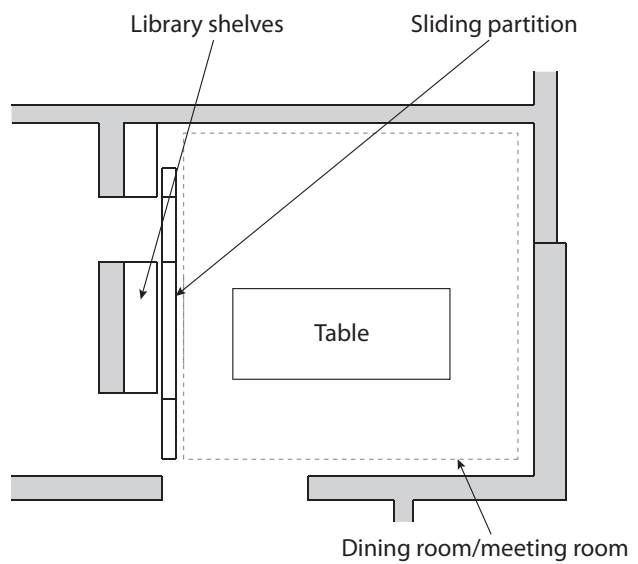

48

\section{Expansion \& Compression}

"Called Switch, the project features one partition that slides out over the dining table to create a meeting room on one side and library on the other." ${ }^{16}$ The sliding panel has a different effect than Chang's apartment: expansion and compression. On one side of the panel is a library, the other a dining room, which easily can be used as a reading/ study space. The panel slides back and forth, compressing and expanding either space.

This mechanism however is rarely utilised mainly because of the wall's singular purpose. The sliding walls

in Chang's apartment were more effective because they consist of other functions rather than a partition and is the same occasion from Chang's early progression.

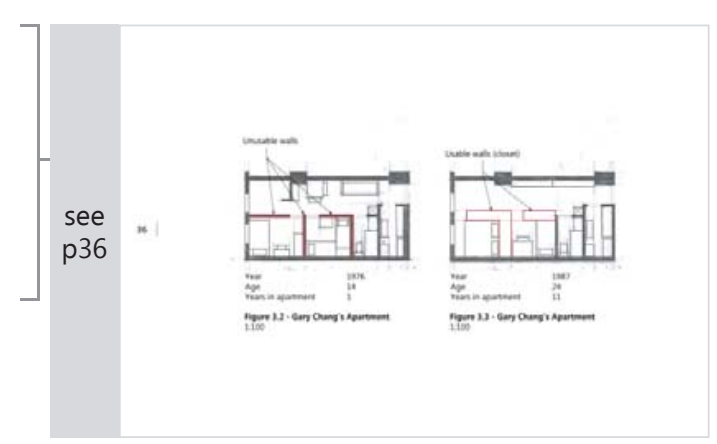



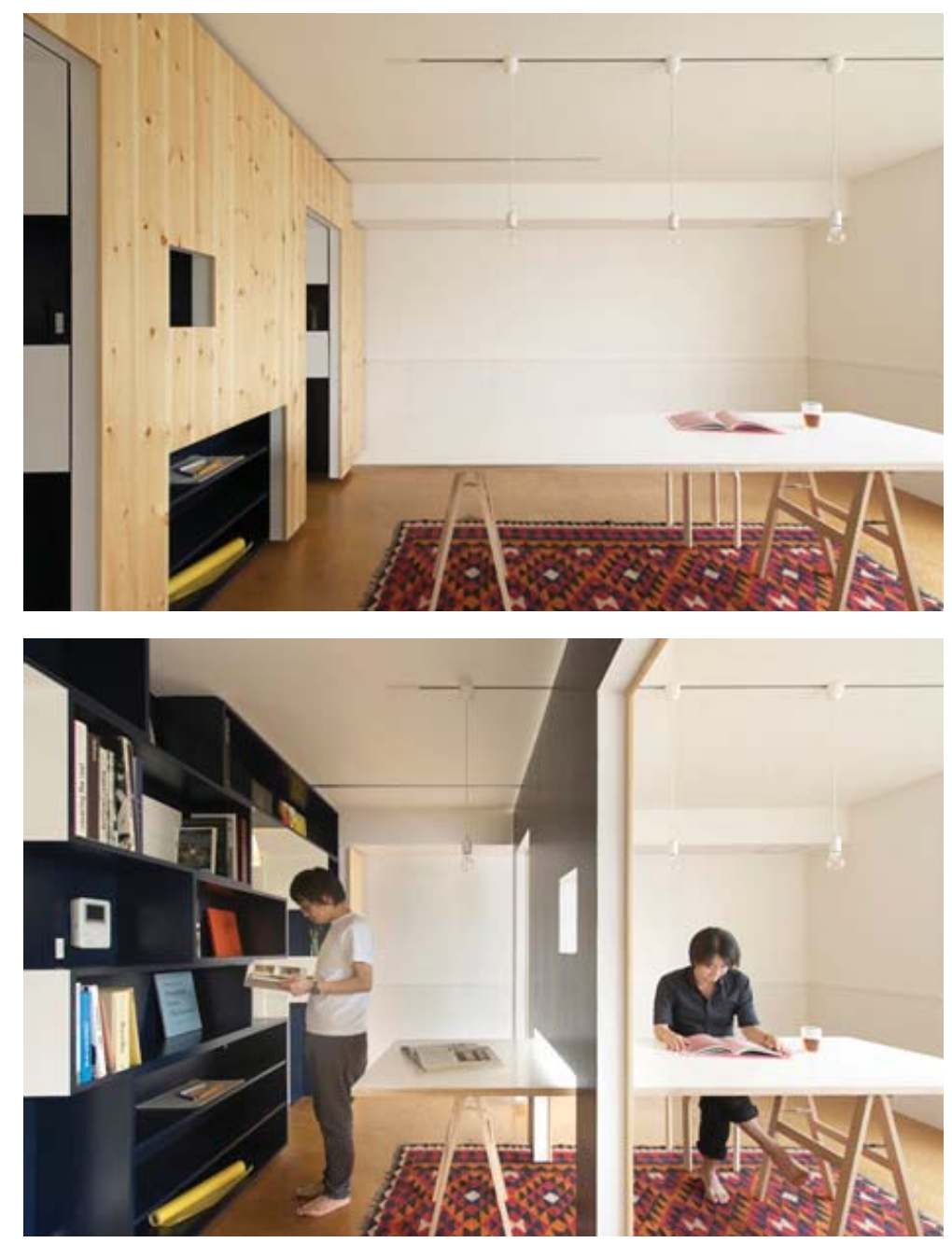

Fig. 3.17 Switch interiors (Retrieved Feb. 5 2014) http://www.dezeen.com/2010/10/09/switch-by-yuko-shibata/ 
Home and Art Gallery Examples

There are multiple examples of homes integrated with art galleries. They vary in how they were done. All are homes to a single household.

\section{Art Gallery and Living Space - Wheeler and Kearns}

This example uses colour and materials to distinguish the gallery from the living amenities. However the use of colour and materials have come to little use because it is more relevant to single entities. It would not work amongst a larger populace within an environment such as an apartment as colour coded spaces without physical boundaries would not create the necessary seclusion and privacy.
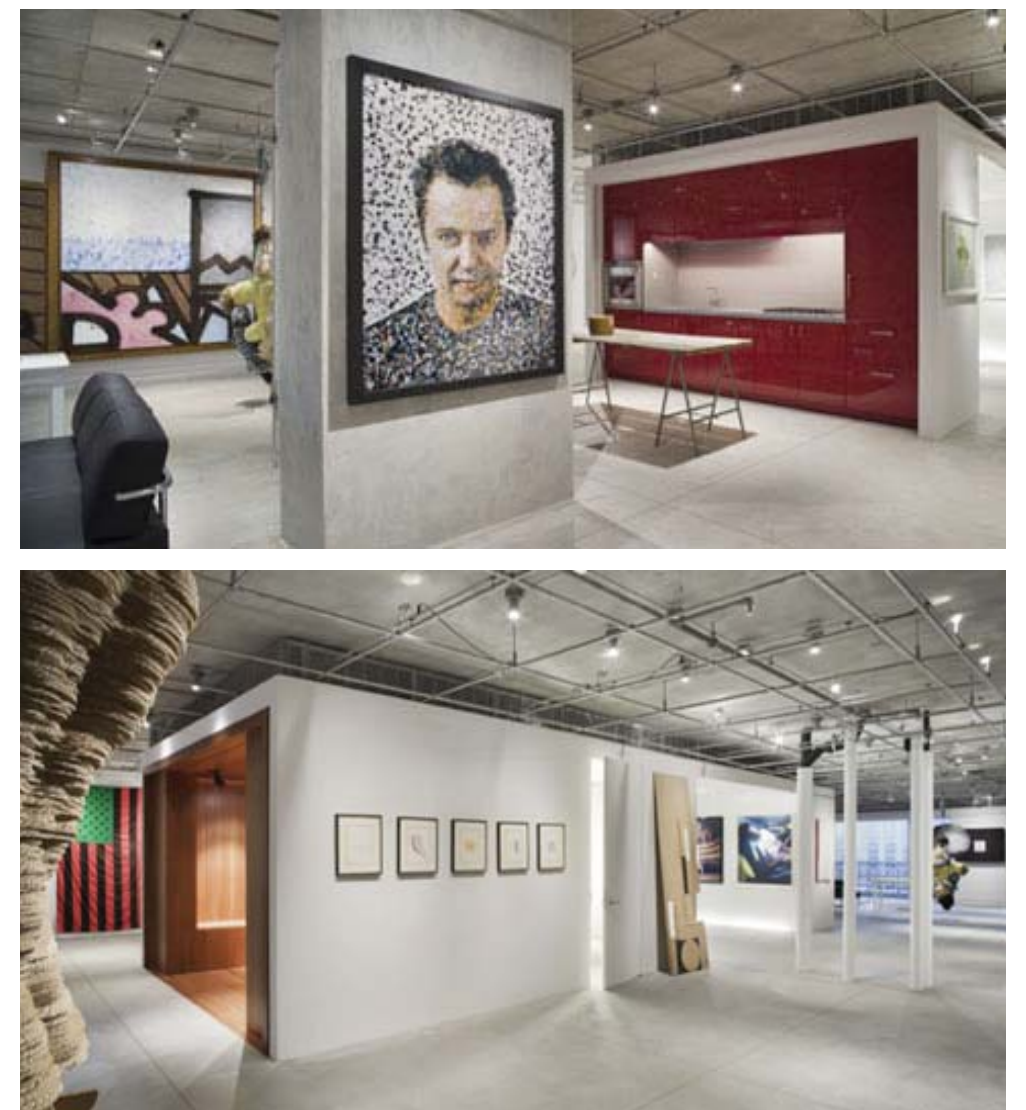

Fig. 3.18 Art Gallery \& living space (Retrieved Feb. 5 2014).

http://www.apartmenttherapy.com/art-gallery-livingspace-by-wh-68971 
Donald Judd's apartments -

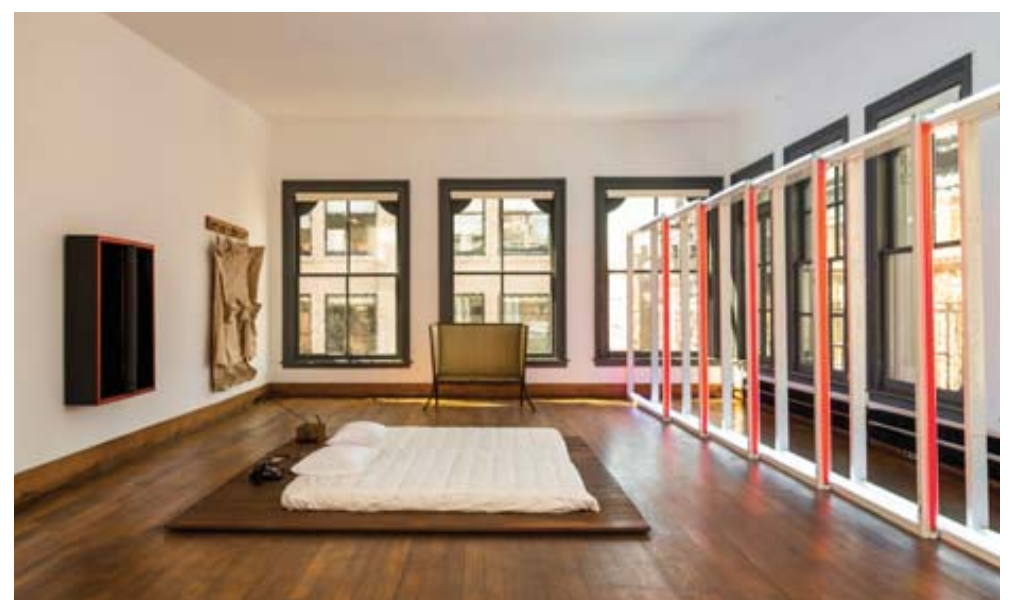

\section{Donald Judd/ARO}

"It was one of the first artist's lofts in Soho - not to mention in New York and is now almost the paradigmatic example of loft living." 17 Donald Judd's apartment is more of a relic to the late minimalist artist. It is a walk-through art gallery of the artist's former studio. The proximity between private and public amenities is similar to the Art Gallery and Living Area.

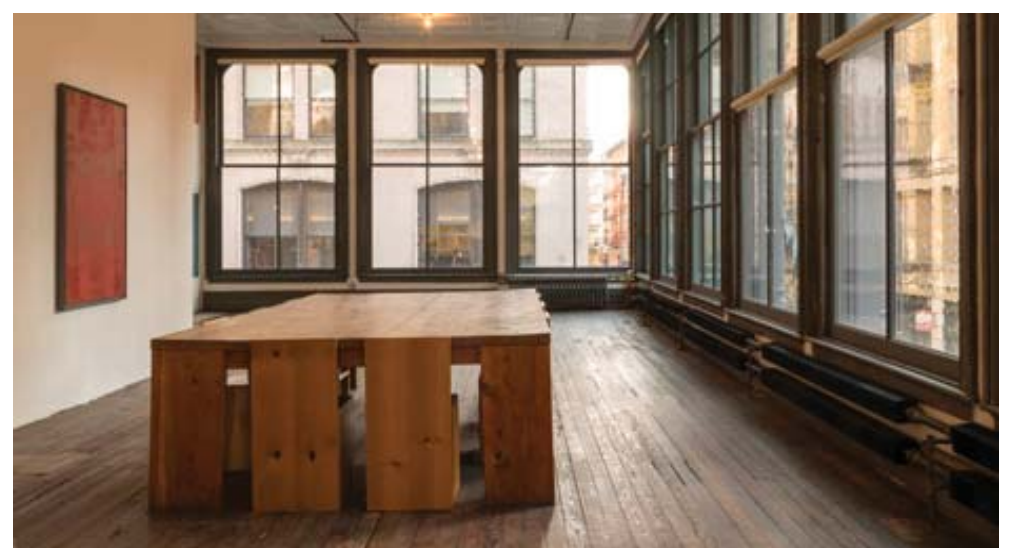

\section{Summary}

Fig. 3.19 Donald Judd's apartment (Retrieved Feb. 5 2014) http://www.dezeen.com/2013/05/23/donald-judds-home-and-studiorestoration-by-architecture-research-office/

The Art Gallery \& Living Space and Donald Judd's New York apartment were the least effective: mainly because of a lack of physical separation between what should be perceived as private and public space. The Art Gallery \& Living Space simply provided colour coded private amenities such as the kitchen and bathroom, while the majority of the space was generally white.

${ }^{17} \mathrm{http}: / /$ blog.ounodesign.com/2009/04/25/ donald-judds-loft-at-101-spring-street/ (March 2014) 


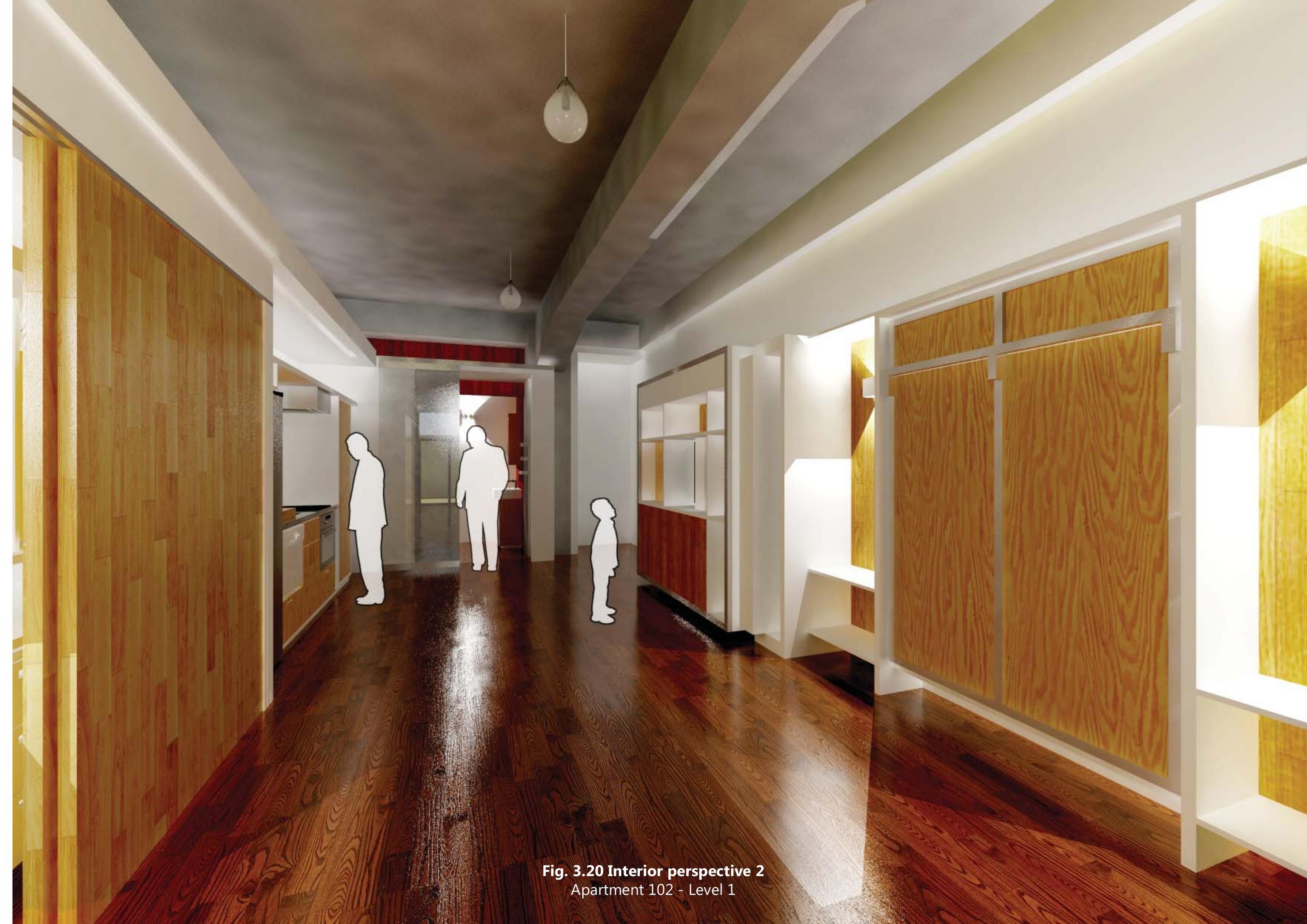




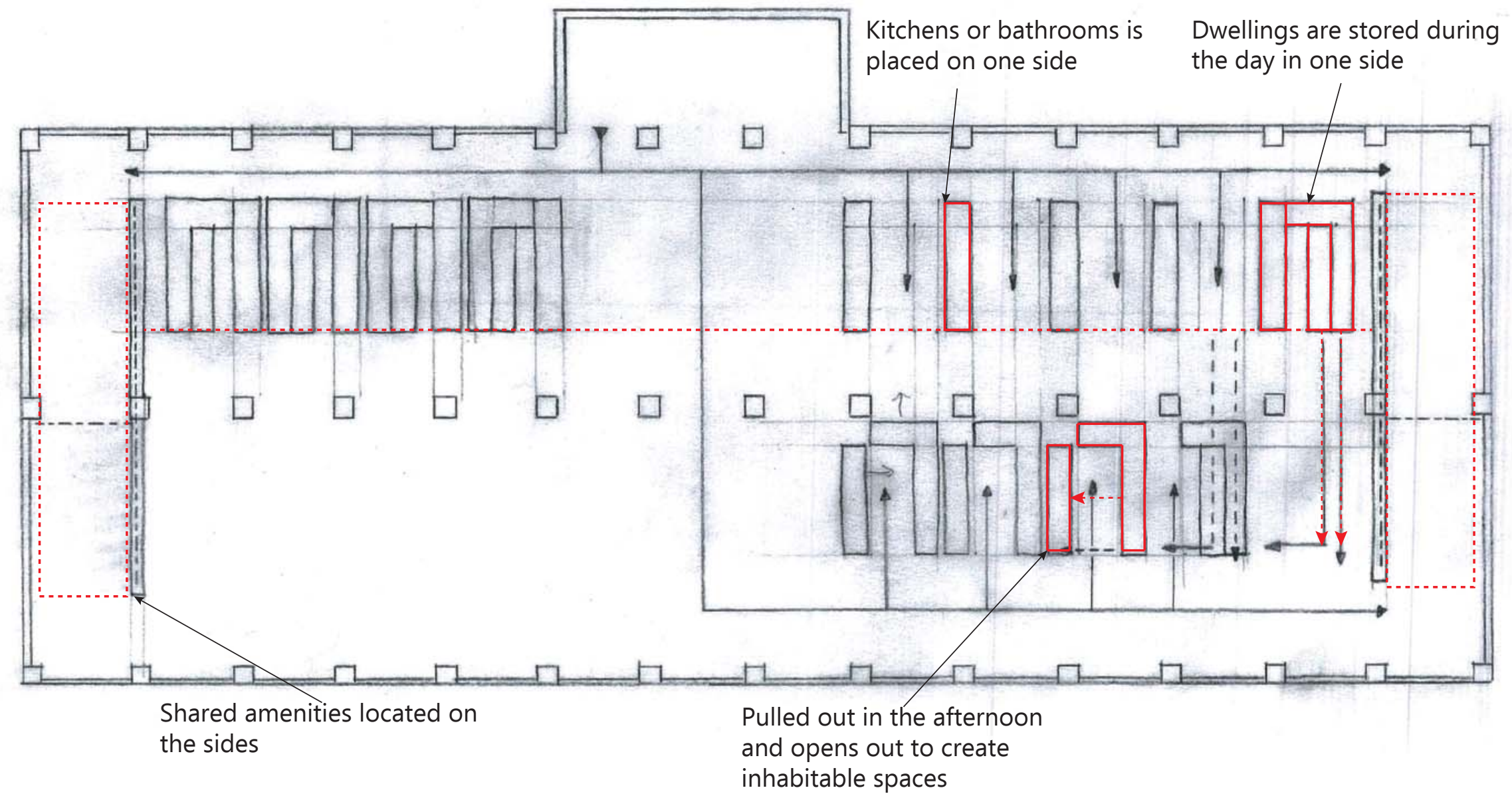

Fig.3.21 Reveal \& conceal iteration 1

Scale: 1:200

Sub-type: Half and half

Level: Undefined 
Sliding walls containing beds and storage reveal and con-

ceal personal spaces

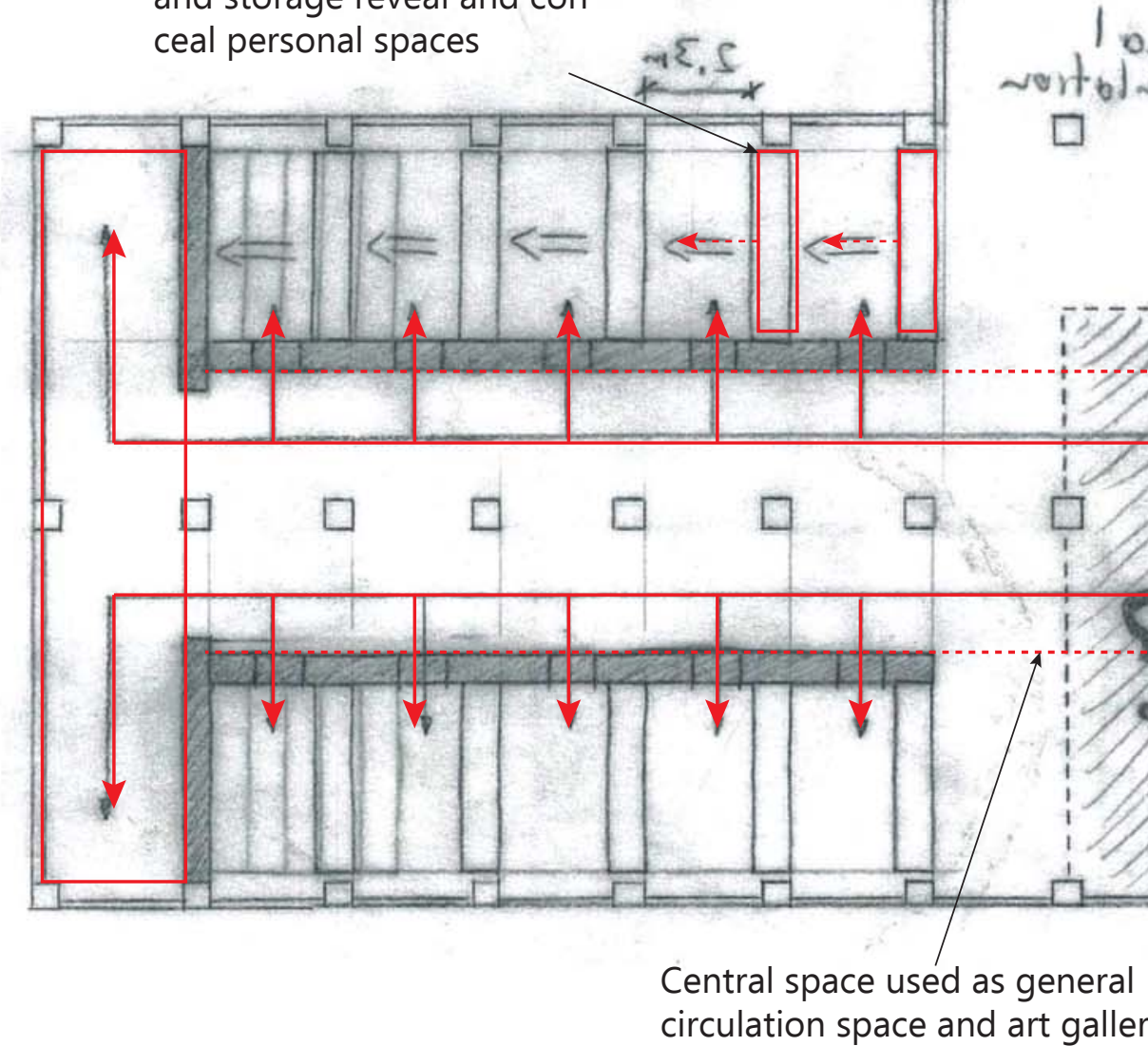

Works much like compactable storage shelves

b)

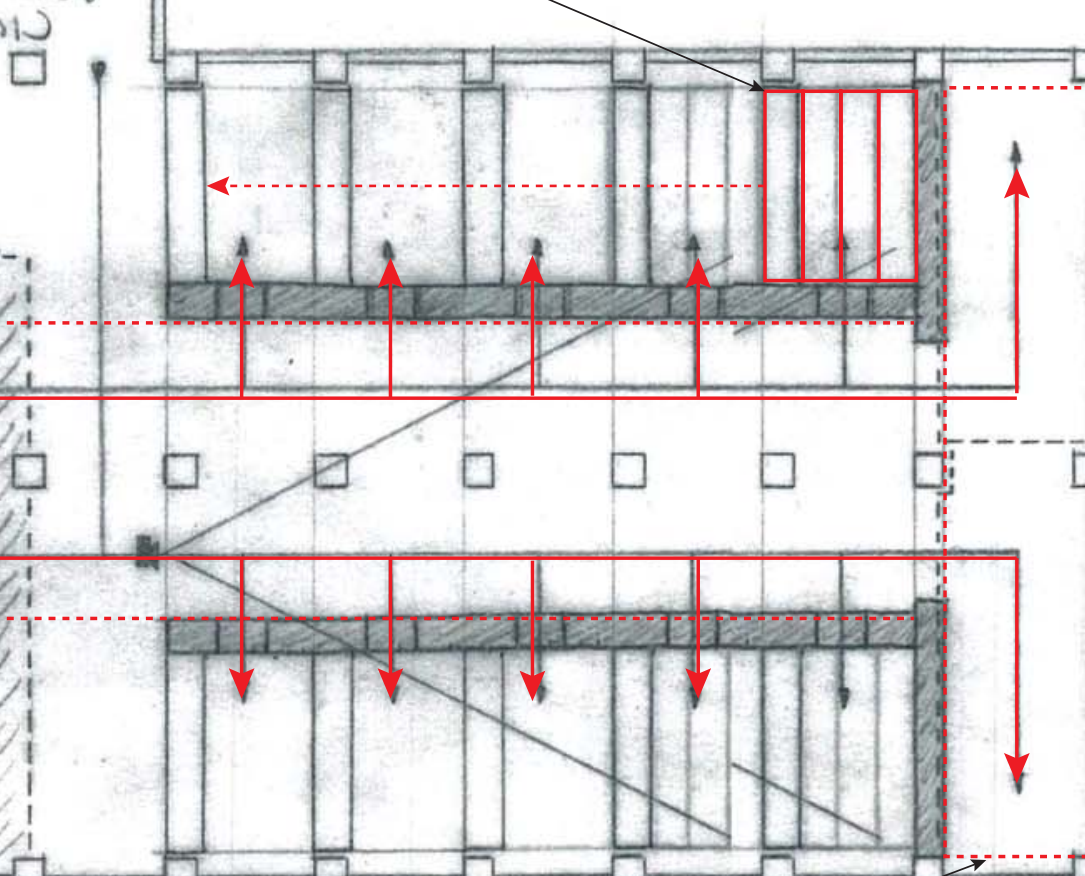

(1)

circulation space and art gallery

Shared household amenities

Fig. 3.22 Reveal \& conceal iteration 2

Scale: 1:200

Sub-type: Corridor

Level: Undefined

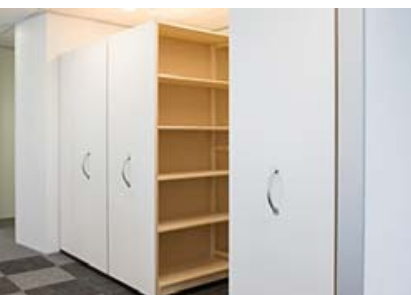

Fig. 3.23 Office storage system (Retrieved Mar. 2 2014) http://www.lundia.co.nz/products/mobile-shelving/manual/manualwestpac/ 


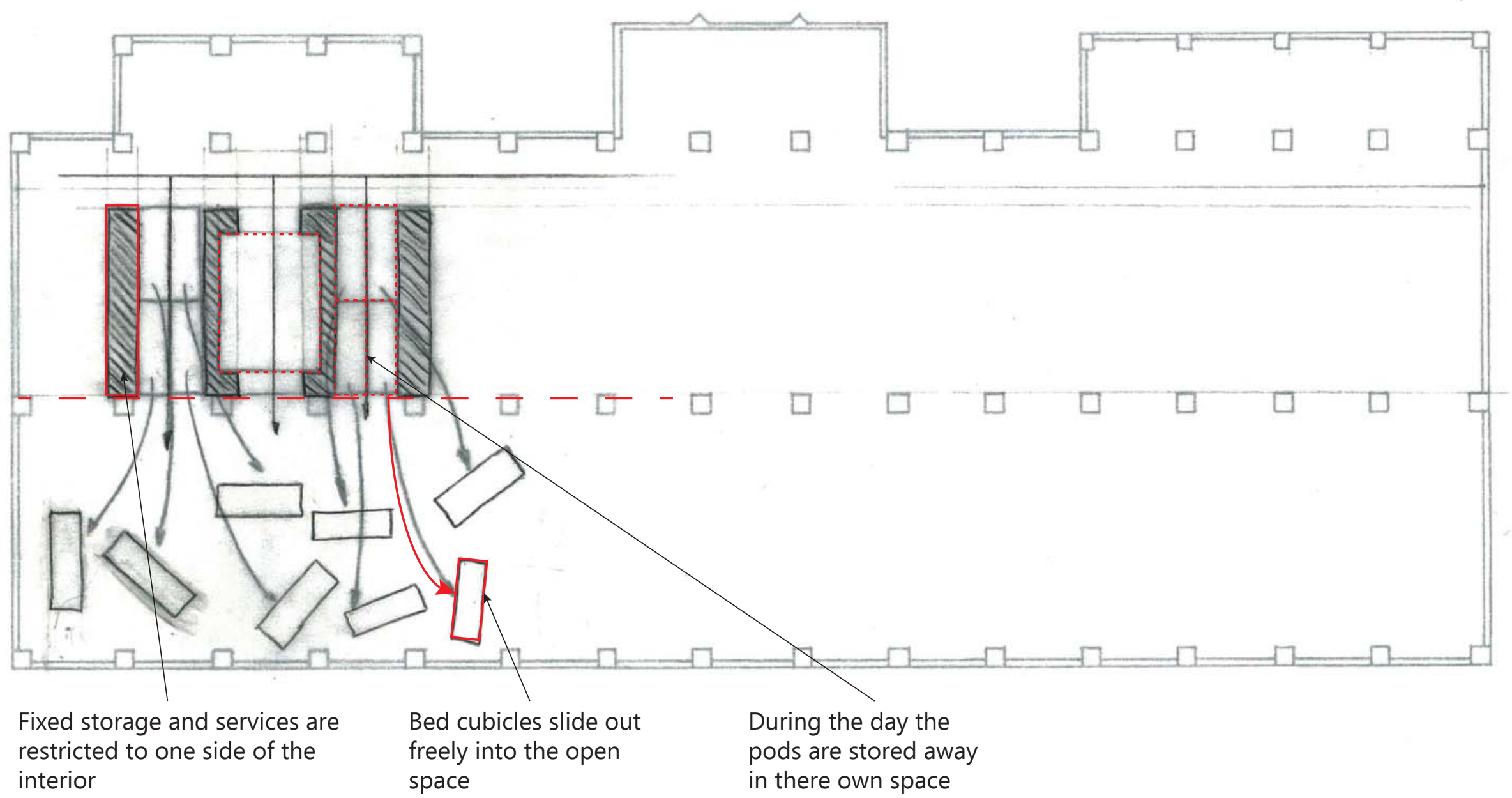

Fig. 3.24 Reveal \& conceal iteration 3

Scale: 1:200

Sub-type: Half and half + Mobile

Level: Undefined 


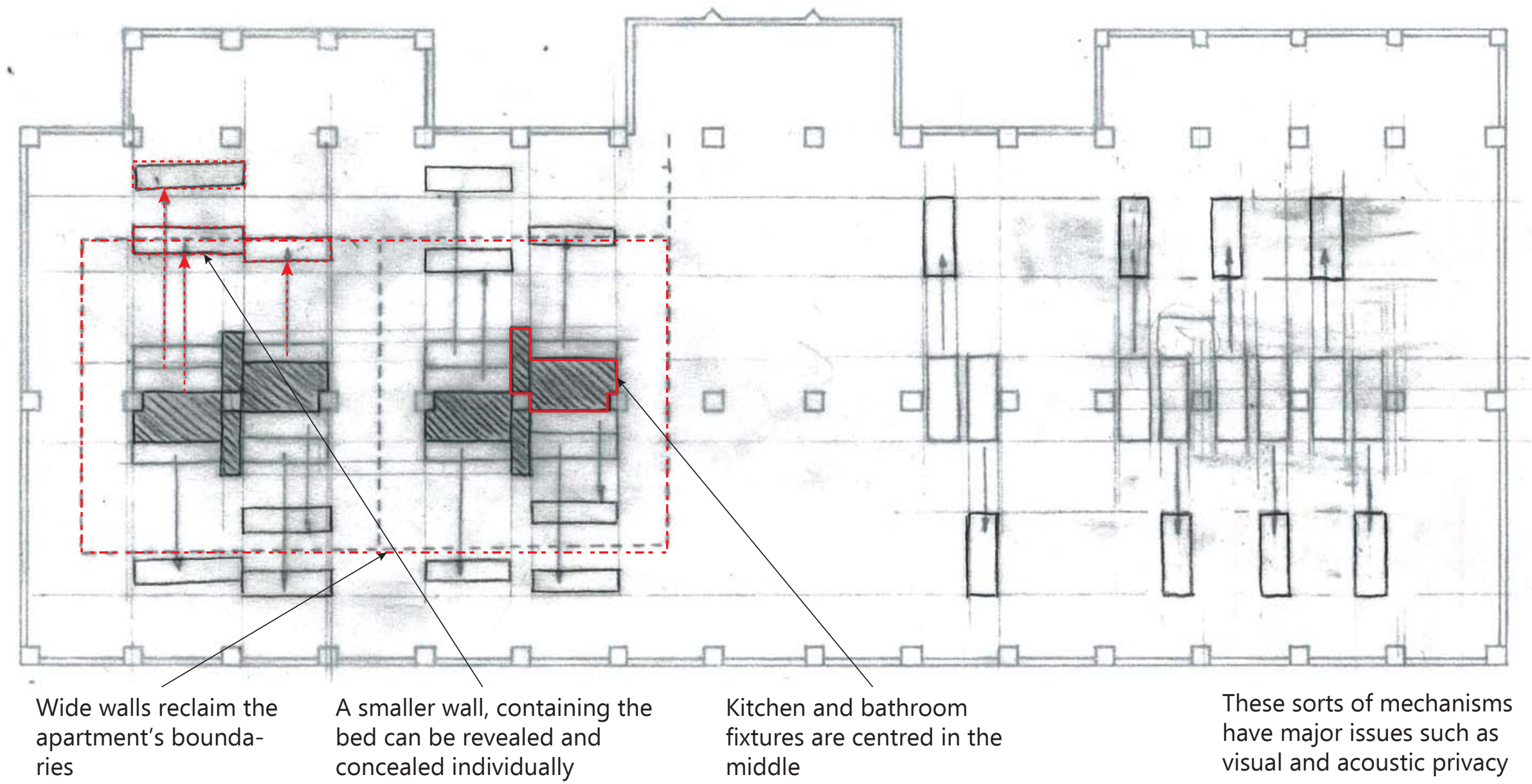

Fig. 3.25 Reveal \& conceal iteration 4

Scale: 1:200

Sub-type: Expansion \& compression

Level: Undefined 


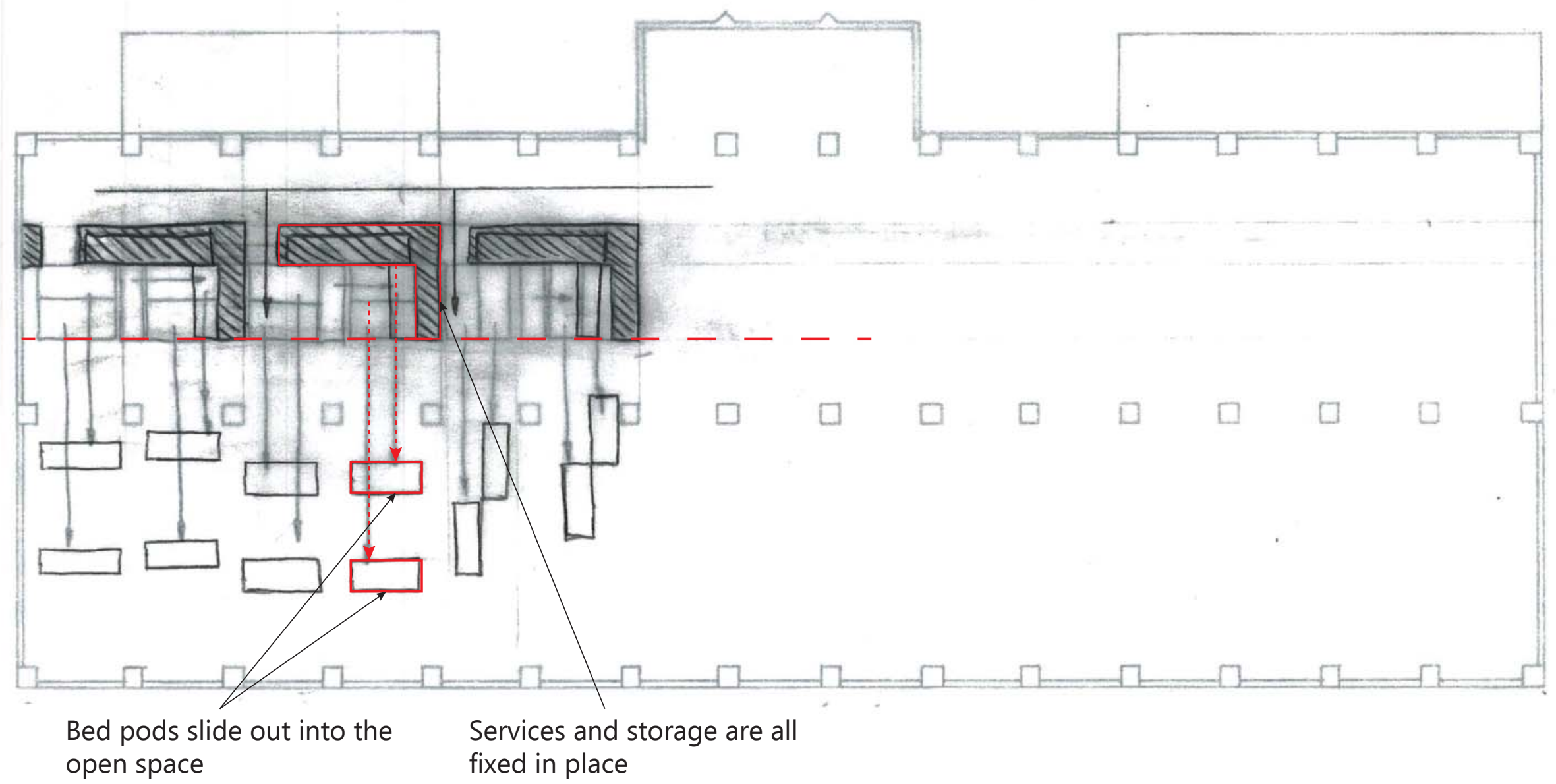

Fig. 3.26 Reveal \& conceal iteration 5

Scale: 1:200

Sub-type: Expansion \& compression

Level: Undefined 


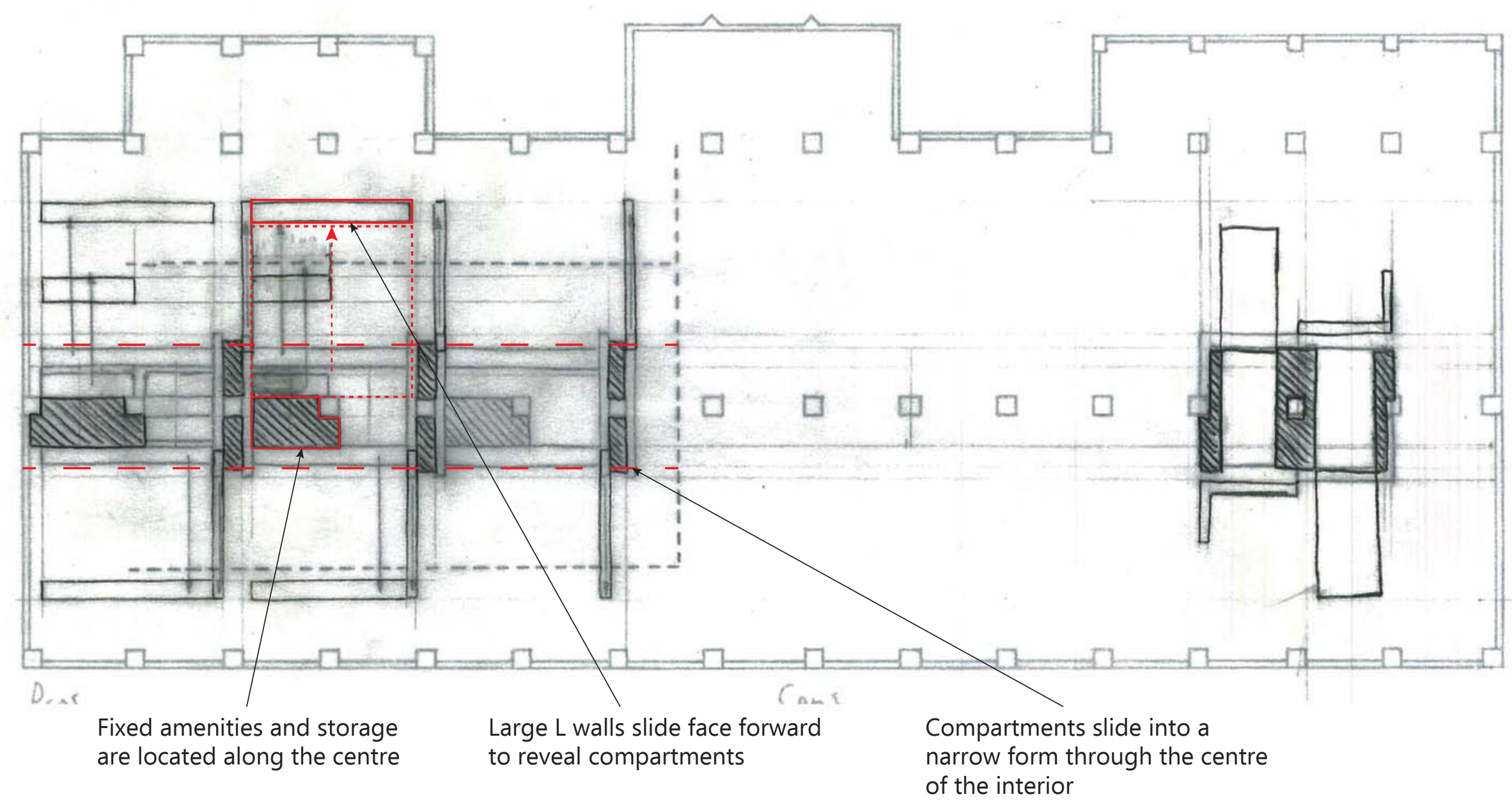

Fig. 3.27 Reveal \& conceal iteration 6

Scale: 1:200

Sub-type: Expransion \& compression

Level: Undefined 


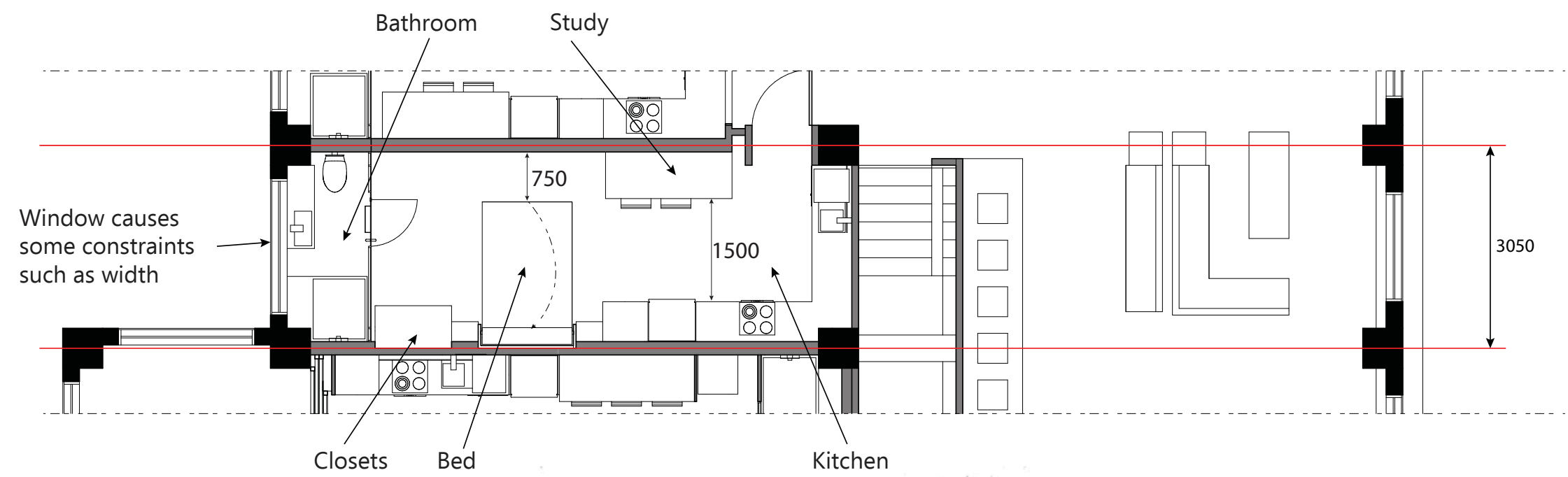

Fig. 3.28 Apartment 203

Level 1 - 1 person - 1 bay $26.2 \mathrm{~m}^{2}$ Width $-3.05 m$

1:100

A major constraint was the widths. The bays between structural grids are little over three meters wide. How the space was divided conforms to the width between structures mainly because of the window location.

Compared to Gary Chang's apartment he had four meters which gave him enough room for multiple layers of sliding walls and features. Three meters was not wide enough. Because of this, some apartments required a simpler and less complex solution than Chang's apartment.

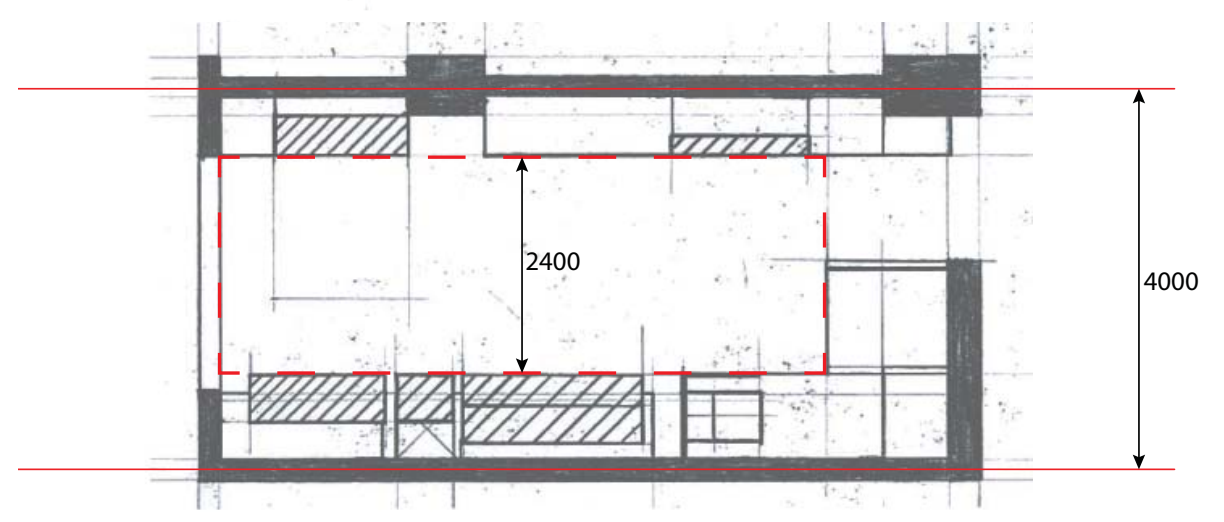

Fig. 3.29 Gary Chang's Apartment

$32 \mathrm{~m}^{2}$

Width $-4 m$

1:100 


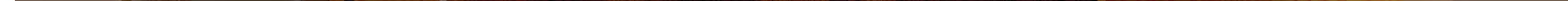



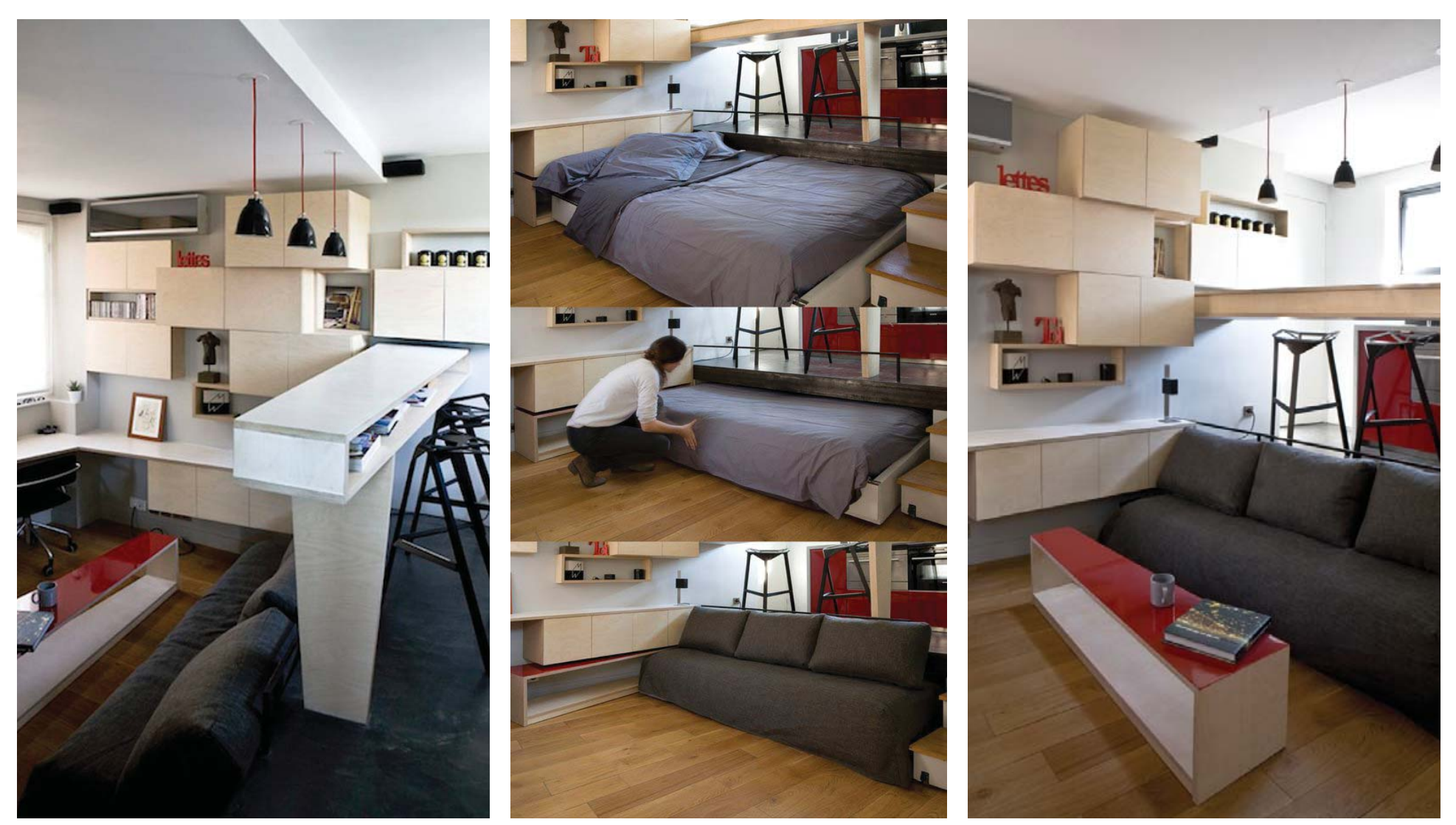

Fig. 3.31 Bien vivre dans - Marc Baillargeon and Julia Nabuchet apartment $16 \mathrm{~m}^{2}$ http://www.treehugger.com/green-architecture/paris-micro-apartment-marc-baillargeon-julie-nabucet.html 

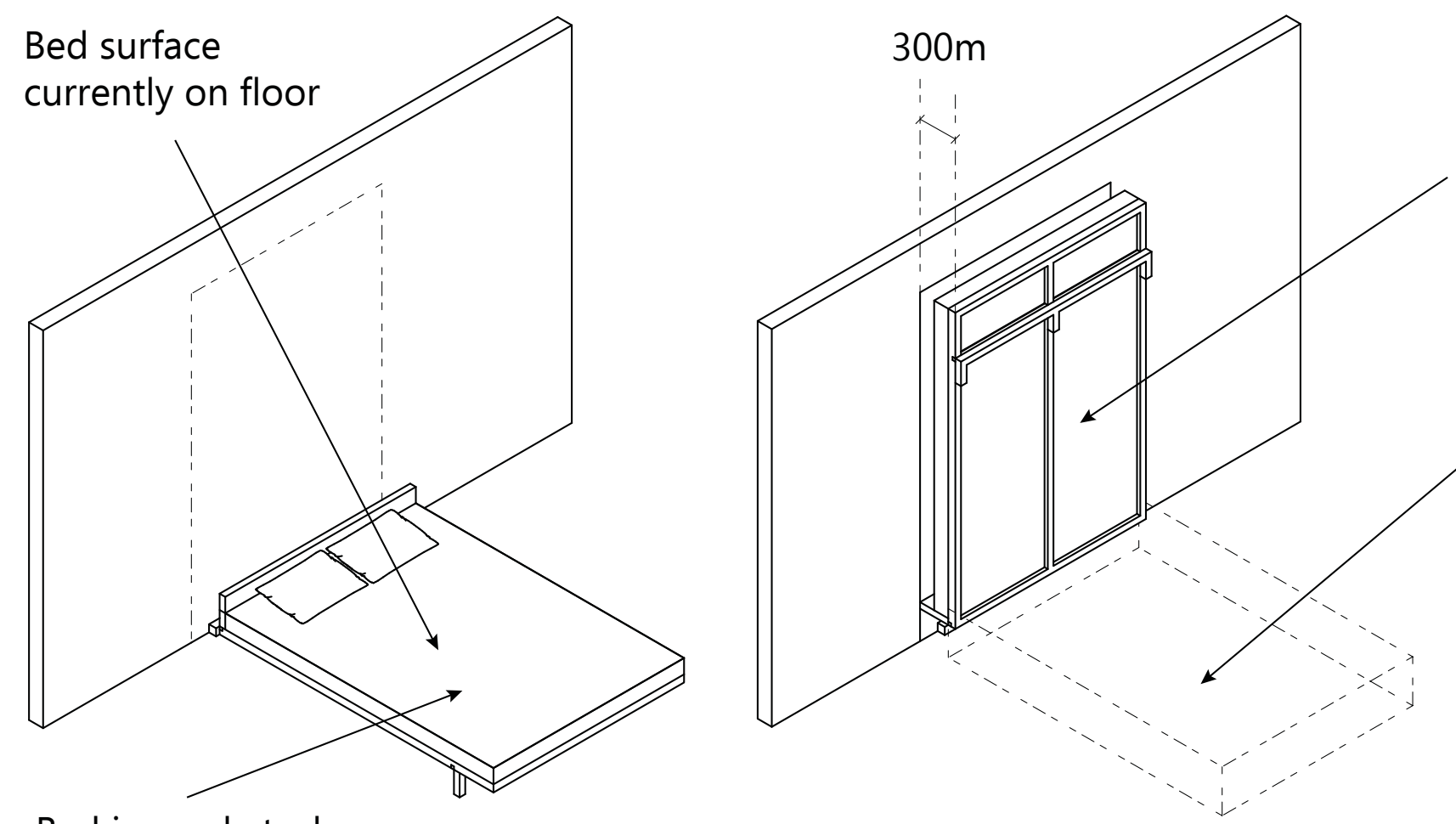

Bed surface transferred on the wall

\section{Bed is an obstacle}

\section{Fig. 3.32 Fold up bed 1:50}

Small apartments like Gary Chang's, Christian Schallert's and others have no bedrooms. Instead they live in a one room living arrangement, utilising various methods of concealing their beds when they are unneeded.

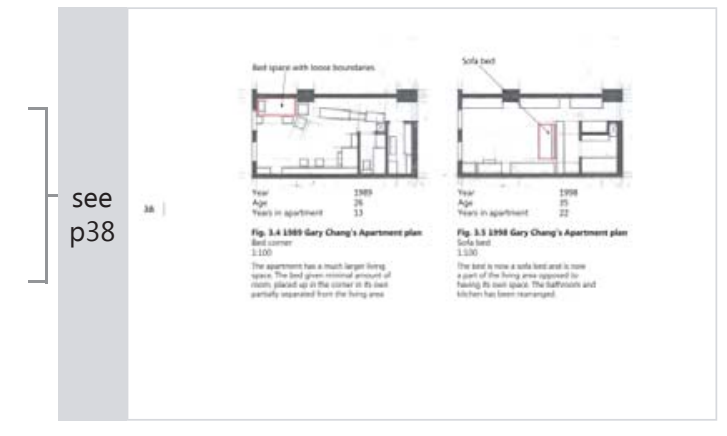

Gary Chang utilised a fold up bed. The advantage of a fold up bed is its ability to transfer the largest face of the bed from the floor to the wall (Fig 3.32).

space 


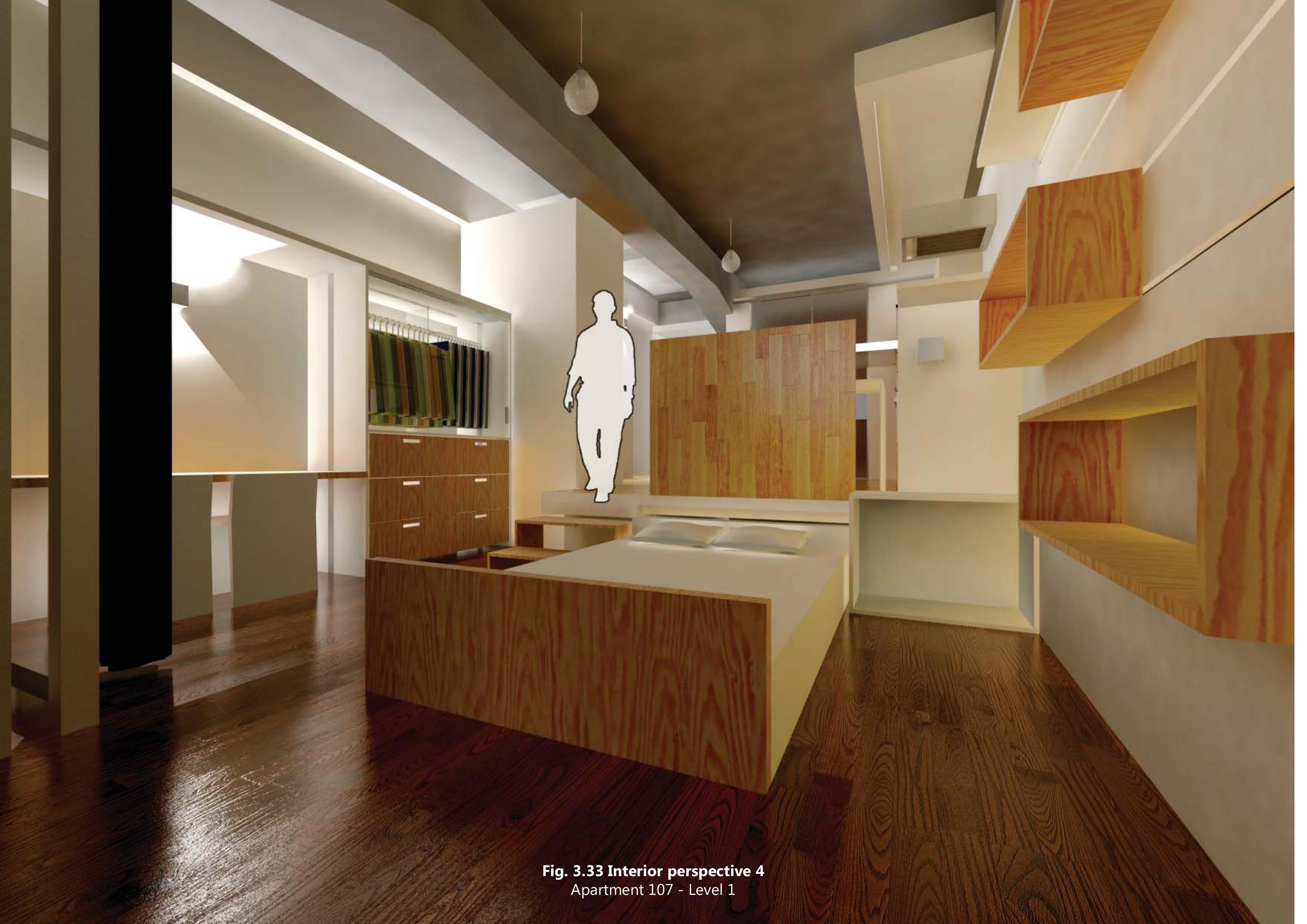




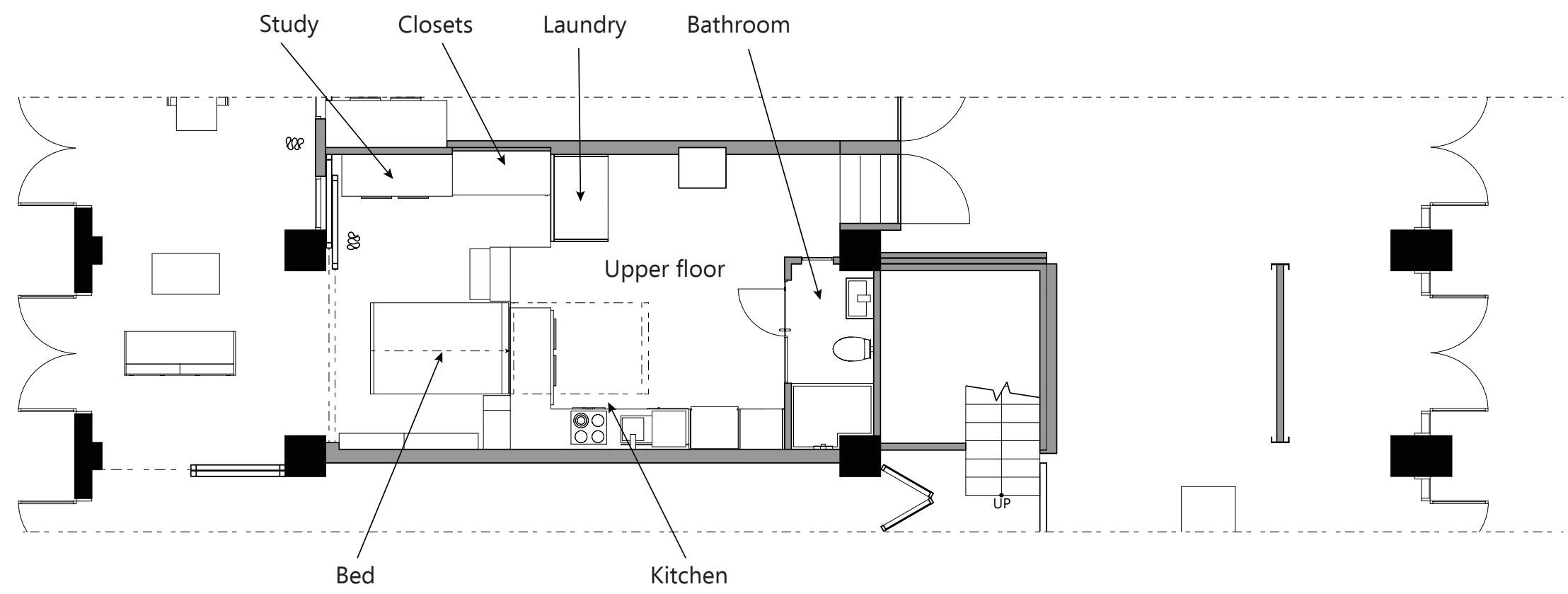

Fig. 3.34 Apartment 107

Level 1 - 1 person - 1.5 bays $37.7 \mathrm{~m}^{2}$

1:100

This single apartment consists of a raised floor. The bed is stored underneath the raised floor and is pulled out from underneath, similar to Christian Schallert's apartment. The raised floor creates two spatial areas that are open to each other. The lower level is for sleeping, relaxing and studying while the upper level consists of the bathroom and kitchen. 
Bed stored

underneath a

raised floor

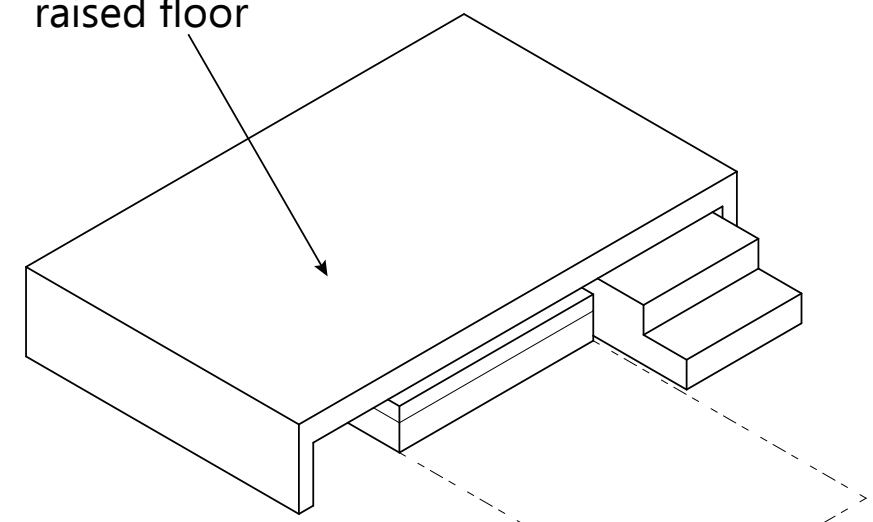

As long as there is room the bed

can slide out

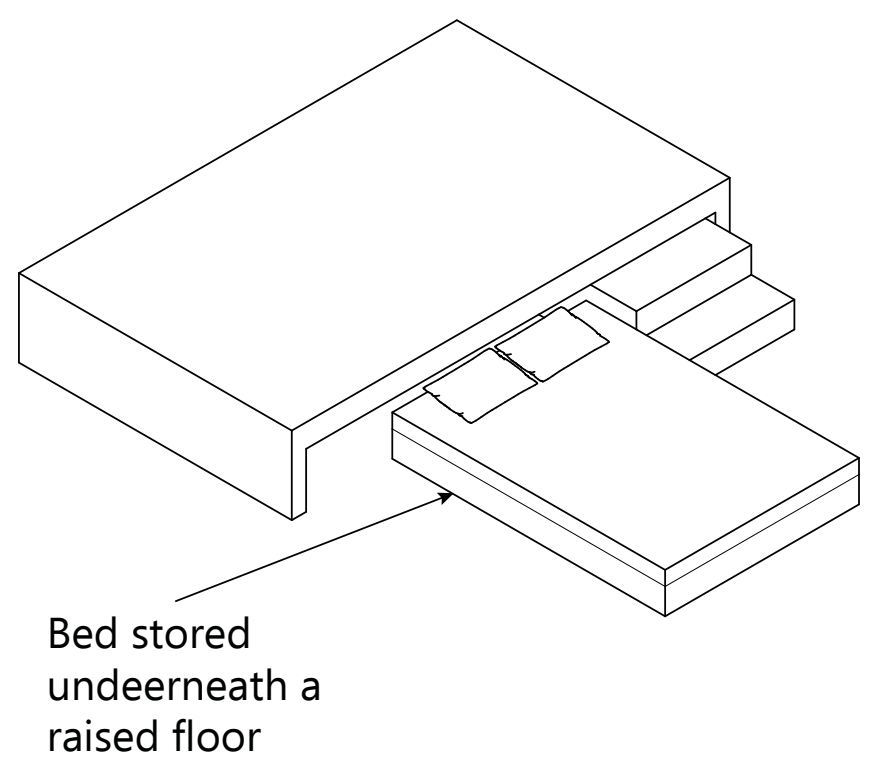

Fig. 3.35 Slide out bed 1:50

Christian Schallert used a bed that slides underneath a raised deck. On this occasion a fold up bed was not used because Schallert's apartment was much smaller $\left(24 m^{2}\right)$.

This type of technique is useful if the space is too small for a fold up bed. Primarily in narrower spaces, a fold up bed will take away up to $300 \mathrm{~mm}$ of floor space. This mechanism does not take away the spatial widths but requires a raised floor to store under. 

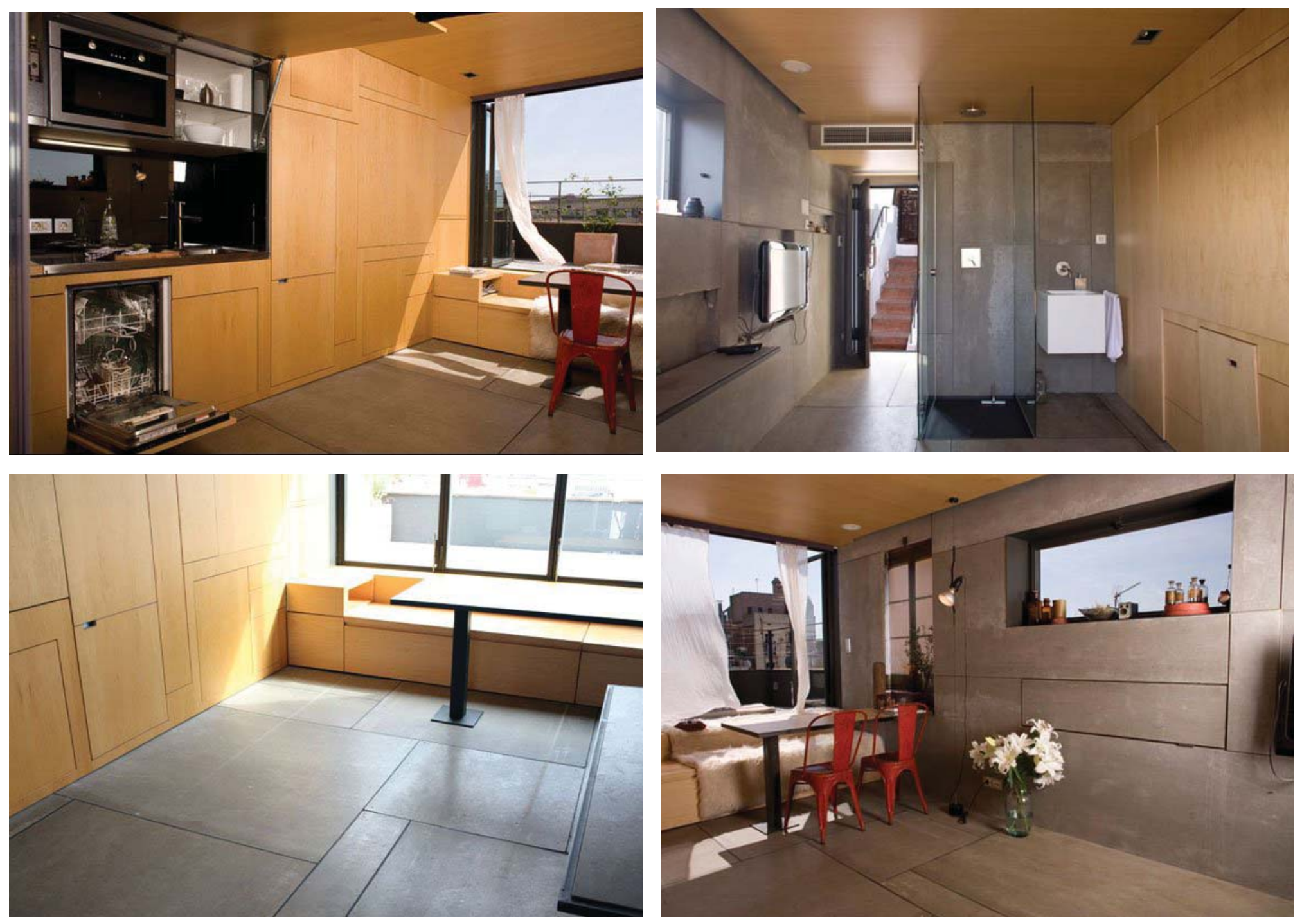

Fig. 3.36 Christian Schallert Apartment - Christian Schallert \& Barbara Appolloni 24m² (Retrieved Feb. 5 2014).

http://www.onekindesign.com/2012/10/12/lego-style-24-square-meters-apartment-in-barcelona/ 


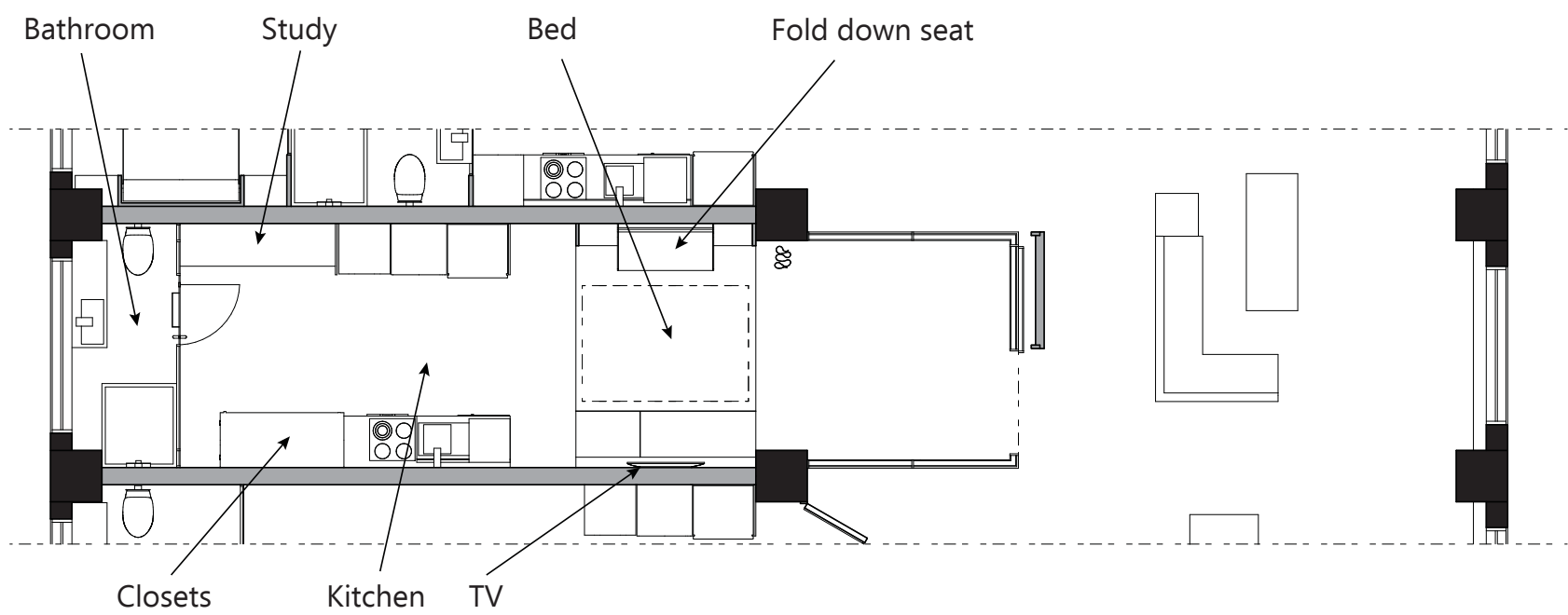

Fig. 3.37 Apartment 408

Level 4 - 1 person - 1 bay $33.7 \mathrm{~m}^{2}$

1:100

Another type of bed concealment is a partition on the floor that can be pulled open to reveal the bed. This idea was inspired from the Suitcase house which was also designed by Gary Chang. Its unique advantage is the bed is not required to move, whereas the previous methods involve a shifting of a large mass. 

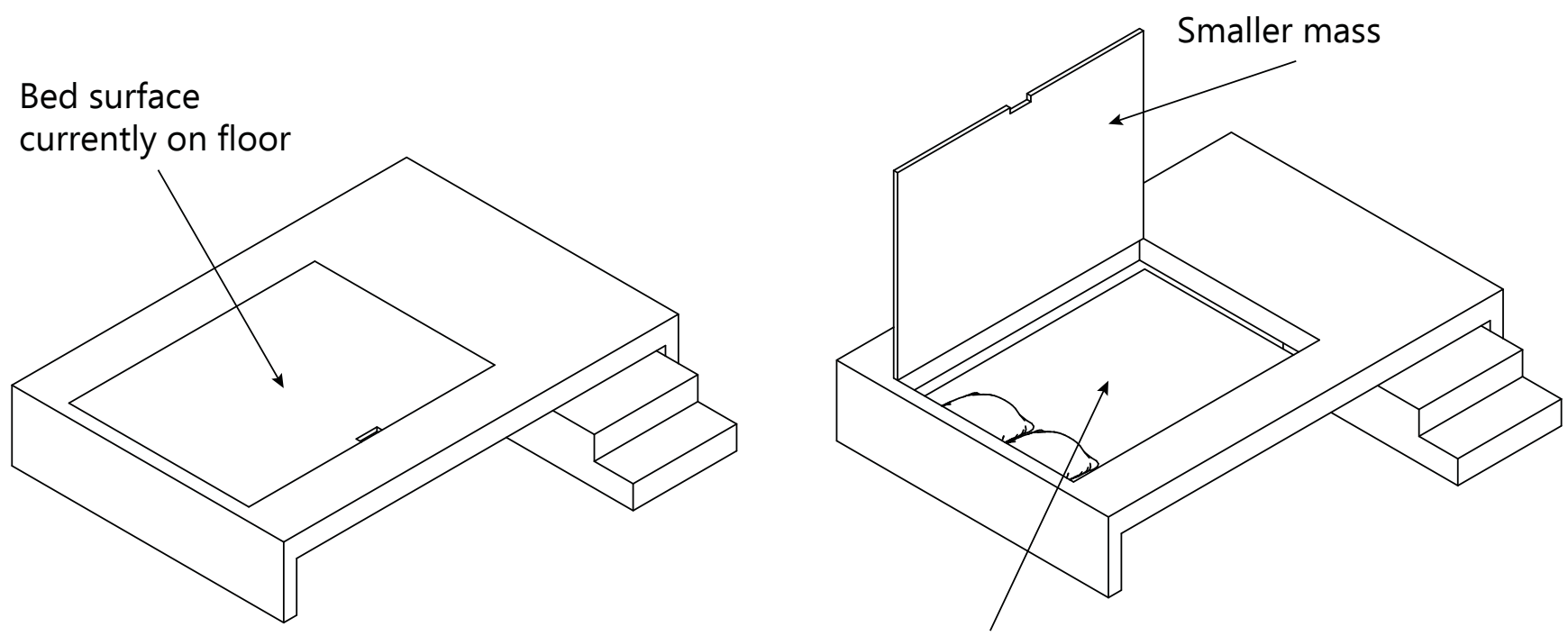

The bed is not

Fig. 3.38 Flip open bed 1:50

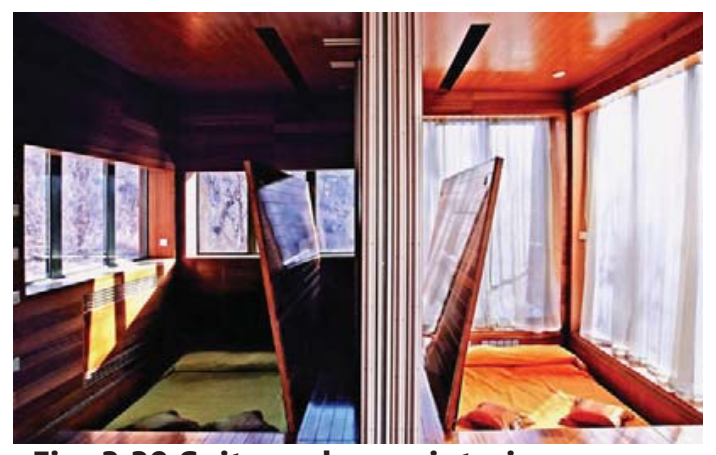

Fig. 3.39 Suitcase house interior (Retrieved

http://travel.cnn.com/shanghai/life/chinas-10-most-

unusual-hotel-features-987867 


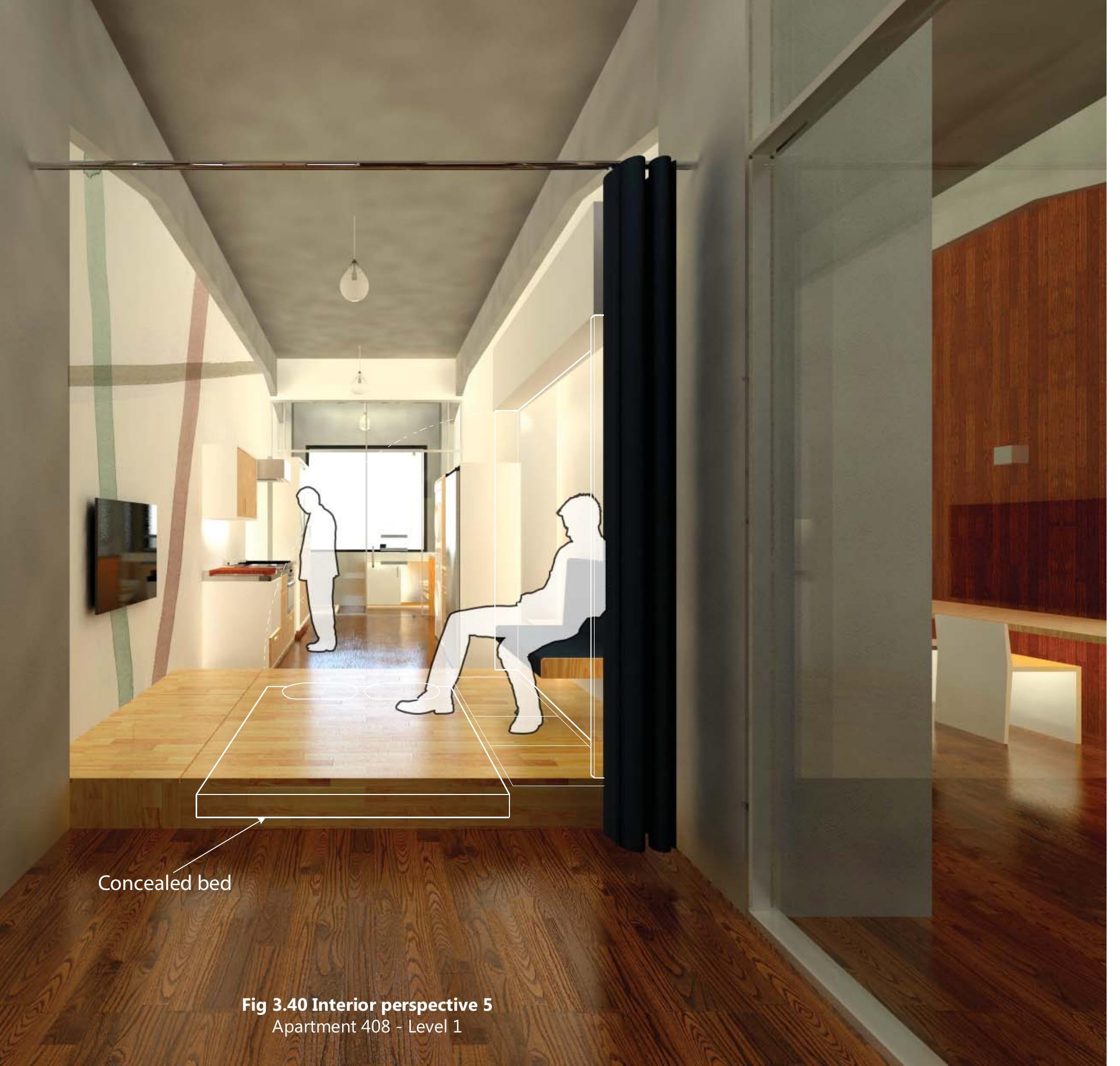



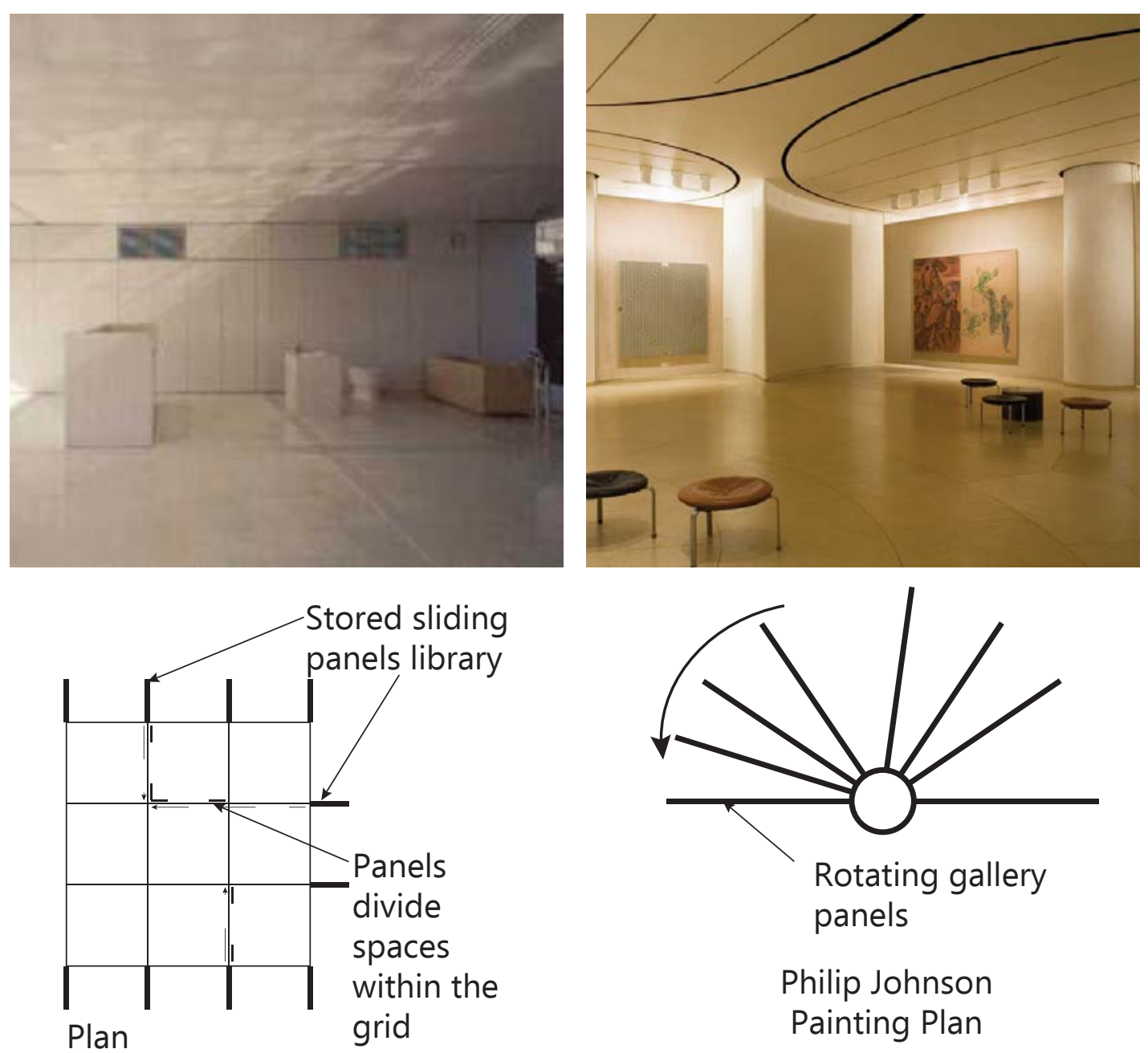

Philip Johnson

Painting Plan

Nine-Square Grid House Shigeru Ban

Hadano, Japan

Fig. 3.41 Nine-square Grid House (Retrieved Feb. 5 2014).

Top: http://www.shigerubanarchitects.com/works/1997 nine-square-grid-house/index.html

\section{Painting Gallery}

Philip Johnson

New Canaan, Connecticut

Fig. 3.42 Philip Johnson Art Gallery (Retrieved Feb. 7 2014)

Top: http://philipjohnsonglasshouse.wordpress. com/2010/08/10/site-spotlight-painting-gallery/ 


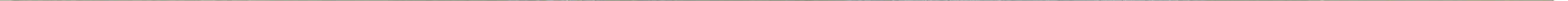




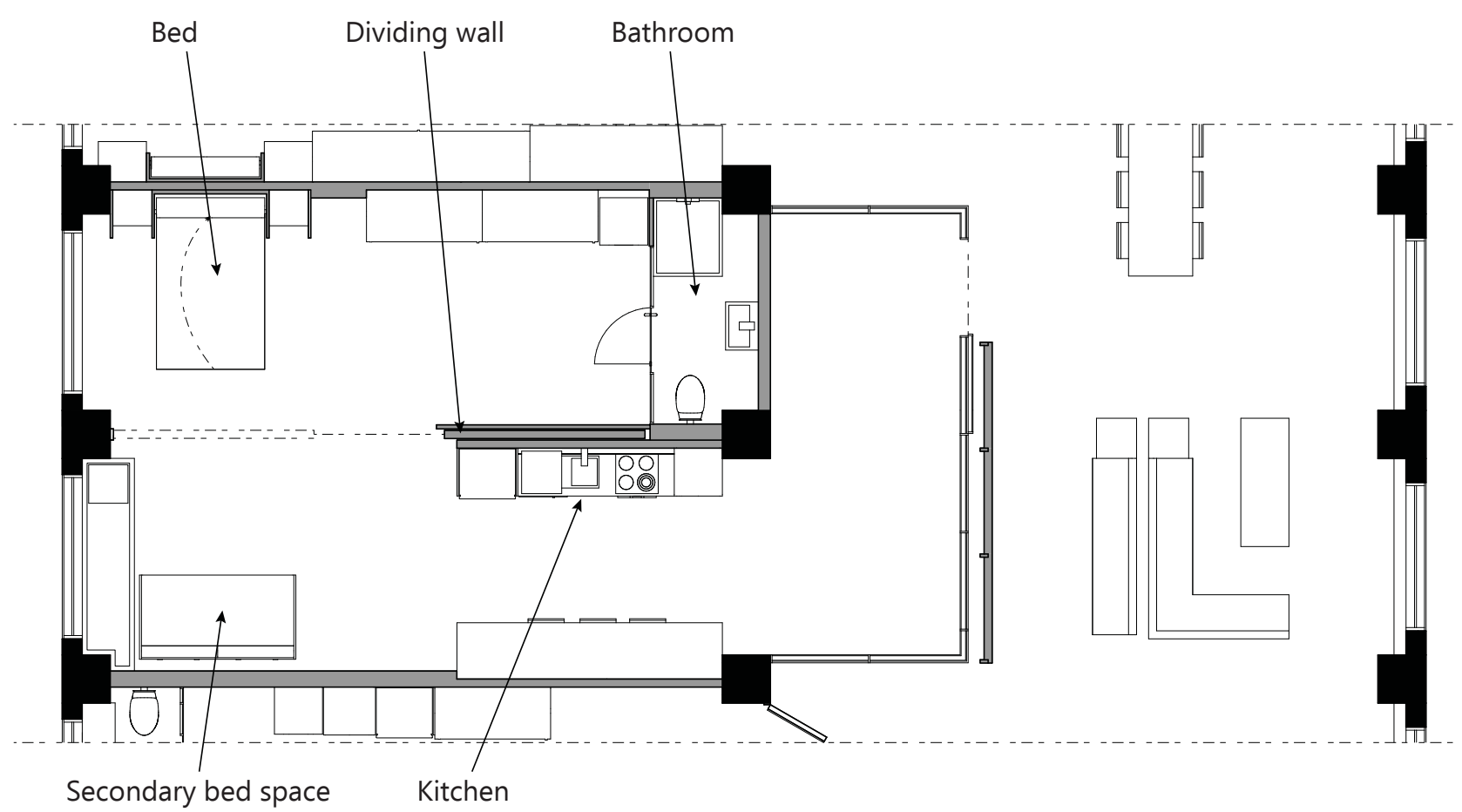

Fig. 3.44 Apartment 404

Level 4 - 2-3 people - 2 bays $66.5 \mathrm{~m}^{2}$

1:100

This apartment has a large sliding wall.

This wall's purpose is to divide the space

to create two rooms. The wall can be

stored away whenever the resident

desires it. Whoever would want to

occupy this apartment could be a young

couple with or without a baby as a

skipping stone apartment. 


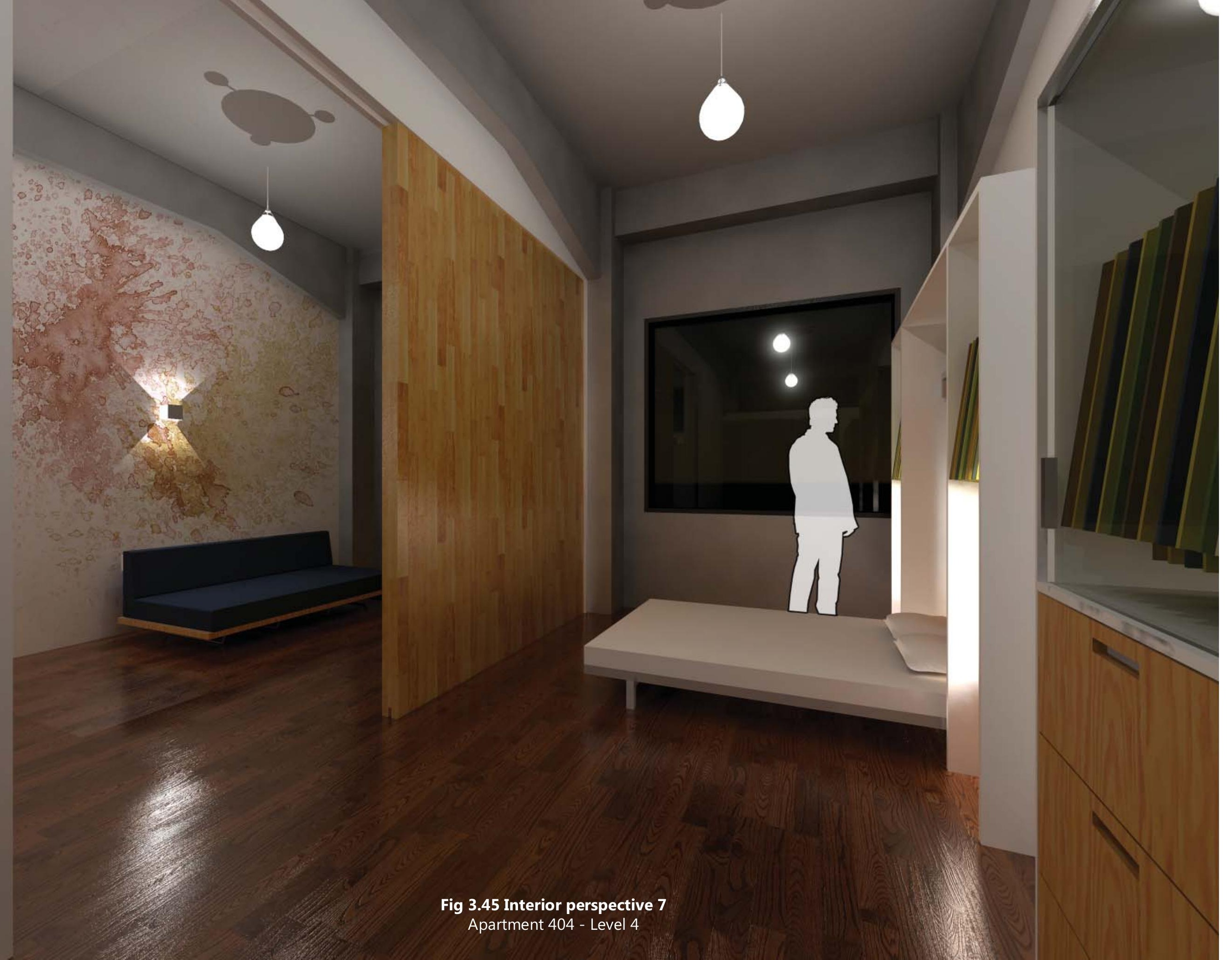




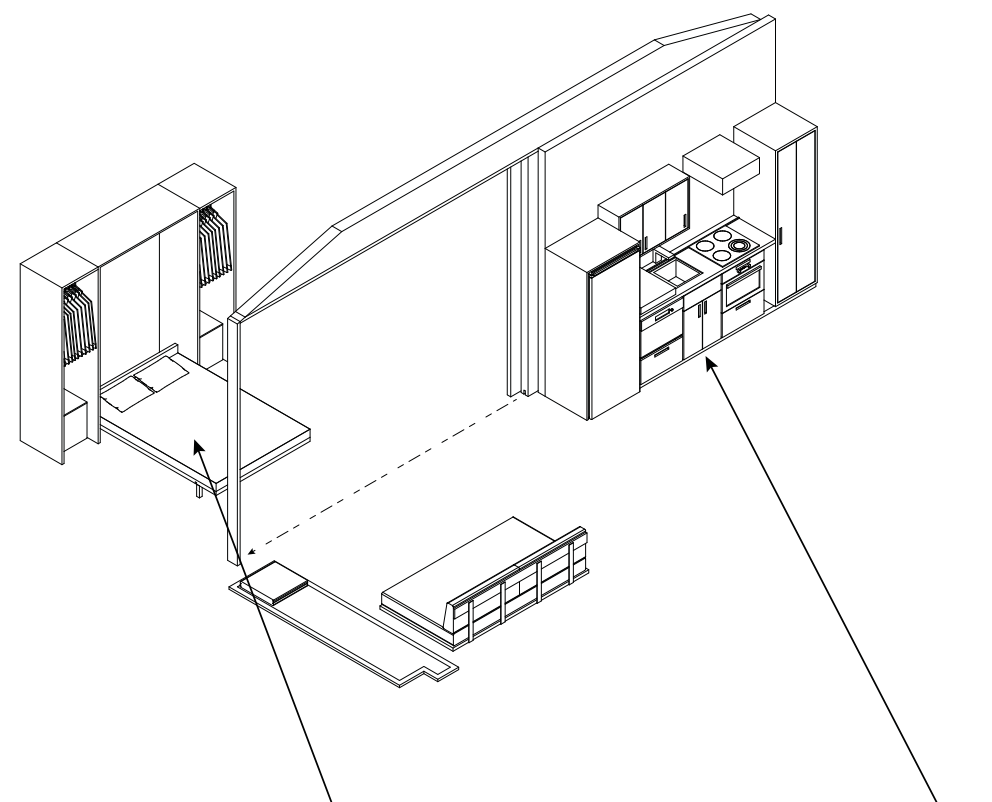

Fold down bed
Kitchen

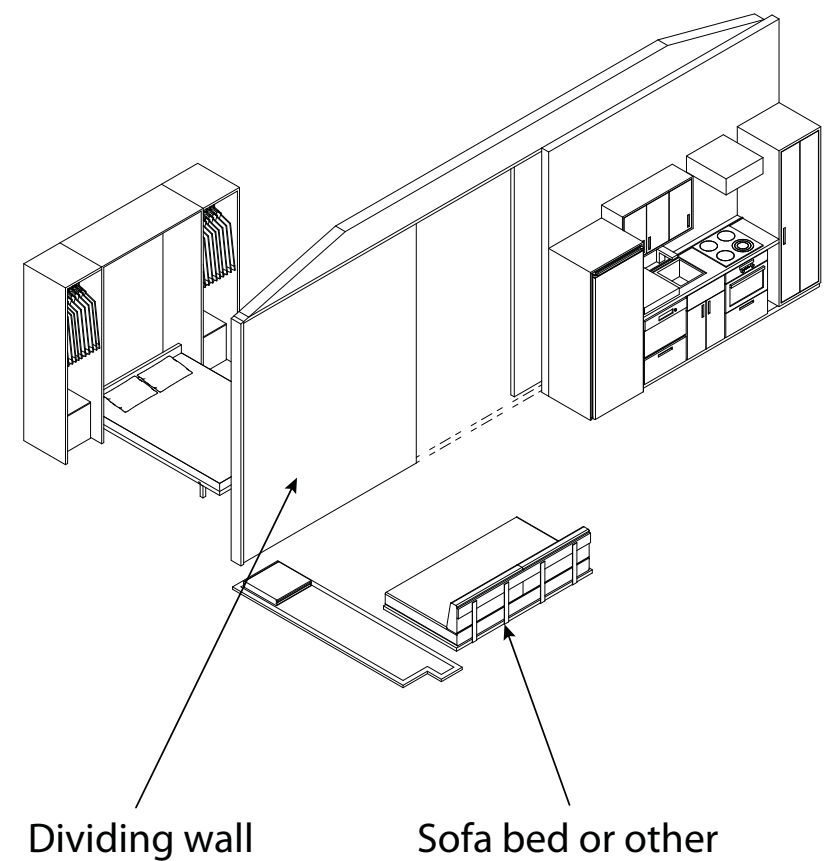

Sofa bed or other

Fig. 3.46 Dividing wall 1:100 


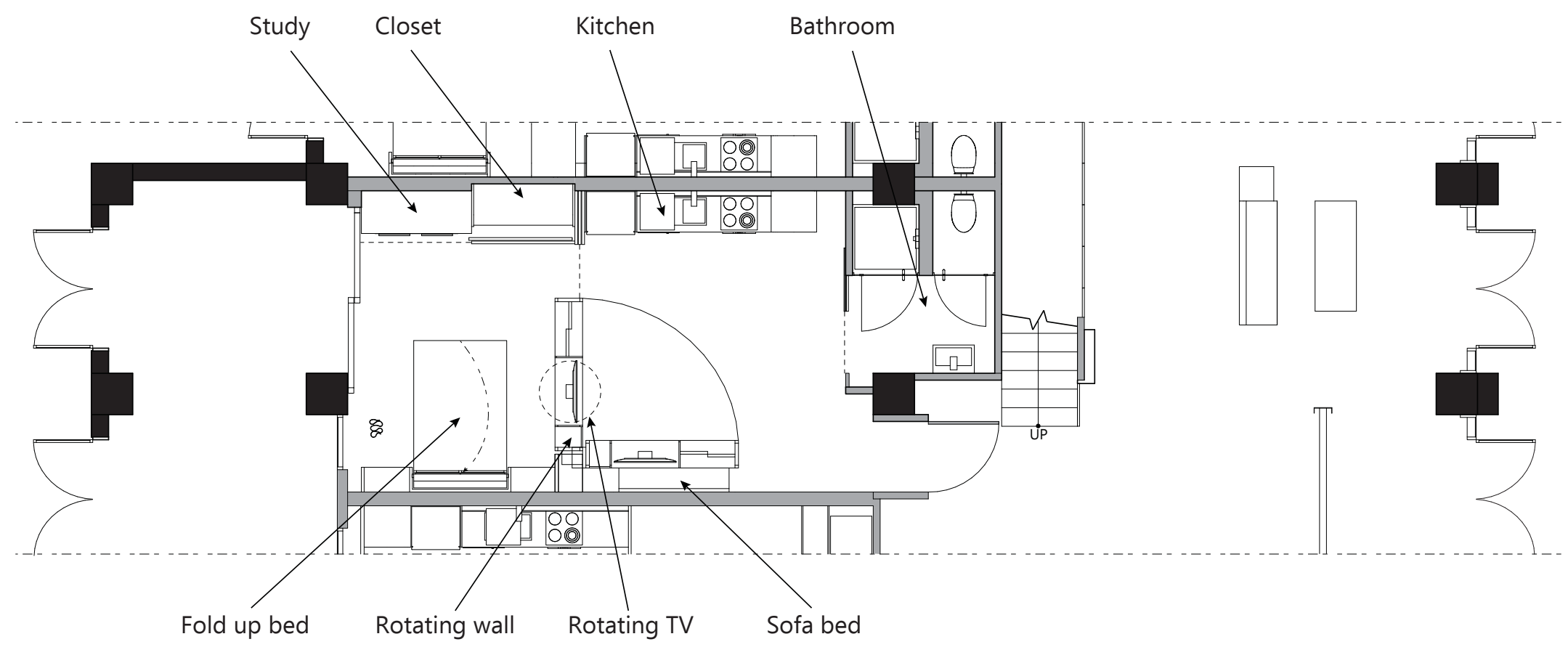

\section{Fig. 3.47 Apartment 102}

Level 1 - 1 people -1.5 bays $37.7 \mathrm{~m}^{2}$

1:100

A rotatable wall divides the single

apartment into two spaces. The rotating wall keeps the view of the kitchen and bedroom out of sight. One space is for the main occupant but the other can also be used as a guest bedroom using the sofa bed. The rotating wall also contains a rotatable TV that can be rotated into view. 


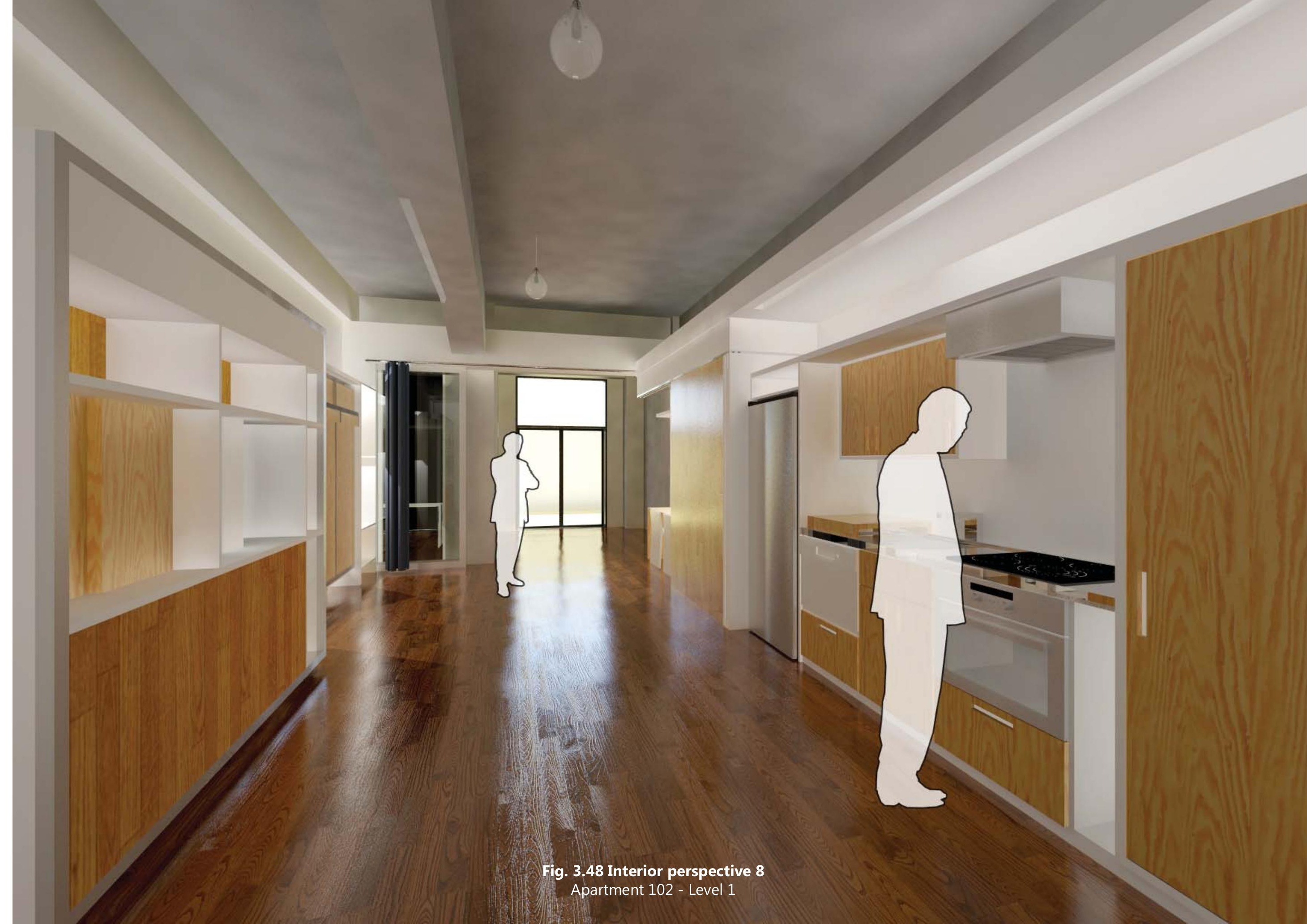




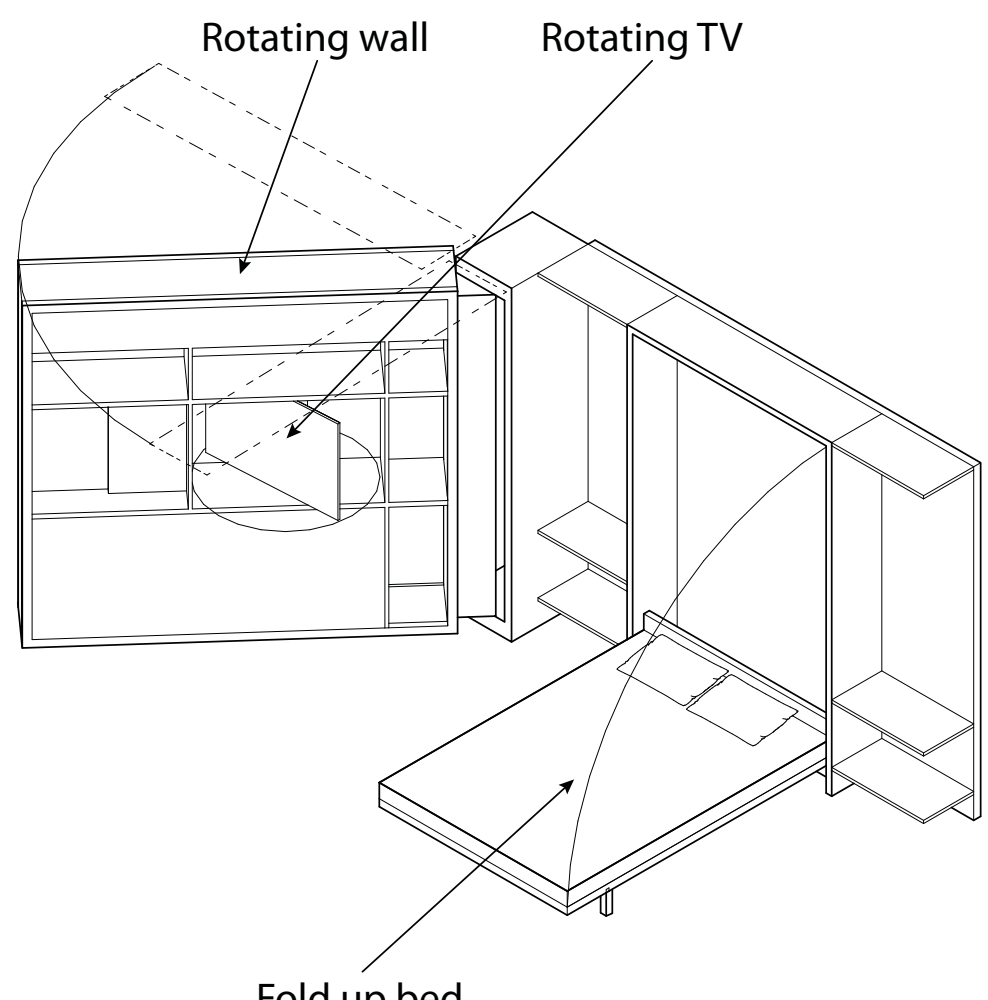

Fig.3.49 Rotating wall 1:50 



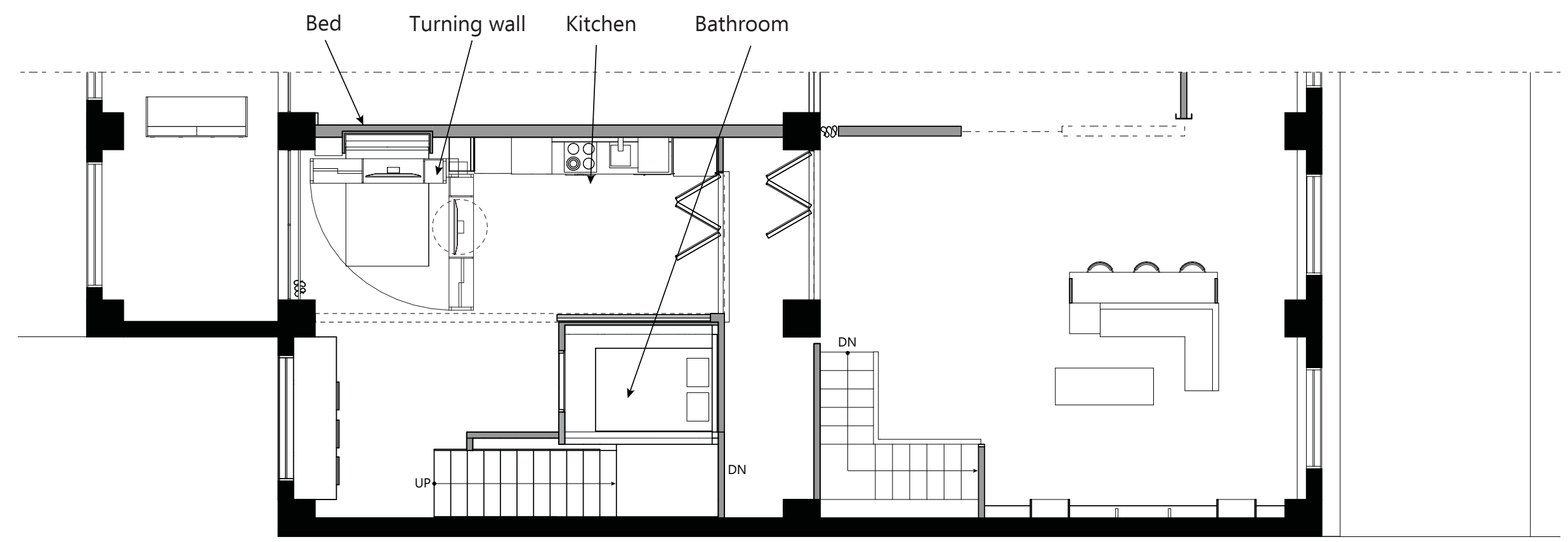

Fig. 3.51 Apartment 201

Level 1 - 2 people - 2 bays $56.8 \mathrm{~m}^{2}$

1:100

This apartment utilises both a dividing wall and rotating wall. Both combine to create an enclosure for a bedroom. Another bedroom is on an elevated position taking advantage of the almost double ceiling height. 


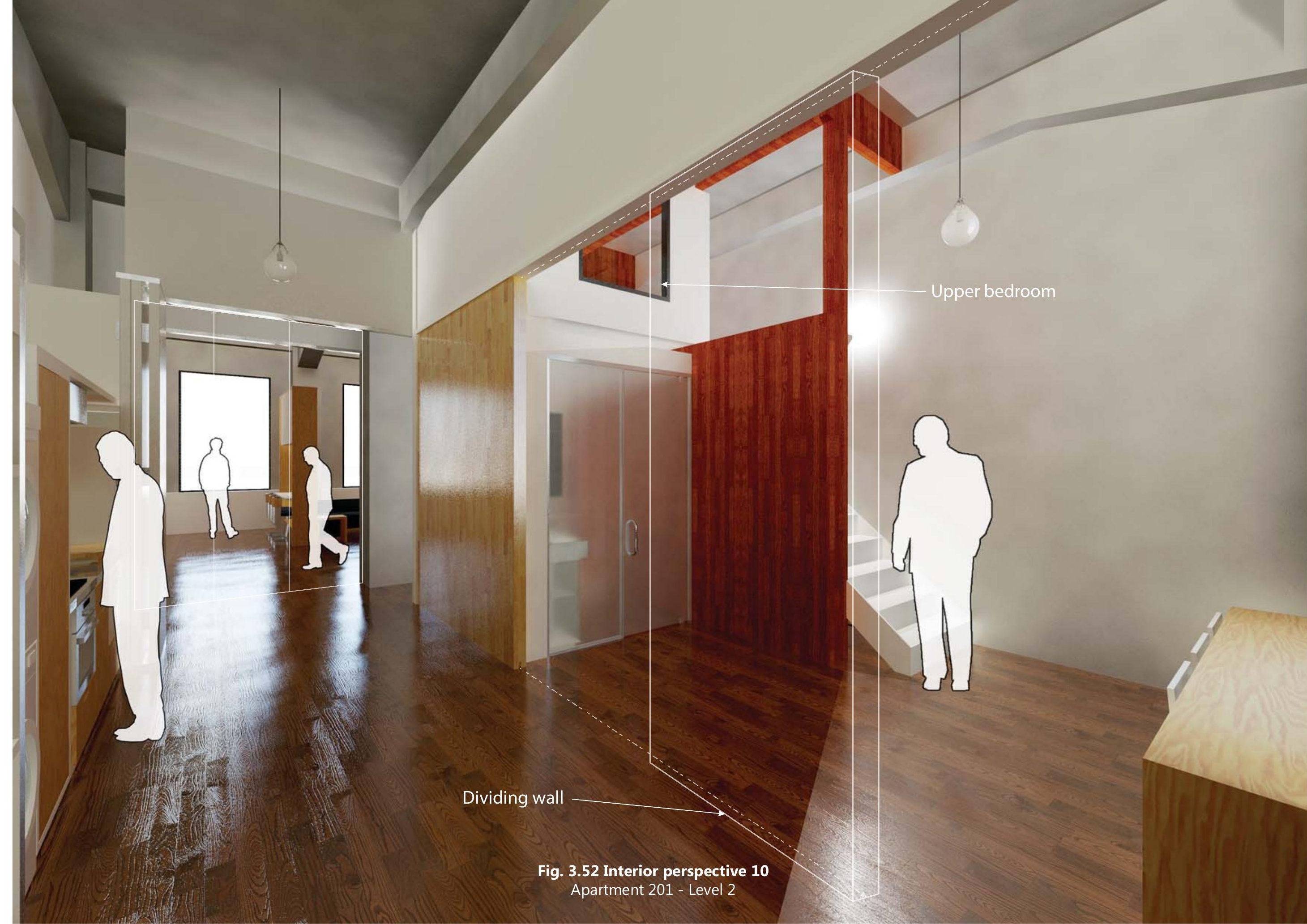




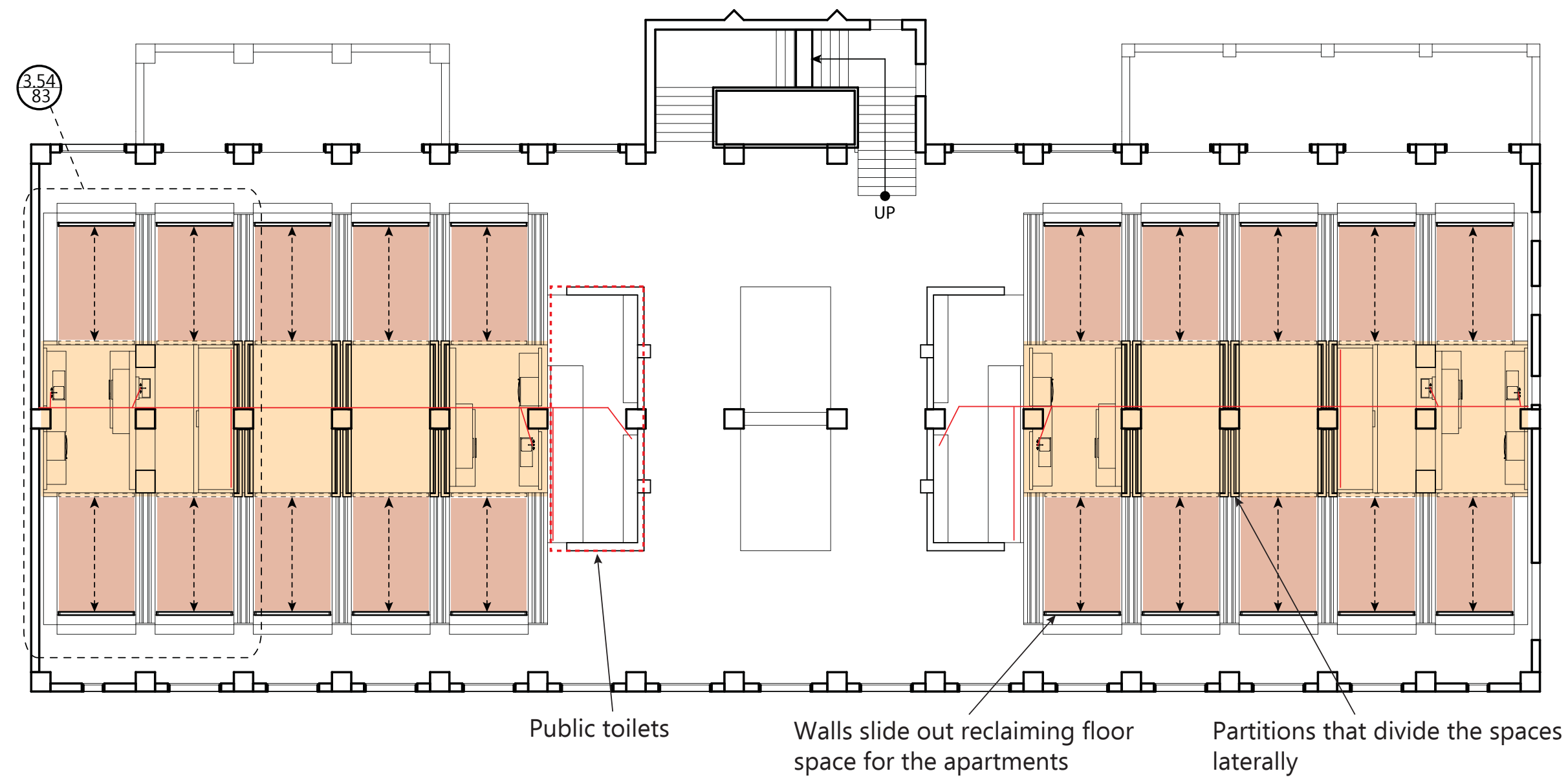

Fig. 3.53 Reveal \& conceal iteration 7 •Red: reclaimable spaces for apartments 17th May review

Scale: $1: 200$

Sub-type: Expansion and compression Level: 3

-Yellow: services such as kitchen and bathroom 


\section{7th May Review Discussion}

The issues at this stage were surrounding the timeline and access to the apartments when they are concealed. This left the residents basically homeless during the day because of a strict transition from apartment to gallery space. The inaccessibility to the apartments during the day causes a severe inconvenience.

Fold up beds, sliding walls and rotating walls are more relevant to the scale of individual apartments. It has some effect with blending together the art gallery with the home but provides technical challenges and issues with acoustics and privacy.

This mechanism does not offer a strong solution, but a method for improving the efficiency of individual apartments.

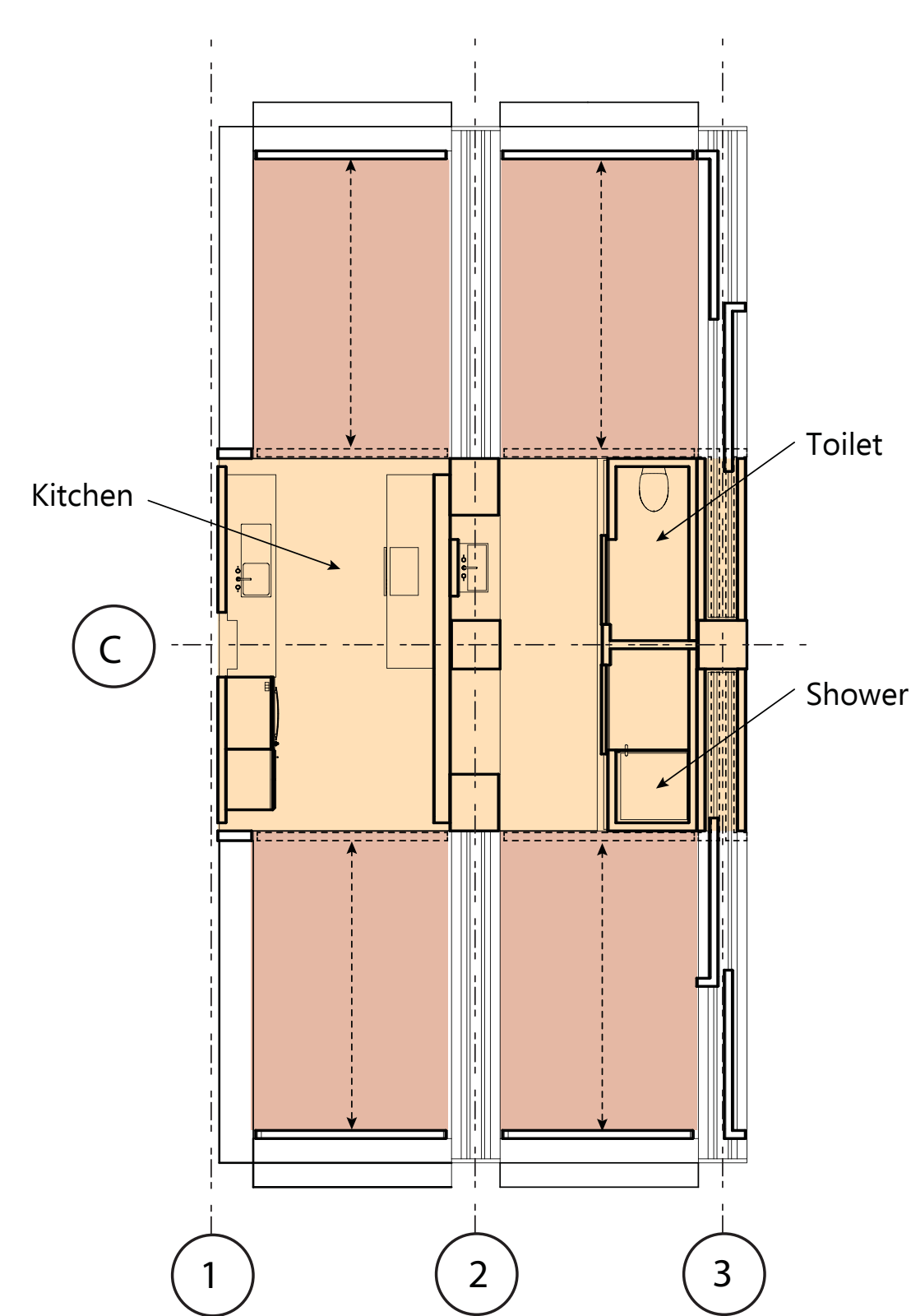

Fig. 3.54 Iteration 7 apartment unit

Level 3

1:100 


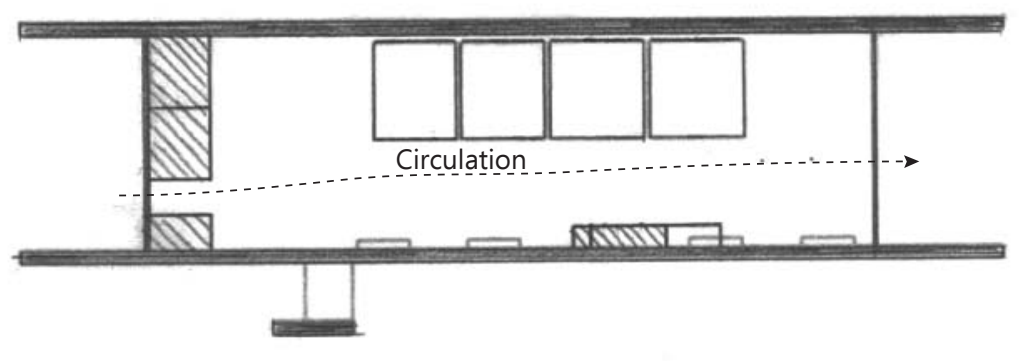

\section{Mobility \\ Mechanism 2}

\section{Case study - Naked house}

Shigeru Ban designed the Naked House, a long greenhouse-like structure. Its most distinct entity is the four mobile cubicles which all serve as bedrooms. They move freely on wheels in a largely open space. "These mobile rooms are meant to hold only a minimum of belongings. They can be placed against walls or in front of heating or air conditioning units, to change how air flows through them. They can also be combined to create a larger room. ${ }^{18}$

The notable strength of the Naked House is how it maintains a large open space yet having rooms within it for privacy. The large openness allows the space to be used more efficiently for a public function rather than a cluster of smaller spaces. Despite the open space, enclosed spaces can still exist within this space but remain flexible because of its physical separation from the general space.

Indoor Outdoor

Fig. 3.55 Naked house plan 1:200

${ }^{18} \mathrm{http}: / /$ nakedhousecasestudy.blogspot. co.nz/p/overview.html (June 2013) 


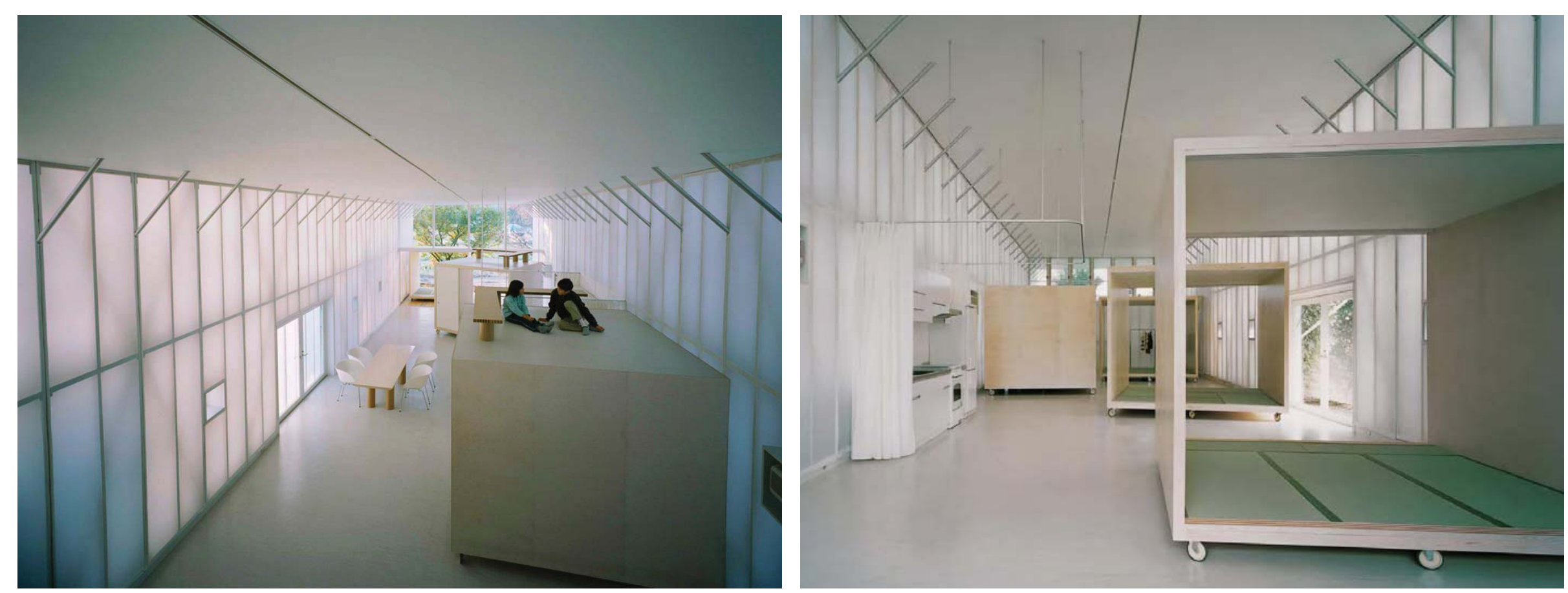

Fig. 3.56 Naked house plan 1:200 (Retrieved Jun. 9 2013).

Left \& right: http://nakedhousecasestudy.blogspot.co.nz/p/overview. 


\section{Space within a Space - Warehouse}

Notably with spaces within a space interiors, the different spaces do not touch the exterior walls and ceiling. Spatially, this type of interior can combat the issue of clusterphobia, commonly created when space is divided from floor to ceiling by use of walls. "It's interesting to note that in open-plan offices designs actually provide divisions in some form or another. ${ }^{119}$

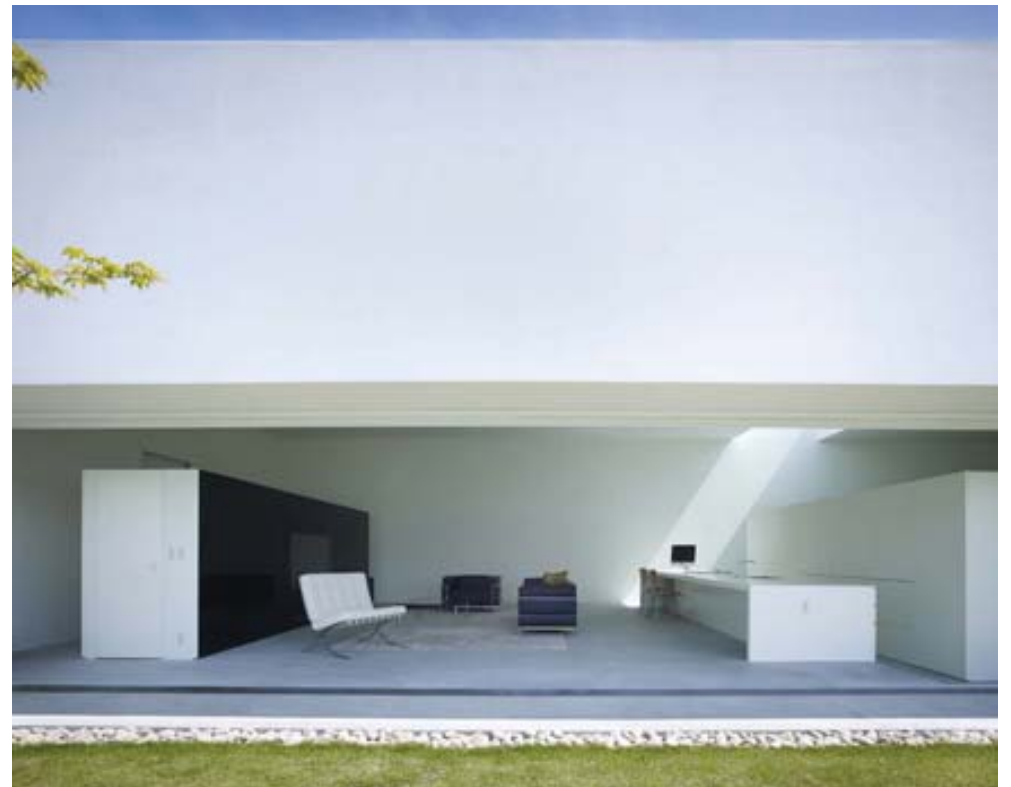

"The interior of this "one room space" is composed of a hall, living/dining room and a kitchen, bathroom, Japanesestyle room, study room, and a master bedroom, which are all laid out in a

linear arrangement." 20 The uninterrupted ceiling creates a visual continuation of the space.

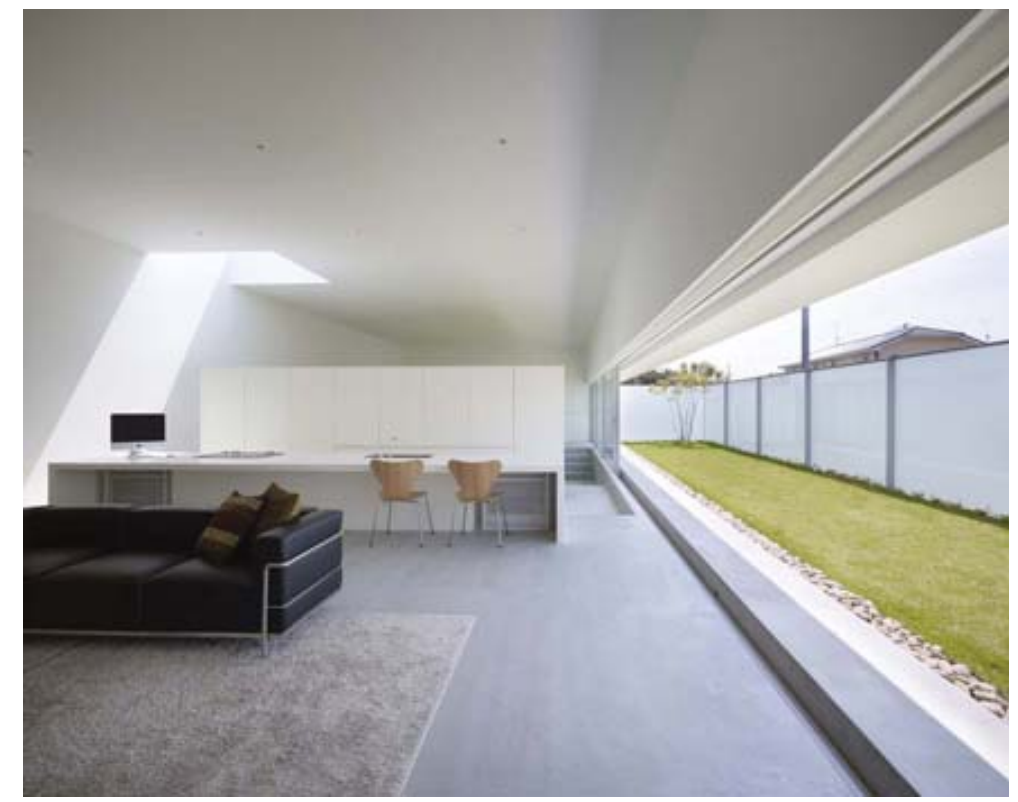

Fig. 3.57 Warehouse interior (Retrieved Feb. 5 2014) Top \& bottom: http://www.dezeen.com/2010/10/30/warehouse-by-shinichi-ogawa-associates/ 

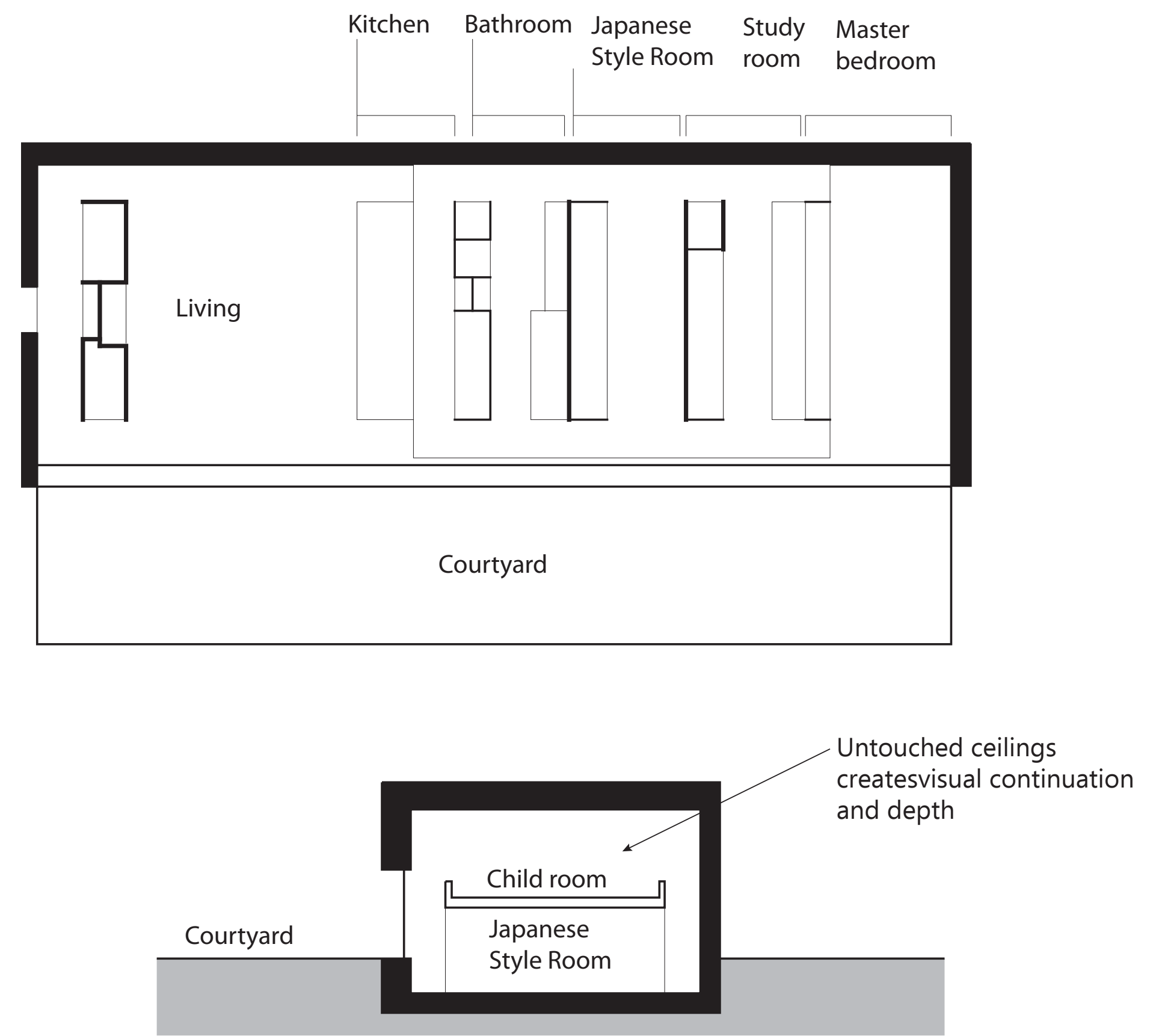

Fig. 3.58 Warehouse plan and section 1:200 


\section{Deviant Spaces - Three Small}

\section{Rooms}

Deviating interiors are a visual, spatial effect that is possible as a result of

interior spaces within a space, such as Three Small Rooms, an apartment in Brooklyn New York where the bedrooms appear like large white boxes in the space. Though fixed, they create a more playful interior because of their appearance as an independent form.

If fixed, these rooms create odd, geometries. However the same effect can be achieved with mobile boxes and with more flexibility.
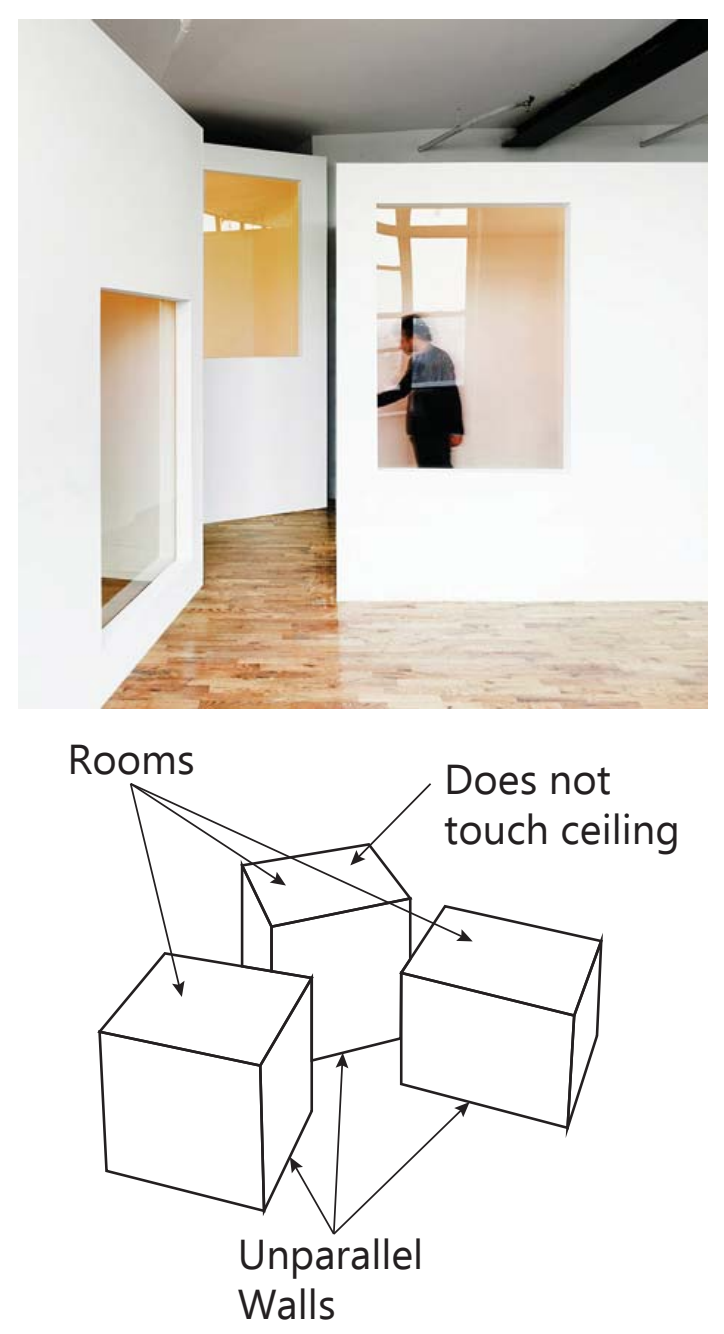

Three Small Rooms Studio Cadena

Brooklyn, New York

Fig. 3.59 Three Small Rooms (Retrieved Feb. 5 2014).

Top: http://www.dezeen.com/2012/12/14/three-smallrooms-loft-interior-studio-cadena/ 
Apartment axis

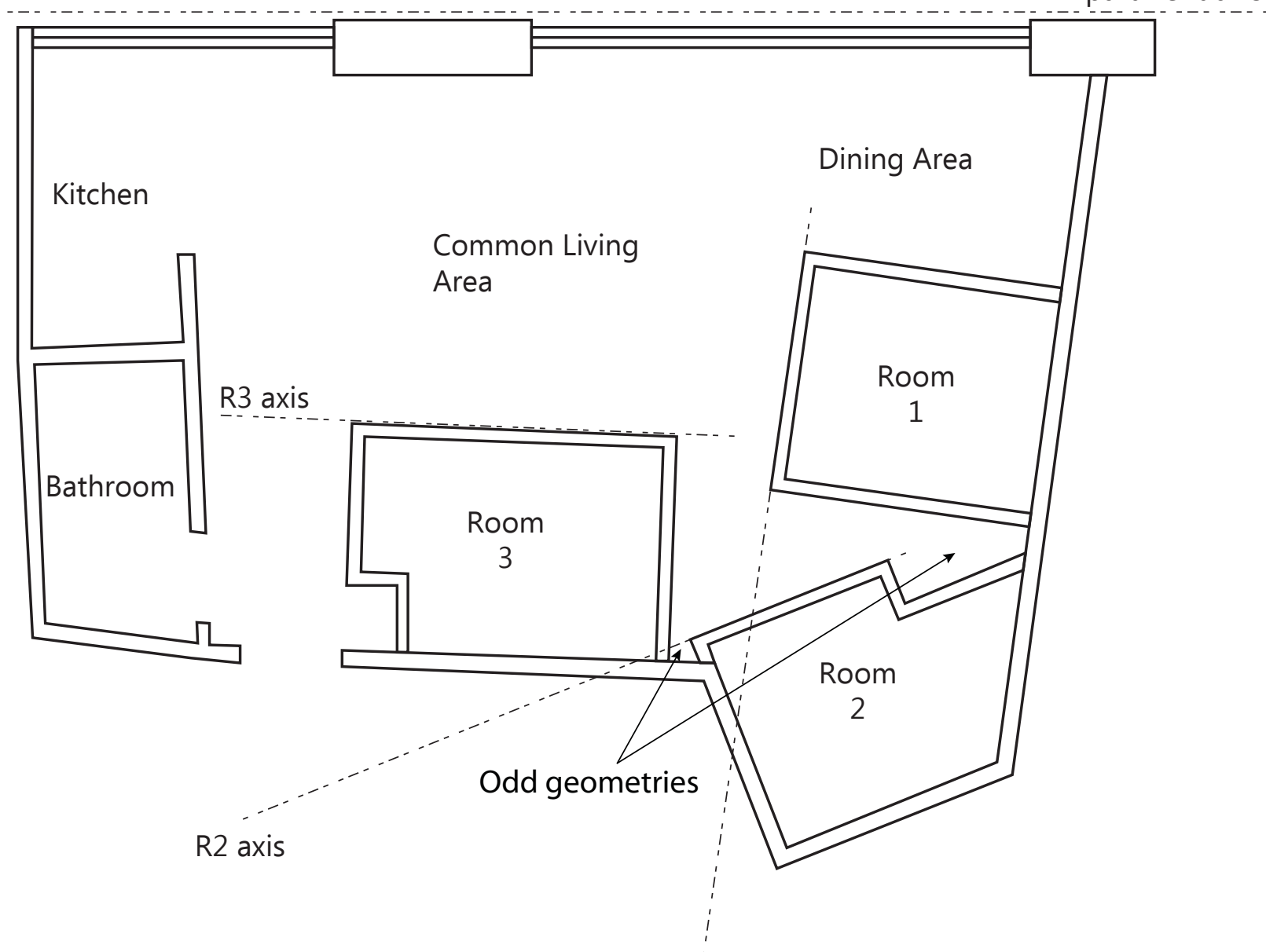

R1 axis

Fig. 3.60 Three Small Rooms plan 1:100

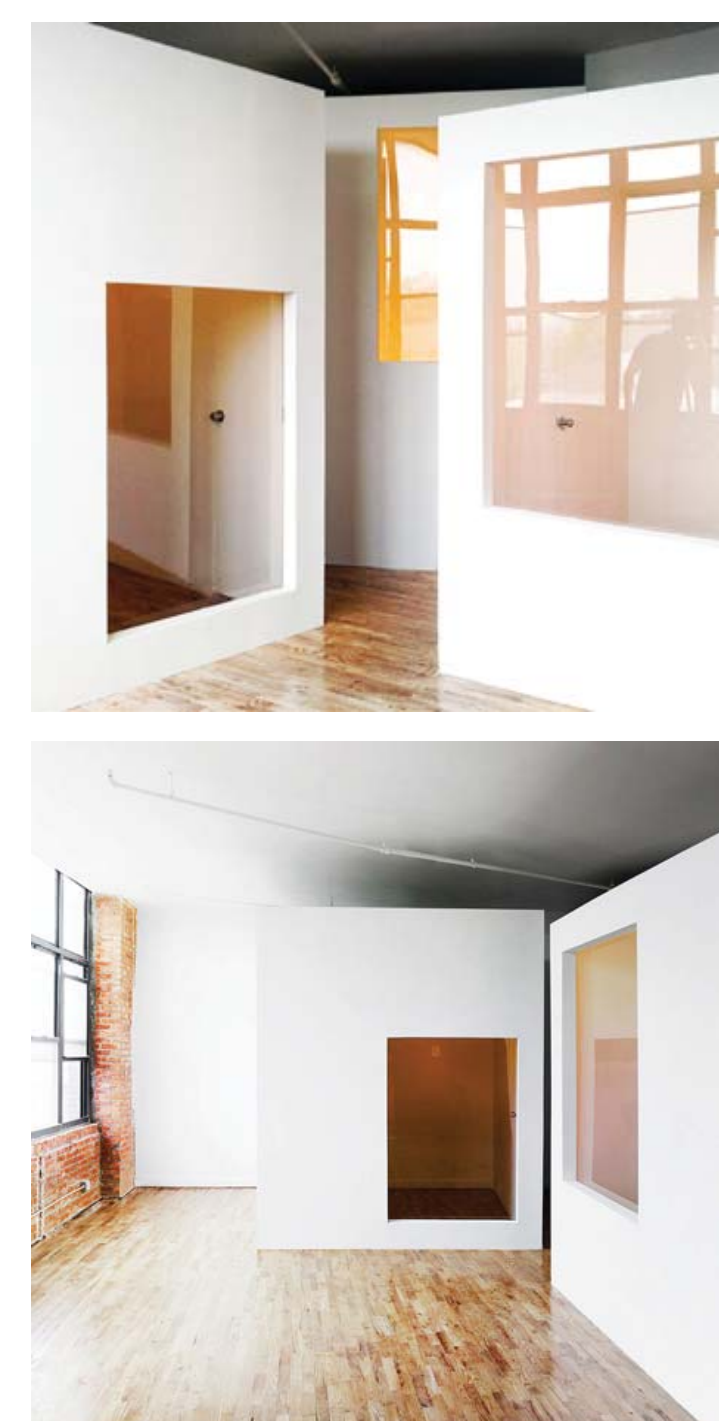

Fig. 3.61 Three small rooms interior (Retrieved Feb. 5 2014).

Top \& bottom: http//www dezeen com/2012/12/14/ three-small-rooms-loft-interior-studio-cadena/ 


\section{Lyon Housemuseum - Lyon Architects}

"The Lyon Housemuseum speculates on the conjunction of art and living, on conventional notions of 'public' and 'private' and explores new relationships between art and architecture through the development of a new hybridised type - a 'housemuseum'." ${ }^{21}$

Notably the interior has a balance of enclosed private spaces and open interconnecting spaces. The public spatial configuration is achieved without the need to divide spaces by walls. There are fully enclosed spaces, creating private spaces for the residents away from the public (Fig. 3.64).

${ }^{21} \mathrm{http}: / /$ www.dezeen.com/2010/06/26/ lyon-housemuseum-by-lyons-architects/ (February 2014)
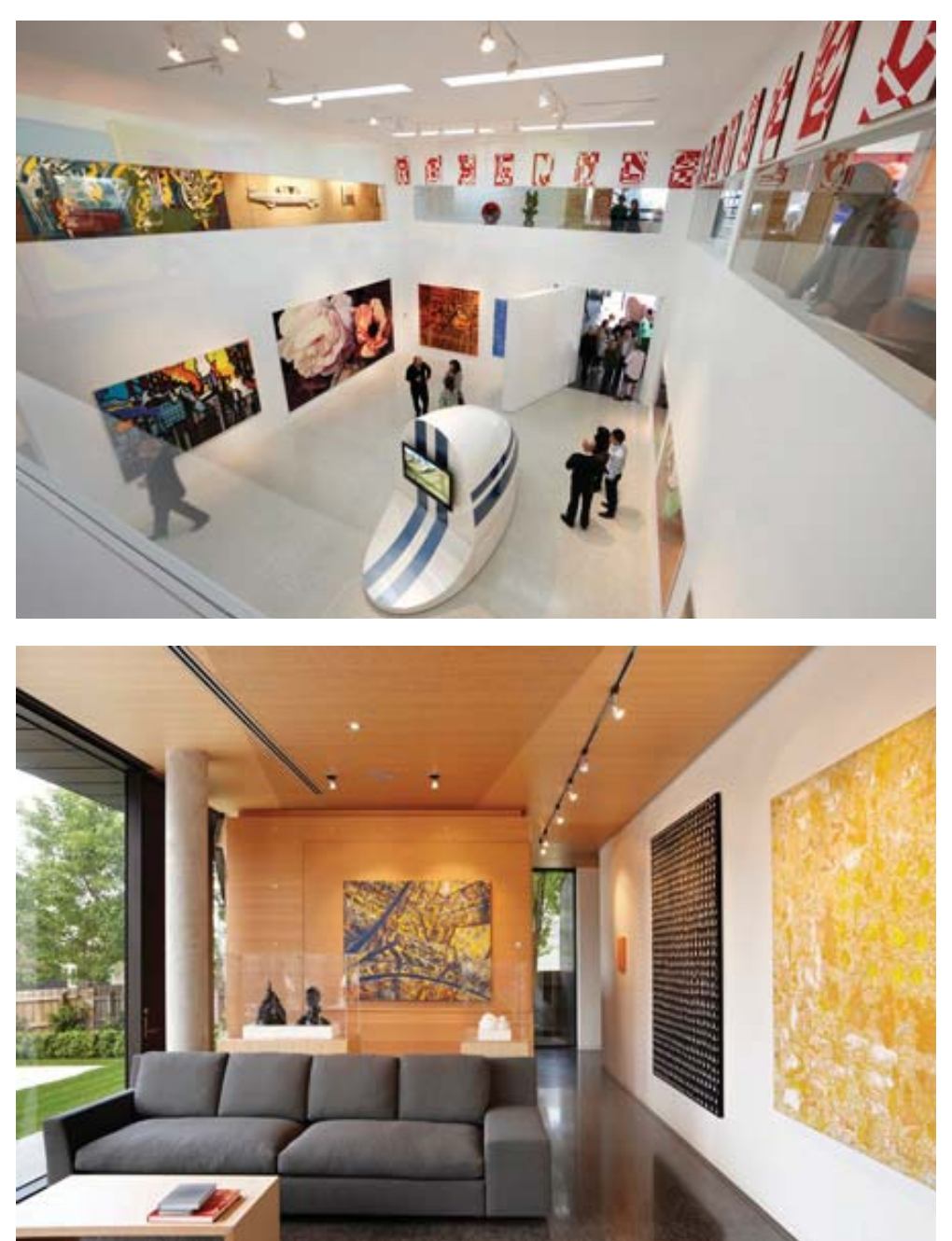

Fig. 3.62 Lyon Housemuseum interiors (Retrieved

$$
\text { Feb. } 5 \text { 2014). }
$$

http://www.dezeen.com/2010/06/26/lyon-housemuseum-bylyons-architects/ 


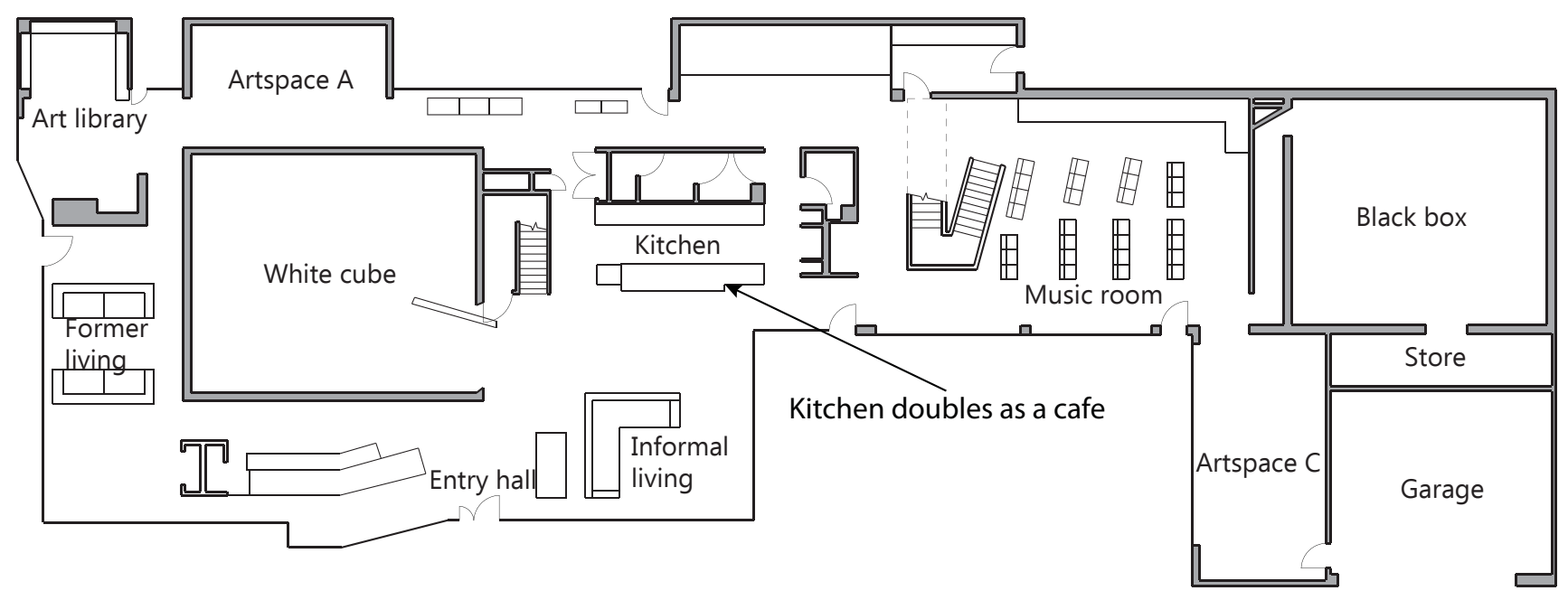

Fig. 3.63 Lyon housemuseum ground floor plan

Level 1 - 1 person - 1.5 bays

1:100

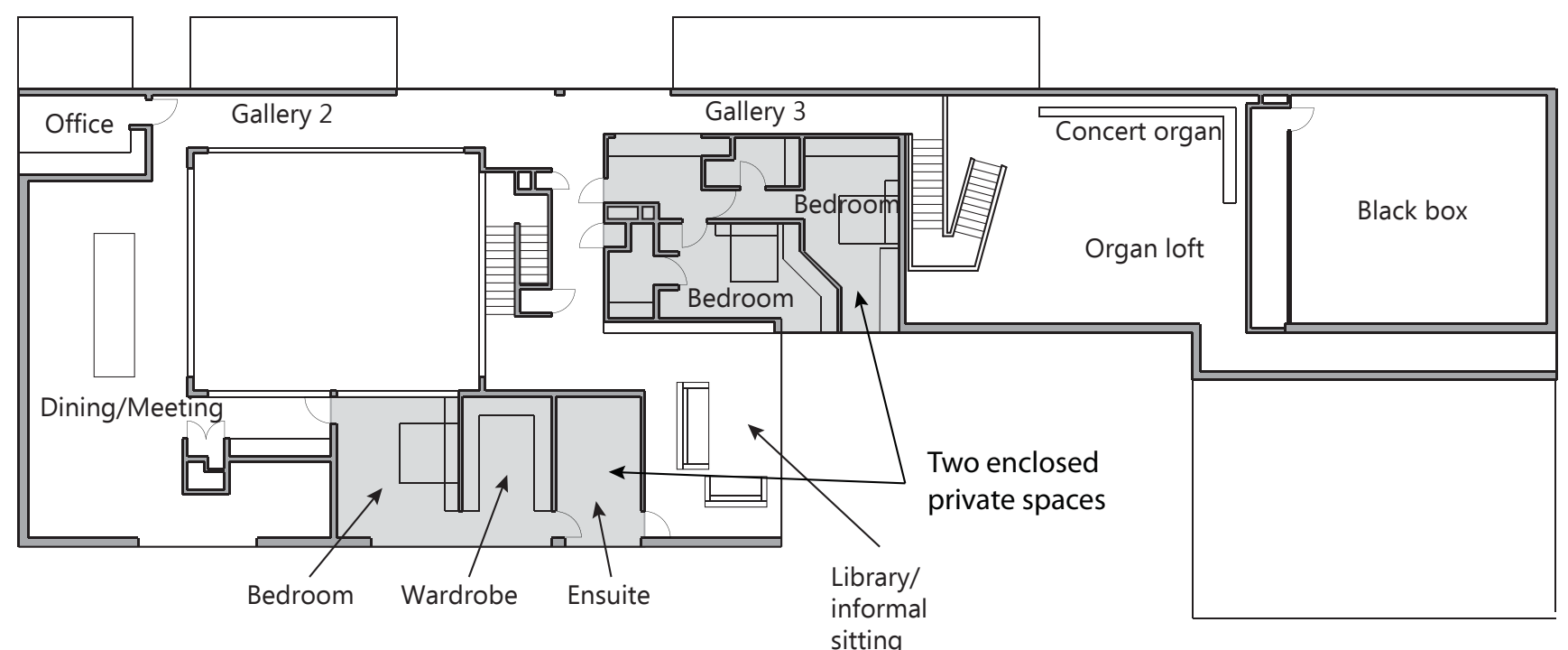

Fig. 3.64 Lyon housemuseum 2nd level plan

Level 1 - 1 person - 1.5 bays

$1: 100$ 


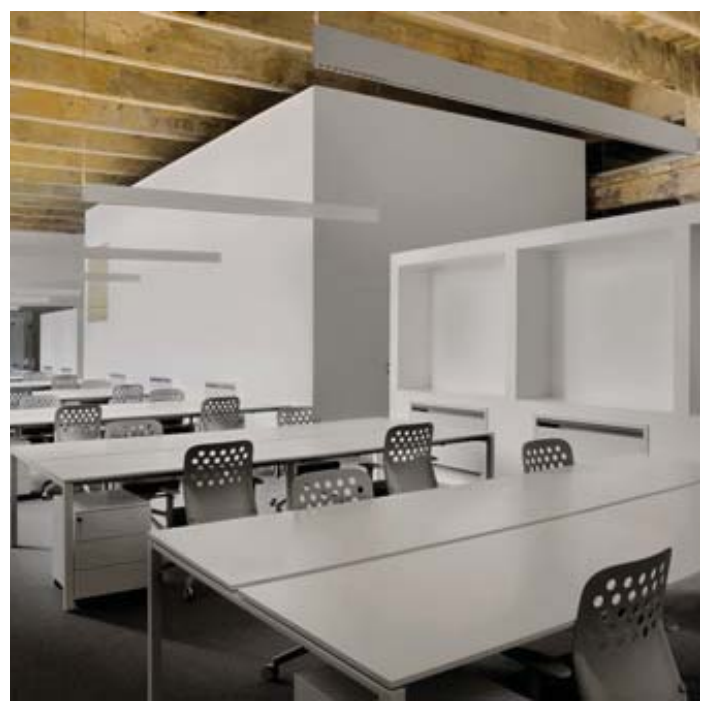

Sempla Offices

DAP Studios

Turin, Italy

Fig. 3.65 Sempla offices (Retrieved Feb. 5 2014). http://www.dezeen.com/2013/03/17/sempla-offices-bydap-studio/

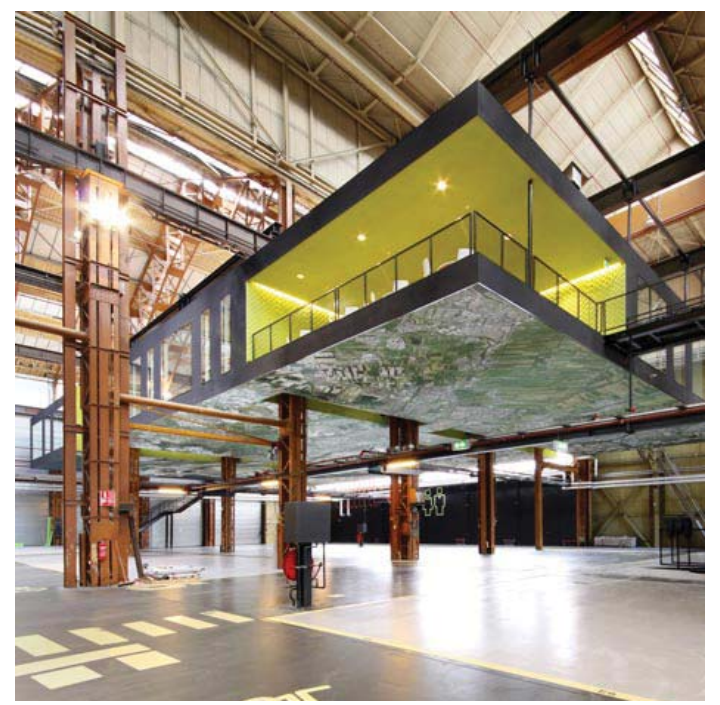

RDM Innovation Deck

Groosman Partners

Rotterdam, Netherlands

Fig. 3.66 RDM innovation deck (Retrieved

Feb. 5 2014).
http://www.dezeen.com/2013/02/07/rdm-innovationdeck-by-groosman-partners/

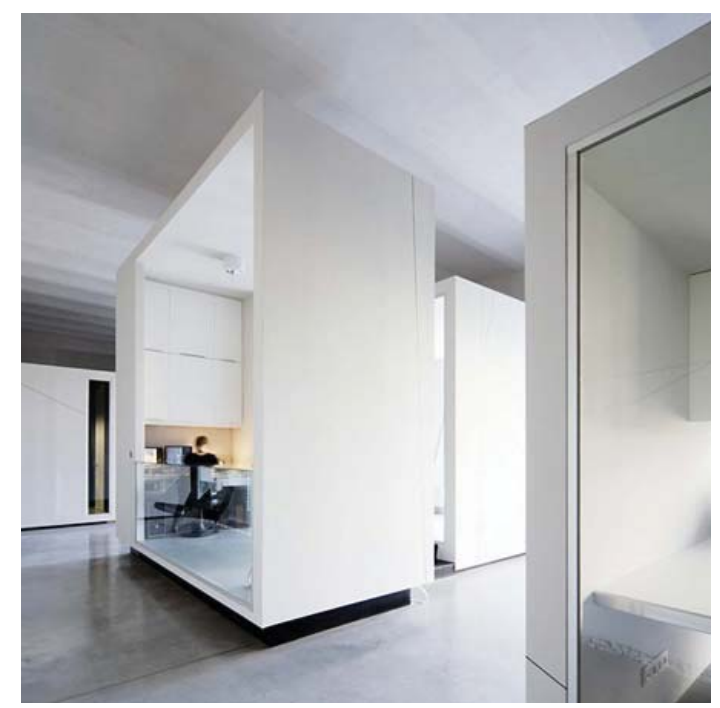

Goldberger

Tervhivatal

Budapest, Hungary

Fig. 3.67 Goldberger (Retrieved Feb. 5 2014). http://www.dezeen.com/2010/04/26/goldberger-bytervhivatal/ 


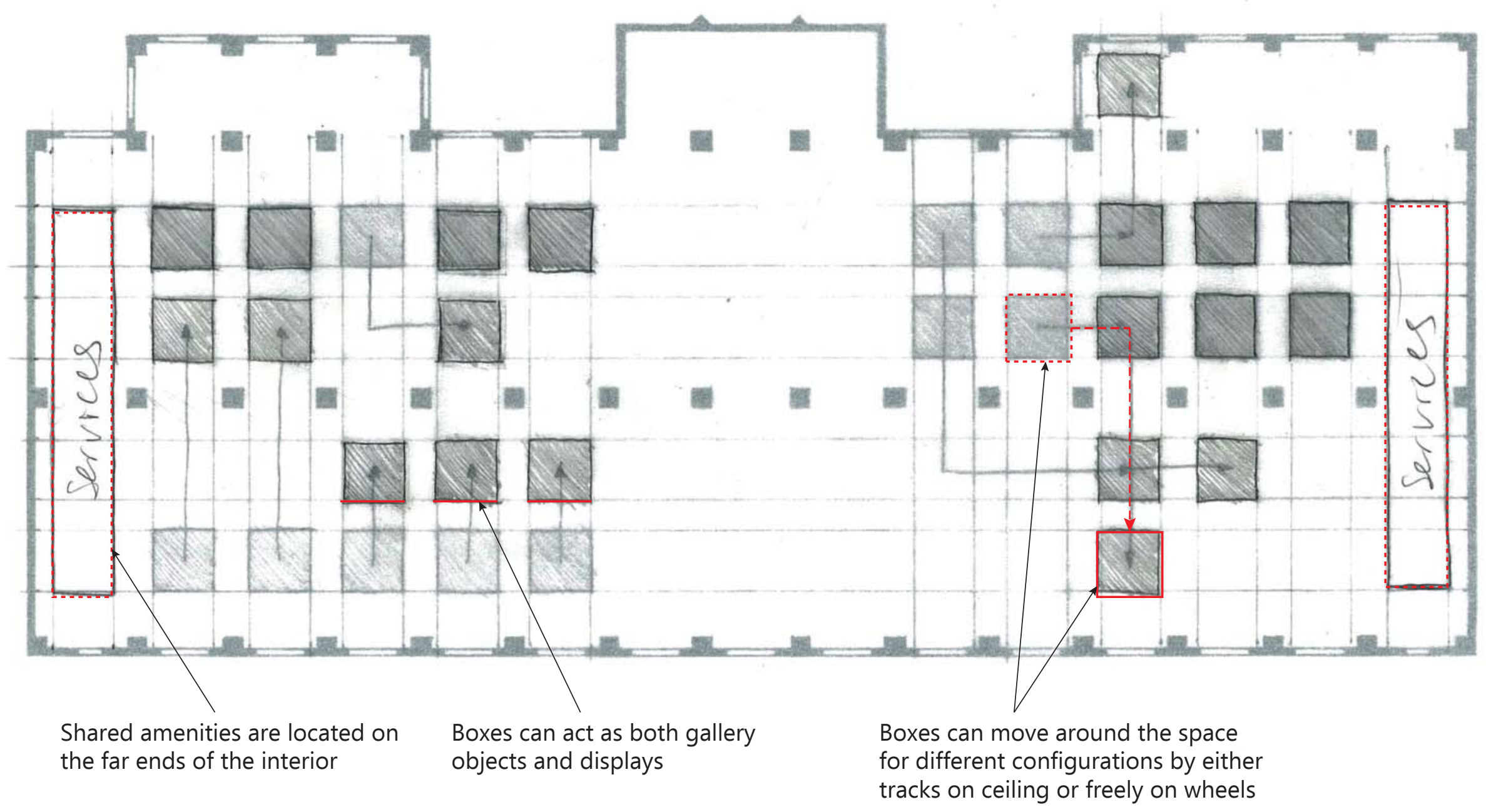

Fig. 3.68 Mobile iteration 1

Scale: 1:200

Sub-type: Mobile

Level: Undefined 


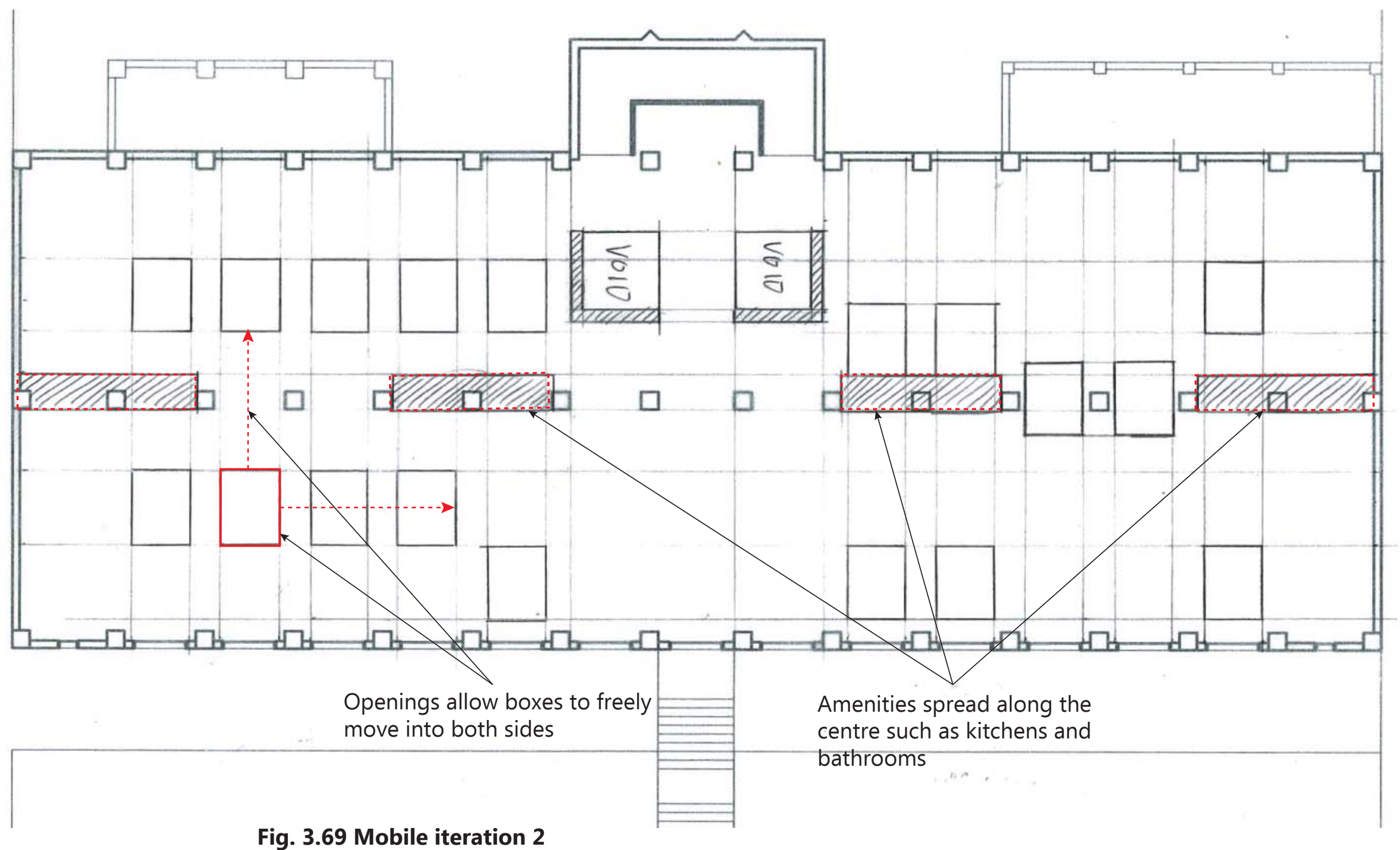

Fig. 3.69 Mobile iteration 2

Scale: 1:200

Sub-type: Mobile

Level: Undefined 
Mobile pods offer a

level of flexibility and playfulness to the interior while keeping the interior a singular cohesive space.

\section{Summary}

Mobile pods offer a level of flexibility and playfulness to the interior while keeping the interior a singular cohesive space. An issue was the incentive to move the pods at all (Fig. 3.68 and Fig. 3.69).

There is an issue with the pods being in the art gallery such as privacy and seclusion from others. "Dwellings opening directly onto busy public spaces and access decks designed to encourage social contact and neighbourliness may also suffer intolerable intrusions." 22 So unless the pods have a place to retreat to away from the public, there is insufficient seclusion.

An incentive however can be found in concepts in the earlier mechanism simply having a space for the pods to compact into during the day and moved later on.

Space within a space and deviant spaces were not as influential on the final

design. They are however some of the advantages of moveable interior spaces.

\section{“Dwellings opening directly onto busy public spaces and access decks designed to encourage social contact and neighbourliness may also suffer intolerable intrusions." 25 Quinton Pickard}

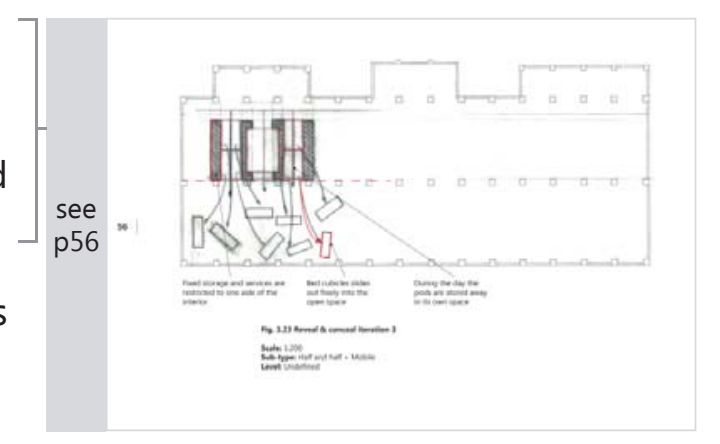




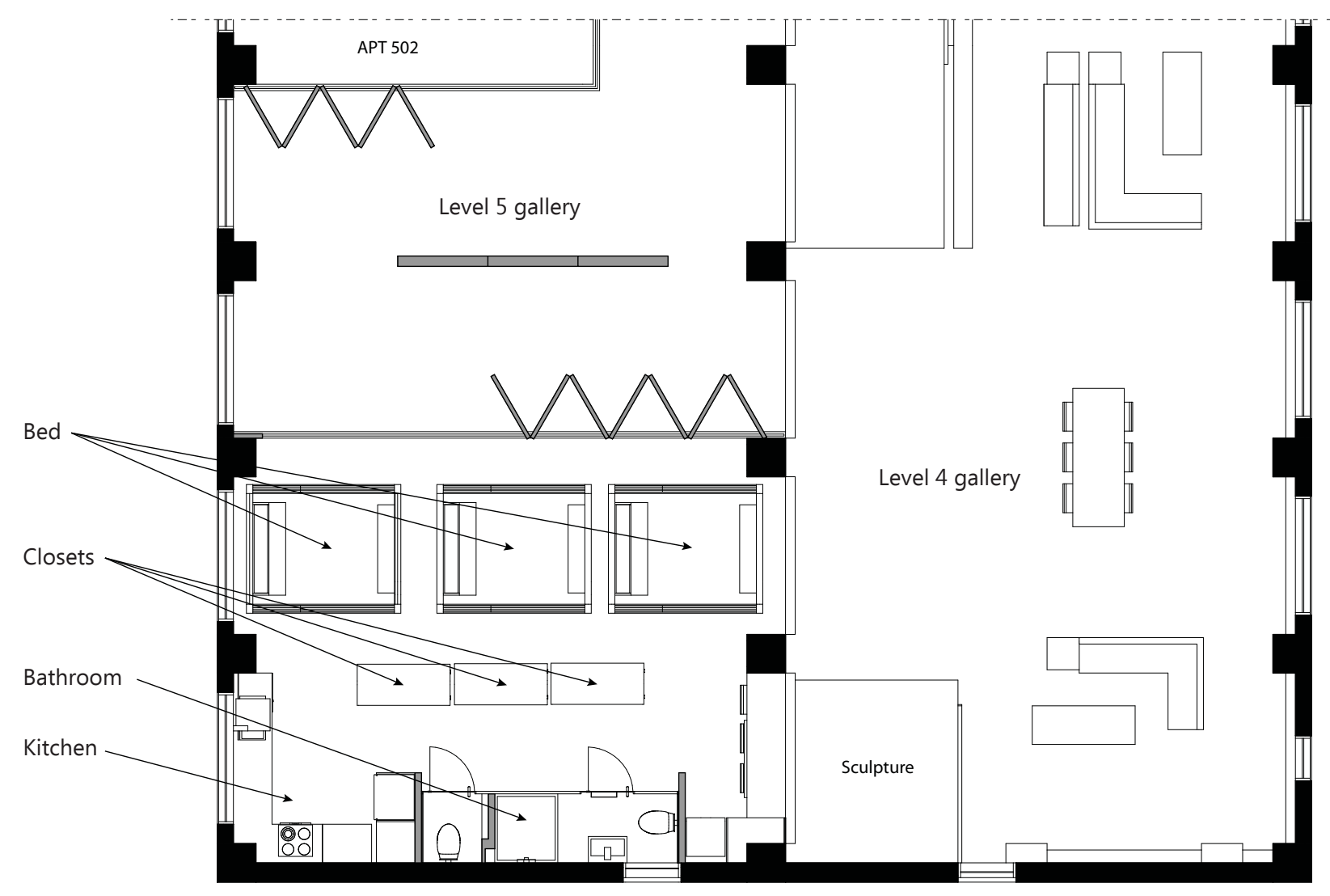

Fig. 3.70 Apartment 501

Level 5 - 3 people -2 bays $56.8 m^{2}$ 1:100

As mentioned earlier the mobile boxes had little incentive to move. Having two zones, however, does: a private zone where the boxes can retreat to and a public zone where they can be moved to.

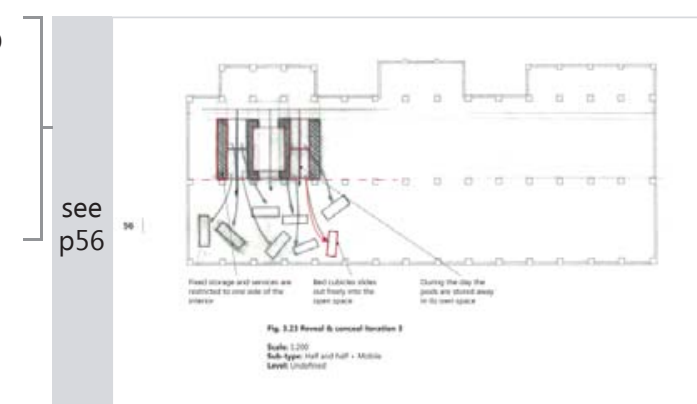




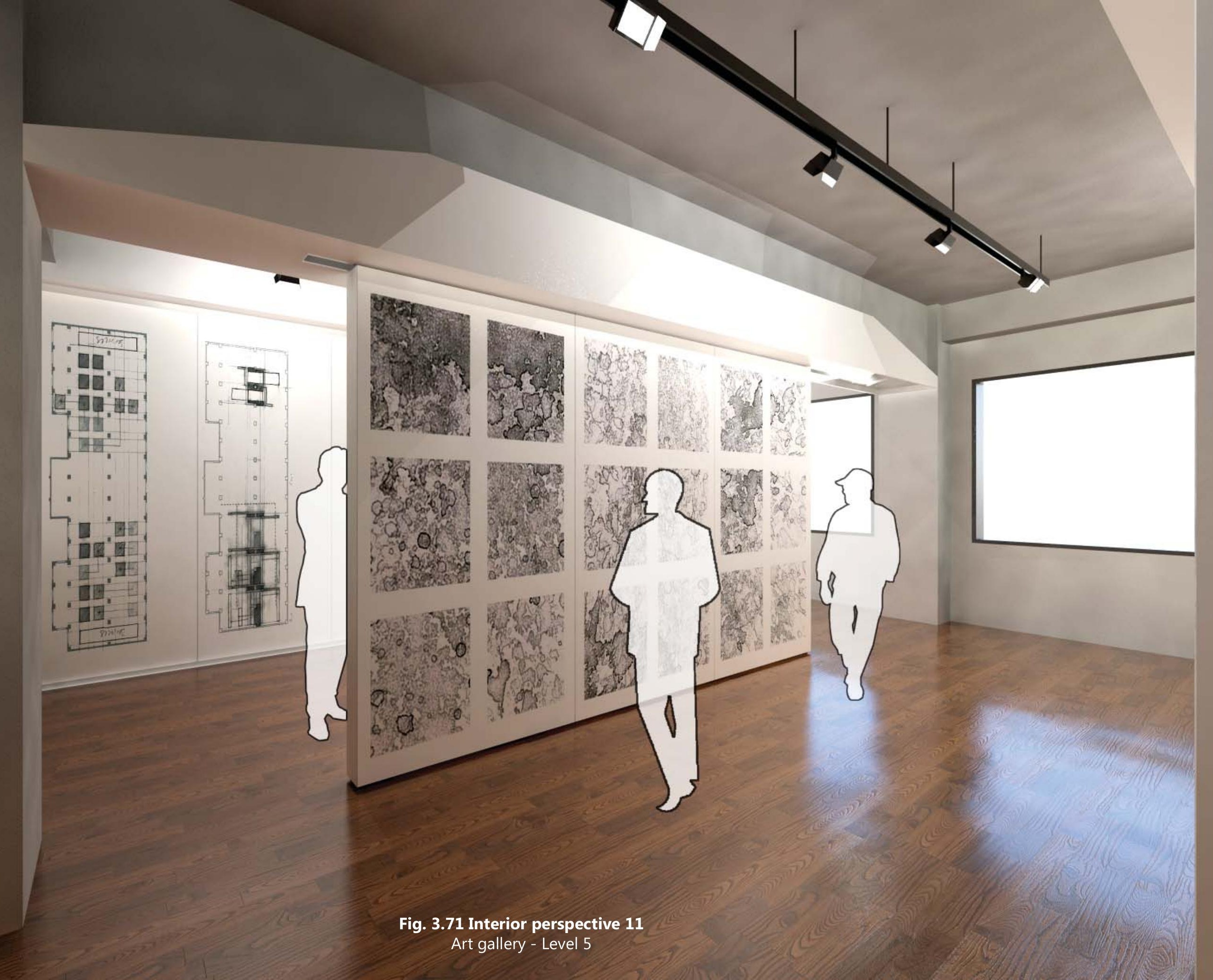




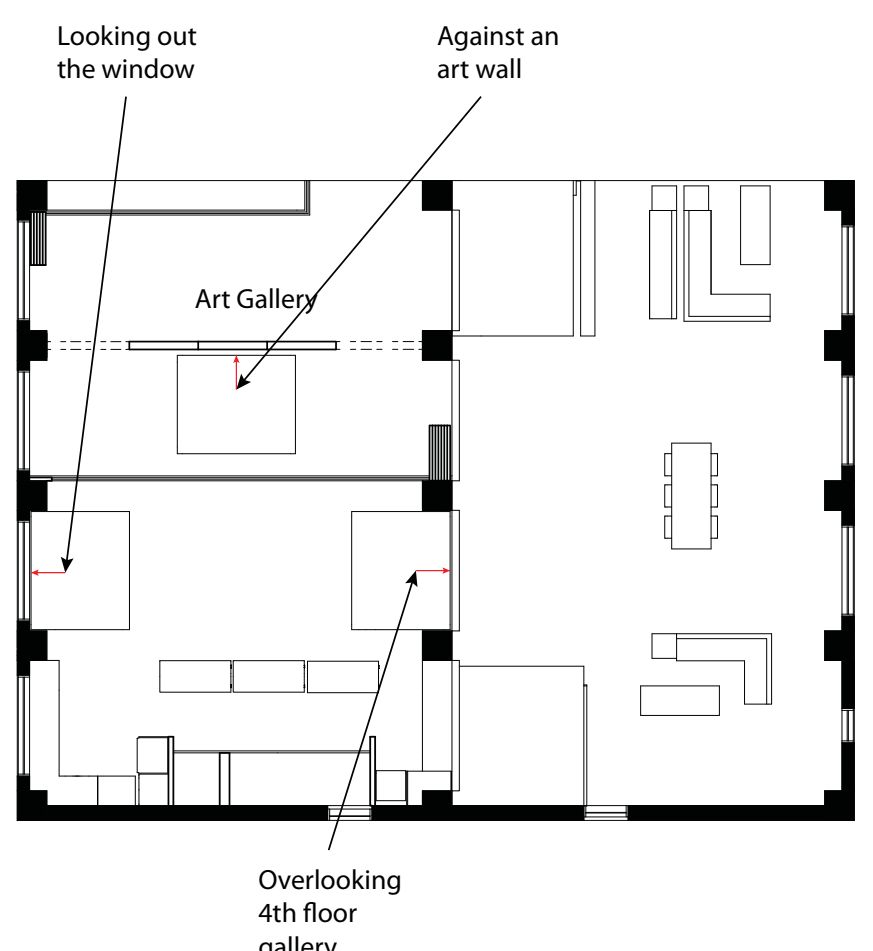

Fig. 3.72 Apartment 501

Daytime enclosed

$1: 200$

During the day the pods are moved into the allocated apartment space.

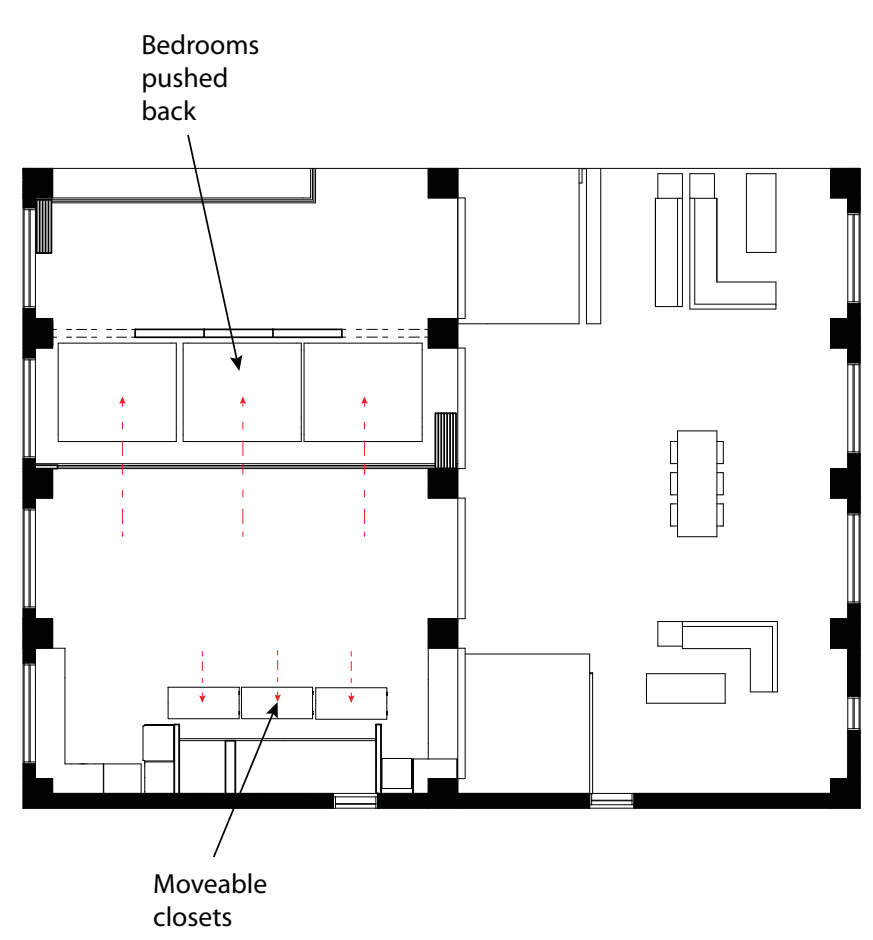

Fig. 3.73 Apartment 501

Restricted expansion

1:200

To create room, the pods and closets can be moved accordingly. 


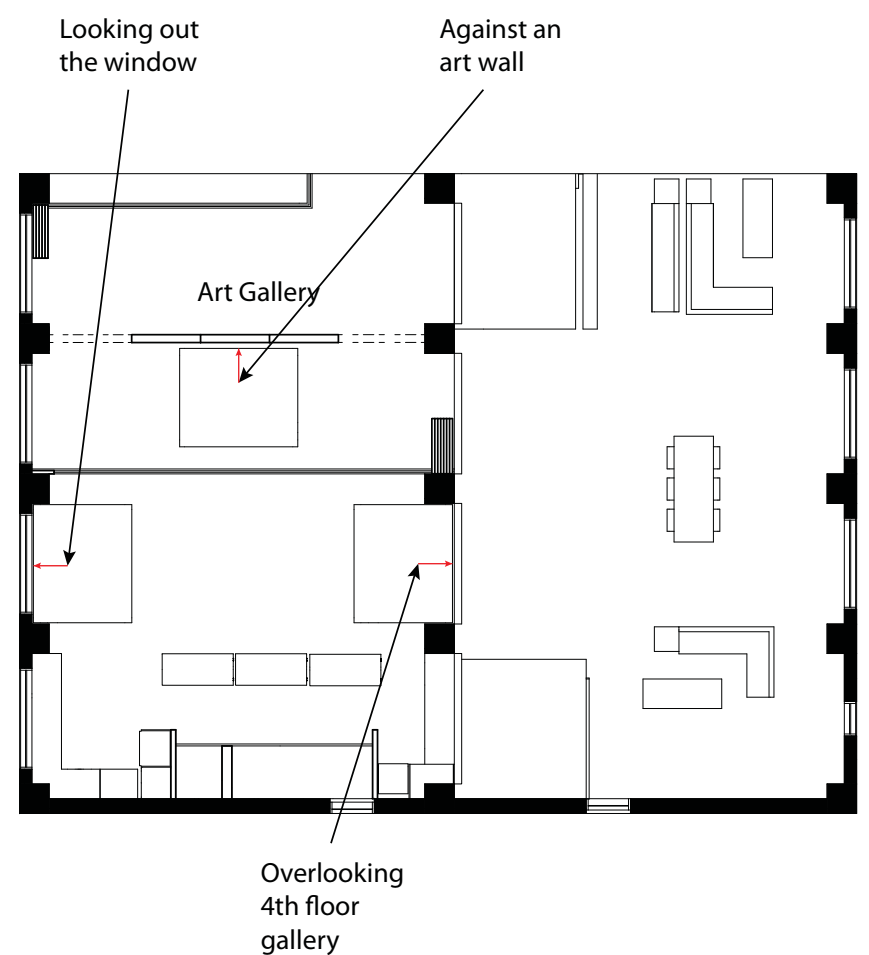

Fig. 3.74 Apartment 501

Possible placements

$1: 200$

The free mobility of the pods can be pushed against various elements of the interior. They can either sit against a panel of art, window or the edge of the mezzanine overlooking the art work below.

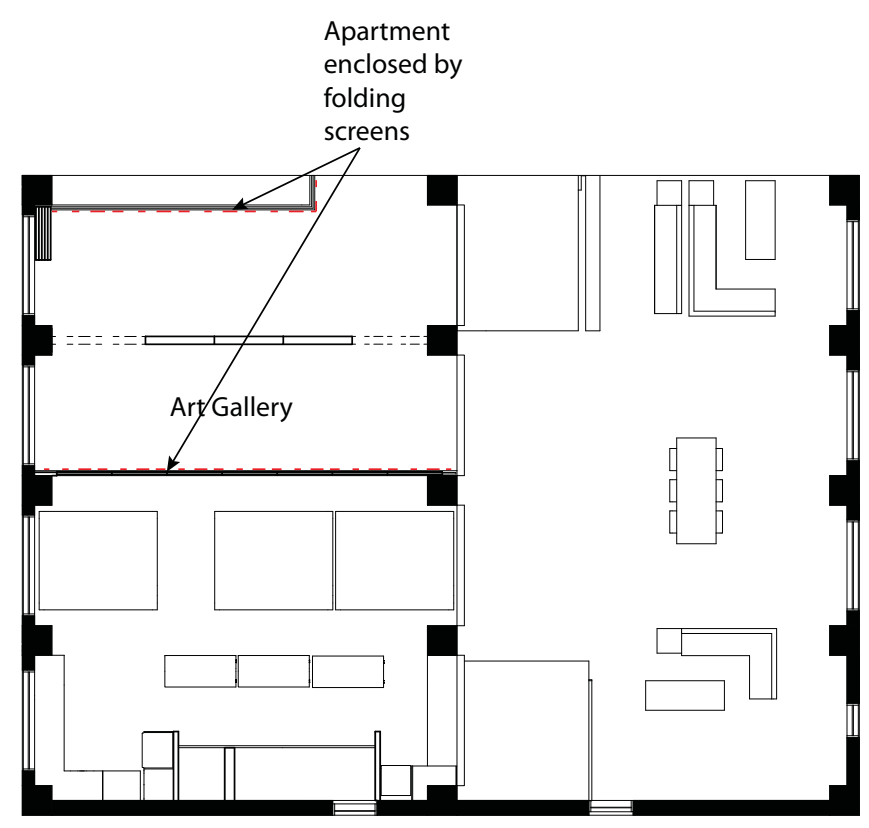

Fig. 3.75 Apartment 501

Merging with apartment 502

1:200

The gallery can also be shared with 502 .

This gives the ability to socially interact

with the other residents on the floor. 


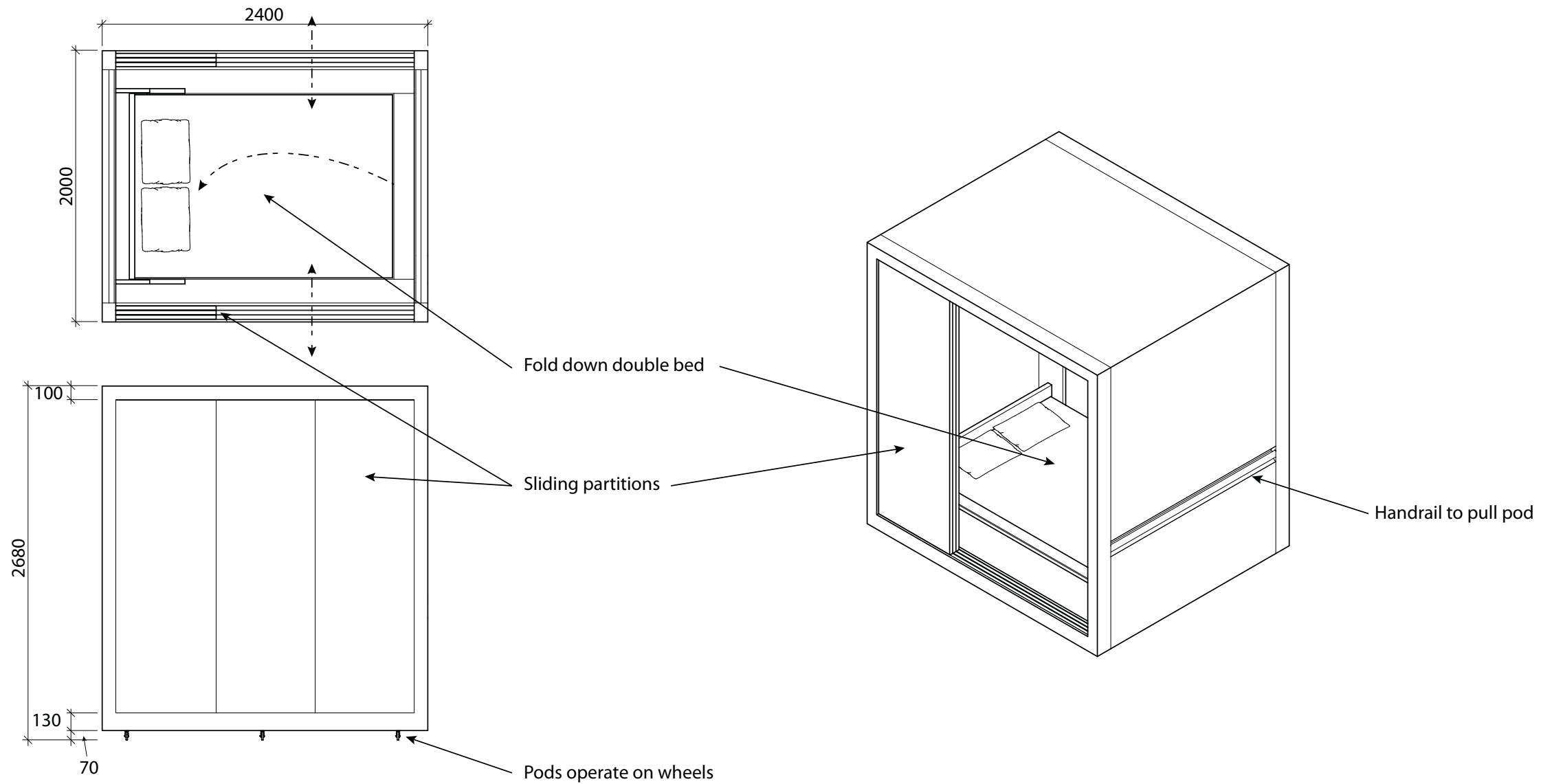

Fig. 3.76 Mobile sleeping boxes

\section{1:50}

The boxes are designed minimally for sleeping to restrict the size of these moving boxes. A major reason is so they can manoeuvre between the structural columns that are $2450 \mathrm{~mm}$ apart.

The boxes are open on two sides and have a fold-up bed to allow movement through these rooms. 


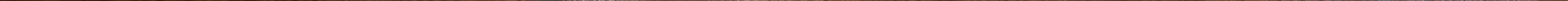




\section{Corridors}

\section{Mechanism 3}

\section{Figures, Doors and Passages}

Corridors are a simple interior device that allow the inhabitants to circulate without impeding on others' privacy. Its development was for the sake of privacy between households. "In sixteenth century Italy a convenient room had many doors; in nineteenth century England a convenient room had but one. The change was important not only because it necessitated a rearrangement of the entire house, but also because it radically recast the pattern of domestic life." ${ }^{23}$
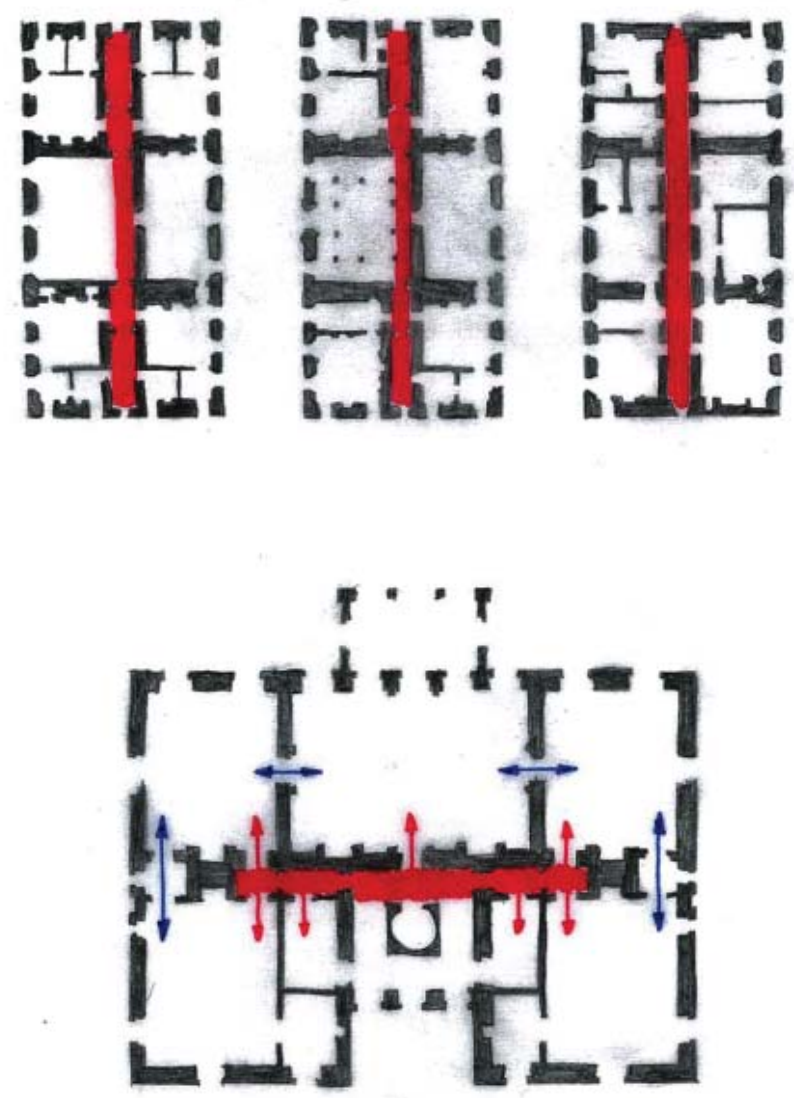

Fig. 3.78 Passages 


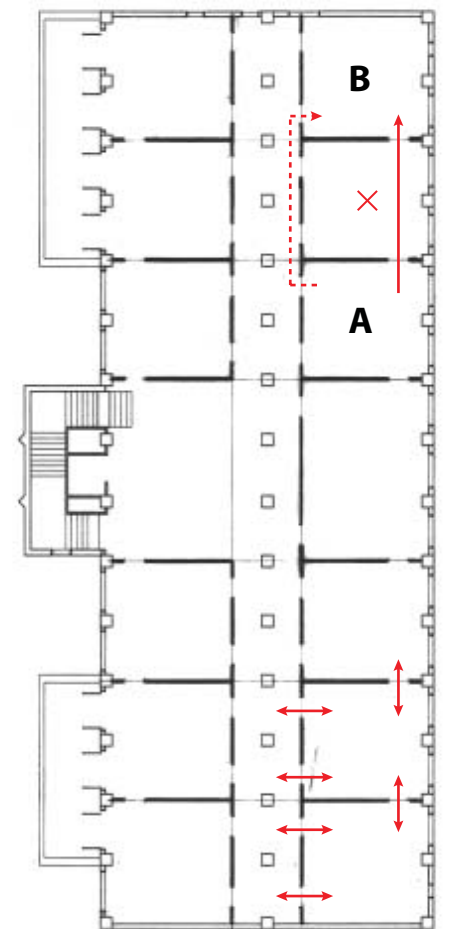

Fig. 3.79 Multiple doors and thoroughfares

"First, the rooms have more than one door - some have two doors, many have three, others four - a feature which since the early years of the nineteenth century, has been regarded as a fault in domestic buildings of whatever kind of size." ${ }^{24}$ With multiple points of entry, some rooms become a thoroughfare to other rooms. This can lead to intrusions among various households.

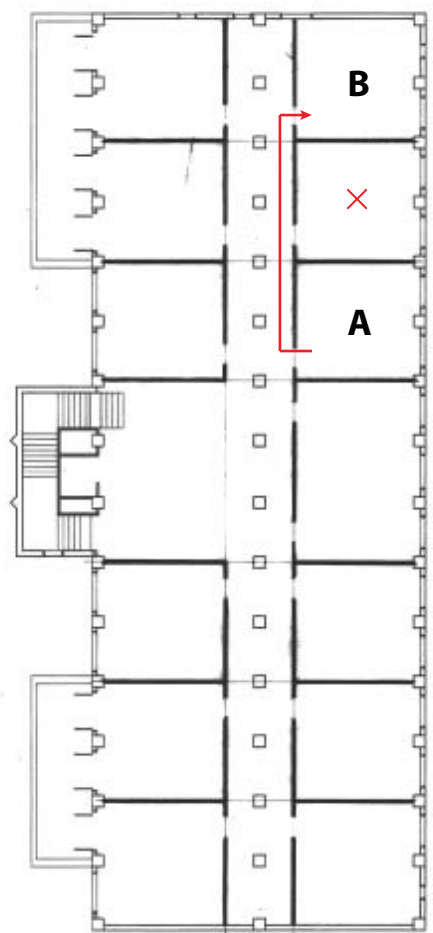

Fig. 3.80 Single doors and terminal space

"The favoured alternative was the terminal room, with only one strategically placed door into the rest of the house." 25 This terminal room allows people to bypass other spaces where they have no business. This terminal room connects all spaces together and prevents households to from intruding on each other. 


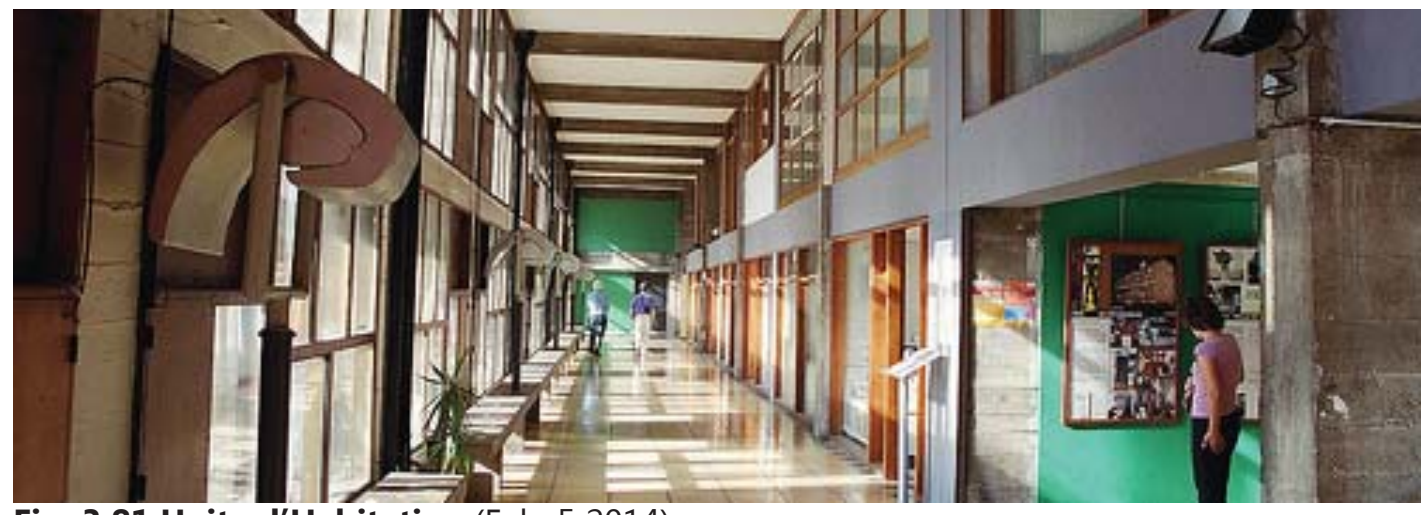

Fig. 3.81 Unite d'Habitation (Feb. 5 2014).

http://manmakehome.com/2009/04/15/mystery-solved-unite-dhabitation-marseille/

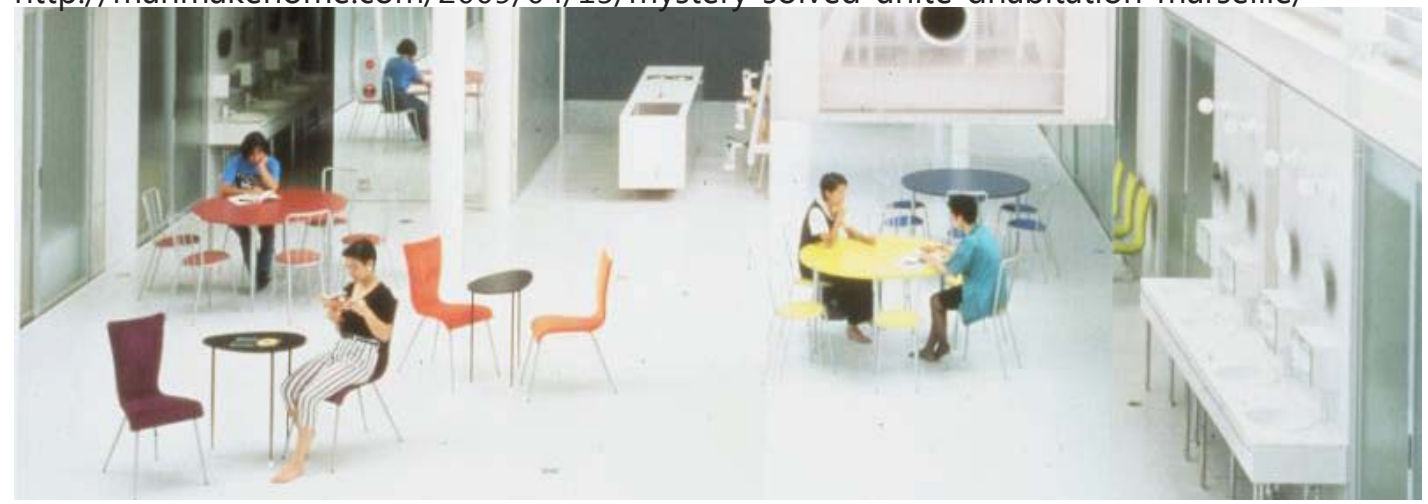

Fig. 3.82 Saishunkan Seiyaku (Feb. 5 2014).

http://www2.hawaii.edu/ kbda/1995-047/index8.htm

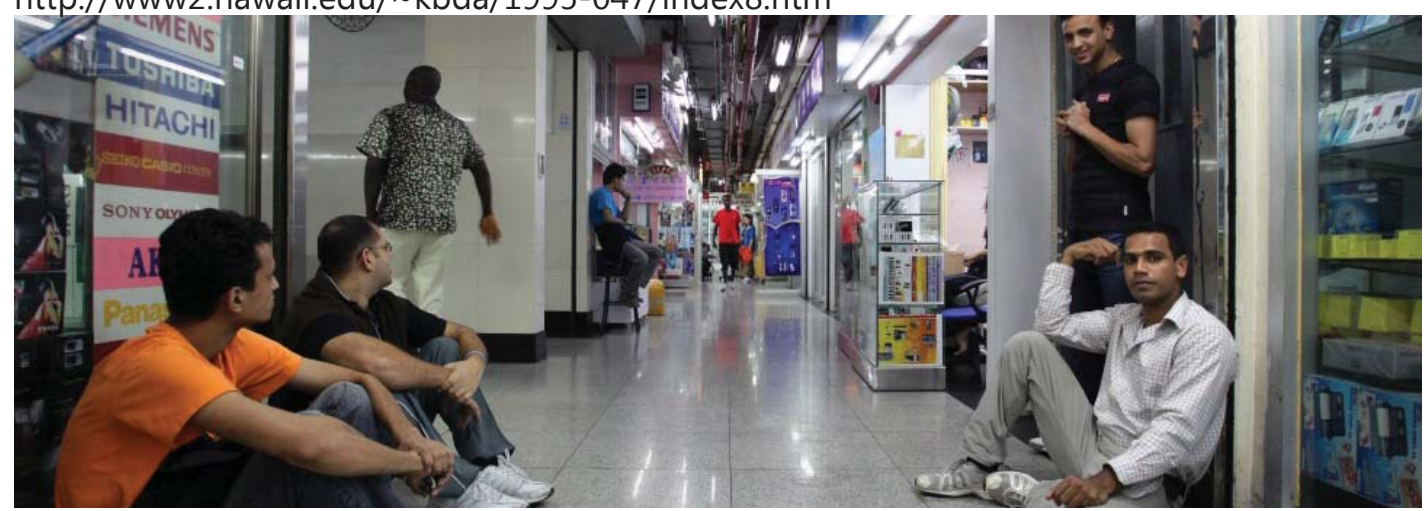

Fig. 3.83 Chungking Mansion (Feb. 5 2014).

http://www.foreignpolicy.com/articles/2011/11/25/inside_hong_kongs_chungking_mansions 


\section{Case Studies}

The following case studies look at the overall composition of the interior and its effects. They mainly focus on circulation and their method of housing a large number of occupants in a single body. The varying compositions all have their individual effects on public and

private spaces. There are varying levels of how private or public these case

studies are because of their composition. 


\section{Unité d'Habitation - Le Corbusier}

Consisting of a corridor with apartments spread along both sides, this corridor takes on the role of 'Interior Street'.

"The Unité d'Habitation's interior streets are much more than mere access corridors. Unlike most collective housing projects where passageways are usually calculated down to the last centimetre so as not to eat into the "useable surface area", here Le Corbusier focused on unleashing a generous amount of circulation space, which takes on the form of a genuine streetscape." ${ }^{26}$ Despite the additional width, it serves strictly as circulation and no other function.

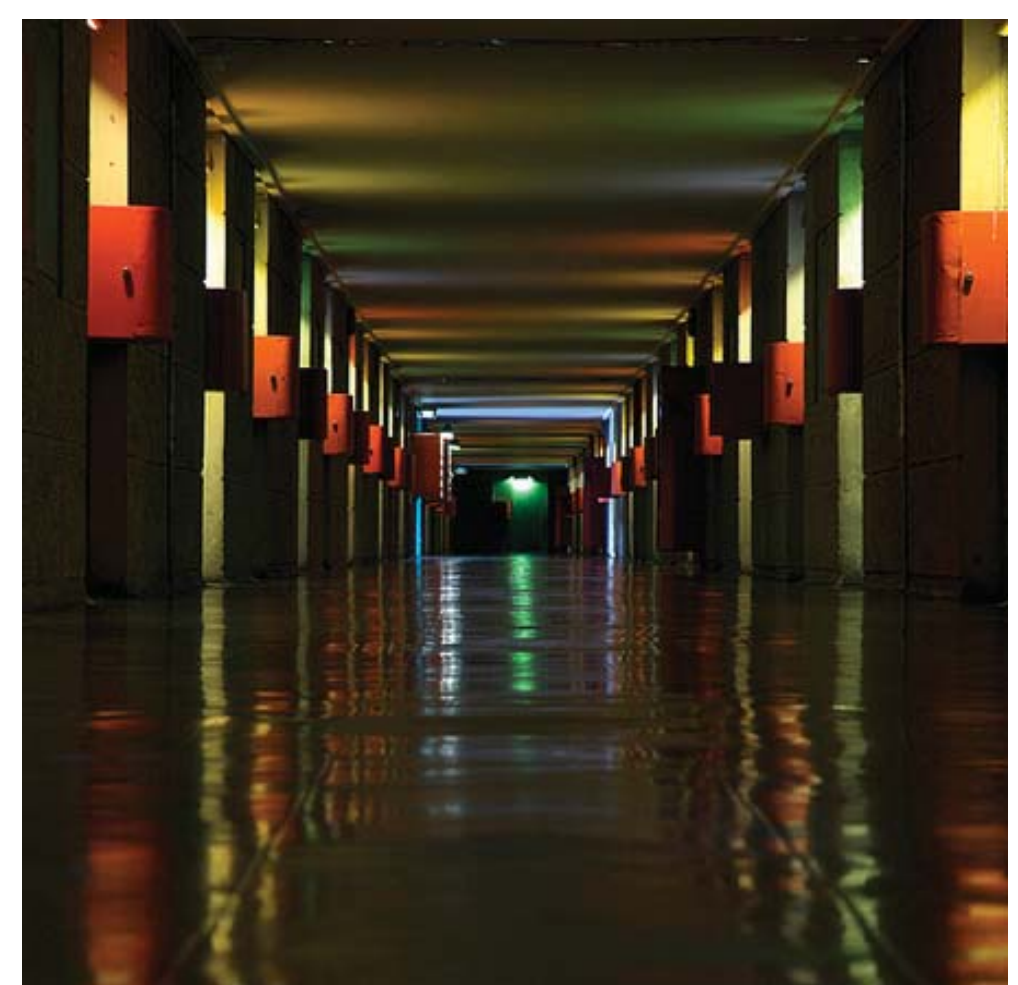

Fig. 3.84 Unite d'Habitation interior street (Retrieved Feb. 5 2014) http://writingtoinform.com/2012/04/10/research-the-extended-lobby-the-resident-as-guest-and-the-unite-dhabitation-as-hotel-11/ 


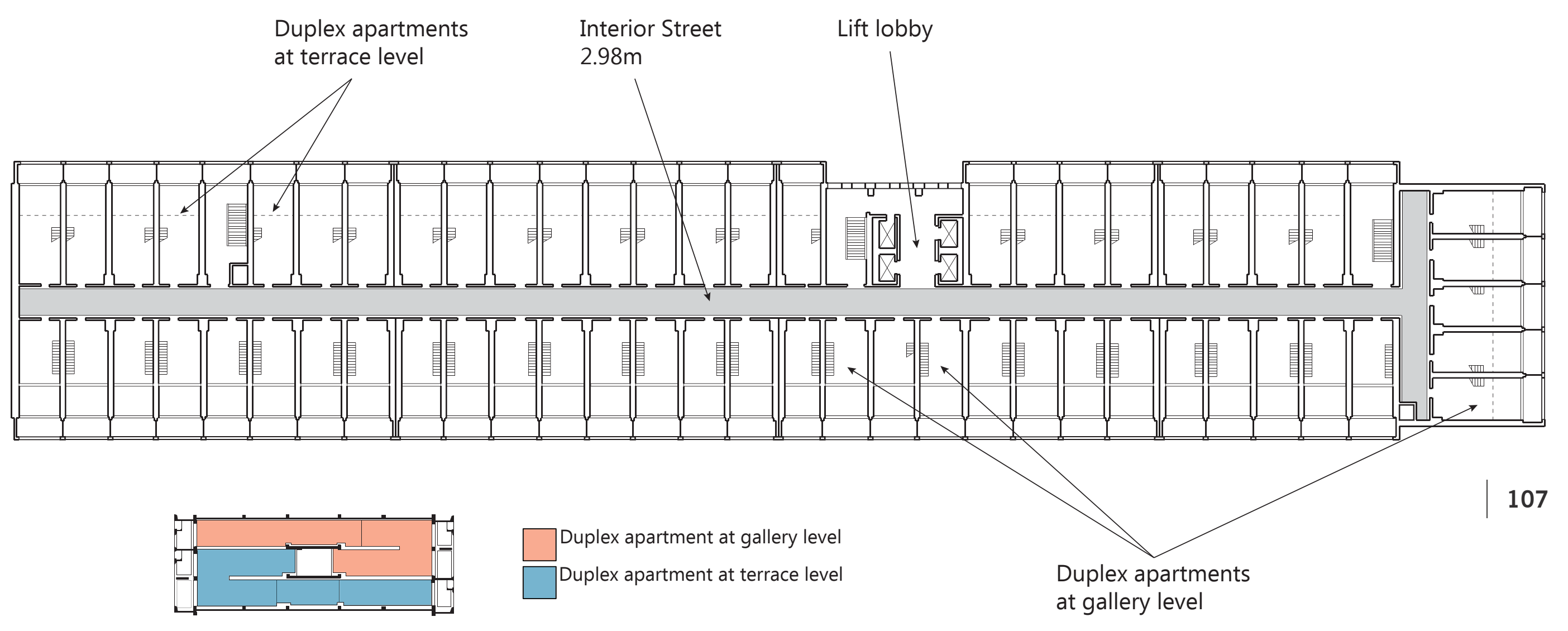

Fig.3.85 Unité d'Habitation, Marseille Le Corbusier plan and section 1:500 


\section{Saishunkan Seiyaku Women's Dormitory - SANAA}

\section{It differs from the Unite d'Habitation because the main circulation} space is much larger and living space.

This dormitory has a large communal living space with shared amenities. It differs from the Unité d'Habitation because the main circulation space is much larger and serves as the actual common living space. "Since the women who inhabit the building live and study here for only their first year of employment, communal living among 80 people instead of comfortable, well equipped private rooms received major design emphasis. For instance, providing a large living zone was considered more important than slightly increasing individual living spaces." ${ }^{27}$

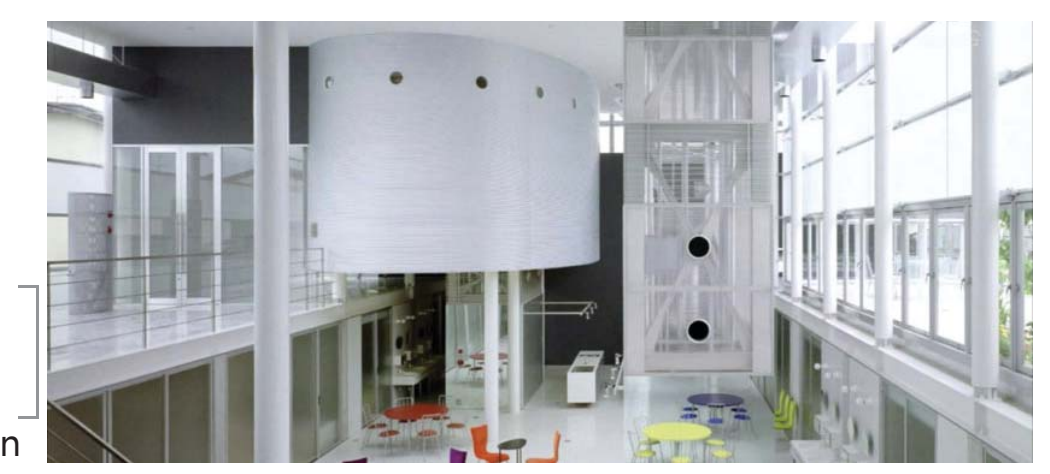

Fig. 3.86 Saishunken Seiyaku interior (Retrieved Feb. 5 2014). http://www.designboom.com/interviews/sanaa-kazuyo-sejima-ryue-nishizawa-designboom-interview/ 


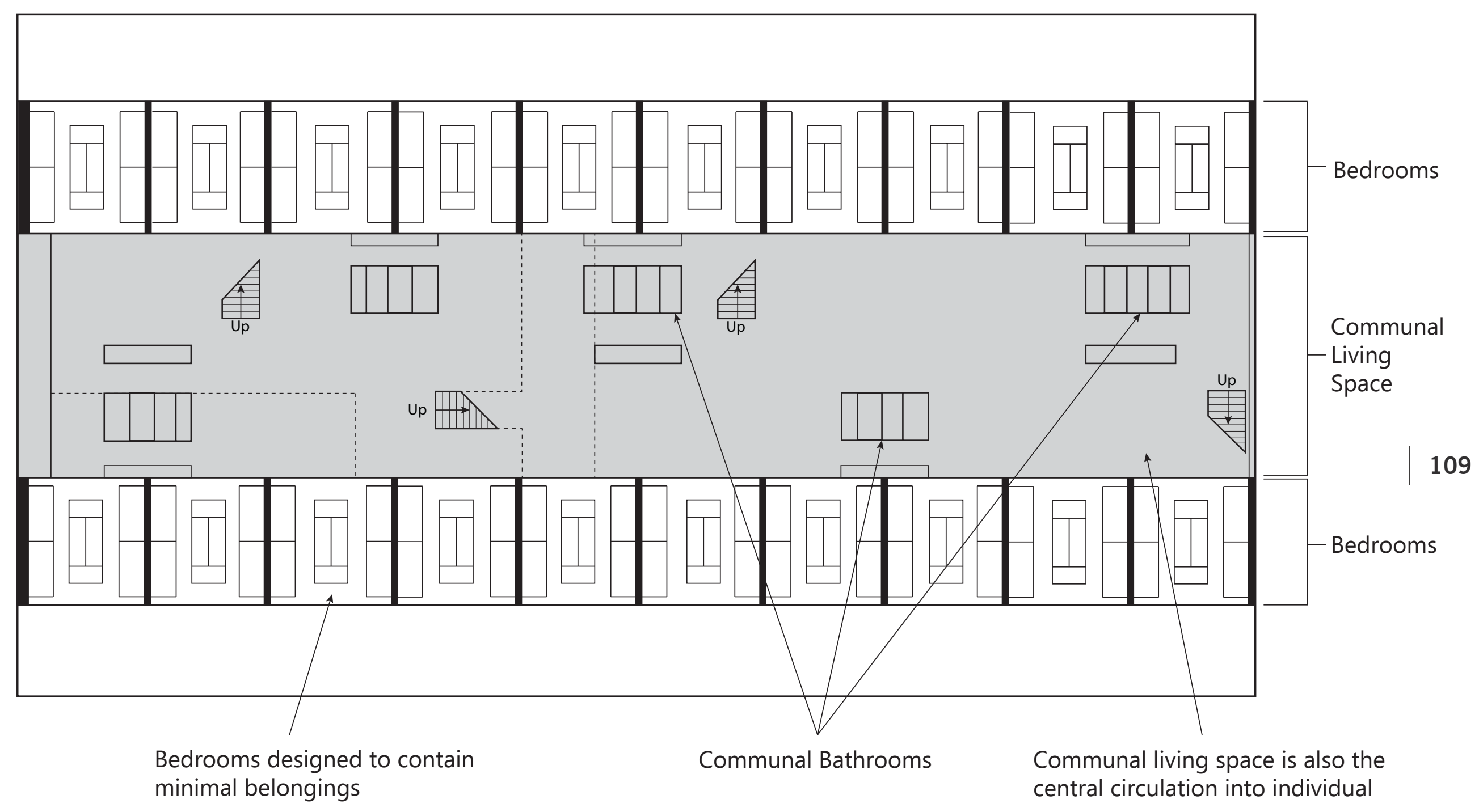

Fig. 3.87 Saishunkan Seiyaku women's dormitory SANAA 1:500 1st floor plan 


\section{Case Study Summary}

The overall composition of apartment interiors is where the challenge exists. The case studies exploring various configurations show that each interior succeeds in its own way, but all through a reliance on central circulation when managing the inhabitants.

The Unité d'Habitation and Saishunkan Seiyaku are almost opposites of each other in what they prioritise between personal amenities and circulation. One is for longer term housing; the other is a temporary dormitory. Both differ based on their shared public amenities and household amenities, which dictate the width of this common corridor space. Though the Saishunkan Seiyaku is more of a large social hall, it ultimately performs the same in terms of circulation.
Chungking Mansions varies differently with a cluster of various programs including housing, hostel living and conduction of business. Despite having the appearance of a labyrinth, there is a form of central circulation from where all varying businesses and homes mediate. Not like a hotel, the central circulation allows for different programs to coexist on one floor but lacks any significant spatial area.

Unité d'Habitation's 'interior street' is designed more than the minimum width that a corridor can be, but minimum to a point that no extensive activity can persist. Saishunkan Seiyaku has a large shared living space but provides minimal personal household amenities. The larger living space works just as a corridor would accessing the bedrooms but with enough width to encourage social activities. Chungking is an example of how many projects of its type appear like cellular interiors. 
111 


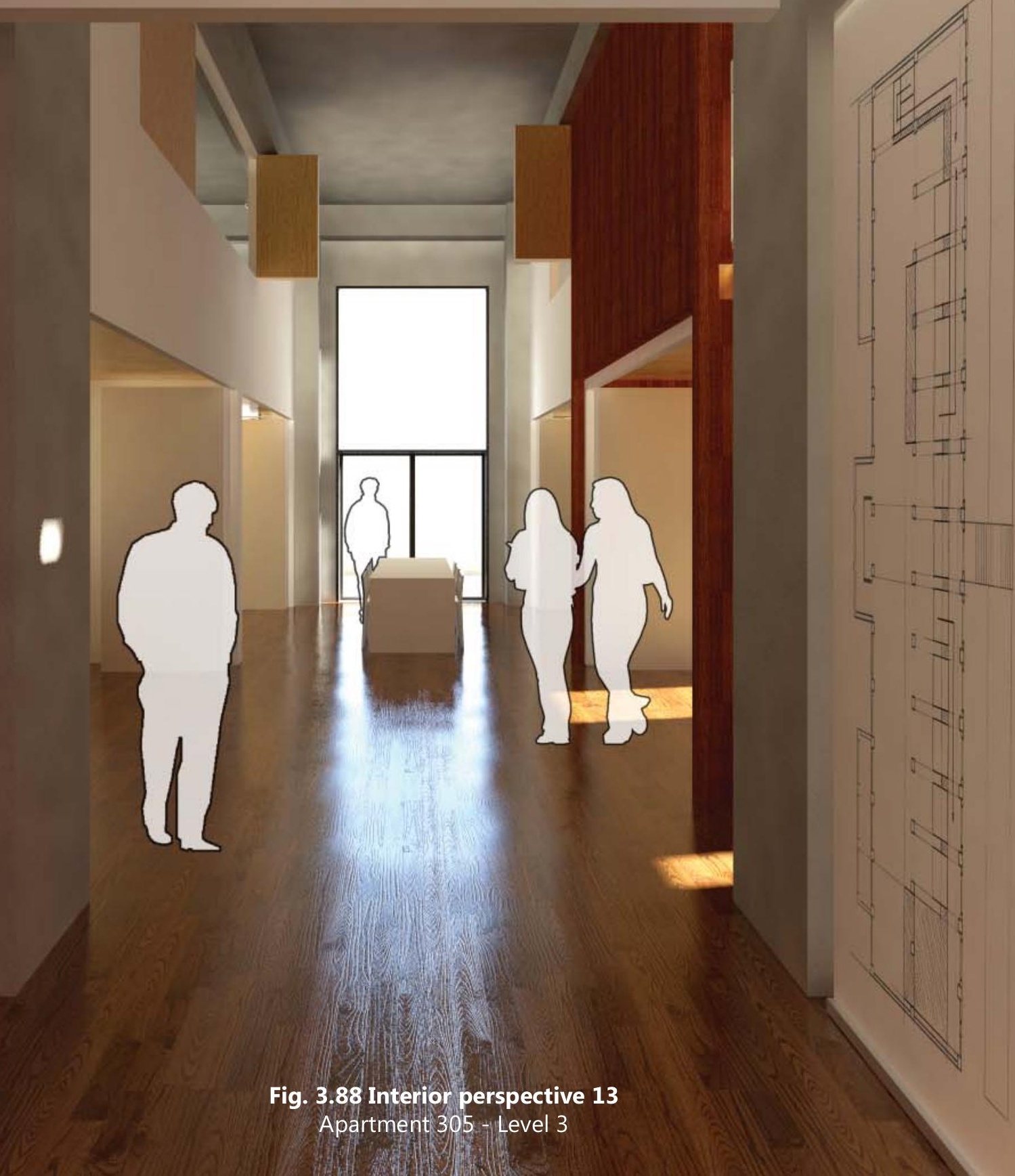




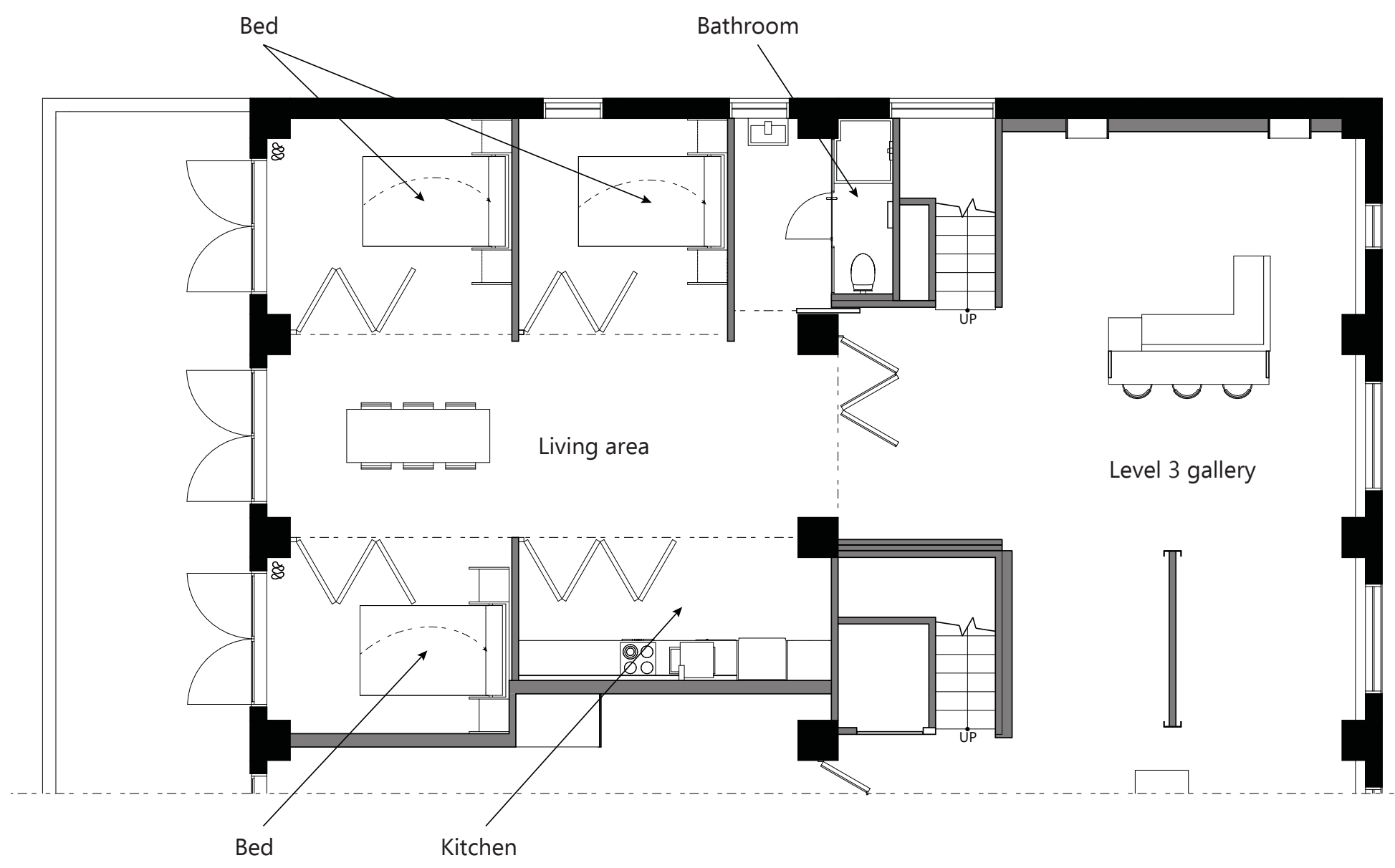

Fig. 3.89 Apartment $\mathbf{3 0 5}$

Level 1 - 2 people - 3 bays $56.8 \mathrm{~m}^{2}$ 1:100 


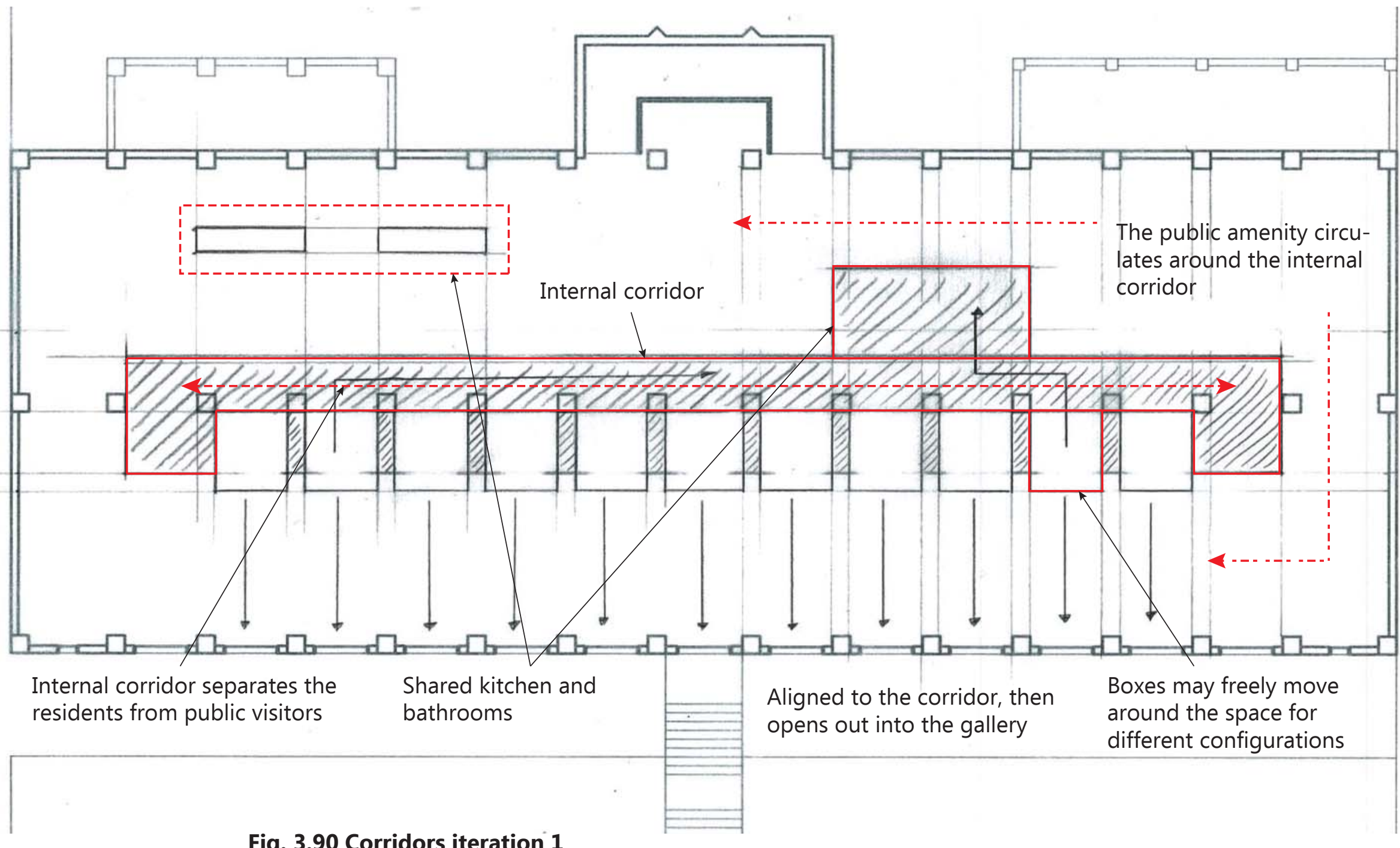

\section{Fig. 3.90 Corridors iteration 1}

Scale: 1:200

Type: Central Linear Corridor

Level: Undefined 


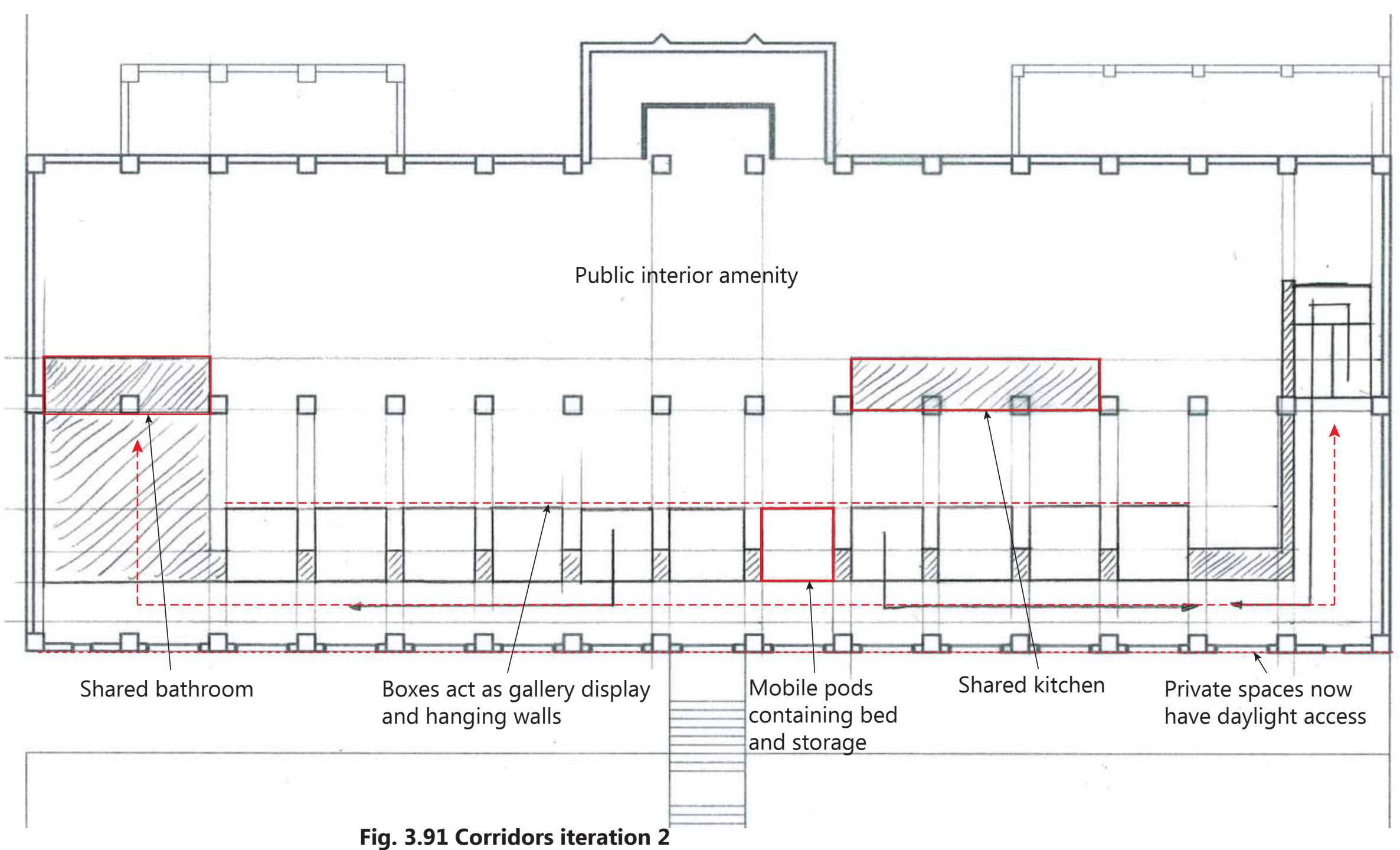

115

Scale: 1:200

Type: Corridor

Level: Undefined 


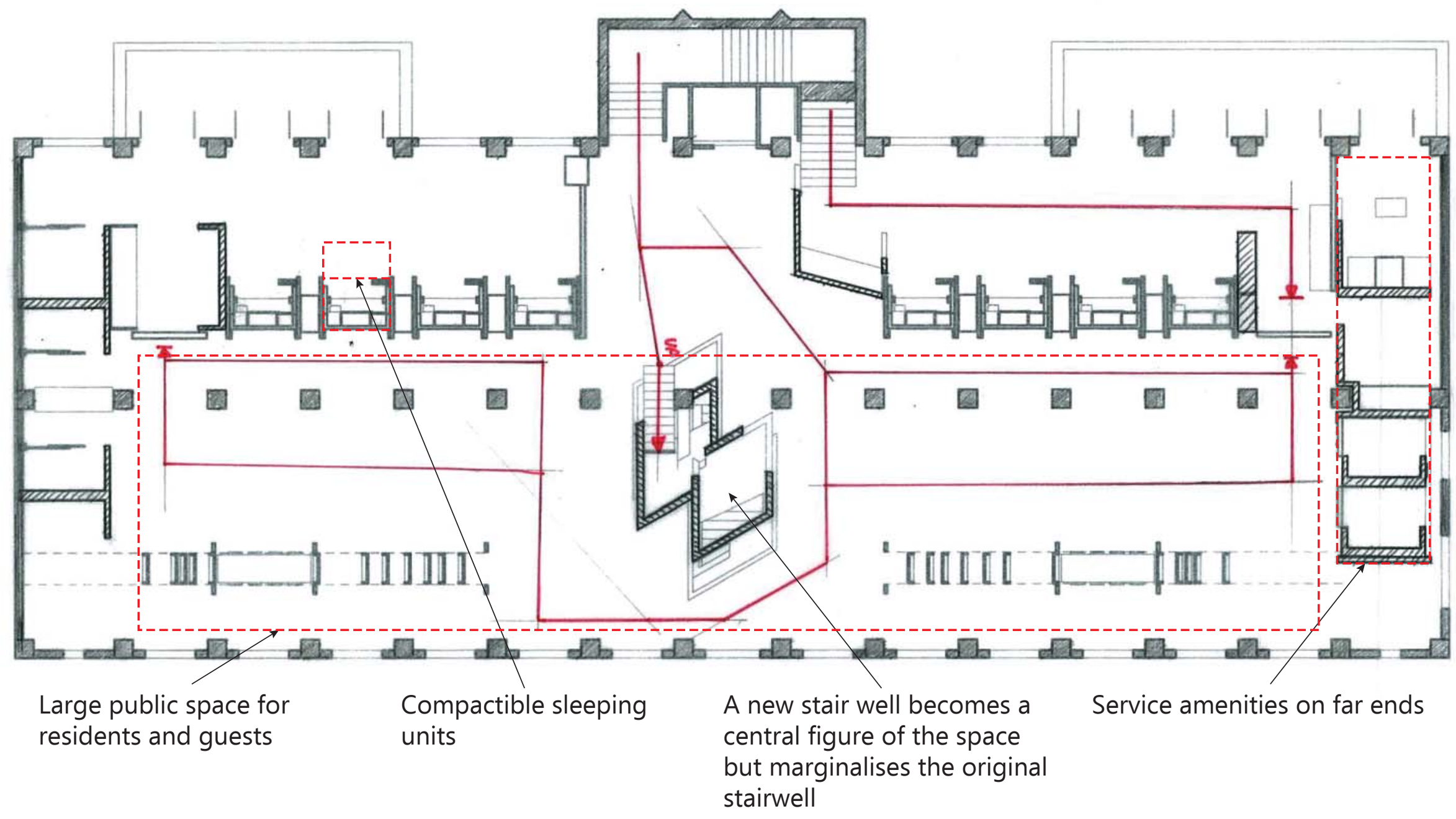

Fig. 3.92 Corridors iteration 3

Scale: 1:200

Type: Corridor

Level: 3 


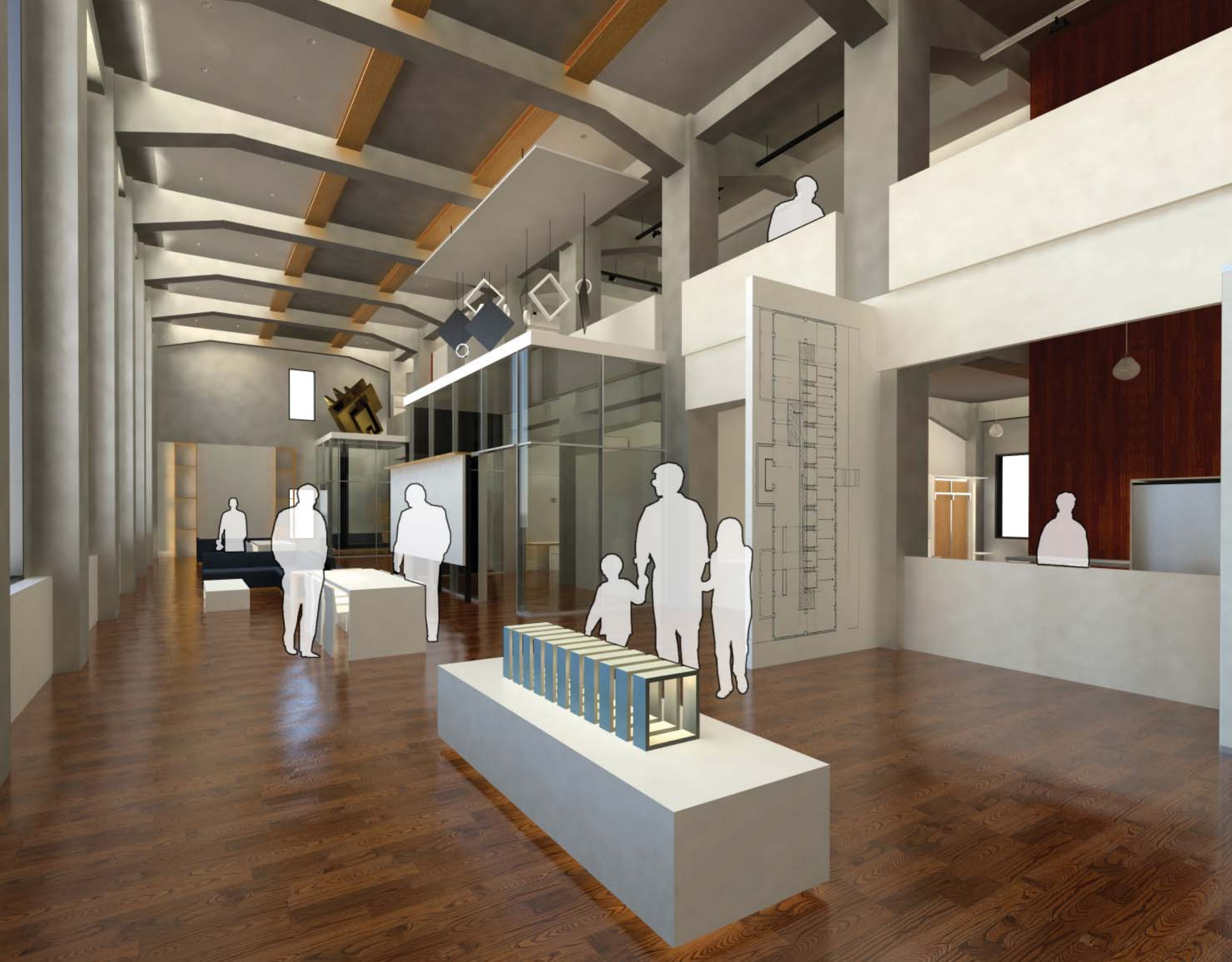

Fig. 3.93 Interior perspective 14

Art gallery - Level 2 


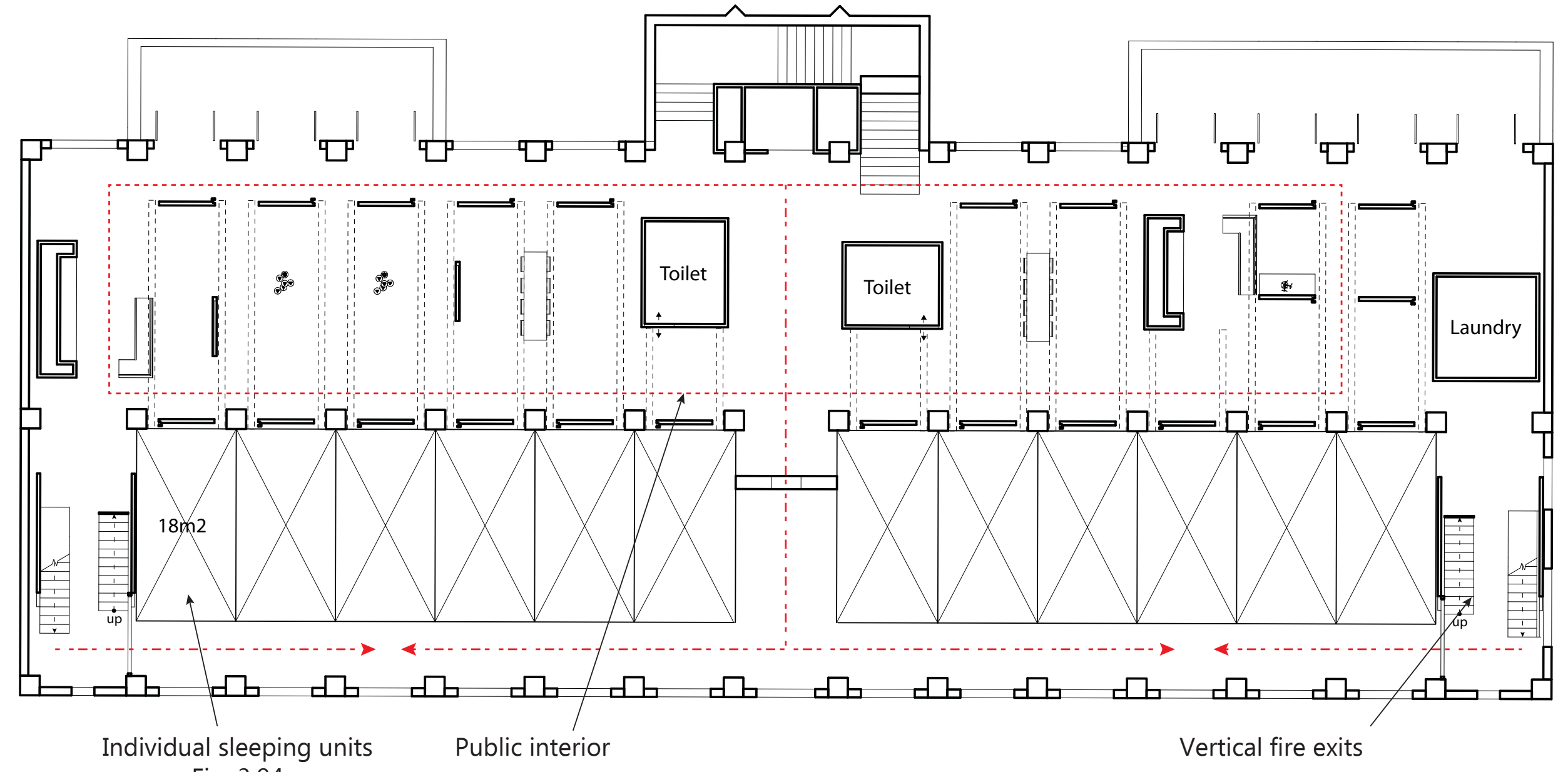

Fig. 3.94

Fig. 3.94 Corridors iteration 4 17th july review

Scale: $1: 200$

Type: Half and half + Corridor

Level: 3 


\section{Iteration 4 - 17th July Review}

There was a separate corridor for the private space to seclude residents from the public; however this was pointless and unnecessary. The public amenity already provides a medium of circulation. The dwellings also remain separate from the public especially when each dwelling now has its own amenities.

Furthermore, household amenities such as bathrooms and kitchens were shared; However this scenario created a dormitory-like situation like the Saishunkan Seiyaku women's dormitory. This required a separate circulation for the residents to access these utilities for privacy.

With studios containing their own household amenities, this meant that the resident is able to live completely separate from the rest of the apartment without the need to. Enter the public space There is little room for social gatherings; however they are compensated by the art gallery adjacent to these enclosed spaces.

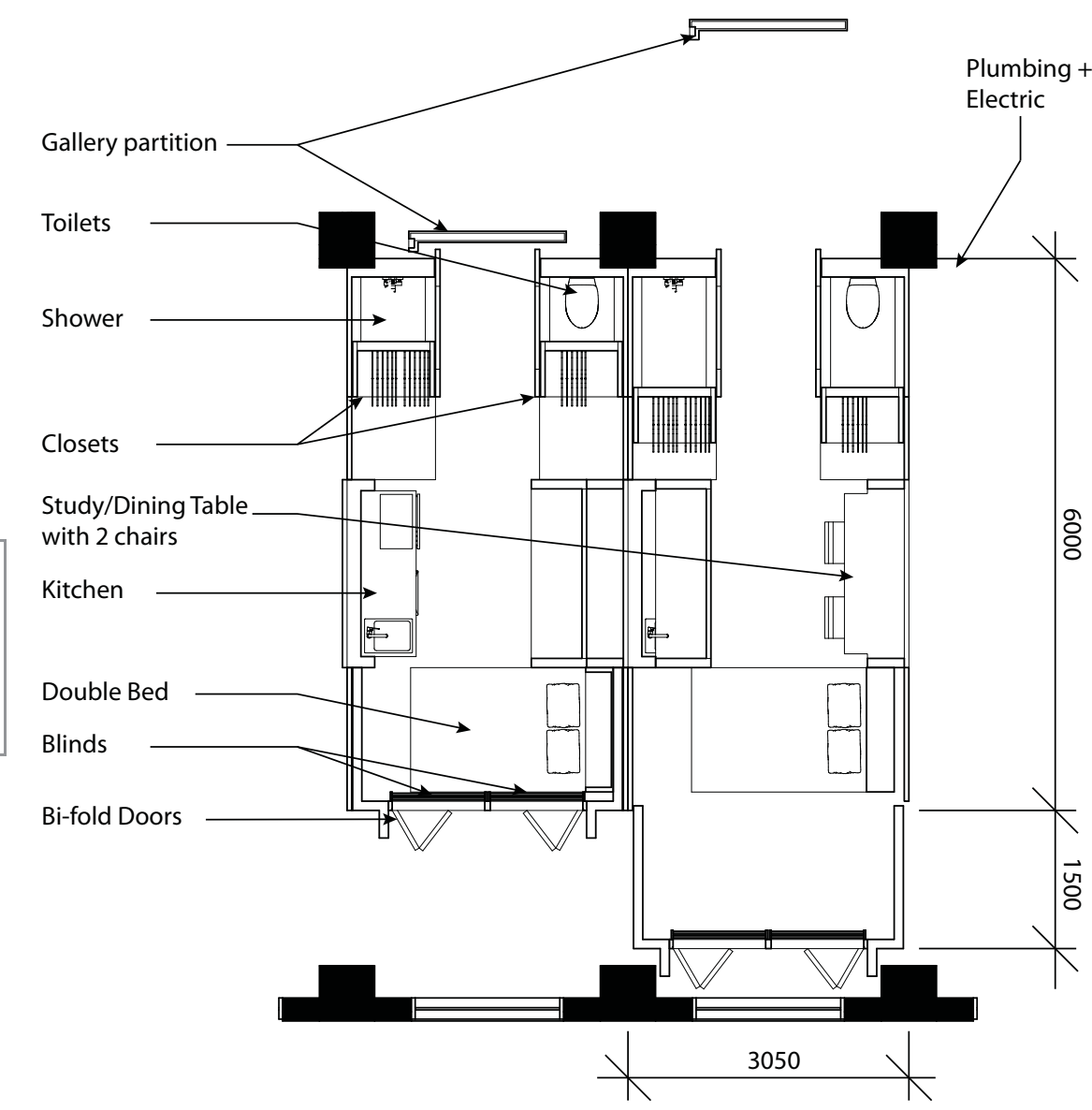

119

Fig. 3.95 Iteration 4 apartment unit Level 3 


\section{Public amenity}

Mechanism 4

With all apartments, corridors are

necessary for the sake of separation. But

this category requires a new name to

establish itself from corridors and better

align with the public amenity.

The reason for the interior public

amenity is to identify ta stronger social function than just circulation. It is also

because it is a similar mechanism of

121

reserving space for public areas like

natural amenities in the town belt, but in the interior.

On one side the spaces are cellular but achieve separation and privacy between residents, rebuking the notion that cellular interiors are a problem but the overuse of walls is. The interior town belt opens to all residents that can encourage more interaction. 


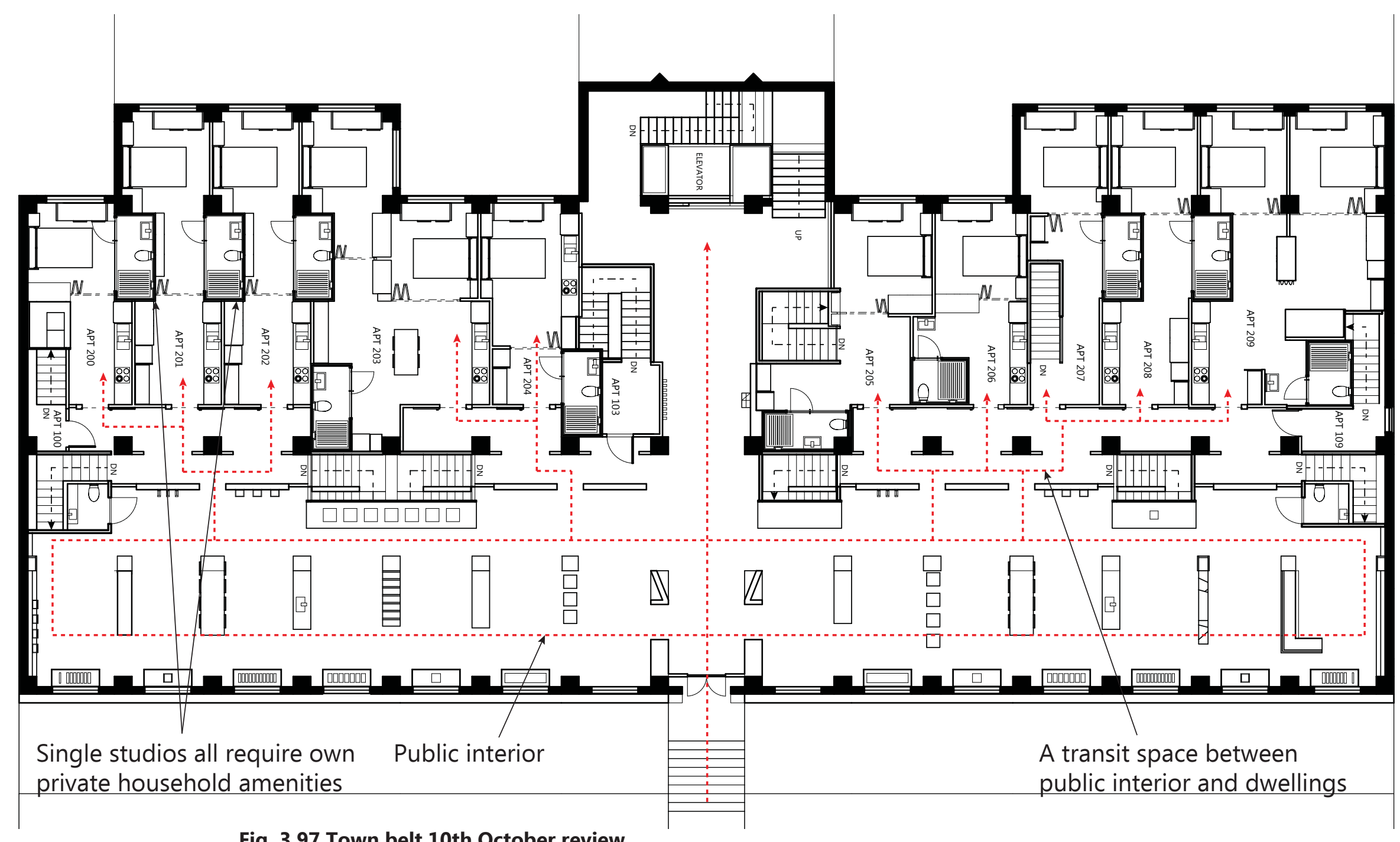

Fig. 3.97 Town belt 10th October review

Scale: 1:200

Type: Town Belt

Level: 2 


\section{0th October Review}

All apartments are single studio homes at this stage. It was initially intended that each resident has their own studio with their own household amenities.

Furthermore many of the dwellings are very repetitive.

Because floor space is a valuable commodity, the single studios had a profound effect, specifically the amount of household amenities there were. They consume large portions of the floor space and affected the quality and number of residents that could be fit in.

There are different demographics to design for and also utilise past methods such as mobile boxes into the design.

An interesting topic which came up in the 10th October review was introverts and extroverts. "The balance obviously varies according to individual character, temperament and age so no perfect solution is possible, but good layout will at least allow some degree of individual choice." ${ }^{128}$

\section{Final Adjustments}

- Scale back amount of amenities; kitchens and bathrooms

-Utilize past methods

- Develop apartments for various households

- Considering introvert and extrovert tendencies and designing for both; enclosed from or opens into 

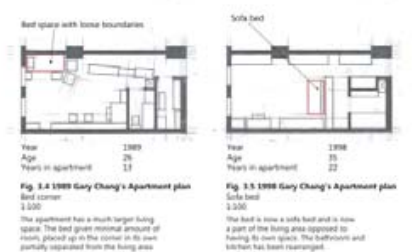

Collins Gallery - Tighe

Architecture

The Collins Gallery is an example of the 'town belt' scheme but at a smaller scale. "Conceptually, that diagonal line divides the building (Fig. 3.99)."29 It is a strict and physical separation of the public and private amenities but provides a simple footprint to a solution. It is a compromise of sorts between cellular and one room spaces.

There is a similarity to Chang's apartment and Soho apartment. The separation guarantees privacy between the host and guests.

${ }^{29} \mathrm{http}: / /$ archrecord.construction.com/ projects/residential/archives/0306HotM-1. asp (February 2014)

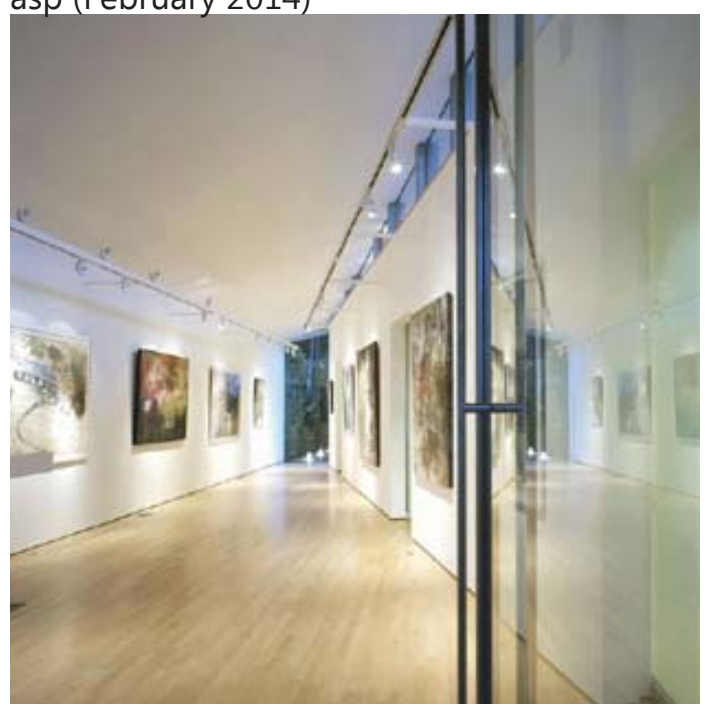

Fig. 3.98 Collins gallery (Retrieved Feb. 5 2014). http://archrecord.construction.com/projects/residential/ archives/0306HotM-1.asp

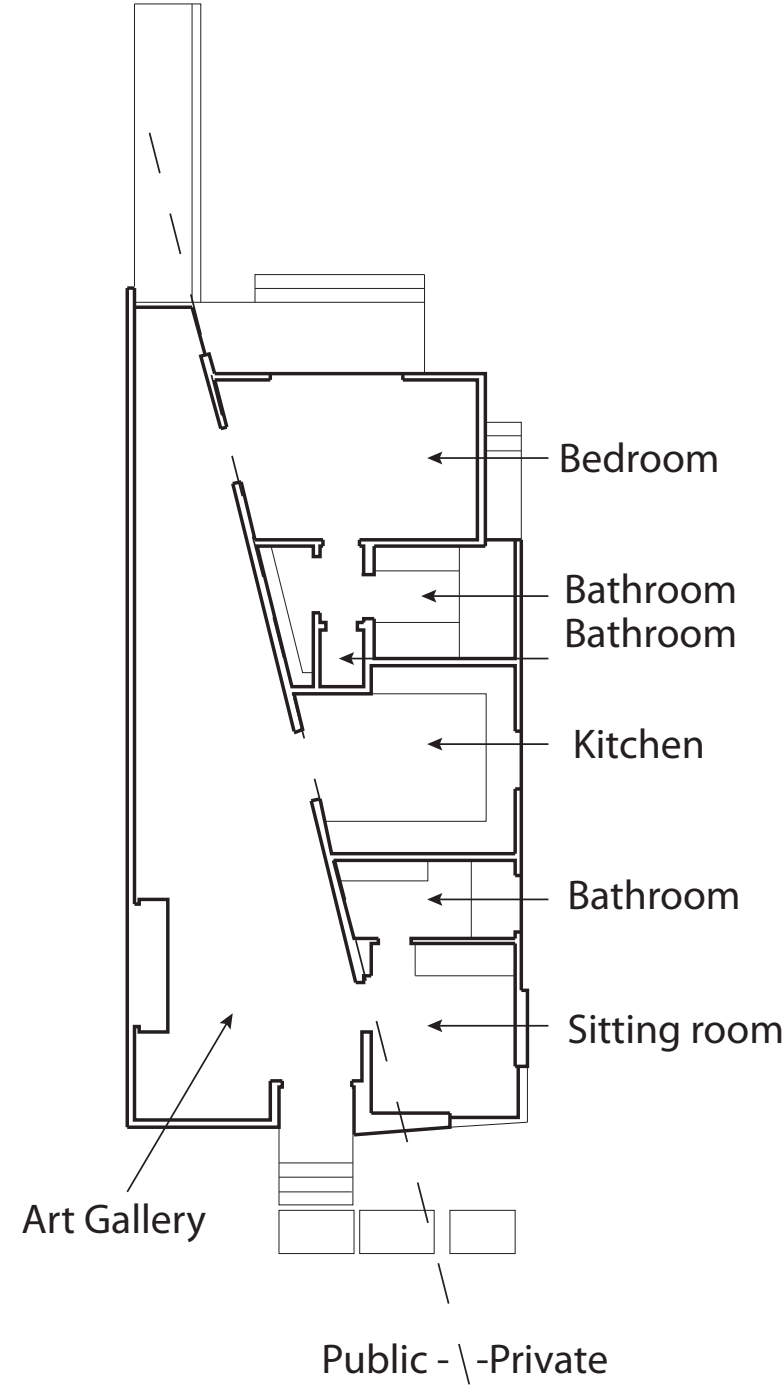

Fig. 3.99 Collins Gallery plan 
The case studies presenting physical separations between public and private sectors include the Collins Gallery and Lyon Housemuseum. These had a much more successful separation between private and public amenities, allowing guests and residents to coexist.

Cellular interiors are not necessarily a flaw in interior design as first perceived. Enclosed spaces are required to have varying forms of separation for visual and acoustic reasons. However, it is perhaps over-utilised such as in Chungking Mansions. Required is a need for a balance between large public spaces and enclosed private spaces.

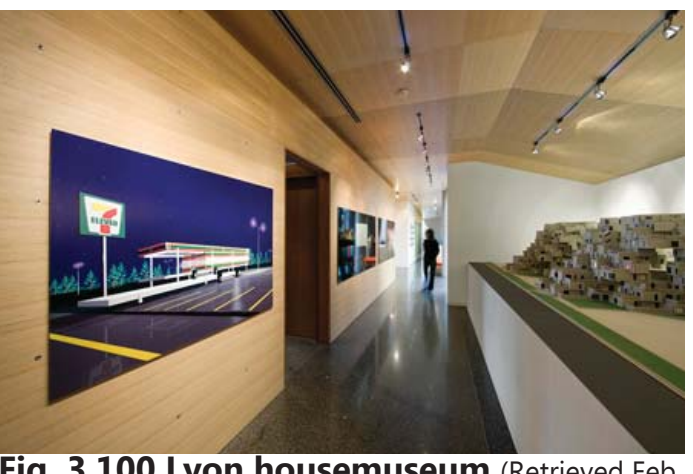

Fig. 3.100 Lyon housemuseum (Retrieved Feb. 5 2014).

http://www.dezeen.com/2010/06/26/lyon-housemuseum-by-lyons-architects/

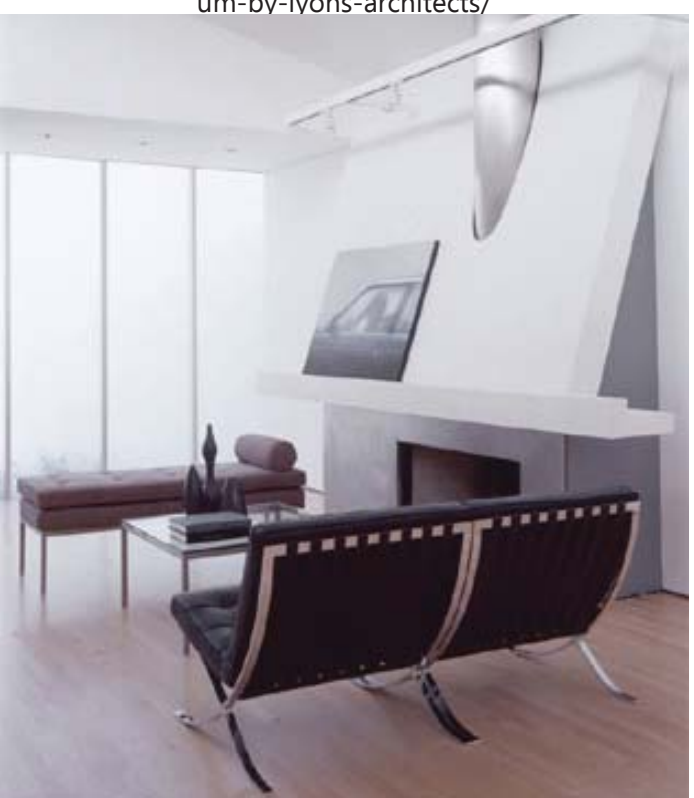

Fig. 3.101 Collins Gallery (Retrieved Feb. 7 2014).

http://archrecord.construction.com/projects/residential/ archives/0306HotM-1.asp 


\section{Final Proposed Design}

Establishing proximity of public and private was achieved by two methods: minimising private spaces and compensating for the small dwellings with a larger public interior space (Fig 3.102).

Red - The public interior is a large space that turns the corridor from a terminal room into more of a thoroughfare space. The large public interior serves both as a social area and terminal room into each individual apartment. Much like Saishunkan Seiyaku women's dormitory, however all household amenities are reintegrated into the private enclosures.

Grey - The household spaces required separation from the public sphere. "Accordingly, the integration of household space was not for the sake of beauty, its separation was for convenience - an opposition which has since become deeply engraved into theory, creating two distinct standards of judgement for two quite separate realities." 30 


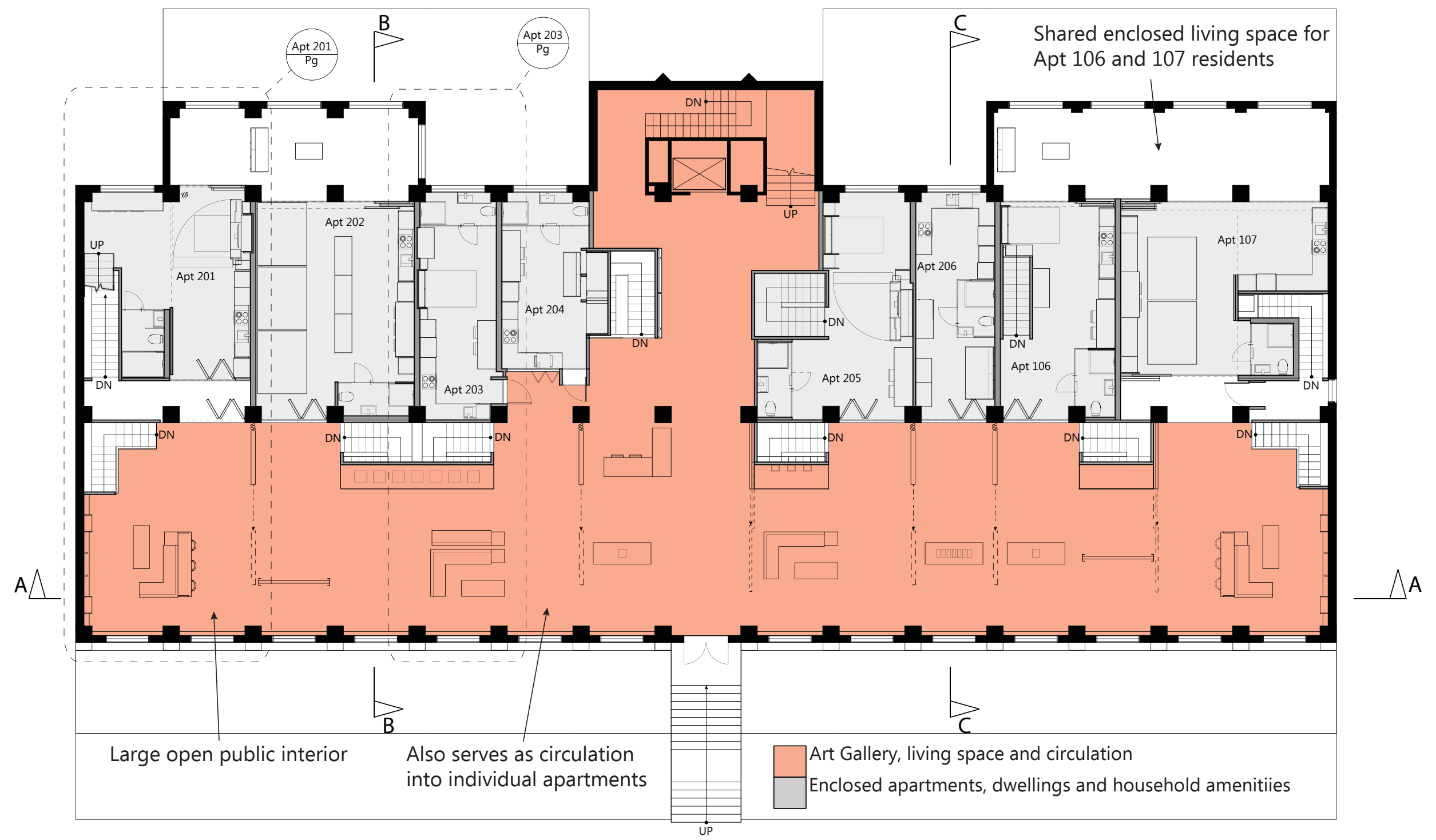


The proposed design consists of two zones. One consists of enclosures of private spaces juxtaposed next to a public interior amenity.

The apartments consist of various

types of micro-homes utilising various methods to compact as much household amenities as possible. It is intended that the public interior alleviate for the smaller apartments. They also have varying degrees of proximity to the public interior space. These spaces are defined as either introvert or extrovert.

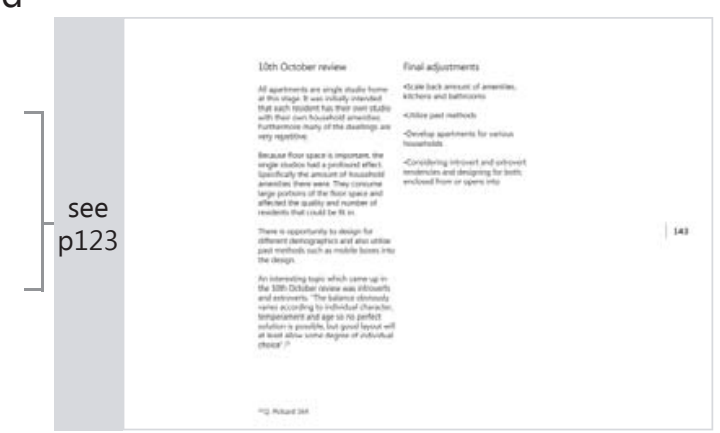




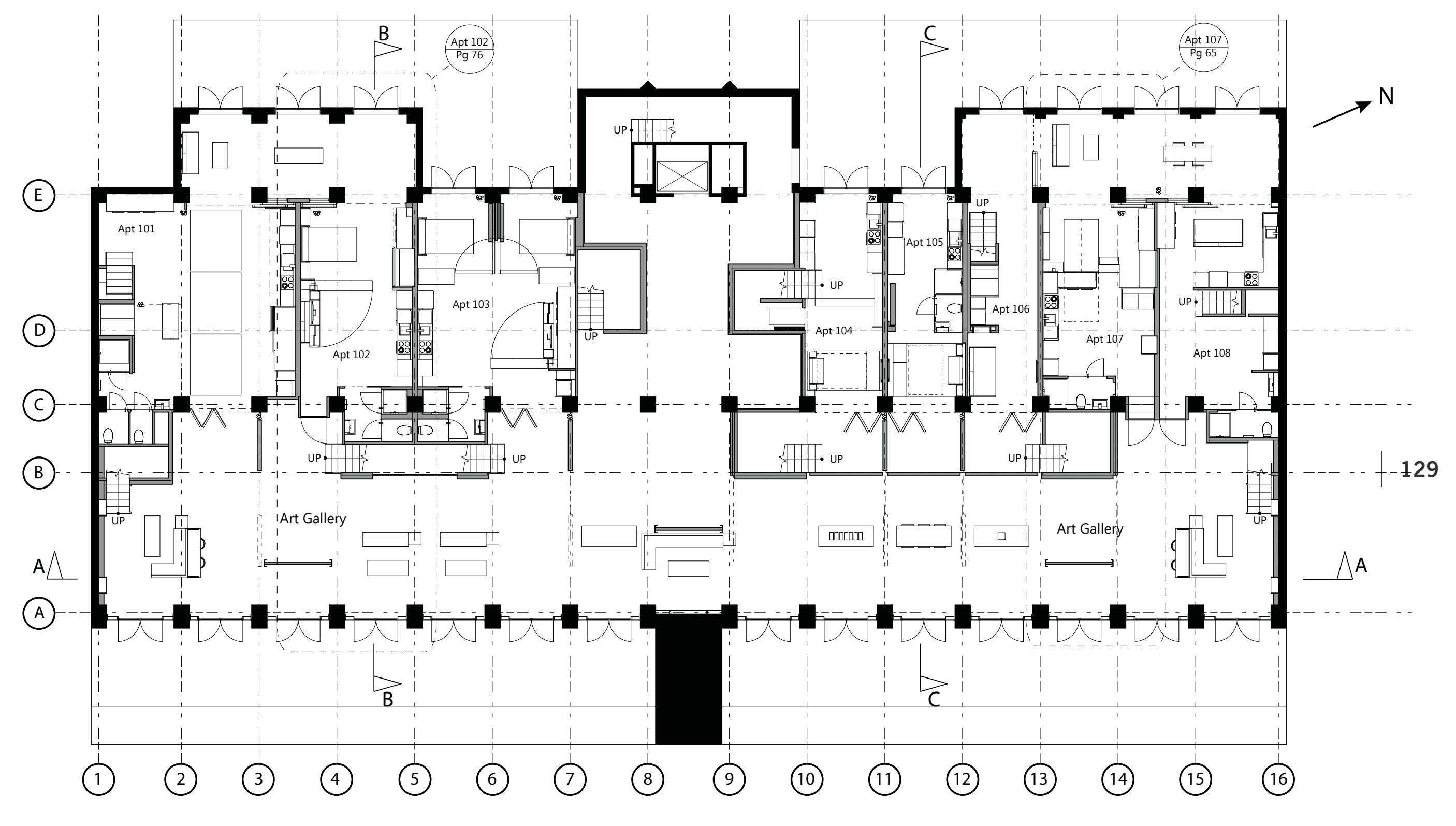

Fig. 3.103 Level 1 Plan

Occupancy: 11 people 1:200 


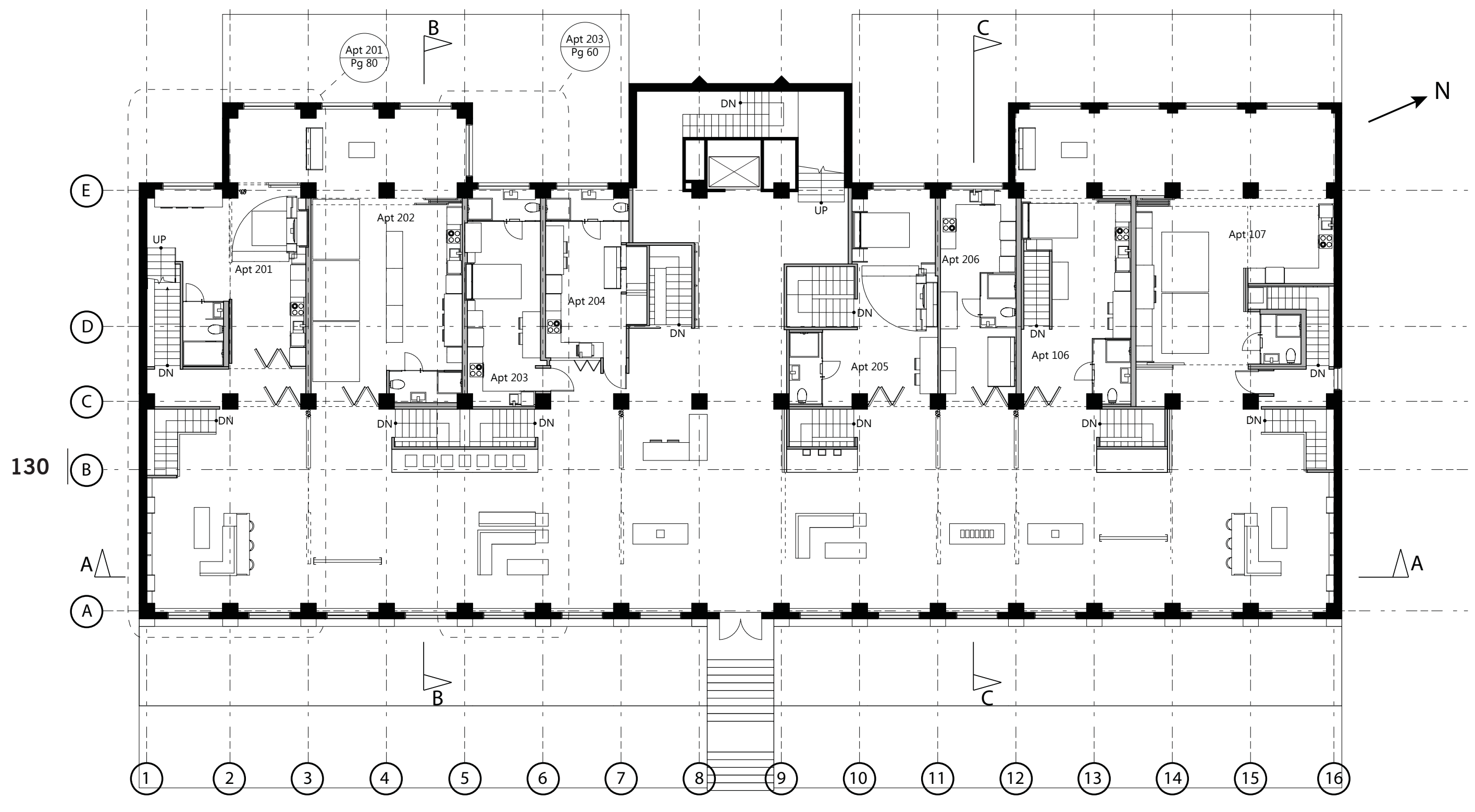

Fig. 3.104 Level 2 Plan

Occupancy: 12 people

1:200 


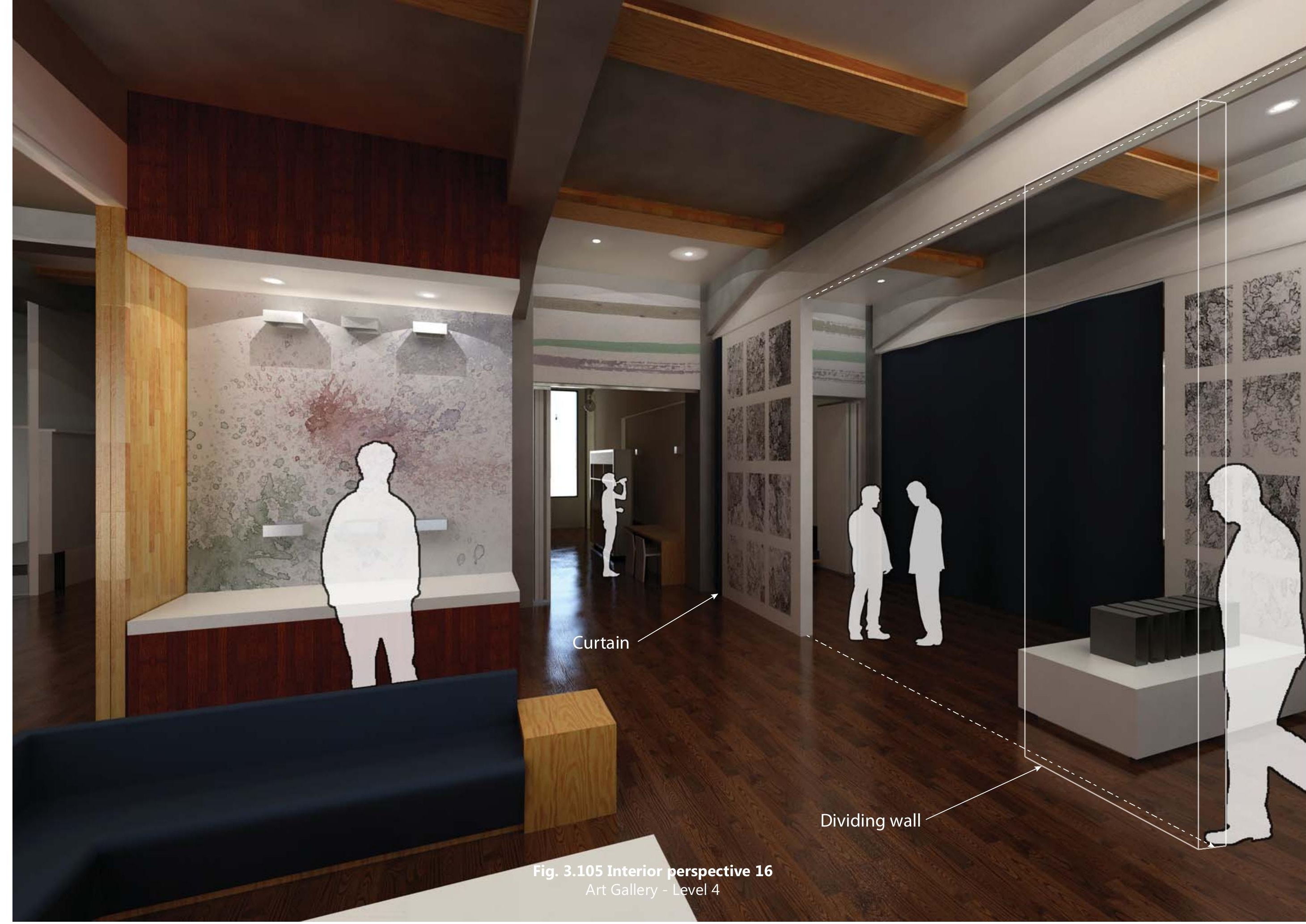




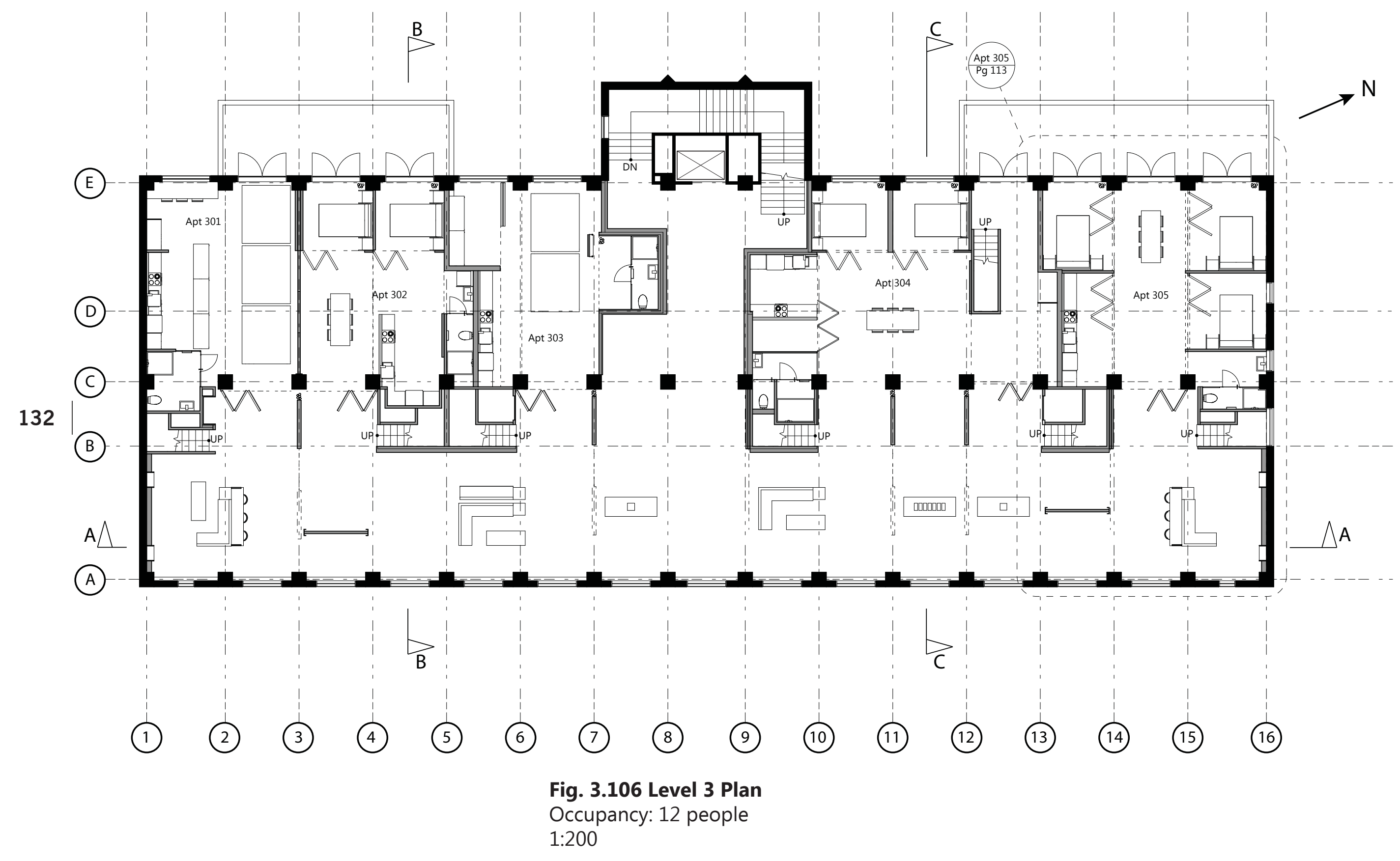




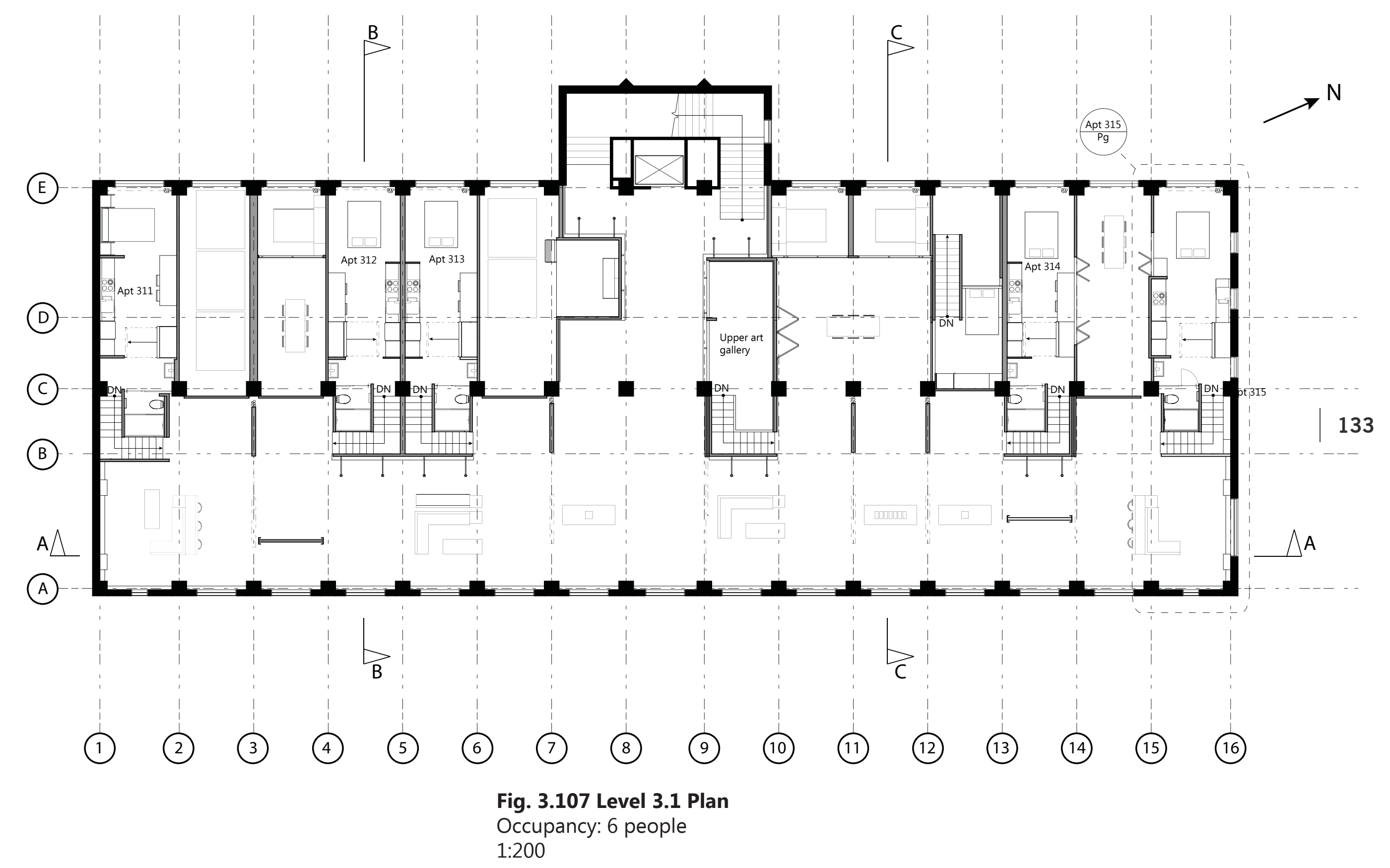




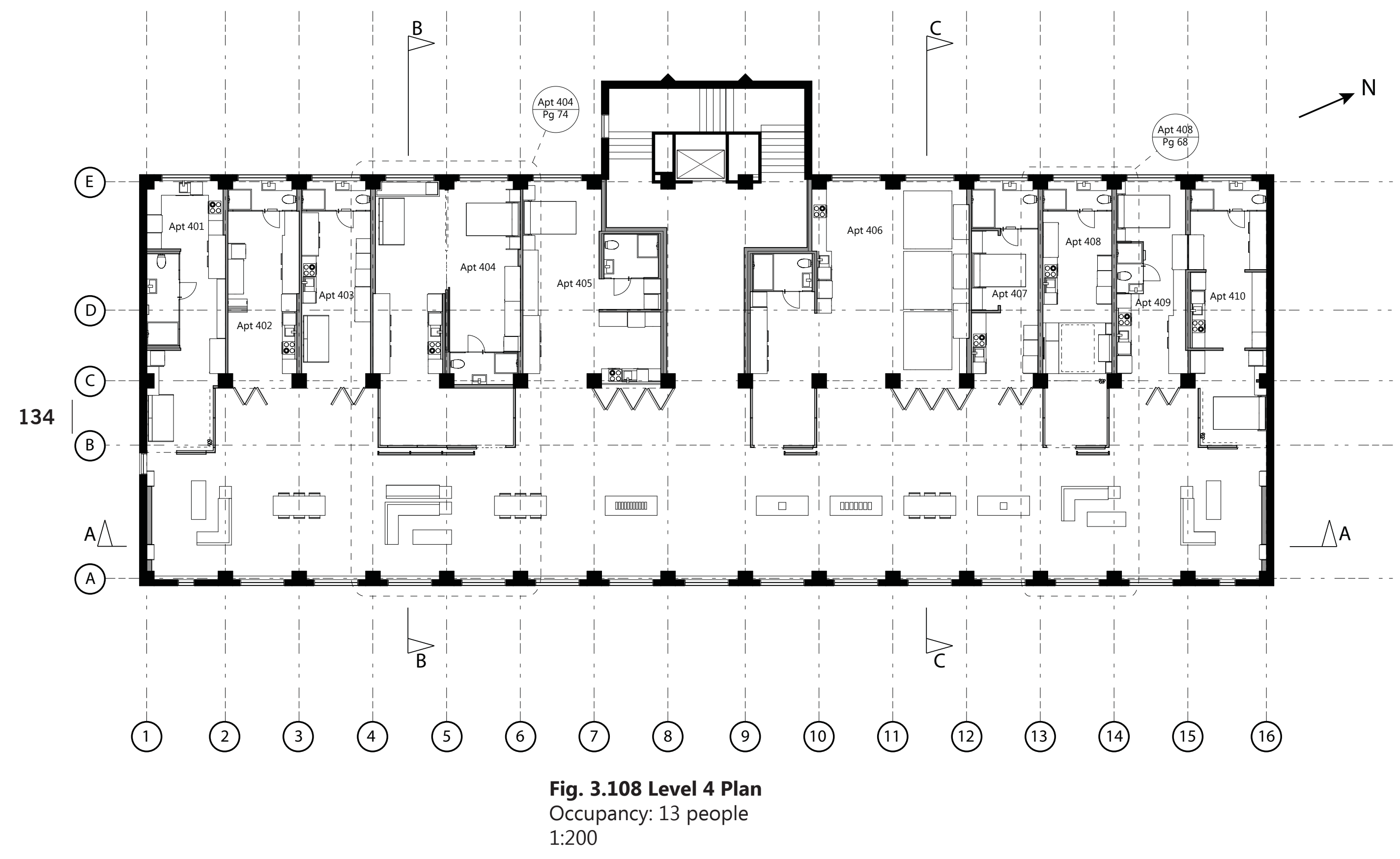




\section{3rd Floor}

The third floor has enough head space for two floors. The current apartment also utilised the double floor height space but extended the mezzanine floor significantly closer to the front. This floor offers the opportunity to increase the number of residents the apartment can hold.

There are two behavioural types of apartments within the proposed design. The lower floor is more open to the art gallery and aimed at the more extroverted personalities and the upper is more private for introverted personalities.

\section{Mezzanine Floor}

Levels 4 \& 5

The mezzanine floor provided its own unique problems due to having half the amount of floor space. The existing built fit-out apartment configuration extended the mezzanine floor closer to the façade. As a result, the large mezzanine space lost its spatial quality.

It is made up of four apartments: one three rooms and three two rooms. The public art gallery area forms an anchor shape. The apartments and art gallery are divided by sliding panels that double as wall art.

\section{"The balance obviously varies according to individual character, temperament and age so no perfect solution is possible, but good layout will at least allow some degree of individual choice." 27 \\ Quinton Pickard}

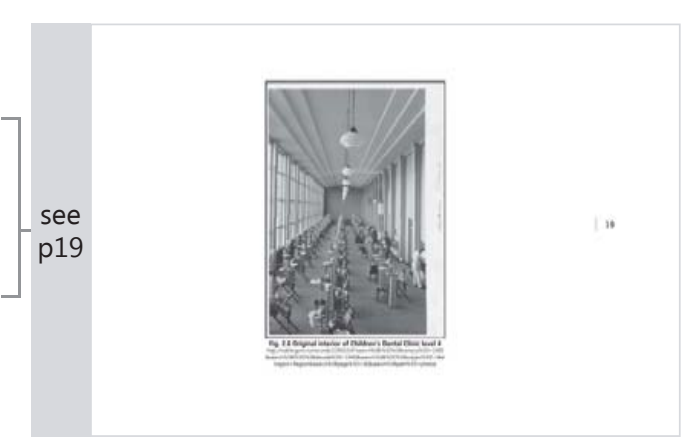




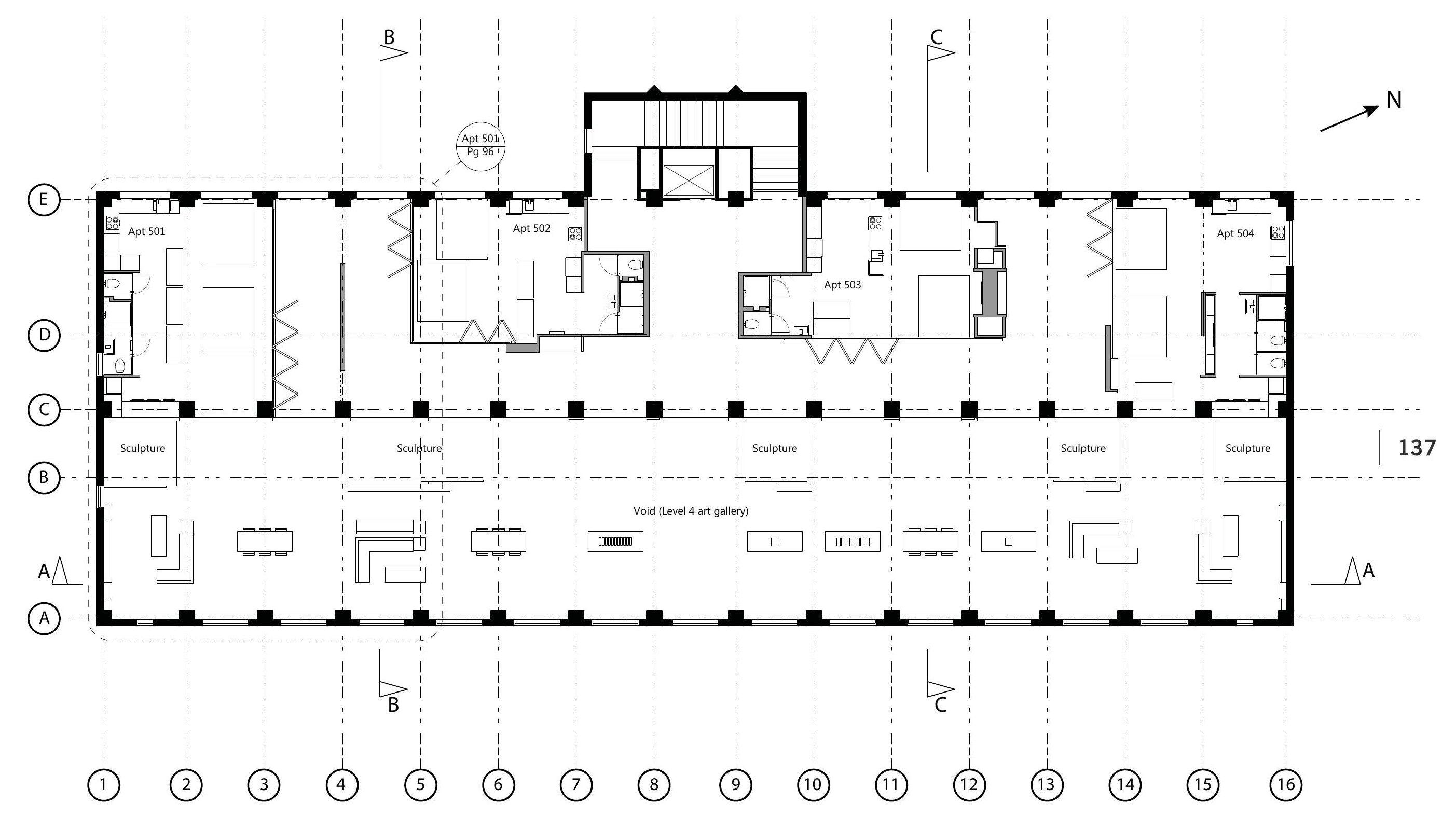

Fig. 3.110 Level 5 Plan Occupancy: 9 
The existing fit-out consists of 30

apartments and houses up to 90 people

including the penthouse floors. The

final proposed design can house up to

63 , not including the penthouse floors.

When reserving significant space for a public interior, ultimately the amount

of floor space for apartments is lost.

Thus the various methods for designing

micro-apartments is important for this

project. 


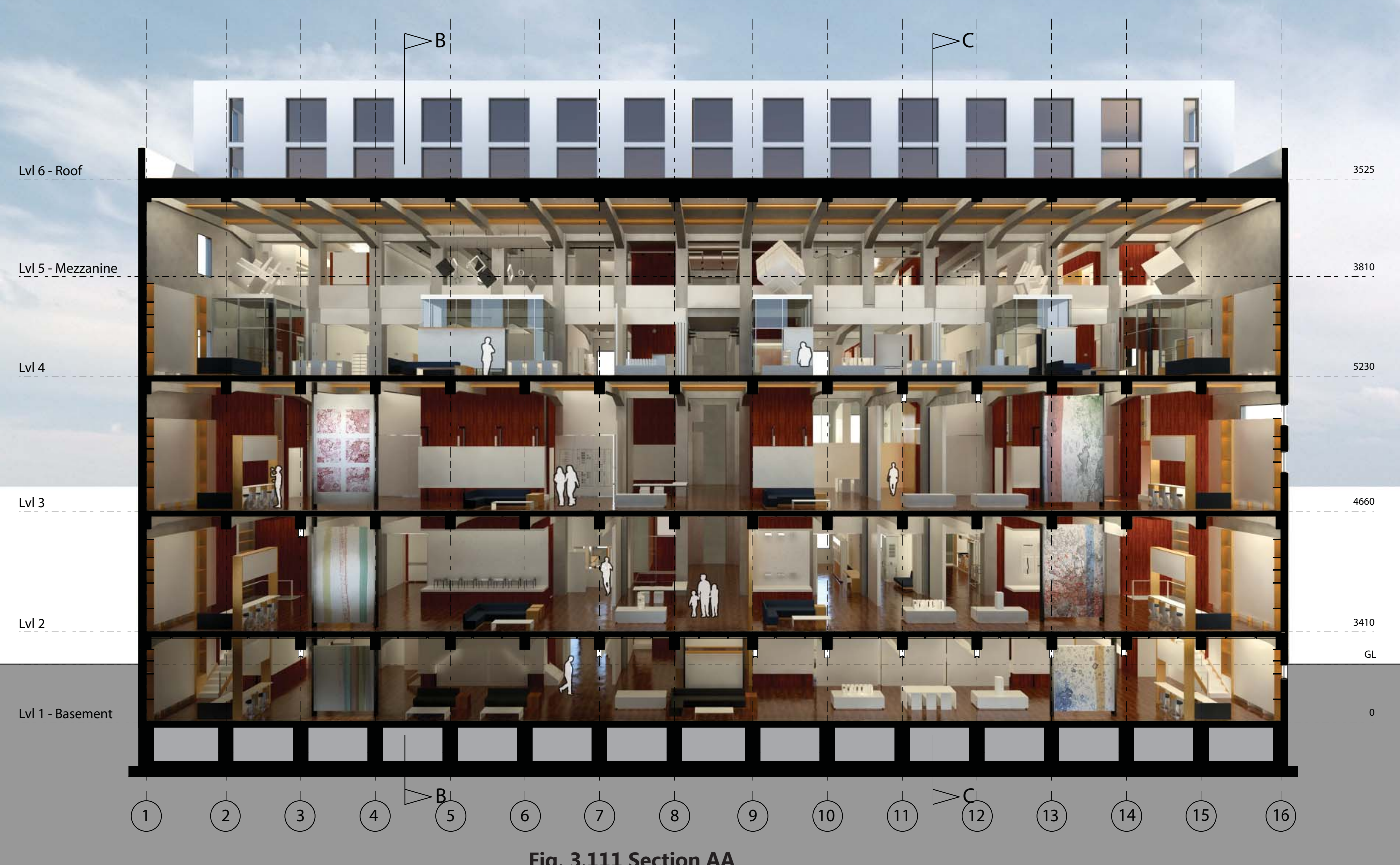

Fig. 3.111 Section AA

View Looking east

1:200 


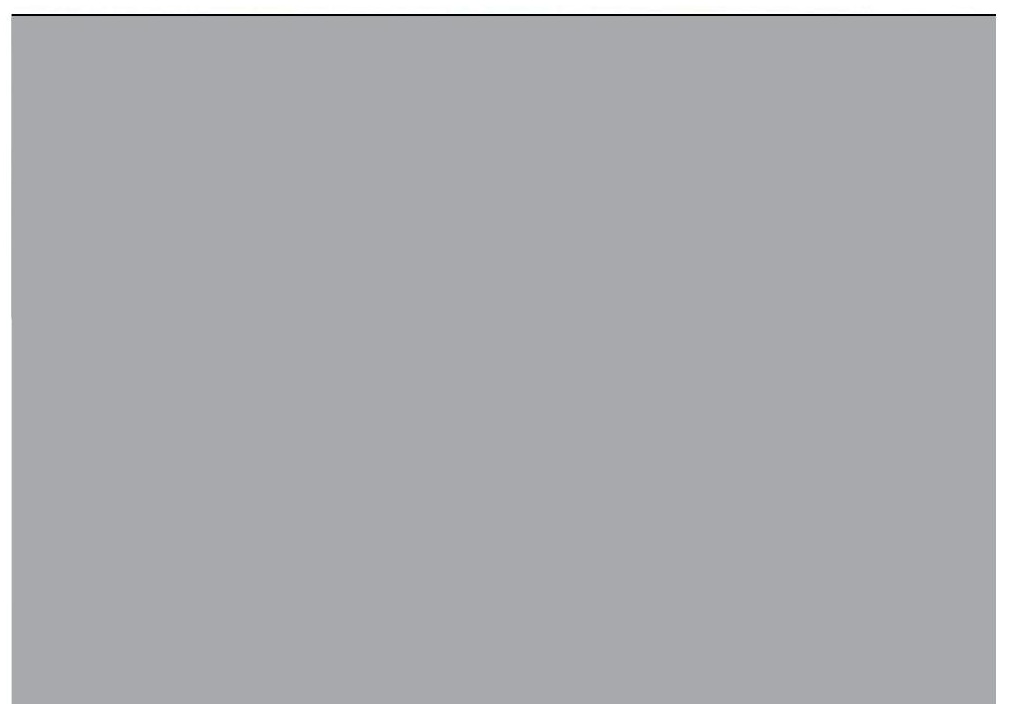


15-Mezzanine

(n)
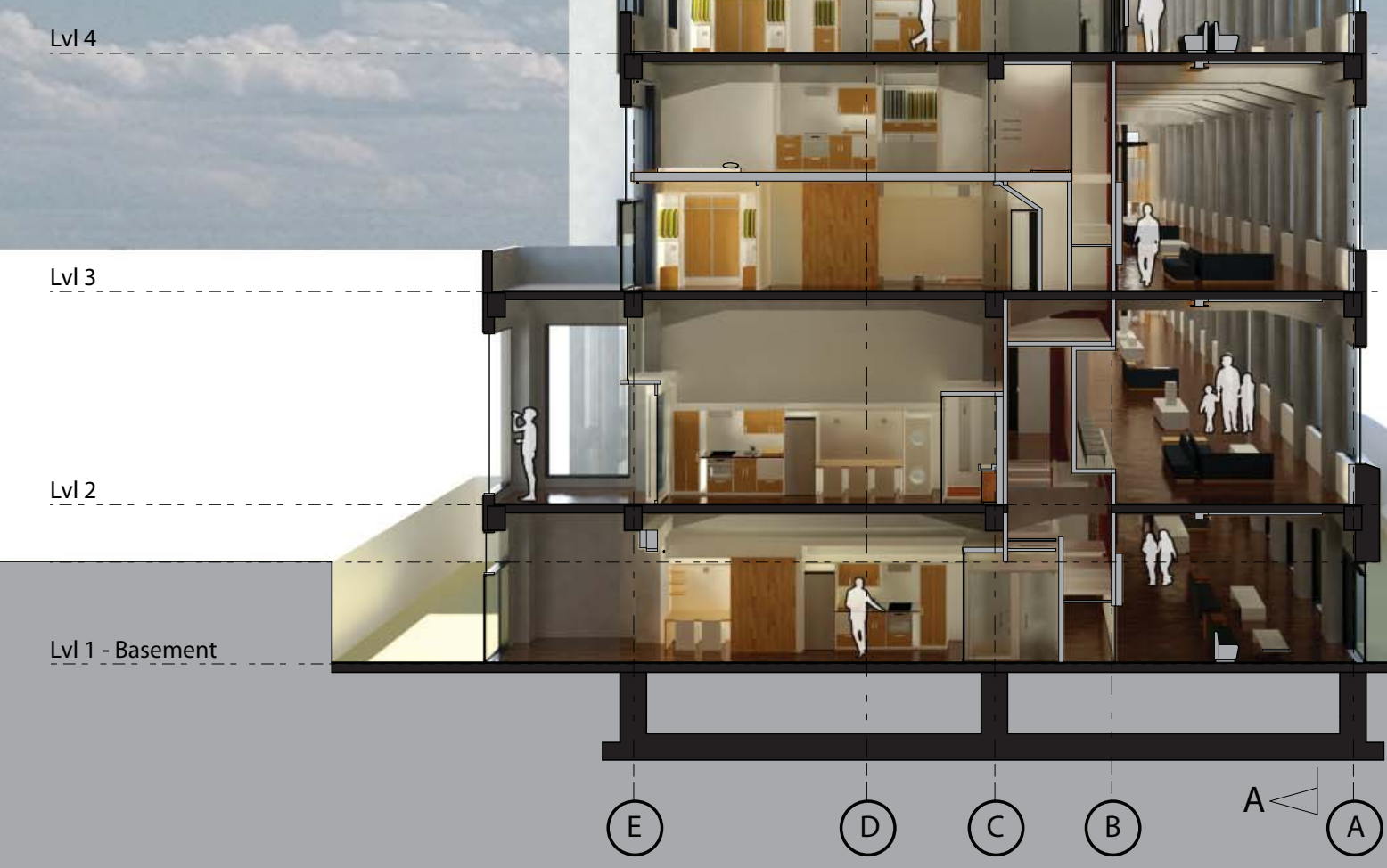


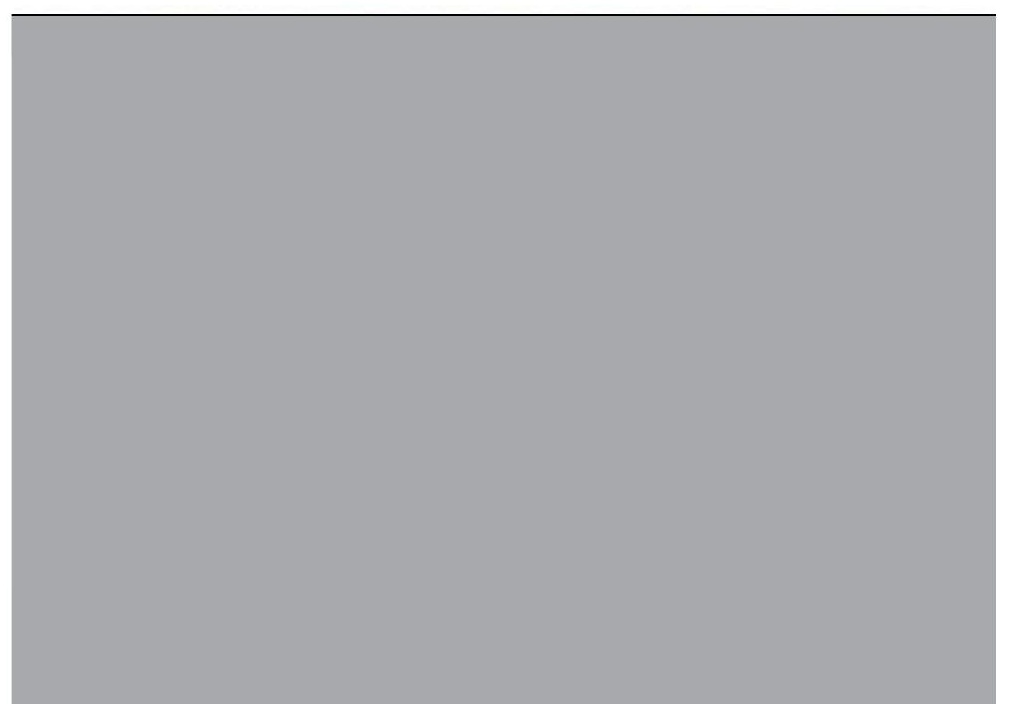




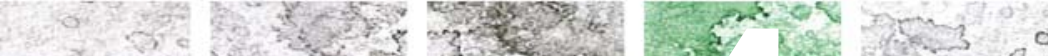

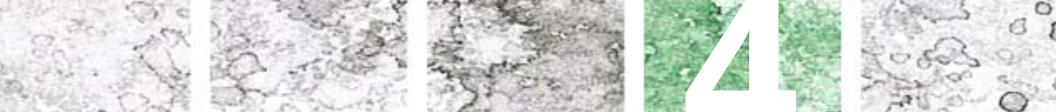

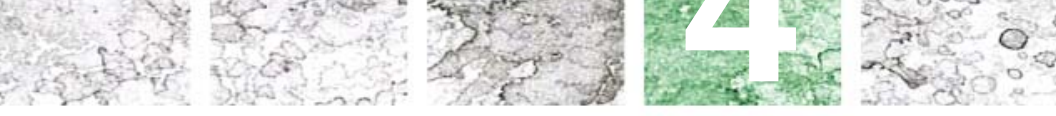

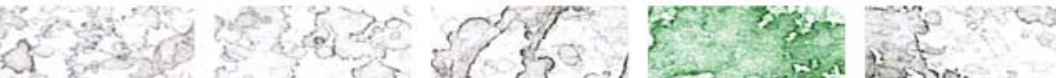

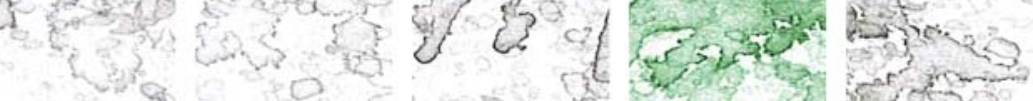

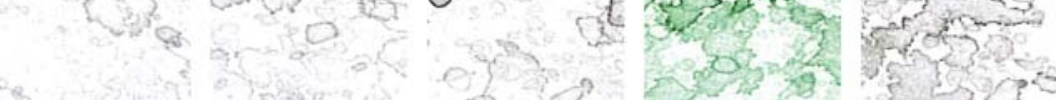


Part 4_Way Forward

Reflection 


\section{Reflection}

A part of the interior town belt's

effectiveness was placing all household amenities, kitchen and bathrooms on one side. It provides a zone for privacy and a zone for social/public purposes.

It can be assessed through two scales: one focused on the overall composition between public and private interiors; the other aspect focused on micro-homes.

The footprint can be applied to other large apartment complexes (Fig. 4.1 and Fig. 4.3). Micro-apartment methods are used to remedy the amount of space lost for the public space.
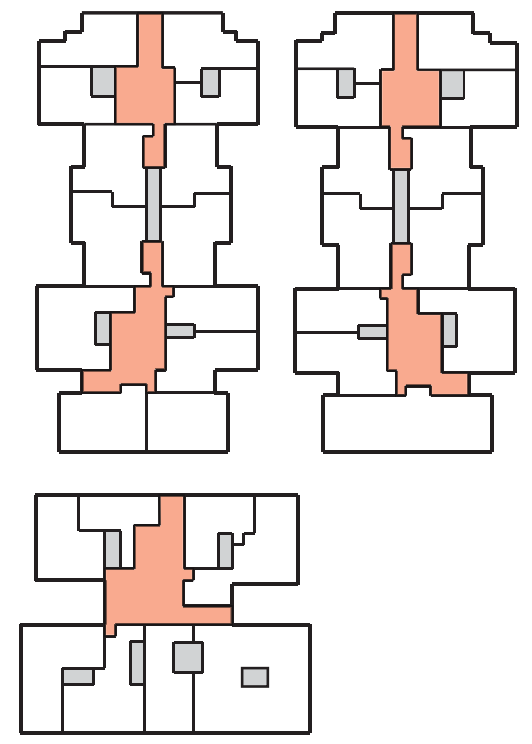

Fig. 4.0 Chungking mansions existing

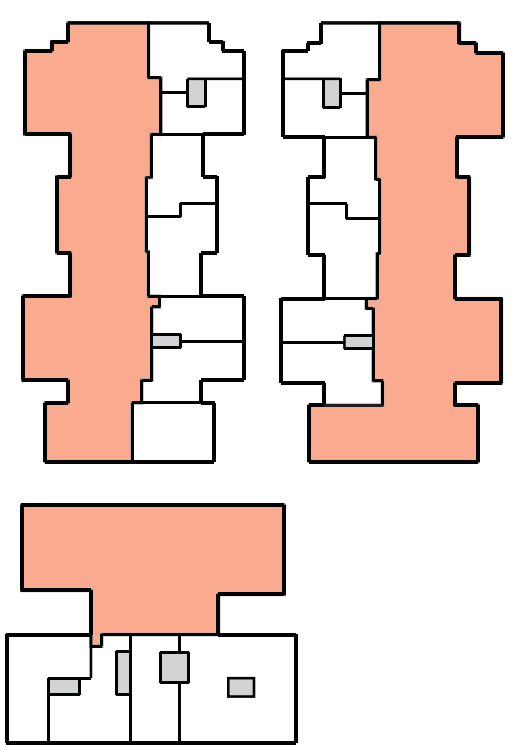

Fig. 4.1 Chungking Mansions with proposed changes 
Often the only common

space the residents have is

the corridor

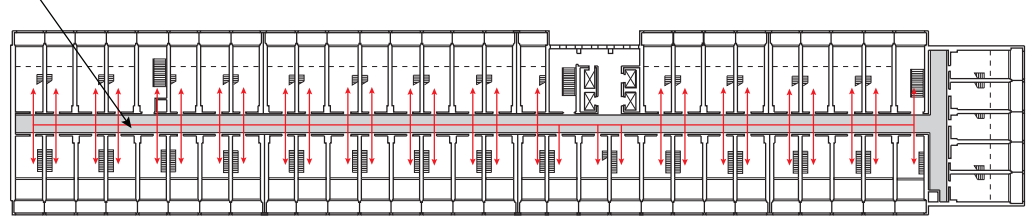

Fig. 4.2 Unité d'Habitation with changes

Large open space gives al residents a common space

to share

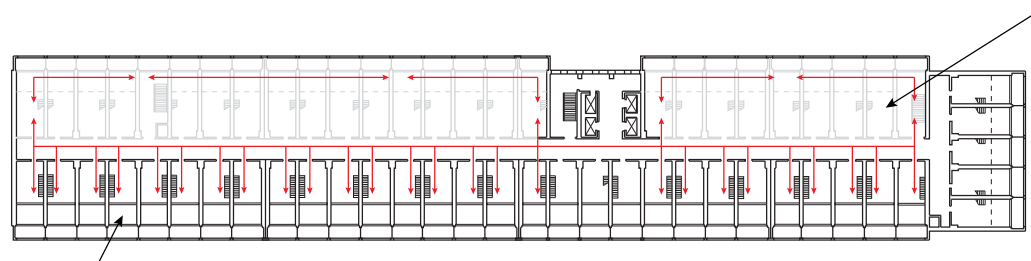

Own enclosures ensures

separation and privacy

afrom others

Fig. 4.3 Unité d'Habitation with changes 
What was achieved was the identification of different zones within apartments. Normally, apartments consist of three zones and the key strategy for this design led thesis was proposing only having two zones. This was achieved by combining two of the zones together, corridors and living areas, providing a significant public interior space. This space provides both the circulation needed for apartments to achieve separation and privacy amongst the residents but also a shared living space that is for all to use.

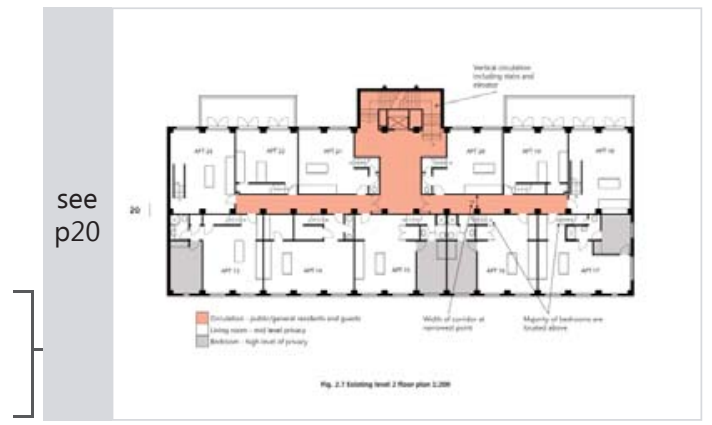




\section{Weaknesses}

The success of these suggestions ultimately depends on the residents. Due to vast demographics, finding a conclusive solution is perhaps elusive especially for long term residents. "We are curious about what exactly constitutes a house, or in fact a home, since a 'house' is all about individual approach to shelter and 'housing' is about dwelling on a mass scale. To us housing is a blanket solution that treats everyone the same. It is homogeneous and often boring. However, houses are unique and allow for one person's perception of 'home' to be completely different from another's." 31

\section{Public Access}

A major issue is how the general public would use the space, for example; will people come inside, which is outside the interior's influence? "A good public interior lies on an urban route, and is therefore easily accessible. It is covered to protect the public from the

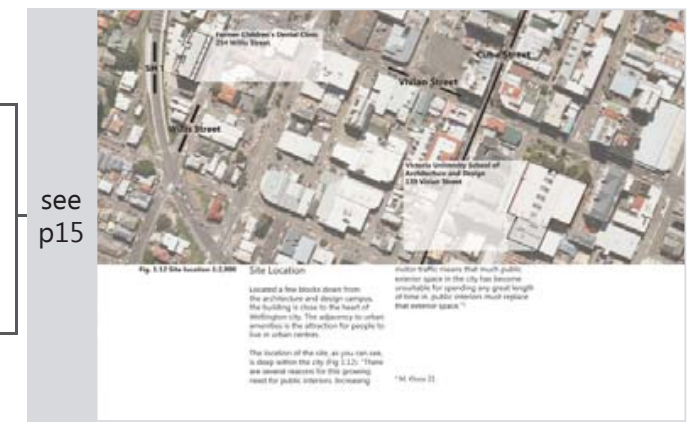
climate and is in principle, accessible to everyone." ${ }^{\prime 32}$ Although it is more site specific, however it is perhaps best for the residents and their guests only and it remedies fears of security from outsiders.

${ }^{31}$ C. Smith \& S. Topham 6

${ }^{32}$ M. Kloos 19 


\section{Vertical Circulation}

A limitation was the location of the existing stairwell and elevator for the general public's circulation of the building. The apartments could have been placed on either the Willis Street side or the State Highway 1 side. Willis Street side would make the stairwell more directly accessible with the interior amenity but hides it from view from Willis Street. An alternative stairwell that is a more central figure was tested but marginalised the existing stairwell.

\section{Security and Privacy}

A major design concern was security and privacy. This is why the corridor was a key mechanism and the key to the success of the apartments. However there are different implications when this corridor is also a living area with people inhabiting it.

There are privacy issues with the shared space itself. Because of varying users, how this space is used may be in conflict with another. Thus the flexibility of the public interior still requires more development such as the capability of dividing sections of the public amenity for more secluded uses.

\section{Cost and Affordability}

With cost being a factor in urban sprawl smaller dwellings can increase affordability. There is an unpredictability of the affordability because of the added value from the proximity to the shared public amenity. It does more for that amenity because of an ability to subsidise funding through housing.

\section{“Dwellings opening directly onto busy public spaces and access decks designed to encourage social contact and neighbourliness may also suffer intolerable intrusions." 33 Quinton Pickard}




\section{Further Research Questions}

Work and home - how can home and work be in closer proximity but achieve sufficient separation between work and home?

A key question is: how can integration of work and home still achieve the separation that can be established? This could provide new opportunities for denser and flexible urban environments.

Housing and shopping centres - What are the possibilities of integrating housing with shopping centres?

Some of the key attractions of living in the city are the shopping centres. They are open during the day but closed during the night. Businesses and homes are almost polar opposites in when they are most utilised during the day.

Housing for the elderly - How can we develop denser housing for an ageing population?

With an ageing population comes the challenge of housing them along with the need for smaller and efficient homes that are safe for the elderly.

\section{Closing Comments}

The opportunities of providing apartments with a shared interior public amenity include further emphasis on the use of the corridors, private and shared amenities and the size of the apartments. It was the same principle used for Wellington's town belt where you reserve an area for a shared public amenity.

The interior equivalent of a beach front house is the micro-apartment, directly adjacent to a shared public interior amenity. A key element was providing the minimum amount of space for the apartments as you can but because of the direct access to the shared interior public amenity, mitigates for the tight living spaces.

Through the principle of the town belt the apartment retains a spatial figure which often is lost or has little function. Despite certain deficiencies in some areas, such as access from the public, vertical circulation, a simple footprint for merging apartment and public amenities was realised. 


\section{Bibliography}

Allman, S., Gontarz, A., Sinn, J., \& Mantha-Blythe, V. $(2012,12$ 8). Naked House case study. Retrieved 6 8, 2013, from http://nakedhousecasestudy.blogspot.co.nz/: http://nakedhousecasestudy.blogspot.co.nz/

Aranguiz, A. C. (2005). Small City Homes. Singapore: Page One Publishing Private Limited.

Architectural Record. $(2003,6)$. The Collins Gallery. Retrieved 2 7, 2012, from www.archrecord.com: http://archrecord.construction.com/projects/residential/ archives/0306HotM-1.asp

Arnardottir, H. (n.d.). Stories of Houses. Retrieved 6 9, 2013, from http:// storiesofhouses.blogspot.co.nz/2005/10/naked-house-in-kawagoe-by-shigeru-ban. html

Bachelard, G. (1958). The Dialectics of Outside and Inside. In The Poetics of Space: the classical look at how we experience intimate places (pp. 211-231). Boston: Beacon Press.

Blaser, W. (1979). Courtyard House in China. Basel, Boston, Stuttgart: Birkhauser Verlag.

Bognar, B. (2008). Beyond the Bubble: The New Japanese Architecture. London: Phaidon.

Botton, A. d. (2004). Status Anxiety. New York: Vintage International.

Brooker, G., \& Stone, S. (2013). From Organisation to Decoration: an Interior Reader. New York: Routledge.

Broto, C. (2005). Compact Interiors. Singapore: Page One Publishing Private Limited. 
Cheung, H. (2013, 12 23). Chungking Mansions: Inside Hong Kong's favourite 'ghetto'. Retrieved 2 7, 2014, from http://www.bbc.com/news/world-asia-24015987

Design Tavern. (2013, 9 10). Small Living: Sliding Apartment. Retrieved from Design Tavern: http://www.designtavern.com/2010/02/small-living-sliding-apartment/

Designboom. (2005, 10 29). SANAA : kazuyo sejima + ryue nishizawa: designboom interview. Retrieved 2 7, 2014, from www.designboom.com: http://www.

designboom.com/interviews/sanaa-kazuyo-sejima-ryue-nishizawa-designboominterview/

Dezeen. (2010, 6 26). Lyon Housemuseum by Lyons Architects. Retrieved 2 5, 2014, from www.dezeen.com: http://www.dezeen.com/2010/06/26/lyon-housemuseumby-lyons-architects/

Dezeen. (2010, 10 9). Switch by Yuko Shibata. Retrieved 2 5, 2014, from www. dezeen.com: http://www.dezeen.com/2010/10/09/switch-by-yuko-shibata/

Dezeen. $(2010,1030)$. Warehouse by Shinichi Ogawa \& Associates. Retrieved 25 , 2014, from www.dezeen.com: http://www.dezeen.com/2010/10/30/warehouse-byshinichi-ogawa-associates/

Design. (2009, 4 25). Donald Judd's loft at 101 Spring Street. Retrieved 2 4, 2014, from http://blog.ounodesign.com/2009/04/25/donald-judds-loft-at-101-springstreet/

Dirksen, K. $(2014,5$ 12). Extreme transformer home in Hong Kong: Gary Chang's 24 rooms in 1 . Retrieved 10 23, 2013, from https://www.youtube.com/watch?v=WB22j9e4co

Eric - Homedsgn. (2011, 5 7). A Tiny Apartment in Hong Kong Transforms into 24 Rooms. Retrieved 2 6, 2014, from www.homedsgn.com: http://www.homedsgn. 
com/2011/05/07/a-tiny-apartment-in-hong-kong-transforms-into-24-rooms/

Evans, R. (1997). Figures, Doors and Passages. In R. Evans, Translations from Drawing to Building and Other Essays (pp. 55-91). London: Architectural Association.

Freeman, M. (2004). Space: Japanese Design Solution for Compact Living. New York: Universe.

Gutierrez, L., Portefaix, V., \& Ruggeri, L. (2005). HK Lab 2: an exploration of Hong Kong Interior Spaces. Hong Kong: Map Book Publishers.

Jenkins, D., \& Corbusier, L. (1993). Unité d'Habitation, Marseilles. London: Phaidon Press Limited.

Jodidio, P. (2012). Shigeru Ban. Cologne: Taschen.

Kloos, M. (1993). Public Interiors. Amsterdam: Architectura \& Natura Press.

Levene, R. C., \& Cecilia, F. M. (1996). El Croquis. Kazuyo Seijima 88-96, 38.

Low, S., Taplin, D., \& Scheld, S. (2005). Rethinking Urban Parks: Public space and Cultural Diversity. Austin: University of Texas Press.

Mok, K. $(2013,10$ 16). Parisian bathroom converted into comfortable $130 \mathrm{sq}$. ft. micro-apartment . Retrieved 2 7, 2014, from www.rteehugger.com: Architectural

Lundia. (n.d.). Office Storage Solution. Retrieved from www.lundia.co.nz: http:// www.lundia.co.nz/products/mobile-shelving/manual/manual-westpac/

National Library of New Zealand. (n.d.). Interior view of the Children's Dental Clinic, Wellington . Retrieved 2 6, 2014, from http://natlib.govt.nz: http://natlib.govt.nz/rec ords/22905334?search\%5Bi\%5D\%5Bcentury\%5D=1900\&search\%5Bi\%5D\%5Bdecad 
e\%5D = 1940\&search\%5Bi\%5D\%5Bsubject\%5D=Wellington+Region\&search\%5Bpa ge\%5D=36\&search\%5Bpath\%5D=photos

Pickard, Q. (2002). The Architects Handbook. Oxford: Blackwell Publishing

Company.

Poucke, V. (2011, 3 21). Kinetic Architecture. Retrieved 11 7, 2013, from http://blog. kineticarchitecture.net/2011/03/32m2/

Record. $(2003,6)$. The Collins Gallery. Retrieved 27,2012 , from www.archrecord. com: http://archrecord.construction.com/projects/residential/archives/0306HotM-1. asp

Rowland, S. (1977). One Room Living. London: Design Centre Book.

Sbriglio, J. (n.d.). Le Corbusier: The Unite d'Habitation in Marseilles. Berlin, Basel, Boston: Birkhauser Publishing.

Scott, F. (2008). unchanging architecture and the case for alteration. In F. Scott, On Altering Architecture (pp. 1-19). London: Routledge.

Smith, C., \& Topham, S. (2002). Xtreme Houses. Munich, Berlin, London, New York: Prestel.

Somol, R., \& Whiting, S. (2009). Notes around the Doppler Effect and other moods of Modernism. In K. Sykes, Constructing a New Agenda: Architectural Theory 19932009 (pp. 188-203). New York: Princeton Architectural Press.

Swaby, R. (2013, 6 13). Tested. Retrieved 11 7, 2013, from www.tested.com: http:// www.tested.com/art/makers/456481-what-its-live-modern-micro-apartment/

Valle, C. D. (2005). Compact Houses. New York: Universe Publishing.

Wise, J. M. (2000). Home:Territory and Identity. 295-310. 


\section{List of Figures}

\section{Part 1}

\section{Part 2}

Fig. 2.0 Hannah's Factory photo - by author

Fig. 2.1 Shed 21 photo - by author

Fig. 2.2 McKenzie's Building photo - by author

Fig. 2.3 Former Children's Dental Clinic (254 Willis Street) - by author

Fig. 2.4 Site location - by author

Fig. 2.5 Axonometric site overview - by author

Fig. 2.6 Interior of Former Children's Dental Clinic (Retrieved Feb. 6). - http:// natlib.govt.nz/records/22905334?search\%5Bi\%5D\%5Bcentury\%5D=1900\&search\% 5Bi\%5D\%5Bdecade\%5D=1940\&search\%5Bi\%5D\%5Bsubject\%5D=Wellington + Regi on\&search\%5Bpage\%5D=36\&search\%5Bpath\%5D=photos

Fig. 2.7 Existing level 2 floor plan - by author

Fig. 2.8 Existing floor plan circulation - by author

Fig. 2.9 Chungking Mansions (Retrieved Feb. 7 2014). - http://www.bbc. co.uk/news/world-asia-24015987

Fig. 2.10 Many faces of Chungking Mansions - by author

Fig. 2.11 Cellular interiors

Fig. 2.12 Public amenities - by author

Fig. 2.13 City to Park/garden diagram - by author

Fig. 2.14 City to Sea diagram - by author

\section{Part 3}

Fig. 3.0 Key design strategy - by author

Fig. 3.1 Gary Chang's apartment (Retrieved Feb. 6). - http://www.homedsgn. com/2011/05/07/a-tiny-apartment-in-hong-kong-transforms-into-24-rooms/

Fig. 3.2 Gary Chang's apartment progression - by author

Fig. 3.3 1976 Gary Chang's apartment plan - by author

Fig. 3.4 1987 Gary Chang's apartment plan - by author

Fig. 3.5 1989 Gary Chang's apartment plan - by author

Fig. 3.6 1998 Gary Chang's apartment plan - by author

Fig. 3.7 1976 Gary Chang's apartment plan - by author 
Fig. 3.8

Fig. 3.9

Typical Soho apartment plan - by author

Fig. 3.10

Town belt concept - by author

Fig. 3.11

Interior perspective 1 - by author

Gary Chang's apartment 32m2 (Retrieved Feb. 5). - http://www.

designboom.com/architecture/gary-chang-on-urbanism-and-his-metamorphicapartment/

Fig. 3.12 Fig. 3.13, Fig. 3.14, and Fig. 3.15 2006 Gary Chang's Apartment

Fig. 3.16 Switch sliding wall plan

Fig. 3.17 Switch interiors (Retrieved Feb. 5 2014). - http://www.dezeen.

com/2010/10/09/switch-by-yuko-shibata/

Fig. 3.18 Art Gallery \& Living Space (Retrieved Fen. 5 2014). - http://www.

apartmenttherapy.com/art-gallery-living-space-by-wh-68971

Fig. 3.19 Donald Judd's apartment (Retrieved Feb. 5 2014). - http://www.

dezeen.com/2013/05/23/donald-judds-home-and-studio-restoration-by-

architecture-research-office/

Fig. 3.20 Interior Perspective 2 - by author

Fig. 3.21 Reveal \& Conceal iteration 1 - by author

Fig. 3.22 Reveal \& Conceal iteration 2 - by author

Fig. 3.23 Office storage system (Retrieved Mar. 2 2014). - http://www.lundia.

co.nz/products/mobile-shelving/manual/manual-westpac/

Fig. 3.24 Reveal \& Conceal iteration 3 - by author

Fig. 3.25 Reveal \& Conceal iteration 4 - by author

Fig. 3.26 Reveal \& Conceal iteration 5 - by author

Fig. 3.27 Reveal \& Conceal iteration 6 - by author

Fig. 3.28 Apartment 203 plan - by author

Fig. 3.29 Gary Chang's Apartment Width

Fig. 3.30 Interior perspective 3 - by author

Fig. 3.31 Bien vivre dans (Retrieved Feb. 5 2014). - Marc Baillargeon and Julia Nabuchet apartment 16m2 - http://www.treehugger.com/green-architecture/parismicro-apartment-marc-baillargeon-julie-nabucet.html

Fig. 3.32 Fold up bed - by author

Fig. 3.33 Interior Perspective 4 - by author

Fig. 3.34 Apartment 107 plan - by author

Fig. 3.35 Slide out bed - by author

Fig. 3.36 Christian Schallert Apartment Christian Schallert \& Barbara Appolloni 24m2 (Retrieved Feb. 5 2014). - http://www.onekindesign.com/2012/10/12/lego-

style-24-square-meters-apartment-in-barcelona/

Fig. 3.37 Apartment 408 plan - by author

Fig. $\mathbf{3 . 3 8}$ Flip open bed 
Fig. 3.39 Suitcase House interior (Retrieved Feb. 7 2014). - http://travel.cnn. com/shanghai/life/chinas-10-most-unusual-hotel-features-987867

Fig. 3.40 Interior Perspective 5 - by author

Fig. 3.41 Nine-Square Grid House (Retrieved Feb. 7 2014). - Top: http://www. shigerubanarchitects.com/works/1997_nine-square-grid-house/index.html Bottom: by author

Fig. 3.42 Philip Johnson art Gallery Retrieved Feb. 7 2014). - Top: http:// philipjohnsonglasshouse.wordpress.com/2010/08/10/site-spotlight-paintinggallery/ Bottom: by author

Fig. 3.43 Interior Perspective 6 - by author

Fig. 3.44 Apartment 404 plan - by author

Fig. 3.45 Interior Perspective 7 - by author

Fig. 3.46 Dividing wall - by author

Fig. 3.47 Apartment 102 plan - by author

Fig. 3.48 Interior Perspective 8 - by author

Fig. 3.49 Rotating wall - by author

Fig. 3.50 Interior Perspective 9 - by author

Fig. 3.51 Apartment 201 plan - by author

Fig. 3.52 Interior Perspective 10 - by author

Fig. 3.53 Reveal \& Conceal iteration 7 17th July Review - by author

Fig. 3.54 Iteration 7 apartment unit - by author

Fig. 3.55 Naked House plans - by author

Fig. 3.56 Naked house interior (Retrieved Jun. 9 2013) - Left \& right: http://

nakedhousecasestudy.blogspot.co.nz/p/overview.html

Fig. 3.57 Warehouse interior (Retrieved Feb. 5 2014). - Top \& bottom: http:// www.dezeen.com/2010/10/30/warehouse-by-shinichi-ogawa-associates/

Fig. 3.58 Warehuse plan and section - by author

Fig. 3.59 Three Small Rooms (Retrieved Feb. 5 2014). - Top: http://www.

dezeen.com/2012/12/14/three-small-rooms-loft-interior-studio-cadna/

Fig. 3.60 Three Small Rooms plan 1:100 - by author

Fig. 3.61 Three Small Rooms (Retrieved Feb. 5, 2014). - http://www.dezeen.

com/2012/12/14/three-small-rooms-loft-interior-studio-cadena/

Fig. 3.62 Lyon Housemuseum interiors (Retrieved Feb. 5 2014). - http://www.

dezeen.com/2010/06/26/lyon-housemuseum-by-lyons-architects/

Fig. 3.63 Lyon Housemuseum Ground floor plan - by author

Fig. 3.64 Lyon Housemuseum 2nd level plan - by author

Fig. 3.65 Sempla Offices (Retrieved feb 5 2014). - http://www.dezeen.

com/2013/03/17/sempla-offices-by-dap-studio/ 
Fig. 3.66 RDM Innovation Deck (Retrieved Feb. 5 2014). - http://www.dezeen. com/2013/02/07/rdm-innovation-deck-by-groosman-partners/

Fig. 3.67 Goldberger (Retrieved Feb. 5 2014). - http://www.dezeen.

com/2010/04/26/goldberger-by-tervhivatal/

Fig. 3.68 Mobile iteration 1 - by author

Fig. 3.69 Mobile iteration 2 - by author

Fig. 3.70 Apartment 501 plan - by author

Fig. 3.71 Interior Perspective 11 - by author

Fig. 3.72, Fig. 3.73, Fig. 3.74 and Fig. 3.75 Apartment 501 diagrams - by author

Fig. 3.76 Mobile sleeping boxes - by author

Fig. 3.77 Interior Perspective 12 - by author

Fig. 3.78 Passages - by author

Fig. 3.79 Multiple doors and thoroughfare - by author

Fig. 3.80 Single doors and terminal space by author

Fig. 3.81 Unité d'habitation (Retrieved Feb. 5 2014). - http://manmakehome.

com/2009/04/15/mystery-solved-unité-dhabitation-marseille/

Fig. 3.82 Saishunkan Seiyaku (Retrieved Feb. 7 2014). - http://www2.hawaii. edu/ kbda/1995-047/index8.htm

Fig. 3.83 Chungking Mansions (Retrieved Feb. 5 2014). - http://www.

foreignpolicy.com/articles/2011/11/25/inside_hong_kongs_chungking_mansions

Fig. 3.84 Unité d'habitation Interior Street Retrieved (Retrieved Feb. 5 2014). -

http://writingtoinform.com/2012/04/10/research-the-extended-lobby-the-resident-

as-guest-and-the-unité-dhabitation-as-hotel-11/

Fig. 3.85 Unité d'habitation, Marseille Le Corbusier - by author

Fig. 3.86 Saishunkan Saiyaku interior (Retrieved Feb 7 2014). - http://www.

designboom.com/interviews/sanaa-kazuyo-sejima-ryue-nishizawa-designboom-

interview/

Fig. 3.87 Saishunkan Seiyaku Women's Dormitory SANAA 1st Floor Plan - by

author

Fig. 3.88 Interior Perspective 13 - by author

Fig. 3.89 Apartment 305 plan - by author

Fig. 3.90 Corridors iteration 1 - by author

Fig. 3.91 Corridors iteration 2 - by author

Fig. 3.92 Corridors iteration 3 - by author

Fig. 3.93 Interior Perspective 14 - by author

Fig. 3.94 Corridors iteration 4 17th July review - by author

Fig. 3.95 Iteration 4 apartment units

Fig. 3.96 Interior perspective 15 - by author 
Fig. 3.97 Town belt iteration 1 10th October review

Fig. 3.98 Collins Gallery (Retrieved Feb. 7 2014). - http://archrecord.

construction.com/projects/residential/archives/0306HotM-1.asp

Fig. 3.99 Collins Gallery plan - by author

Fig. 3.100 Lyon Housemuseum (Retrieved Feb. 5 2014). - http://www.dezeen.

com/2010/06/26/lyon-housemuseum-by-lyons-architects/

Fig. 3.101 Collins Gallery (Retrieved Feb. 7 2014). - http://archrecord.

construction.com/projects/residential/archives/0306HotM-1.asp

Fig. 3.102 Level 2 private, public zones

Fig. 3.103 Level 1 plan - by author

Fig. 3.104 Level 2 plan - by author

Fig. 3.105 Interior Perspective 16 - by author

Fig. 3.106 Level 3 plan - by author

Fig. 3.107 Level 3.1 plan - by author

Fig. 3.108 Level 4 plan - by author

Fig. 3.109 Interior Perspective 17 - by author

Fig. 3.110 Level 5 plan - by author

Fig. 3.111 Rendered section AA - by author

Fig. 3.112 Rendered section BB - by author

Fig. 3.113 Rendered section CC - by author

Part 4

Fig. 4.0 Chungking Mansions existing

Fig. 4.1 Chungking Mansions with changes

Fig. 4.2 Unité d'Habitation with changes

Fig. 4.3 Unité d'Habitation with changes 